\title{
Estudo da musculatura dorsal dos arcos branquiais de Characiformes (Teleostei: Ostariophysi): diversidade morfológica e significado filogenético
}

Study of the dorsal musculature of the branchial arch of the Characiformes (Teleostei:

Ostariophysi): morphologic diversity and phylogenetic significance

André Luis da Silva Casas

São Paulo

2012

André Luis da Silva Casas 


\section{Introdução}

Os peixes ósseos pertencentes ao táxon Teleostei constituem o maior grupo de vertebrados existente, estando amplamente distribuídos em diversos ambientes, com representantes marinhos e dulcícolas compreendendo aproximadamente $50 \%$ das espécies descritas para todos os vertebrados (Nelson, 2006). Dentre eles, os Otophysi são um dos táxons mais especiosos representando aproximadamente $75 \%$ da fauna recente de peixes de água doce do mundo que são diagnosticados pela presença do aparelho de Weber, e incluem as Ordens Cypriniformes, Characiformes, Siluriformes e Gymnotiformes (Fink e Fink 1981 e 1996).

Os Characiformes são um dos táxons mais morfologicamente diversos entre os Otophysi (Vari, 1998) e seus representantes atuais estão restritos às águas doces dos continentes africano e americano compreendendo 18 famílias, 270 gêneros e 1674 espécies (Nelson, 2006). Os membros africanos dessa ordem compreendem três linhagens: os citarinoídeos, os alestídeos e os hepsetídeos totalizando aproximadamente 209 espécies (Nelson, 2006). Os representantes neotropicais totalizam aproximadamente 80\% das espécies de Characiformes descritas (Gery, 1977), com 13 famílias reconhecidas no estudo morfológico de Mirande (2010) e 24 no estudo molecular de Oliveira et al (2011).

Os trabalhos anatômicos de Weitzman (1954, 1960, 1962), e o de Roberts (1969) constituem um marco importante a partir do qual estudos subsequentes sobre sistemática de Characiformes passaram a enfatizar estudos morfológicos detalhados (principalmente osteológicos) e a incluir um maior número de táxons examinados dentro de um contexto comparativo (Vari, 1998:117). Estudos anatômicos a partir de 
então passaram a ser associados a nascente metodologia da sistemática filogenética, que define os táxons com base em caracteres derivados compartilhados, o que acarretou num grande avanço do conhecimento sobre as relações filogenéticas na Ordem nos últimos 40 anos (Vari, 1979, 1983 e 1995; Fink e Fink, 1981 e 1996; Buckup, 1998; Lucena e Menezes, 1998).

Vari (1998) e Buckup (1998) resumem o conhecimento acumulado sobre a sistemática de Characiformes até o final do século XX. Em particular, Buckup (1998) ressalta a falta de uma hipótese de relações filogenéticas para Characiformes que sirva de base para estudos de sistemática na Ordem, pois a maioria desses estudos era voltada para demonstrar o monofiletismo de táxons menos inclusivos, sem propor hipóteses de relações entre famílias. Trabalhos voltados para a elucidação de relações supra familiares em Characiformes eram restritos a poucas famílias, destacando-se os trabalhos de Vari (1979, 1983 e 1995) e Lucena e Menezes (1998). Em 1979 Vari propôs uma hipótese de relações entre as famílias africanas Citharinidae e Distichodontidae, que formam uma unidade monofilética, posteriormente corroborada por Fink e Fink (1981) que estabeleceram essas famílias como o grupo irmão de todos os outros Characiformes. Vari (1983) estabeleceu uma hipótese de relacionamento filogenético entre quatro famílias neotropicais: Curimatidae, Prochilodontidae, Anostomidae e Chilodontidae, agrupando-as em uma unidade monofilética. Posteriormente Buckup (1998) denominou esse táxon como superfamília Anostomoidea.

As famílias neotropicais Ctenoluciidae, Erytrinidae, Hepsetidae e Lebiasinidae formam a superfamília Erythrinoidea (Buckup 1998), uma unidade monofilética proposta por Vari (1995), baseando-se em três sinapomorfias osteológicas e uma 
relacionada à posição das escamas em relação ao espinho supraoccipital, que corroborou a hipótese anterior de Fink e Fink (1981). Em sua análise Buckup (1998) estabelece o mesmo agrupamento proposto por Vari (1995) e propõe Acestrorhynchidae como grupo irmão de Erythrinoidea, sem ter incluído em sua análise exemplares de Cynodontinae. Finalmente o estudo de Lucena e Menezes (1998) propõe a família Acestrorhynchidae como grupo irmão da família Cynodontidae, diferentemente da hipótese proposta por Buckup (1998).

$\mathrm{Na}$ última década, estudos morfológicos têm contribuído com novas informações sobre a sistemática de Characiformes em diversos níveis taxonômicos (Zanata, 2000; Moreira, 2002; Castro e Vari, 2004; Zanata e Vari, 2005; Lima, 2006; Netto-Ferreira, 2006; Toledo-Piza, 2000 e 2007; Ingenito, 2008; Sidlauskas e Vari, 2008, Datovo e Castro, 2012 e Mattox e Toledo-Piza, 2012). A questão do monofiletismo da família Characidae, a mais diversificada da Ordem com cerca de 1000 espécies incluídas em 165 gêneros (Nelson, 2006) e de suas relações com os demais Characiformes foi abordada recentemente por Mirande (2009 e 2010) que examinou 160 espécies e 360 caracteres morfológicos. O estudo deste autor corroborou o monofiletismo de Characidae com base em sete sinapomorfias. Sua análise estabeleceu a família Serrasalmidae e incluiu Acestrorhynchidae e Cynodontidae em Characidae. Engraulisoma taeniatum foi transferido de Characidae para Gasteropelecidae. Uma nova subfamília de Characidae foi proposta: Heterocharacinae, posteriormente redefinida por Mattox e Toledo-Piza (2012) incluindo Gnathocharax na base; e as subfamílias Aphyocharacinae, Aphyoditeinae, Characinae e Gymnocharacinae. Mirande (2010) tentou incluir a maioria dos gêneros incertae sedis em um clado diagnosticado.

O estudo de Buckup (1998) que em uma tentativa de posicionar filogeneticamente a subfamília Characidiinae, realizou uma análise com representantes de 16 famílias, 
representando a primeira análise cladística de Characiformes num contexto mais abrangente somado ao estudo molecular de Calcagnotto et al (2005) e a tese de Moreira (2007), que incluiu 97 táxons e 410 caracteres morfológicos, são as principais tentativas em se compreender as relações em Characiformes como um todo. As hipóteses resultantes destes estudos corroboram muitas hipóteses previamente propostas para alguns táxons, assim como sugerem novos agrupamentos, alguns conflitantes com hipóteses prévias, outros representando hipóteses inéditas. Esse cenário sugere que as tentativas em se compreender as relações na Ordem não foram esgotadas possibilitando que futuras análises, morfológicas ou moleculares, possam ser realizadas para um melhor entendimento das relações em Characiformes.

Os estudos da anatomia dos peixes vêm se mostrando uma ferramenta importante para o entendimento das relações entre diversos táxons, mas exames restritos à anatomia dos arcos branquiais como fonte de informações taxonômicas ganharam importância a partir dos trabalhos de Nelson (1968 e 1969) sobre os arcos branquiais de Acanthodes e posteriormente sobre a utilização de informações anatômicas dessas estruturas para a compreensão da filogenia dos peixes, destacando a importância desse complexo de caracteres para o entendimento da história evolutiva dos gnatostomados, com especial ênfase aos peixes Teleostomi. Os elementos estruturais que formam os arcos branquiais dos peixes são derivados dos arcos viscerais, formando o viscerocranium: o primeiro arco visceral dando origem ao arco mandibular, o segundo arco visceral aos elementos do arco hioide e os cinco arcos viscerais subsequentes aos arcos branquiais (Harder, 1975). O arco mandibular recebe inervação do nervo trigêmeo e o arco hioide do nervo facial. O primeiro arco branquial é inervado pelo nervo glossofaríngeo (IX) e os arcos branquiais posteriores pelo nervo vago (X). A musculatura associada a esses arcos recebem fibras motoras dos nervos IX e X (Allis, 1897; Nakae e Sasaki, 2008). 
A sustentação do aparato branquial é realizada pelo esqueleto branquial que é formado por componentes endocondrais e dérmicos (Patterson, 1977): o endoesqueleto, derivado de componentes endocondrais, é formado pelos ossos e cartilagens que sustentam a faringe e os filamentos branquiais. Normalmente nos peixes gnatostomados existe uma série de cinco arcos, cada um composto por vários ossos e cartilagens, pares ou não, arranjados em uma forma de anel ao redor do lúmen da faringe (Nelson, 1968) que podem ser convenientemente divididos em partes ventral e dorsal. Na parte ventral ocorrem os elementos pares ceratobranquial e hipobranquial e um elemento ímpar basibranquial. Na parte dorsal ocorrem apenas elementos pares epibranquial e faringobranquial (Nelson, 1969; Harder, 1975). Sobre as estruturas do endoesqueleto podem ocorrer elementos dérmicos tais como escamas placóides, placas de dentes e rastros branquiais. Entre os peixes Teleostomi recentes, os elementos dérmicos variam grandemente entre as espécies. As estruturas mais estáveis de origem dérmica parecem ser as placas de dentes associadas aos basibranquiais, ao quinto ceratobranquial e aos faringobranquiais (Nelson, 1968 e 1969).

Alguns autores estudaram a variação anatômica dessas estruturas em alguns táxons e propuseram sinapomorfias em diversos níveis em Teleostei. Nelson (1969) afirma que esse táxon é único entre os peixes, a apresentar placas de dentes dérmicos associadas aos faringobranquiais dos arcos dois, três e quatro. Segundo o autor, do ponto de vista das estruturas dos arcos branquiais, esse táxon é o mais bem definido entre os grandes grupos de peixes (Nelson, 1969:528). Estudos posteriores ressaltaram a importância das maxilas faríngeas (Rosen, 1973) para a compreensão dos mecanismos de alimentação e para a taxonomia do grupo: Nos Teleostei basais as placas de dentes dérmicos são pobremente conectadas aos elementos do endoesqueleto dos arcos branquiais, condição não encontrada em Clupeochephala que apresenta como uma de suas sinapomorfias as 
placas de dentes faríngeos dorsais completamente fundidas aos elementos do endoesqueleto e uma única placa de dentes fundida ao ceratobranquial 5 (Lauder e Liem, 1983). Essas estruturas estão diretamente relacionadas à manipulação, processamento e direcionamento do alimento para o esôfago, pois as maxilas (dentário, maxilar e pré maxilar) estão envolvidas no mecanismo de sucção inercial presente na maioria dos Teleostei (Lauder e Liem, 1983).

Nos Characiformes a descrição osteológica de Brycon meeki realizada por Weitzman (1962) estabeleceu um padrão para o reconhecimento das estruturas dos arcos branquiais nesse táxon e contribuiu posteriormente para a compreensão de especializações presentes em outras espécies da Ordem. Vari (1979) propõe como sinapomorfias de Citharinidae e Distichodontidae as seguintes estruturas relacionados aos arcos branquiais: fusão das placas de dentes dorsais dos faringobranquiais 4 e 5 , perda do faringobranquial 1, alongamento do faringobranquial 2 e 3, presença de órgãos epibranquiais em Citharinidae, e perda secundária dessas estruturas em Distichodontidae. Posteriormente Vari (1983) estabelece o monofiletismo em Anostomoidea propondo duas sinapomorfias restritas as estruturas dorsais arcos branquiais: eliminação do contato direto entre as placas de dentes faríngeos quatro e cinco e ausência de dentes dérmicos na placa de dentes faríngeos quatro. $\mathrm{O}$ autor propõe o táxon formado pelas famílias Curimatidae e Prochilodontidae com base em oito sinapomorfias observadas na parte dorsal dos arcos branquiais, sendo uma delas a presença de órgãos epibranquiais musculares. As famílias Chilodontidae e Anostomidae também formam um agrupamento monofilético baseado em oito sinapomorfias provenientes dos arcos branquiais, uma das quais exclusivamente relacionadas aos músculos oblíquos dorsais (Vari, 1983). 
Não só as estruturas osteológicas dos arcos branquiais têm mostrado importância para a compreensão das relações em Teleostei. A musculatura associada a essas estruturas veem se mostrando uma fonte promissora de caracteres, como por exemplo, o músculo retrator dorsal (RD), uma das estruturas mais importantes para a compreensão das relações em Teleostei (Lauder, 1982), Johnson (1992) propõe que o RD é a única sinapomorfia neste nível sendo posteriormente corroborada como uma das sinapomorfias de Neoteleostei (Wiley e Johnson, 2010), sendo esta uma das maiores inovações estruturais na evolução desse táxon. O RD é um músculo pareado bilateralmente que frequentemente conecta os elementos faringobranquiais posteriores à coluna vertebral (Winterbottom, 1974), e está associado aos mecanismos de movimentação das maxilas faríngeas, aumentando o controle sobre a manipulação e mastigação do alimento na faringe (Lauder e Liem, 1983). Em resumo a consolidação das placas de dentes faríngeos aos elementos do endoesqueleto em Clupeochephala, a presença do RD nos Neoteleostei e a origem do músculo pharyngohyoideus no uruhyal em Ctenosquamata refletem o aumento da versatilidade funcional dos elementos osteológicos e miológicos na evolução de Teleostei (Lauder, 1982).

Os músculos dorsais dos arcos branquiais dos Teleostei foram abordados por Winterbottom (1974), o autor propôs uma nomenclatura para todos os músculos esqueléticos estriados desse táxon, que passou a ser referencial em estudos subsequentes. Segundo o autor essa musculatura pode ser diferenciada entre músculos extrínsecos e intrínsecos aos arcos branquiais. Os primeiros são formados pelos músculos levantadores e retratores que conectam os arcos branquiais ao crânio e a coluna vertebral. Os últimos são representados pelos músculos que apresentam origem e inserção em estruturas exclusivas dos arcos branquiais. Apenas os músculos dorsais dos arcos branquiais de Brycon guatemalensis, em um universo de aproximadamente 1700 
espécies de Characiformes, foi representado em uma ilustração em vista lateral por Winterbottom (1974), deixando dúvidas quanto à topografia e descrição anatômica dos mesmos.

Recentemente, um trabalho sobre musculatura dos arcos branquiais dos peixes Teleostomi, com especial referência aos Actinopterygii abriu novas perspectivas no estudo deste complexo de caracteres (Springer e Johnson, 2004). Estes autores examinaram a musculatura dorsal dos arcos branquiais de representantes de 200 famílias e 400 espécies de peixes ósseos, num total de 500 espécimes examinados. O trabalho destes autores contribuiu para elucidar várias questões de homologia e resultou na elaboração de uma nova nomenclatura para os músculos dorsais dos arcos branquiais. Acima de tudo, o estudo revelou uma grande diversidade morfológica neste complexo de caracteres, tendo servido de base para uma análise filogenética que incluiu 168 táxons representantes de 147 famílias de Acanthomorpha e 56 caracteres de musculatura e osteologia dos quais 36 são restritos aos músculos dorsais dos arcos branquiais (Springer e Orrell, 2004). Esses caracteres foram amplamente baseados em dados sobre a topografia e forma dos músculos levantadores, especialmente a posição de inserção, dos músculos oblíquos e alguns músculos transversos. A análise de Springer e Orrel (2004) resultou em algumas hipóteses nunca antes propostas e os autores ressaltaram que algumas destas deveriam ser fortemente consideradas. Apenas após o estudo de Springer e Johnson (2004) foi possível ter uma compreensão das variações nos músculos dorsais dos arcos branquiais em Teleostei e da sua importância como fonte de caracteres para futuros estudos filogenéticos como o realizado recentemente por Grey e Mabee (2012) em Catostomidae, que constatou grande variação nos músculos dorsais dos arcos branquiais entre as famílias Catostomidae e Cyprinidae, dos Cypriniformes. 
Dada à abrangência taxonômica do estudo de Springer e Johnson (2004), a representatividade de vários táxons foi obviamente pequena, sendo que apenas três espécies de Characiformes (Brycon guatemalensis, Brycon melanopterus e Xenocharax spilurus), dentre as mais de 1600 espécies válidas na Ordem, foram examinadas. Springer e Johnson (2004:3) reconhecem esta deficiência e enfatizam que qualquer um dos táxons poderia por si só ser objeto de um estudo independente.

Diante da grande diversidade de espécies e consequentemente da grande diversidade morfológica dos Characiformes, o presente estudo pretende ampliar o estudo de Springer e Johnson (2004) para os representantes da Ordem com os objetivos de investigar a diversidade morfológica dos músculos dorsais dos arcos branquiais e analisar o significado filogenético dessas variações nos músculos extrínsecos que compreendem os músculos levantadores externos (Le) e internos (Li), e nos músculos intrínsecos que compreendem os músculos oblíquos (Od), adutores $(\mathrm{Ad})$, transversos e um músculo esfíncter, que podem compor esse complexo de caracteres.

\section{Objetivos}

1) Descrever a anatomia dos músculos dorsais dos arcos branquiais em representantes de Characiformes.

2) Documentar as variações dos músculos dorsais dos arcos branquiais nos representantes examinados.

3) Discutir o significado das variações desse complexo anatômico em um contexto filogenético. 


\section{Material e métodos}

\subsection{Táxons incluídos}

A escolha do material levou em consideração os táxons que melhor representassem a diversidade morfológica das principais linhagens de Characiformes e a disponibilidade de obtenção do material junto às instituições museológicas: Museu de Zoologia da Universidade de São Paulo (MZUSP) e South African Institute for Aquatic Biodiversity (SAIAB).

A anatomia dos músculos dorsais dos arcos branquiais foi descrita para 64 gêneros, 70 espécies, representando as famílias de Characiformes sensu Reis et al (2003), listadas a seguir:

\section{Família Acestrorhynchidae:}

Acestrorhynchus nasutus, não catalogado, $1,85,1 \mathrm{~mm} \mathrm{CP.}$

Acestrorhynchus lacustris, não catalogado, 1, 134,3mm CP.

\section{Família Alestidae:}

Alestes sp, SAIAB 77149, 1, 154,1 mm CP.

Bathyaethiops sp, SAIAB 77630, 1, 18,1mm CP.

Brycinus lateralis, SAIAB 84821, 1, 82,7mm CP.

Bryconaethiops boulengeri, SAIAB, 2, 43, 1-58,2mm CP.

Chalceus spilogyros, MZUSP 19698, 3, 80,9-152,1mm CP, 1, c\&s, 80,9mm CP.

Hydrocynus vittatus, SAIAB 71299, 2, 97,2-99,6mm CP.

\section{Família Anostomidae:}

Leporinus octofasciatus, MZUSP 73226, 3, 122,1-243,3 mm CP, 1, c\&s, 122,1 mm CP.

\section{Família Characidae:}

Acestrocephalus sardina, MZUSP 101081, 1, 81,8 mm CP. 
Agoniates halecinus, MZUSP 102345, 1? CP.; MZUSP 101617, 2, 153,4-163,1 mm CP. Aphyocharax dentatus, MZUSP 4015, 3, 44,5-46,1 mm CP, 1, c\&s, 44,5 mm CP. Astyanax fasciatus, MZUSP 16743, 1, 88,6 mm CP. Astyanax ribeirae, MZUSP 70006, 1, 41,1 mm CP.

Brycon falcatus, MZUSP 56945, 2, 171,2-175,4 mm CP; MZUSP 38255, 1, c\&s, 115,3 $\mathrm{mm}$ CP.

Brycon opalinus, MZUSP 28338, 2, 171,5-176,2 mm CP.

Bryconamericus turiuba, MZUSP 79799, 3, 49,8-56,5 mm, 1, c\&s, 49,8 mm CP.

Bryconops alburnoides, MZUSP 34585, 3, 132,1-149,8 mm, 1, c\&s, 132,1 mm CP.

Charax pauciradiatus, MZUSP 20291, 3, 74,5-91,5 mm, 1, c\&s, 75,9 mm CP.

Cheirodon interruptus, MZUSP 19063, 2, 23,6-25,9 mm CP.

Cynopotamus kincaidi, MZUSP 19987, 3, 91,5-105,7 mm CP, 1, c\&s, 92,3 mm CP.

Exodon paradoxos, MZUSP 5165, 3, 55,9-79,1 mm CP, 1, c\&s, 55,9 mm CP.

Gnathocharax steindachneri, MZUSP 74248, 2, 36,5-37,4 mm CP.

Hemigrammus coeruleus, MZUSP 75437, 3, 40,2-41,9 mm CP, 1, c\&s, 40,2 mm CP.

Hyphessobrycon luetkenii, MZUSP 27563, 3, 27,5-37,8 mm CP, 1, c\&s, 27,5 mm CP.

Iguanodectes spilurus, MZUSP 92559, 3, 69,4-81,8 mm CP, 1, c\&s, 69,4 mm CP.

Lonchogenys ilisha, não catalogado, 1, 53,9 mm CP.

Metynnis sp, MZUSP 95326, 3, 65,9-84,3 mm CP, 1, c\&s, 84,3 mm CP.

Mimagoniates microlepis, MZUSP 72850, 3, 41,7-45,9 mm CP, 1, c\&s, 45,9 mm CP.

Moenkhausia tergimacula, MZUSP 97940, 3, 57,1-68,2 mm CP, 1, c\&s, 57,1 mm CP.

Myleus setiger, MZUSP 15809, 3, 108,8-128,1 mm CP, 1, c\&s, 108,8 mm CP.

Oligosarcus hepsetus, MZUSP 42890, 3, 76,5-83,7 mm CP, 1, c\&s, 76,5 mm CP.

Poptella paraguayensis, MZUSP 59914, 3, 47,6-56,1 mm CP, 1, c\&s, 47,6 mm CP.

Roeboexodon guyanensis, MZUSP 97250, 1, 74,6 mm CP.

Serrasalmus brandtii, MZUSP 57550, 3, 89,1-92,3 mm CP, 1, c\&s, 89,1 mm CP.

Tetragonopterus argenteus, MZUSP 27756, 3, 78,6-97,9 mm CP, 1, c\&s, 78,6 mm CP.

Tetragonopterus sp, MZUSP 96610,1, 49,6 mm CP. 
Triportheus auritus, MZUSP 98044, 1, 99,6 mm CP.

Triportheus signatus, MZUSP 37962, 1, 86,7 mm CP.

Triportheus pantanensis, MZUSP 54147, 1, 83,3 mm CP.

\section{Família Citharinidae}

Citharinus latus, MZUSP 84480, 1, 117,6 mm CP.

\section{Família Curimatidae:}

Curimata vittata, MZUSP 35158, 3, 66,1-191,9 mm CP, 1, c\&s, 66,1 mm CP.

Curimatopsis myersi MZUSP 74778, 3, 54,6-56,1 mm CP, 1, c\&s, 54,6 mm CP.

\section{Família Cynodontidae}

Cynodon gibbus, MZUSP 89905, 3, 103,9-231,1 mm CP, 1, c\&s, 103,9 mm CP.

Hydrolycus tatanaia, MZUSP 99870, 2, 118,3-129,1 mm CP, 1, c\&s, 118,3 mm CP.

Rhaphiodon vulpinus, MZUSP 15219, 2, 102,8-126,7 mm CP, 1, c\&s, 102,8 mm CP.

Gilbertolus alatus, MCNG 56104, 1, 92,7 mm CP.

Família Ctenoluciidae:

Boulengerella cuvieri, MZUSP 101733, 1, 248,1 mm CP.

\section{Família Chilodontidae:}

Chilodus punctatus, MZUSP 21692, 3, 63,1-68,8 mm CP, 1, c\&s, 63,1 mm CP.

Chilodus puntactus, MZUSP 89116, 2, 45,2-49,7 mm CP.

\section{Família Crenuchidae:}

Characidium oiticicai, MZUSP 87569, 3, 48,2-54,8 mm CP, 1, c\&s, 48,2 mm CP.

Crenuchus spilurus, MZUSP 85582, 3, 39,2-33,9 mm CP, 1, c\&s, 39,2 mm CP.

Família Disthicodontidae:

Distichodus sp, SAIAB 78008, 2, 59,5-64,3 mm CP.

Eugnathichthys sp, SAIAB 77702, 1, 59,2 mm CP.

Hemigrammocharax multifasciatus, SAIAB 72800, 2, 30,7-34,7 mm CP.

Nannocharax sp, SAIAB 76637, 2, 44,2-46,1 mm CP.

Neolebias trilineatus, SAIAB 96789, 1, 36,9 mm CP.

Phago intermedius, SAIAB 77986, 2, 66,9-68,5 mm CP. 


\section{Família Erythrinidae:}

Erythrinus erythrinus, MZUSP 34351, 2, 83,6-97,7 mm CP, 1, c\&s, 83,6 mm CP. Hoplias malabaricus, MZUSP 97913, 2, 92,2-164,5 mm CP, 1, c\&s, 92,2 mm CP.

Família Gasteropelecidae:

Gasteropelecus sternicla, MZUSP 38238, 3, 39,1-41,1 mm CP, 1, c\&s, 39,4 mm CP.

Thoracocharax stellatus, MZUSP 90656, 3, 46,9-48,3 mm CP, 1, c\&s, 46,9 mm CP.

Família Hemiodontidae:

Bivibranchia velox, MZUSP 97228, 3, 128,8-134,8 mm CP, 1, c\&s, 128,8 mm CP.

Hemiodus argenteus, MZUSP 95721, 3, 99,2-108,9 mm CP, 1, c\&s, 99,2 mm CP.

Família Hepsetidae:

Hepsetus odoe, SAIAB 80799, 1, 132,4 mm CP.

Hepsetus odoe, SAIAB 72802, 1, 154,1 mm CP.

Família Lebiasinidae:

Copeina sp, MZUSP 27088, 2, 53,9-63,1 mm CP.

Nannostomus trifasciatus, MZUSP 29296, 6, 20,8-25,5 mm CP, 1, c\&s, 23,7mm CP.

\section{Família Parodontidae:}

Parodon nasus, MZUSP 19345, 3, 81,8-105,4 mm CP, 1, c\&s, 87,8 mm CP.

Apareiodon affinis, MZUSP 19437, 1, 111,2 mm CP.

\section{Família Prochilodontidae:}

Semaprochilodus taeniurus, MZUSP 35767, 3, 105,6-143,6 mm CP, 1, c\&s, 105,6 mm CP.

Prochilodus brevis, MZUSP 37550, 2, 137,2-135,5 mm CP.

\subsection{Nomenclatura anatômica.}

A nomenclatura osteológica seguiu a proposta de Weitzman (1962), Nelson (1968, 1969) e Fink e Fink (1981, 1996), com a tradução para o português seguindo Castro e Castro (1987), com as devidas adequações às novas regras ortográficas para a língua 
portuguesa. Os nomes dos músculos dorsais dos arcos branquiais foram empregados seguindo Springer e Johnson (2004) (tabelas 1 e 2).

O conceito de origem e inserção está relacionado, nos livros clássicos de anatomia ao tipo de movimento do músculo, sendo, portanto um conceito relativo, o que pode causar confusões. Em relação à origem e inserção dos músculos levantadores, oblíquos e adutores seguimos o que foi estabelecido por Springer e Johnson (2004) bem como a padronização de descrição proposta pelos mesmos autores para os músculos transversos.

Nas descrições anatômicas o termo "não observado" refere-se a estruturas que não foram examinadas devido às condições inadequadas do material, ou a estruturas que foram danificadas durante as dissecções. O termo "ausente" refere-se a estruturas que não estão presentes nos exemplares examinados.

Tabela 1. Abreviações utilizadas no texto.

\begin{tabular}{cc}
\hline Abreviação & Nome da estrutura \\
\hline Ad4 & Adductor 4 \\
Ad5 & Adductor 5 \\
Eb1-4 & Epibranchial 1-4 \\
Le1 & Levator externus 1 \\
Le2 & Levator externus 2 \\
Le3 & Levator externus 3 \\
Le4 & Levator externus 4 \\
Li1 & Levator internus 1 \\
Li2 & Levator internus 2 \\
Li3 & Levator internus 3 \\
LP & Levator posterioris \\
Od3 & Obliquus dorsalis 3 \\
\hline
\end{tabular}




\begin{tabular}{|c|c|}
\hline Od4 & Obliquus dorsalis 4 \\
\hline Od4' & Obliquus dorsalis 4' \\
\hline $\mathbf{O P}$ & Obliquus posterioris \\
\hline Pb 1-4 & Pharyngobranchialis 1-4 \\
\hline PO & Proótico \\
\hline $\mathbf{P P}$ & Protractor pectoralis \\
\hline PT & Pterótico \\
\hline SO & Sphincter esophagi \\
\hline TEb2 & Transversus epibranchialis 2 \\
\hline TEb4 & Transversus epibranchialis 4 \\
\hline TPb3 & Transversus pharyngobranchialis 3 \\
\hline TPb3a-Eb2 & Transversus pharyngobranchialis 3anterioris epibranchialis 2 \\
\hline TPb3-Eb2 & Transversus pharyngobranchialis 3 epibranchialis 2 \\
\hline TPb3p & Transversus pharyngobranchialis 3posterioris \\
\hline TPb3-TPb4 & Transversus pharyngobranchialis 3 transversus pharyngobranchialis 4 \\
\hline $\begin{array}{l}\text { TPb3-TPb4- } \\
\text { TEb4 }\end{array}$ & $\begin{array}{c}\text { Transversus pharyngobranchialis } 3 \text { Transversus pharyngobranchialis } 4 \text { Transversus } \\
\text { epibranchialis } 4\end{array}$ \\
\hline TPb4 & Transversus pharyngobranchialis 4 \\
\hline TPb4-Eb4 & Transversus pharyngobranchialis 4 epibranchialis 4 \\
\hline TPb4-Eb4 & Transversus pharyngobranchialis 4 epibranchialis 2 \\
\hline IX & Nervo glossofaríngeo \\
\hline UP5-Cb4-Eb5 & Pharyngobranchialis 5 ceratobranquialis 4 epibranquialis 5 \\
\hline Oe & Órgão epibranquial \\
\hline $\mathbf{X}$ & Nervo vago \\
\hline
\end{tabular}


Tabela 2. Resumo da topografia dos músculos dorsais dos arcos branquiais baseados em Winterbottom (1974) e Springer e Johnson (2004).

\begin{tabular}{|c|c|c|c|c|}
\hline & & & Origem & Inserção \\
\hline \multirow{8}{*}{$\begin{array}{l}\text { Músculos } \\
\text { Extrínsecos }\end{array}$} & \multirow{5}{*}{$\begin{array}{c}\text { L. externos } \\
\text { (Músculos pares) }\end{array}$} & Le1 & Crânio (PO) & $\mathrm{Eb} 1$ \\
\hline & & Le2 & Crânio (PO) & $\mathrm{Eb} 2$ \\
\hline & & Le3 & Crânio (PO) & Eb3 \\
\hline & & Le4 & Crânio (PO) & $\mathrm{Eb} 4$ \\
\hline & & LP & Crânio (PT) & Eb4 \\
\hline & \multirow{3}{*}{$\begin{array}{c}\text { L. internos } \\
\text { (Músculos pares) }\end{array}$} & Li1 & Crânio (PO) & $\mathrm{Pb} 2$ \\
\hline & & $\mathrm{Li} 2$ & Crânio (PO) & $\mathrm{Pb} 3$ \\
\hline & & Li3 & Crânio (PO) & $\mathrm{Pb} 4$ \\
\hline \multirow[t]{5}{*}{$\begin{array}{l}\text { Músculos } \\
\text { Intrínsecos }\end{array}$} & \multicolumn{2}{|c|}{$\begin{array}{c}\text { Transversos } \\
\text { (Músculos ímpares) }\end{array}$} & $\begin{array}{l}\text { Ligam uma } \\
\text { estrutura de um } \\
\text { lado ao outro }\end{array}$ & $\begin{array}{l}\text { Ligam uma } \\
\text { estrutura de um } \\
\text { lado ao outro }\end{array}$ \\
\hline & \multirow{2}{*}{$\begin{array}{c}\text { Oblíquos } \\
\text { (Músculos pares) }\end{array}$} & $\mathrm{Od} 3$ & Eb3 & $\mathrm{Pb} 3$ \\
\hline & & $\mathrm{Od} 4$ & Eb4 & $\mathrm{Pb} 4$ \\
\hline & \multirow{2}{*}{$\begin{array}{c}\text { Adutores } \\
\text { (Músculos pares) }\end{array}$} & Ad4 & Eb4 & $\mathrm{Cb} 4$ \\
\hline & & Ad5 & Eb5 & $\mathrm{Cb} 5$ \\
\hline
\end{tabular}

\subsection{Preparação do material e dissecção}

Todos os exemplares destinados ao exame da musculatura foram corados utilizando-se o método de Taylor e Van Dyke (1985) para a coloração de cartilagem e Springer e Johnson (2000) para a coloração de tecidos calcificados.

A remoção total dos arcos branquiais, como descrita por Springer e Johnson (2004) foi empregada durante a dissecação dos primeiros exemplares: Curimata vittata, Brycon falcatus e B. opalinus, mostrando-se extremamente eficiente para a descrição anatômica das inserções dos músculos levantadores, bem como para as descrições dos músculos oblíquos, adutores e transversos. Porém informações importantes sobre a origem dos músculos levantadores na base do neurocrânio são perdidas com a utilização desse método. 
Para se identificar com precisão as origens dos músculos levantadores, bem como as relações topográficas entre esses músculos e os demais músculos dorsais dos arcos branquiais foi desenvolvido outro método de dissecção, realizado em vista lateral esquerda removendo-se os ossos infraorbitais, os músculos mandibulares e faciais, o opérculo, pré-opérculo e o hiomandibular, este último seguindo o procedimento de Weitzman (1974) deixando os arcos branquiais intactos, sendo então possível evidenciar a região de origem dos músculos levantadores no proótico e no pterótico.

Em alguns casos, para uma melhor visualização dos músculos levantadores externos e internos, foi realizada a enucleação do bulbo ocular. Após a retirada cuidadosa de tecido conjuntivo e adiposo da região posterior à órbita foi possível visualizar todas as origens dos músculos levantadores, bem como os nervos responsáveis pela inervação de todos os músculos dorsais dos arcos branquiais (glossofaríngeo (IX) e vago (X)). A observação desses nervos proporcionou a obtenção de informações topográficas importantes para a descrição da musculatura.

Após a observação em vista lateral esquerda, o mesmo procedimento foi repetido no antímero direito do exemplar examinado. E em seguida os arcos branquiais foram completamente removidos através de cortes nas origens dos músculos levantadores, para a observação dos demais músculos dorsais dos arcos branquiais (transversos, oblíquos e adutores), seguindo o procedimento inicial de Springer e Johnson (2004). 


\subsection{Registro}

As peças dissecadas foram amplamente registradas através de fotografias digitais tanto em vista dorsal, como ilustrado por Springer e Johnson (2004), quanto em vista lateral a fim de se reconhecer e examinar as origens dos músculos levantadores.

Ilustrações em vista dorsal foram realizadas por uma profissional especializada em ilustração científica. Cada ilustração apresentada foi conferida comparativamente com a peça anatômica juntamente com a ilustradora.

\subsection{Diafanização}

Concomitantemente a preparação das peças para o exame da musculatura foram preparadas peças diafanizadas e coradas para uma melhor compreensão dos pontos de origem e inserção da musculatura dorsal dos arcos branquiais nas estruturas esqueléticas seguindo o método de Taylor e Van Dyke (1985). O emprego dessa técnica auxiliou na orientação das dissecções, nas descrições dos músculos e na ilustração da musculatura dorsal dos arcos branquiais.

\subsection{Utilização dos nomes dos táxons na descrição de caracteres.}

No tópico 4.2. (Descrição e discussão de caracteres) serão utilizados os nomes dos gêneros e/ou famílias para se referir as espécies listadas no tópico 3.1. (Táxons incluídos), porém isso não implica que o caráter em discussão esteja presente em todas as espécies do gênero, mas sim que está presente nas espécies do gênero ou família examinadas no presente estudo. 
3.7. Procedimentos para discussão da variação encontrada.

Para se compreender a variação nos músculos dorsais dos arcos branquiais foi necessário acessar as hipóteses previamente propostas por diversos autores sobre as relações filogenéticas de Characiformes nos mais diversos níveis taxonômicos (supraespecíficos).

A fim de se obter uma ferramenta para verificar o comportamento dos caracteres quando analisados sozinhos e discutir a distribuição dos seus estados nos táxons examinados uma matriz de caracteres foi construída utilizando-se o programa WinClada versão 1.00.08 (Nixon, 1999-2002) utilizando-se 68 táxons e 33 caracteres provenientes exclusivamente da musculatura dorsal dos arcos branquiais. Bathyaethiops e Chilodus não foram incluídos na matriz, pois muitos dos seus músculos branquias não foram descritos devido às condições do material examinado. A codificação dos caracteres desses táxons levaria ao inflacionamento de estados não aplicáveis na matriz não sendo, portanto informativos.

A matriz foi analisada utilizando-se o programa de análise de máxima parcimônia TNT 1.1 (Goloboff, Farris e Nixon, 2008) através de uma busca tradicional com os seguintes parâmetros: “hold” de 500000 árvores; 1000 réplicas; 500 árvores por réplica, "random seed" iniciando-se com 1, utilização do algoritmo TBR (tree bisection reconnection). $\mathrm{O}$ número de passos, o consenso estrito, os índices de consistência e retenção foram também obtidos utilizando-se o programa TNT 1.1 (Goloboff, Farris e Nixon, 2008). Os caracteres multiestado foram analisados de forma não ordenada.

As árvores obtidas foram enraizadas em Distichodus, um representante da família Distichodontidae que conjuntamente com Citharinidae formam um clado 
monofilético, considerado por Vari (1979) e Fink e Fink (1981) o grupo irmão das demais famílias de Characiformes, seguindo o método de comparação com o grupo externo proposto por Nixon e Carpenter (1993).

\section{Resultados.}

4.1. Descrição da musculatura.

\subsubsection{Família Acestrorhynchidae}

Acestrorhynchus lacustris.

Le1. Origina-se no proótico dorsalmente à articulação do $\mathrm{Pbl}$ com o crânio, lateralmente à origem do Li1. Insere-se lateralmente ao processo uncinado do Eb1. Músculo em forma de fita.

Le2. Origina-se no proótico medialmente à origem do Li1 e lateralmente às origens do Li2 e Li3. Insere-se na extremidade cartilaginosa e na margem anterior do processo uncinado do Eb2. Músculo em forma de fita.

Le3. Origina-se no proótico ventro medialmente às origens dos músculos Li2 e Li3. Insere-se na extremidade cartilaginosa do processo uncinado do Eb3. Músculo cilíndrico com o ventre pouco desenvolvido se comparado aos outros músculos levantadores.

Le4. Origina-se no proótico medialmente à origem do Le3. Insere-se no processo levantador do Eb4 ventralmente à inserção do LP. Músculo em forma de fita. 
LP. Origina-se no pterótico idem B. falcatus e insere-se na extremidade dorsal do processo levantador do Eb4.

Li1. Origina-se no proótico medialmente à origem do Le1 e lateralmente ao Le2. Inserese no Pb2 idem Springer e Johnson (2004). Músculo em forma de fita.

Li2. Origina-se no proótico, lateralmente ao Le2. Está muito próximo ao Li3, dorsalmente, ao longo do seu trajeto. Insere-se no Pb3 idem Springer e Johnson (2004). Músculo em forma de fita.

Li3. Origina-se no proótico dorsalmente à origem do Li2. Insere-se dorsalmente na região anterior do $\mathrm{Pb} 4$. Músculo em forma de fita.

Od3. Origem idem Springer e Johnson (2004), inserção ocorre ventralmente à inserção do Le3 compreendendo parte da extremidade dorsal e da margem anterior do processo uncinado do Eb3.

Od4. Idem Springer e Johnson (2004).

Od4'. Ausente.

OP. Idem Springer e Johnson (2004).

Ad4. Origina-se na face medial do processo levantador do Eb4 e insere-se no Cb4. Músculo em forma de fita.

Ad5. Idem Springer e Johnson (2004).

SO. Idem Springer e Johnson (2004). 
TEb2. Liga-se no Eb2 esquerdo e conecta-se na mesma estrutura do lado direito. Um feixe de fibras musculares conectadas ao Eb2 segue posteriormente até o $\mathrm{Pb} 3$ esquerdo. O músculo não apresenta um par simétrico para esse feixe de fibras.

TPb3. Liga-se no Pb3 esquerdo e conecta-se na mesma estrutura lado direito. Seu limite posterior não está claro e suas fibras se confundem com as do TPb4.

TPb4. Liga-se no Pb4 esquerdo e conecta-se na mesma estrutura do lado direito.

TEb4. Liga-se medialmente ao processo levantador na parte medial do Eb4 esquerdo e conecta-se na mesma estrutura no lado direito. Suas fibras se confundem com as fibras musculares do $\mathrm{TPb} 4$ anteriormente e com as fibras do $\mathrm{SO}$ posteriormente.

Nota: $\mathrm{O}$ processo uncinado Eb1 articula-se com um processo ósseo do $\mathrm{Pb} 2$. As extremidades articulares são revestidas por cartilagem articular em ambos os processos citados.

Acestrorhynchus nasutus.

Le1. Origina-se no proótico dorsalmente à articulação do $\mathrm{Pb1}$ ao crânio, na origem relaciona-se medialmente com o Le2. Insere-se na margem lateral do processo uncinado do Eb1. Músculo fusiforme.

Le2. Origina-se no proótico medialmente à origem do Le1 e lateralmente à origem do Li2 e Li3. Insere-se na extremidade dorsal do processo uncinado do Eb2. Músculo fusiforme.

Le3. Origem idem $A$. lacustris, inserção lateral a extremidade dorsal do processo uncinado do Eb3. 
Le4. Apresenta duas origens distintas no proótico, uma delas dorsal à origem do Le3 e outra localizada medialmente à primeira. Insere-se na extremidade dorsal do processo levantador do Eb4. Esse músculo se caracteriza por ter duas cabeças e uma cauda.

LP. Origem e inserção idem A.lacustris. Músculo delgado em forma de fita.

Li1. Origina-se no proótico dorsalmente à origem dos outros músculos levantadores. $\mathrm{Na}$ origem apresenta um alargamento do ventre muscular. Insere-se no $\mathrm{Pb} 2$ idem Springer e Johnson (2004), com o estreitamento do ventre muscular.

Li2. Origina-se no proótico juntamente com o Li3. Situa-se medialmente à origem do Le1 e do Li1. Insere-se no Pb3 idem A.lacustris. Músculo em forma de fita.

Li3. Idem A. lacustris. Os músculos Li2 e Li3 estão muito próximos tornando-os de difícil distinção.

Od3. Idem A.lacustris.

Od4. Idem A.lacustris.

Od4'. Idem A.lacustris.

OP. Idem A.lacustris.

Ad4. Origina-se na face medial do processo levantador do Eb4. Na região da origem apresenta forma de leque. Insere-se no $\mathrm{Cb} 4$.

Ad5. Origina-se no Eb5 e insere-se no Cb5. Músculo mais alongado se comparado com o Ad5 de A. lacustris.

SO. Idem A. lacustris. 
TEb2. Liga-se na região anterior do Eb2 esquerdo e conecta-se na mesma estrutura no lado direito.

$\mathrm{TPb} 3$. Liga-se no $\mathrm{Pb} 3$ esquerdo e conecta-se na mesma estrutura lado direito. Seu limite posterior não está claro e suas fibras se confundem com as do $\mathrm{TPb} 4$.

$\mathrm{TPb} 4$. Liga-se no $\mathrm{Pb} 4$ esquerdo e conecta-se na mesma estrutura do lado direito. A distinção do limite entre as fibras do TPb3 e TPb4 não é clara.

TEb4. Idem A. lacustris, porém o seu limite anterior é estabelecido pelo TPb3-TPb4.

\subsubsection{Família Alestidae.}

Alestes sp.

Le1. Origina-se no proótico medialmente a articulação do Pb1 com o crânio. Origem tendínea. Insere-se na face lateral óssea do processo uncinado do Eb1. Músculo fusiforme.

Le2. Origina-se na incisura do proótico medialmente ao Li1. Insere-se na margem anterior do processo uncinado do Eb2 (osso e cartilagem). Músculo em forma de fita.

Le3. Origina-se no proótico medialmente a origem dos músculos Le1, Le2, Li1, Li2 e Li3. Insere-se ao longo da margem anterior do processo uncinado do Eb3 (osso e cartilagem). Músculo em forma de fita.

Le4. Origina-se no proótico dorsalmente a origem do Le3. Insere-se na margem anterior da extremidade dorsal do processo levantador do Eb4. Músculo em forma de fita. 
LP. Origina-se na margem ventral do pterótico. Insere-se na extremidade dorsal cartilaginosa do processo levantador do Eb4 juntamente com o PP. Músculo em forma de fita.

Li1. Origina-se na incisura do proótico medialmente a origem do Le1. Insere-se na superfície dorsal do $\mathrm{Pb} 2$. Músculo em forma de fita.

Li2. Origina-se na incisura do proótico dorsalmente a origem do Le2. Insere-se na superfície dorsal do $\mathrm{Pb} 2$. Músculo em forma de fita.

Li3. Origina-se dorsalmente a origem do Li2 no proótico. Insere-se na superfície dorsal do Pb4. Músculo em forma de fita. O Li3 é muito mais desenvolvido que o Li2.

Od3. Origina-se anteriormente na extremidade anterior do $\mathrm{Pb} 3$. Insere-se na extremidade dorsal cartilaginosa do processo uncinado do Eb3. Músculo fusiforme.

Od4. Origina-se anteriormente no $\mathrm{Pb} 4$. Insere-se na margem lateral óssea do processo levantador do Eb4. Músculo em forma de leque.

Od4'. Ausente.

OP. Origina-se na margem medial do Eb4, próximo às fibras do TEb4 e termina na rafe do esôfago.

Ad4. Na margem ventral da extremidade posterior do Eb4 e na margem dorsal da extremidade posterior do $\mathrm{Cb} 4$, medialmente ao ângulo interno da articulação Eb4-Cb4 músculo reduzido.

Ad5. Na margem posterior do Eb5 (cartilagem) e na extremidade posterior do Cb5. 
SO. Camada de músculo que circunda o esôfago, com aumento no tamanho das fibras dorsalmente, com uma projeção anterior mediana de fibras que se estendem ventralmente ao TEb4.

TEb2. Liga-se medialmente ao processo uncinado do Eb2 esquerdo e conecta-se na mesma estrutura no lado direito.

$\mathrm{TPb} 3$. Liga-se na face médio dorsal do $\mathrm{Pb} 3$ esquerdo e conecta-se na mesma estrutura no lado esquerdo. Está localizado ventralmente ao TEb2 e na região do seu limite posterior suas fibras confundem-se com as do $\mathrm{TPb} 4$.

$\mathrm{TPb} 4$. Liga-se ao longo da margem medial do $\mathrm{Pb} 4$ esquerdo e insere-se na mesma região do lado direito. Anteriormente seu limite não é bem definido, pois suas fibras musculares se confundem com as fibras do $\mathrm{TPb} 3$. Seu limite posterior é bem estabelecido pelo músculo TEb4.

TEb4. Liga-se medialmente no Eb4 esquerdo e conecta-se nas mesmas estruturas no lado direito. Músculo em forma de fuso, com as fibras ligeiramente mais desenvolvidas que as do $\mathrm{TPb} 4$.

Nota:

. Pb1 apresenta um ligamento com o crânio.

.Os músculos Le1, Le2, Li1, Li2 e Li3 originam-se em uma incisura do proótico sendo possível reconhecer seus pontos de origem distintos. 


\section{Brycinus lateralis.}

Le1. Origina-se no proótico medialmente a articulação do $\mathrm{Pb} 1$ com o crânio. Origem tendínea juntamente com o Li1. Insere-se na face lateral óssea do processo uncinado do Eb1. Músculo fusiforme. O Ligamento do $\mathrm{Pb} 1 \mathrm{com}$ o crânio passa lateralmente ao músculo e se conecta ao crânio dorsalmente a sua origem.

Le2. Origina-se no proótico medialmente ao Li1. Insere-se na margem anterior do processo uncinado do Eb2 (osso e cartilagem). Músculo em forma de fita.

Le3. Origina-se no proótico medialmente a origem dos músculos, Li2 e Li3. Insere-se ao longo da margem anterior do processo uncinado do Eb3 (osso e cartilagem). Músculo em forma de fita.

Le4. Origina-se no proótico medialmente a origem do Le3. Insere-se na margem anterior da extremidade dorsal do processo levantador do Eb4. Músculo em forma de fita.

LP. Origina-se na margem ventral do pterótico. Insere-se na extremidade dorsal cartilaginosa do processo levantador do Eb4. Músculo em forma de fita. O PP está ausente.

Li1. Origina-se no proótico conjuntamente a origem do Le1. Insere-se na superfície dorsal do Pb2. Músculo em forma de fita.

Li2. Origina-se no proótico medialmente a origem do Le2. Insere-se na superfície dorsal do $\mathrm{Pb} 2$. Músculo em forma de fita.

Li3. Origina-se dorsalmente a origem do Le2 no proótico. Insere-se na superfície dorsal do Pb4. Músculo em forma de fita. O Li3 é muito mais desenvolvido que o Li2. 
Od3. Origina-se anteriormente na extremidade anterior do $\mathrm{Pb}$. Insere-se na extremidade dorsal cartilaginosa do processo uncinado do Eb3. Músculo fusiforme.

Od4. Origina-se anteriormente no $\mathrm{Pb} 4$. Insere-se na margem lateral óssea do processo levantador do Eb4. Músculo em forma de leque.

Od4'. Ausente.

OP. Origina-se na margem medial do Eb4, próximo às fibras do TEb4 e termina na rafe do esôfago.

Ad4. Na margem ventral da extremidade posterior do Eb4 e na margem dorsal da extremidade posterior do $\mathrm{Cb} 4$, medialmente ao ângulo interno da articulação Eb4-Cb4 músculo reduzido.

Ad5. Na margem posterior do Eb5 (cartilagem) e na extremidade posterior do Cb5.

SO. Camada de músculo que circunda o esôfago, com aumento no tamanho das fibras dorsalmente, com uma projeção anterior mediana de fibras que se estendem ventralmente ao TEb4.

TEb2. Liga-se medialmente ao processo uncinado do Eb2 esquerdo e conecta-se na mesma estrutura no lado direito.

TPb3. Liga-se na face médio dorsal do Pb3 esquerdo e conecta-se na mesma estrutura no lado esquerdo. Está localizado ventralmente ao TEb2 e na região do seu limite posterior suas fibras confundem-se com as do $\mathrm{TPb} 4$.

TPb4. Liga-se ao longo da margem medial do $\mathrm{Pb} 4$ esquerdo e insere-se na mesma região do lado direito. Anteriormente seu limite não é bem definido, pois suas fibras 
musculares se confundem com as fibras do $\mathrm{TPb} 3$. Seu limite posterior é bem estabelecido pelo músculo TEb4.

TEb4. Liga-se medialmente no Eb4 esquerdo e conecta-se nas mesmas estruturas no lado direito. Músculo em forma de fuso, com as fibras ligeiramente mais desenvolvidas que as do $\mathrm{TPb} 4$.

Nota: presença de ligamento do Pb1 com o crânio.

Bryconaethiops boulengeri.

Le1. Origina-se no proótico dorsalmente a articulação do Pb1 com o crânio. Origem tendínea. Insere-se na face lateral e medial óssea do processo uncinado do Eb1, posterior a cartilagem. Músculo fusiforme.

Le2. Origina-se no proótico medialmente a origem do Li1. Insere-se na extremidade dorsal cartilaginosa do processo uncinado do Eb2. Músculo em forma de fita.

Le3. Origina-se no proótico medialmente a origem dos músculos Li2 e Li3. Insere-se na extremidade dorsal cartilaginosa do processo uncinado do Eb3. Músculo em forma de fita.

Le4. Origina-se no proótico dorsalmente a origem do Le3. Insere-se na margem anterior (osso e cartilagem) da extremidade dorsal do processo levantador do Eb4. Músculo em forma de fita. 
LP. Origina-se na margem ventral do pterótico. Insere-se na extremidade dorsal cartilaginosa do processo levantador do Eb4. Músculo em forma de fita.

Li1. Origina-se no proótico conjuntamente a origem do Le1. Insere-se na superfície dorsal do $\mathrm{Pb} 2$. Músculo em forma de fita.

Li2. Origina-se no proótico dorsalmente a origem do Le2. Insere-se na superfície dorsal do Pb2. Músculo em forma de fita.

Li3. Origina-se dorsalmente a origem do Li2 no proótico. Insere-se na superfície dorsal do Pb4. Músculo em forma de fita. O Li3 é muito mais desenvolvido que o Li2.

Od3. Origina-se anteriormente na extremidade anterior do $\mathrm{Pb} 3$. Insere-se na extremidade dorsal cartilaginosa do processo uncinado do Eb3. Músculo fusiforme.

Od4. Origina-se anteriormente no $\mathrm{Pb} 4$. Insere-se na margem lateral óssea do processo levantador do Eb4. Músculo em forma de leque.

Od4'. Ausente.

OP. Origina-se na margem medial do Eb4, próximo às fibras do TEb4 e termina na rafe do esôfago.

Ad4. Na margem ventral da extremidade posterior do Eb4 e na margem dorsal da extremidade posterior do $\mathrm{Cb} 4$, medialmente ao ângulo interno da articulação Eb4-Cb4 músculo.

Ad5. Na margem posterior do Eb5 (cartilagem) e na extremidade posterior do $\mathrm{Cb} 5$. 
SO. Camada de músculo que circunda o esôfago, com aumento no tamanho das fibras dorsalmente, com uma projeção anterior mediana de fibras que se estendem ventralmente ao TEb4.

TEb2. Liga-se medialmente ao processo uncinado do Eb2 esquerdo e conecta-se na mesma estrutura no lado direito.

$\mathrm{TPb} 3-\mathrm{TPb} 4$. Liga-se na face médio dorsal do $\mathrm{Pb} 3$ e $\mathrm{Pb} 4$ esquerdos e conecta-se nas mesmas estruturas no lado esquerdo. Está localizado ventralmente ao TEb2 e está limitado posteriormente pelas fibras do $\mathrm{TPb} 4$.

TEb4. Liga-se medialmente no Eb4 esquerdo e conecta-se nas mesmas estruturas no lado direito. Músculo em forma de fuso, com as fibras ligeiramente mais desenvolvidas que as do $\mathrm{TPb} 4$.

Nota: $\mathrm{O} \mathrm{Pb} 1$ apresenta um pequeno ligamento com o crânio.

Chalceus spilogyros.

Le1. Origina-se no proótico medialmente a articulação do Pb1 com o crânio. Insere-se posteriormente ao processo uncinado na face medial do Eb1. Compartilha um tendão de origem com o Li1. Músculo fusiforme.

Le2. Origina-se no proótico dorsalmente a origem do Le1. Insere-se na extremidade cartilaginosa do processo uncinado do Eb2. Músculo fusiforme.

Le3. Origina-se no proótico dorsalmente a origem do Le2. Insere-se na margem anterior do processo uncinado do Eb3. Músculo fusiforme. 
Le4. Origina-se no proótico dorsalmente à origem do Li2-Li3. Insere-se na margem dorsal do processo levantador do Eb4.

LP. Origina-se no pterótico, compartilhando um tendão de origem com o músculo protractor pectoralis, evidenciado uma única origem para dois músculos. Insere-se na extremidade cartilaginosa do processo levantador do Eb4.

Li1. Idem origem do Le1. Insere-se na superfície dorsal e na margem lateral do $\mathrm{Pb} 2$, posteriormente ao processo articular do $\mathrm{Pb} 2$ com o Eb1.

Li2. Origina-se no proótico dorsalmente a origem do Le2. Insere-se no Pb3. Músculo em forma de fita.

Li3. Origina-se no proótico dorsalmente a origem do Li2. Insere-se no Pb4. Músculo em forma de fita.

Od3. Origina-se no $\mathrm{Pb} 3$ anteriormente, ventralmente ao TEb2. Insere-se na extremidade cartilaginosa do processo uncinado do Eb3.

Od4. Origina-se no $\mathrm{Pb} 4$ anteriormente e insere-se na face lateral do processo levantador do Eb4. Na origem apresenta forma de fita, na inserção apresenta forma de leque.

Od4'. Ausente

OP. Origina-se na margem medial do Eb4, próximo às fibras do TEb4 e termina na rafe do esôfago.

Ad4. Na margem medial do Eb4 da extremidade dorsal do processo levantador do Eb4 até a superfície dorsal do $\mathrm{Cb} 4$, medialmente ao ângulo interno da articulação do Eb4$\mathrm{Cb} 4$. 
Ad5. No Eb5 (cartilagem) posteriormente e no Cb5.

SO. Camada de músculo que circunda o esôfago, com aumento no tamanho das fibras dorsalmente, com uma projeção anterior mediana de fibras que se estendem ventralmente ao TEb4.

TEb2. Liga-se medialmente ao processo uncinado do Eb2 esquerdo e conecta-se na mesma estrutura no lado direito.

$\mathrm{TPb} 3$. Liga-se na face médio dorsal do $\mathrm{Pb} 3$ esquerdo e conecta-se na mesma estrutura no lado esquerdo. Está localizado ventralmente ao $\mathrm{TEb} 2$ e na região do seu limite posterior suas fibras confundem-se com as do TPb4.

TPb4. Liga-se ao longo da margem medial do Pb4 esquerdo e insere-se na mesma região do lado direito. Anteriormente seu limite não é bem definido, pois suas fibras musculares se confundem com as fibras do $\mathrm{TPb} 3$. Seu limite posterior é bem estabelecido pelo músculo TEb4.

TEb4. Liga-se medialmente no Eb4 esquerdo e conecta-se nas mesmas estruturas no lado direito. Músculo em forma de fuso, com as fibras ligeiramente mais desenvolvidas que as do $\mathrm{TPb} 4$.

Hydrocynus vittatus.

Le1. Origina-se no proótico medialmente a articulação do Pb1 com o crânio. Origem tendínea. Insere-se na margem dorsal óssea do processo uncinado do Eb1. Músculo fusiforme. 
Le2. Origina-se no proótico medialmente ao Li1. Insere-se na extremidade dorsal cartilaginosa do processo uncinado do Eb2. Músculo em forma de fita.

Le3. Origina-se no proótico medialmente a origem dos músculos Li2 e Li3. Insere-se na margem anterior da extremidade dorsal do processo uncinado do Eb3 (osso e cartilagem). Músculo em forma de fita.

Le4. Origina-se no proótico dorsalmente a origem do Le3. Insere-se na margem anterior da extremidade dorsal do processo levantador do Eb4. Músculo em forma de fita.

LP. Origina-se na margem ventral do pterótico. Insere-se na extremidade dorsal cartilaginosa do processo levantador do Eb4. Músculo em forma de fita. O PP está presente e compartilha o tendão de origem com o LP.

Li1. Origina-se no proótico dorsalmente a origem do Le1. Insere-se na superfície dorsal do $\mathrm{Pb} 2$. Músculo em forma de fita.

Li2. Origina-se no proótico dorsalmente a origem do Le2. Insere-se na superfície dorsal do Pb2. Músculo em forma de fita.

Li3. Origina-se dorsalmente a origem do Li2 no proótico. Insere-se na superfície dorsal do Pb4. Músculo em forma de fita. O Li3 é muito mais desenvolvido que o Li2.

Od3. Origina-se anteriormente na extremidade anterior do $\mathrm{Pb}$. Insere-se na extremidade dorsal cartilaginosa do processo uncinado do Eb3. Músculo fusiforme.

Od4. Origina-se anteriormente no $\mathrm{Pb} 4$. Insere-se na margem lateral óssea do processo levantador do Eb4. Músculo em forma de leque.

Od4'. Ausente. 
OP. Origina-se na margem medial do Eb4, próximo às fibras do TEb4 e termina na rafe do esôfago.

Ad4. Na margem ventral da extremidade posterior do Eb4 e na margem dorsal da extremidade posterior do $\mathrm{Cb} 4$, medialmente ao ângulo interno da articulação Eb4-Cb4 músculo reduzido.

Ad5. Na margem posterior do Eb5 (cartilagem) e na extremidade posterior do Cb5.

SO. Camada de músculo que circunda o esôfago, com aumento no tamanho das fibras dorsalmente, com uma projeção anterior mediana de fibras que se estendem ventralmente ao TEb4.

TEb2. Liga-se medialmente ao processo uncinado do Eb2 esquerdo e conecta-se na mesma estrutura no lado direito.

TPb3-TPb4. Liga-se na face médio dorsal do $\mathrm{Pb} 3$ e $\mathrm{Pb} 4$ esquerdos e conecta-se nas mesmas estruturas no lado esquerdo. Está localizado ventralmente ao TEb2 e está limitado posteriormente pelas fibras do $\mathrm{TPb} 4$.

TEb4. Liga-se medialmente no Eb4 esquerdo e conecta-se nas mesmas estruturas no lado direito. Músculo em forma de fuso, com as fibras ligeiramente mais desenvolvidas que as do $\mathrm{TPb} 4$.

\subsubsection{Família Anostomidae.}

Leporinus octofasciatus. 
Le1. Origina-se no proótico, medialmente ao $\mathrm{Pb} 1$. Insere-se em duas porções distintas do Eb1: no processo uncinado do Eb1 e na extremidade anterior do Eb1.

Le2. Origina-se no proótico medialmente a origem do Li1. Insere-se na extremidade cartilaginosa do processo uncinado do Eb2.

Le3. Origina-se no proótico medialmente a origem do Li3. Insere-se na extremidade dorsal do processo uncinado do Eb3.

Le4. Origina-se no proótico medialmente a origem do Le3. Insere-se na margem anterior do processo levantador do Eb4.

LP. Origina-se no pterótico medialmente ao Le4. Insere-se na margem dorsal do processo levantador do Eb4.

Li1. Origina-se no proótico medialmente a origem do Le1. Insere-se em duas partes distintas na margem dorsal do $\mathrm{Pb} 2$, caracterizando um músculo bicaudado.

Li2. Origina-se no proótico dorso medialmente a origem do Le2. Insere-se na superfície dorsal do Pb3. Na região de origem suas fibras estão muito próximas das fibras do Li3.

Li3. Origina-se no proótico dorsalmente a origem do Li2. Inserção não observada.

Od3. Origina-se anteriormente no $\mathrm{Pb}$ 3. Insere-se na extremidade do processo uncinado do Eb3 na sua margem anterior.

Od4. Origina-se sobre a superfície dorsal do $\mathrm{Pb} 4$. Apresenta dois pontos de inserção: medialmente ao processo levantador do Eb4 e lateralmente ao processo levantador do Eb4, onde apresenta forma de leque. O músculo apresenta duas porções distintas: uma dorsal e outra ventral. 
Od4'. Ausente.

OP. Origina-se na superfície póstero medial do Eb4 ventralmente ao TEb4 pouco separada do SO, terminando ventralmente na rafe do esôfago.

Ad4. Origina-se na superfície póstero medial do Eb4 pouco separada do $\mathrm{SO}$, terminando ventralmente na rafe do esôfago.

Ad5. Músculo bulboso. No Eb5 médio posteriormente e Cb5 posteriormente, com uma extensão tendínea dorso lateralmente, cruzando o Eb5 dorsalmente a extremidade distal do Eb4. Une-se a rafe do esôfago ventralmente e OP lateralmente, idem Springer e Johnson (2004).

SO. Camada de músculo que circunda o esôfago, com aumento no tamanho das fibras dorsalmente, delgado em outras partes, idem Springer e Johnson (2004).

TEb2. Liga-se medialmente ao processo uncinado do Eb2 esquerdo e conecta-se na mesma estrutura no lado direito.

$\mathrm{TPb} 3$. Ausente.

$\mathrm{TPb} 4$. Ausente.

TEb4. Liga a extremidade posterior da margem medial do Eb4 esquerdo e conecta-se a mesma estrutura no lado direito.

\subsubsection{Família Characidae}

Acestrocephalus sardina 
Le1. Origina-se na extremidade dorsal na face posterior do $\mathrm{Pb} 1$ e na incisura do proótico dorsalmente a articulação do Pb1 com o crânio. Origem muscular. Insere-se na extremidade dorsal na face anterior do processo uncinado do Eb1. Músculo em forma de fita, com duas cabeças. Na origem esse músculo está localizado juntamente com outros músculos levantadores na incisura do proótico.

Le2. Origina-se na incisura do proótico dorsalmente a origem do Le1. Origem muscular. Insere-se na face anterior do processo uncinado do Eb2. Músculo em forma de fita.

Le3. Origina-se no proótico medialmente a incisura do proótico. Insere-se na face anterior do processo uncinado do Eb3 ventralmente a inserção do Od3. Músculo em forma de fita.

Le4. Origina-se no proótico medialmente a origem do Le3. Insere-se na extremidade dorsal na margem anterior do processo levantador do Eb4. Músculo em forma de fita.

LP. Origina-se na extremidade posterior na margem ventral do pterótico juntamente com o PP. Origem tendínea. Insere-se na extremidade dorsal na superfície medial do processo levantador do Eb4. Músculo fusiforme.

Li1. Origina-se na incisura proótico medialmente a origem da cabeça medial do Le1. Insere-se na superfície dorsal do $\mathrm{Pb} 2$. Músculo em forma de fita

Li2. Origina-se na incisura do proótico medialmente a origem do Le2. Insere-se na superfície dorsal do Pb3. Músculo em forma de fita.

Li3. Origina-se na incisura do proótico dorsalmente a origem do Li2. Insere-se na superfície dorsal do Pb4. Músculo em forma de fita. 
Od3. Origina-se anteriormente na extremidade anterior óssea do $\mathrm{Pb} 3$ ventralmente ao TEb2. Insere-se na extremidade dorsal (cartilagem) do processo uncinado do Eb3. Músculo fusiforme.

Od4. Origina-se anteriormente no Pb4 (cartilagem). Insere-se na face lateral do processo levantador do Eb4. Músculo largo.

Od4'. Presente. Esse músculo está localizado lateralmente ao Od4 e insere-se na face lateral do processo levantador do Eb4. Sua origem ocorre na parte óssea posterior do Pb3. O limite das fibras entre o Od4 e Od4' não é claro podendo esse ser confundido com o Od4 ou classificado como um ventre do Od4 que apresenta origem de suas fibras no $\mathrm{Pb} 3$.

OP. Origina-se na margem medial do Eb4, próximo às fibras do TEb4 e termina na rafe do esôfago.

Ad4. Na face medial do processo levantador do Eb4 e na margem dorsal da extremidade posterior do $\mathrm{Cb} 4$, medialmente ao ângulo interno da articulação Eb4-Cb4.

Ad5. Na margem posterior do Eb5 (cartilagem) e na extremidade posterior do $\mathrm{Cb} 5$.

SO. Camada de músculo que circunda o esôfago, com aumento no tamanho das fibras dorsalmente, delgado em outras partes, suas fibras são limitadas anteriormente pelo TEb4.

TEb2. Liga-se medialmente a extremidade cartilaginosa do processo uncinado do Eb2 esquerdo e conecta-se a mesma estrutura do lado direito. Localiza-se dorsalmente ao Od3. 
TPb3-TPb4. Liga-se na face médio dorsal do Pb3 e Pb4 esquerdos e conecta-se nas mesmas estruturas no lado esquerdo. Está localizado ventralmente ao TEb2. É limitado posteriormente pelas fibras do TEb4.

TEb4. Liga-se na face medial ventral do Eb4 esquerdo e insere-se na mesma estrutura do lado direito. Anteriormente limita-se pelas fibras do TPb3-TPb4.

Agoniates halecinus.

Le1. Origina-se no proótico dorsalmente a articulação do Pb1 com o crânio. Insere-se na margem anterior do processo uncinado do Eb1. Músculo fusiforme.

Le2. Origina-se no proótico medialmente a origem do Li1. Insere-se na margem anterior do processo uncinado do Eb2. Músculo em forma de fita.

Le3. Origina-se no proótico medialmente a origem do Li2-Li3. Insere-se na margem anterior do processo uncinado do Eb3. Músculo em leque.

Le4. Origina-se no proótico dorsalmente a origem do Le3. Insere-se na extremidade dorsal na margem anterior do processo levantador do Eb4. Suas fibras estão envoltas por uma fáscia muscular que também engloba o LP. Músculo em forma de fita.

LP. Origina-se na margem ventral da extremidade posterior do pterótico juntamente com o PP através de um tendão afilado. Insere-se na extremidade dorsal do processo levantador do Eb4. Músculo fusiforme com dois ventres musculares. O LP representa o ventre medial do complexo LP-PP.

Li1. Origina-se no proótico dorsalmente a origem do Le1. Insere-se na superfície dorsal do $\mathrm{Pb} 2$. Músculo fusiforme. 
Li2. Origina-se no proótico medialmente a origem do Le2. Insere-se na superfície dorsal do $\mathrm{Pb} 2$. Músculo em forma de fita.

Li3. Origina-se no proótico dorsalmente a origem do Le2 e Li2. Insere-se na superfície dorsal do $\mathrm{Pb} 4$. Músculo em forma de fita.

Od3. Origina-se anteriormente na extremidade anterior óssea do $\mathrm{Pb} 3$, ventralmente ao TEb2 Insere-se na extremidade dorsal do processo uncinado do Eb3. Músculo fusiforme.

Od4. Origina-se anteriormente no $\mathrm{Pb} 4$. Insere-se na margem anterior e na face lateral do processo levantador do Eb4. Músculo em leque.

Od4'. Ausente.

OP. Origina-se na face medial do Eb4, próximo às fibras do TEb4 e termina na rafe do esôfago.

Ad4. Na face medial do processo levantador do Eb4 e na margem dorsal da extremidade posterior do $\mathrm{Cb} 4$, medialmente ao ângulo interno da articulação Eb4-Cb4.

Ad5. Na margem posterior do Eb5 (cartilagem) e na extremidade posterior do Cb5.

SO. Camada de músculo que circunda o esôfago, com aumento no tamanho das fibras dorsalmente, delgado em outras partes, anteriormente suas fibras se projetam ventralmente ao TEb4.

TEb2. Liga-se medialmente a extremidade cartilaginosa do processo uncinado do Eb2 esquerdo e conecta-se a mesma estrutura do lado direito. Localiza-se dorsalmente ao Od3. 
TPb3. Liga-se na face médio dorsal do Pb3 esquerdo e conecta-se na mesma estrutura no lado esquerdo. Está localizado ventralmente ao TEb2. É limitado posteriormente pelas fibras do $\mathrm{TPb} 4$.

$\mathrm{TPb} 4$. Liga-se ao longo da margem medial do $\mathrm{Pb} 4$ esquerdo e conecta-se na mesma região do lado direito. É limitado posteriormente pelas fibras do TEb4.

TEb4. Liga-se na face medial ventral do Eb4 esquerdo e insere-se na mesma estrutura do lado direito. Anteriormente limita-se pelas fibras do TPb4. Músculo delgado.

\section{Aphyocharax dentatus.}

Le1. Origina-se no proótico dorsalmente a articulação do $\mathrm{Pb} 1$ com o crânio. Insere-se no processo uncinado do Eb1. Músculo em forma de fita.

Le2. Origina-se no proótico. Insere-se na face lateral do processo uncinado do Eb2. Músculo em forma de fita.

Le3. Origina-se no proótico medialmente a origem do Li2-Li3. Insere-se na face lateral do processo uncinado do Eb3. Músculo em forma de fita.

Le4. Origina-se no proótico medialmente a origem do Le3. Insere-se na margem dorsal do processo levantador do Eb4. Músculo em forma de fita.

LP. Origina-se na margem ventral do pterótico juntamente com o PP. Insere-se na extremidade dorsal (cartilagem) do processo levantador do Eb4. Músculo em forma de fita. 
Li1. Origina-se no proótico dorso-lateralmente a origem do Le1. Insere-se na superfície dorsal do Pb2. Músculo em forma de leque.

Li2. Origina-se no proótico medialmente a origem do Le2. Insere-se na superfície dorsal do Pb3. Músculo em forma de fita.

Li3. Origina-se no proótico dorsalmente a origem do Li2. Insere-se na superfície dorsal do Pb4. Músculo em forma de fita.

Od3. Origina-se anteriormente na extremidade anterior óssea do $\mathrm{Pb} 3$ ventralmente ao TEb2. Insere-se na extremidade dorsal na margem anterior do processo uncinado do Eb3. Músculo fusiforme.

Od4. Origina-se anteriormente no $\mathrm{Pb} 4$. Insere-se na face lateral do processo levantador do Eb4. Músculo em leque.

Od4'. Presente. Esse músculo está localizado lateralmente ao Od4 e insere-se na face lateral do processo levantador do Eb4. Sua origem ocorre na parte óssea posterior do $\mathrm{Pb} 3$.

OP. Origina-se na margem medial do Eb4, próximo às fibras do TEb4 e termina na rafe do esôfago.

Ad4. Na face medial do processo levantador do Eb4 e na margem dorsal da extremidade posterior do $\mathrm{Cb} 4$, medialmente ao ângulo interno da articulação Eb4-Cb4.

Ad5. Na margem posterior do Eb5 (cartilagem) e na extremidade posterior do Cb5.

SO. Camada de músculo que circunda o esôfago, com aumento no tamanho das fibras dorsalmente, delgado em outras partes, anteriormente suas fibras se projetam ventralmente ao TEb4. 
TEb2. Liga-se medialmente a extremidade cartilaginosa do processo uncinado do Eb2 esquerdo e conecta-se a mesma estrutura do lado direito. Localiza-se dorsalmente ao Od3.

$\mathrm{TPb} 3$. Liga-se na face médio dorsal do Pb3 esquerdo e conecta-se na mesma estrutura no lado esquerdo. Está localizado ventralmente ao TEb2. É limitado posteriormente pelas fibras do $\mathrm{TPb} 4$.

$\mathrm{TPb} 4$. Liga-se ao longo da margem medial do $\mathrm{Pb} 4$ esquerdo e conecta-se na mesma região do lado direito. É limitado posteriormente pelas fibras do TEb4.

TEb4. Liga-se na face medial ventral do Eb4 esquerdo e insere-se na mesma estrutura do lado direito. Anteriormente limita-se pelas fibras do TPb4.

Astyanax fasciatus.

Le1. Origina-se no proótico dorsalmente a articulação do $\mathrm{Pb} 1$ com o crânio. Origem tendínea. Insere-se na face lateral do processo uncinado do Eb1. Músculo em forma de fita.

Le2. Origina-se no proótico dorso medialmente a origem do Le1-Li1. Insere-se na face lateral do processo uncinado do Eb2. Músculo em forma de fita.

Le3. Origina-se no proótico medialmente origem do Li3. Insere-se através de tendão afilado na extremidade dorsal do processo uncinado do Eb3. Músculo em forma de leque. 
Le4. Origina-se no proótico dorsalmente a origem do Le3. Insere-se através de tendão afilado na extremidade dorsal na margem anterior do processo levantador do Eb4. Músculo em forma de leque.

LP. Insere-se na extremidade dorsal na face medial do processo levantador do Eb4. Músculo em forma de fita.

Li1. Origina-se no proótico ventralmente a origem do Le1. Origem tendínea. Insere-se na superfície dorsal do $\mathrm{Pb} 2$. Músculo em forma de fita.

Li2. Origina-se no proótico dorsalmente a origem do Le2. Insere-se na superfície dorsal do $\mathrm{Pb3}$. Músculo em forma de fita.

Li3. Origina-se no proótico em uma incisura própria (incisura do Li3). Insere-se na superfície dorsal do $\mathrm{Pb} 4$. Músculo em forma de fita.

Od3. Origina-se anteriormente na extremidade anterior óssea do $\mathrm{Pb} 3$ ventralmente ao TEb2. Insere-se na extremidade dorsal na margem anterior do processo uncinado do Eb3. Músculo fusiforme.

Od4. Origina-se anteriormente no $\mathrm{Pb} 4$ com dois ventres musculares. Insere-se na face lateral do processo levantador do Eb4. Músculo em forma de leque.

Od4'. Presente.

OP. Origina-se na margem medial do Eb4, próximo às fibras do TEb4 e termina na rafe do esôfago.

Ad4. Na face medial do processo levantador do Eb4 e na margem dorsal da extremidade posterior do $\mathrm{Cb} 4$, medialmente ao ângulo interno da articulação Eb4-Cb4. 
Ad5. Na margem posterior do Eb5 (cartilagem) e na extremidade posterior do Cb5.

SO. Camada de músculo que circunda o esôfago, com aumento no tamanho das fibras dorsalmente, delgado em outras partes, anteriormente suas fibras se projetam ventralmente ao TEb4.

TEb2. Liga-se medialmente a extremidade cartilaginosa do processo uncinado do Eb2 esquerdo e conecta-se a mesma estrutura do lado direito. Localiza-se dorsalmente ao Od3.

$\mathrm{TPb} 3$. Liga-se na face médio dorsal do $\mathrm{Pb} 3$ esquerdo e conecta-se na mesma estrutura no lado esquerdo. Está localizado ventralmente ao TEb2. É limitado posteriormente pelas fibras do $\mathrm{TPb} 4$.

TPb4. Liga-se ao longo da margem medial do Pb4 esquerdo e conecta-se na mesma região do lado direito. É limitado posteriormente pelas fibras do TEb4.

TEb4. Liga-se na face medial ventral do Eb4 esquerdo e insere-se na mesma estrutura do lado direito. Anteriormente limita-se pelas fibras do TPb4.

\section{Astyanax ribeirae}

Le1. Origina-se no proótico dorsalmente a articulação do $\mathrm{Pb} 1$ com o crânio. Origem muscular. Insere-se na face lateral do processo uncinado do Eb1. Músculo em forma de fita.

Le2. Origina-se no proótico dorso medialmente a origem do Le1-Li1. Insere-se na face lateral do processo uncinado do Eb2. Músculo em forma de fita. 
Le3. Origina-se no proótico medialmente origem do Li3. Insere-se na extremidade dorsal e na margem anterior do processo uncinado do Eb3. Músculo em forma de leque na região de inserção.

Le4. Origina-se no proótico dorsalmente a origem do Le3. Insere-se na extremidade dorsal e na margem anterior do processo levantador do Eb4. Músculo em forma de fita.

LP. Insere-se na extremidade dorsal na face medial do processo levantador do Eb4. Músculo em forma de fita.

Li1. Origina-se no proótico ventralmente a origem do Le1. Origem tendínea. Insere-se na superfície dorsal do $\mathrm{Pb} 2$. Músculo em forma de fita.

Li2. Origina-se no proótico dorsalmente a origem do Le2. Insere-se na superfície dorsal do Pb3. Músculo em forma de fita.

Li3. Origina-se no proótico em uma incisura própria (incisura do Li3). Insere-se na superfície dorsal do $\mathrm{Pb} 4$. Músculo em forma de fita.

Od3. Origina-se anteriormente na extremidade anterior óssea do $\mathrm{Pb} 3$ ventralmente ao TEb2. Insere-se na extremidade dorsal na margem anterior do processo uncinado do Eb3. Músculo fusiforme.

Od4. Origina-se no $\mathrm{Pb} 4$ anteriormente. Insere-se na face lateral do processo levantador do Eb4. Músculo em forma de leque.

Od4'. Presente. Esse músculo está localizado lateralmente ao Od4 e insere-se na face lateral do processo levantador do Eb4. Sua origem ocorre na parte óssea posterior do Pb3. O limite das fibras entre o Od4 e Od4' não é claro podendo esse ser confundido 
com o Od4 ou classificado como um ventre do Od4 que apresenta origem de suas fibras no $\mathrm{Pb} 3$.

OP. Origina-se na margem medial do Eb4, próximo às fibras do TEb4 e termina na rafe do esôfago.

Ad4. Na face medial do processo levantador do Eb4 e na margem dorsal da extremidade posterior do $\mathrm{Cb} 4$, medialmente ao ângulo interno da articulação Eb4-Cb4.

Ad5. Na margem posterior do Eb5 (cartilagem) e na extremidade posterior do Cb5.

SO. Camada de músculo que circunda o esôfago, com aumento no tamanho das fibras dorsalmente, delgado em outras partes, anteriormente suas fibras se projetam ventralmente ao TEb4.

TEb2. Liga-se medialmente a extremidade cartilaginosa do processo uncinado do Eb2 esquerdo e conecta-se a mesma estrutura do lado direito. Localiza-se dorsalmente ao Od3.

$\mathrm{TPb} 3$. Liga-se na face médio dorsal do Pb3 esquerdo e conecta-se na mesma estrutura no lado esquerdo. Está localizado ventralmente ao TEb2. É limitado posteriormente pelas fibras do $\mathrm{TPb} 4$.

$\mathrm{TPb} 4$. Liga-se ao longo da margem medial do Pb4 esquerdo e conecta-se na mesma região do lado direito. É limitado posteriormente pelas fibras do TEb4.

TEb4. Liga-se na face medial ventral do Eb4 esquerdo e insere-se na mesma estrutura do lado direito. Anteriormente limita-se pelas fibras do TPb4. 
Bryconops alburnoides.

Le1. Origem não observada. Insere-se no processo uncinado do Eb1. Músculo fusiforme.

Le2. Origem não observada. Insere-se no processo uncinado do Eb2. Músculo em forma de fita.

Le3. Origem não observada. Insere-se na extremidade dorsal na face lateral do processo uncinado do Eb3. Músculo em forma de fita.

Le4. Origem não observada. Insere-se na extremidade dorsal na margem anterior do processo levantador do Eb4. Músculo em forma de fita.

LP. Origem não observada. Insere-se na extremidade dorsal cartilaginosa do processo levantador do Eb4. Músculo em forma de fita.

Li1. Origem não observada. Insere-se na superfície dorsal do $\mathrm{Pb}$. Músculo em forma de fita. Apresenta dois ventres.

Li2. Origem não observada. Insere-se na superfície dorsal do Pb3. Músculo em forma de fita

Li3. Origem não observada. Insere-se na superfície dorsal do Pb4. Músculo em forma de fita.

Od3. Origina-se anteriormente na extremidade anterior óssea do $\mathrm{Pb} 3$, ventralmente ao TEb3. Insere-se na extremidade dorsal cartilaginosa do processo uncinado do Eb3. Músculo fusiforme. 
Od4. Origina-se anteriormente no $\mathrm{Pb} 4$. Insere-se na face lateral do processo levantador do Eb4. Músculo em forma de leque.

Od4'. ausente.

OP. Origina-se na margem medial do Eb4, próximo às fibras do TEb4 e termina na rafe do esôfago.

Ad4. Na face medial do processo levantador do Eb4 e na margem dorsal da extremidade posterior do $\mathrm{Cb} 4$, medialmente ao ângulo interno da articulação Eb4-Cb4.

Ad5. Na margem posterior do Eb5 (cartilagem) e na extremidade posterior do Cb5.

SO. Camada de músculo que circunda o esôfago, com aumento no tamanho das fibras dorsalmente, delgado em outras partes, anteriormente suas fibras se projetam ventralmente ao TEb4.

TEb2. Liga-se medialmente a extremidade cartilaginosa do processo uncinado do Eb2 esquerdo e conecta-se a mesma estrutura do lado direito. Localiza-se dorsalmente ao Od3.

TPb3. Liga-se na face médio dorsal do Pb3 esquerdo e conecta-se na mesma estrutura no lado esquerdo. Está localizado ventralmente ao TEb2. É limitado posteriormente pelas fibras do $\mathrm{TPb} 4$.

TPb4. Liga-se ao longo da margem medial do $\mathrm{Pb} 4$ esquerdo e conecta-se na mesma região do lado direito. É limitado posteriormente pelas fibras do TEb4.

TEb4. Liga-se na face medial ventral do Eb4 esquerdo e insere-se na mesma estrutura do lado direito. Anteriormente limita-se pelas fibras do TPb4. 


\section{Brycon falcatus.}

Le1. Origina-se no proótico dorsalmente à articulação do $\mathrm{Pb} 1$ com o crânio e medialmente ao nervo (IX), através de um tendão afilado que também serve de origem ao músculo Li1. Insere-se na superfície dorsal do Eb1, lateralmente a extremidade cartilaginosa do processo uncinado idem Springer e Johnson (2004). Músculo fusiforme.

Le2. Origina-se no proótico medialmente à origem do Le1/Li1. Insere-se no Eb2 ventralmente a extremidade cartilaginosa do processo uncinado idem Springer e Johnson (2004). Apresenta ventre muscular mais desenvolvido na região da inserção em relação à região da origem.

Le3. Origina-se no proótico ventro medialmente às origens dos músculos Le1/Li1, Le2 e Li2. E insere-se no processo uncinado do Eb3. Na região de inserção esse músculo apresenta dois ventres distintos: dorsal, diretamente inserido na cartilagem do processo uncinado do Eb3 e ventral, inserido ventralmente à cartilagem do processo uncinado do Eb3.

Le4. Origina-se no proótico medialmente à origem do Le3 e lateralmente ao plexo branquial do (X). Inserção no processo levantador do Eb4 e base tendínea do LP idem Springer e Johnson (2004). Músculo em forma de fita.

LP. Origina-se no pterótico através de tendão. Compartilha a mesma origem com o músculo protractor pectoralis, sugerindo a presença de uma única origem para dois músculos. Inserção na extremidade dorsal do processo levantador do Eb4 idem Springer e Johnson (2004). Músculo fusiforme. 
Li1. Idem origem do Le1. Insere-se na região dorso posterior do $\mathrm{Pb} 2$ idem Springer e Johnson (2004). Músculo fusiforme que juntamente com o músculo Lel caracterizam um músculo bicaudado.

Li2. Origina-se no proótico, medialmente às origens do Le1/Li1 e Le2 e ventralmente à origem do Li3. Insere-se na superfície dorsal do $\mathrm{Pb} 3$ posteriormente idem Springer e Johnson (2004). Músculo em forma de fita com uma subdivisão medial (Li2m) mais evidenciada na região da inserção. Devido à proximidade dos ventres musculares de Li2 e Li3 a sua separação precisa ser cuidadosa.

Li3. Origina-se no proótico, medialmente às origens do Le1/Li1 e Le2 e dorsalmente à origem do Li2. Insere-se dorsalmente na margem lateral do $\mathrm{Pb} 4$.

Od3. Origina-se no $\mathrm{Pb} 3$ anteriormente e insere-se na extremidade cartilaginosa do processo uncinado do Eb3, medialmente a inserção do Le3 idem Springer e Johnson (2004). Músculo fusiforme.

Od4. Origem no $\mathrm{Pb} 4$ anteriormente com fibras conectadas ao $\mathrm{Pb} 3$ na região de articulação entre o $\mathrm{Pb} 4$ e o $\mathrm{Pb} 3$. Insere-se ao longo da margem lateral do processo levantador do Eb4 idem Springer e Johnson (2004). O Od4 está dividido em dois ventres musculares podendo ser dividido em Od4 lateral e Od4 medial.

Od4'. Ausente.

OP. Origina-se na superfície póstero medial do Eb4 pouco separada do SO, terminando ventralmente na rafe do esôfago. As fibras musculares continuam ventralmente a partir da rafe do esôfago incluindo o Ad5 e o SO, idem Springer e Johnson (2004). 
Ad4. No Eb4 dorso posteriormente e na superfície dorsal do Cb4, medialmente ao ângulo interno da articulação do Eb4-Cb4, idem Springer e Johnson (2004).

Ad5. No Eb5 médio posteriormente e Cb5 posteriormente, com uma extensão tendínea dorso lateralmente, cruzando o Eb5 dorsalmente a extremidade distal do Eb4. Une-se a rafe do esôfago ventralmente e OP lateralmente, idem Springer e Johnson (2004).

SO. Camada de músculo longitudinal que circunda o esôfago, com aumento no tamanho das fibras dorsalmente, delgado em outras partes, idem Springer e Johnson (2004).

TEb2. Liga-se medialmente ao processo uncinado do Eb2 esquerdo e conecta-se na mesma estrutura no lado direito.

$\mathrm{TPb} 3$. Liga-se na face médio dorsal do Pb3 esquerdo e conecta-se na mesma estrutura no lado esquerdo. Está localizado ventralmente ao TEb2 e na região do seu limite posterior suas fibras confundem-se com as do $\mathrm{TPb} 4$.

TPb4. Liga-se ao longo da margem medial do Pb4 esquerdo e insere-se na mesma região do lado direito. Anteriormente seu limite não é bem definido, pois suas fibras musculares se confundem com as fibras do $\mathrm{TPb} 3$. Seu limite posterior é bem estabelecido pelo músculo TEb4.

TEb4. Liga-se medialmente às origens dos músculos LE4 e Od4 no Eb4 esquerdo e conecta-se nas mesmas estruturas no lado direito. Músculo em forma de fuso, com as fibras ligeiramente mais desenvolvidas que as do $\mathrm{TPb} 4$.

Brycon opalinus. 
Le1. Origina-se no proótico dorsalmente a articulação do $\mathrm{Pb} 1$ com o crânio, medialmente ao nervo glossofaríngeo. Localiza-se lateralmente às origens dos outros músculos levantadores. Músculo fusiforme. Não foi possível verificar a inserção devido à perda do Eb1, durante o processo de remoção dos arcos branquiais.

Le2. Origina-se no proótico dorsalmente a articulação do $\mathrm{Pbl}$ com o crânio, medialmente a origem do Le1. Localiza-se lateralmente ao Le3, Le4, LP e Li2. Sua inserção idem Springer e Johnson (2004) para B.melanopterus. Músculo fusiforme.

Le3. Origina-se no proótico dorsalmente a articulação do $\mathrm{Pb} 1$ com o crânio, medialmente a origem do Le2 e do Li2. Sua inserção ocorre na margem lateral do processo uncinado do Eb3, próximo a inserção do músculo Od3 na extremidade cartilaginosa do processo uncinado. Músculo fusiforme, apresentando o menor ventre entre os músculos levantadores.

Le4. Origina-se no proótico ventro medialmente à origem dos músculos Le1, Le2, Li1, Li2 e Li3 e dorsalmente à origem do Le3. Insere-se idem Springer e Johnson (2004). Seu ventre é alongado apresentando forma de fita.

LP. Origina-se no pterótico através de tendão. Compartilha a mesma origem com o músculo protractor pectoralis, sugerindo a presença de uma única origem para dois músculos. Sua inserção idem Springer e Johnson (2004). Músculo fusiforme.

Li1. Origina-se no proótico localizando-se medialmente ao Le1 e lateralmente ao Le2. Sua inserção idem Springer e Johnson (2004).

Li2. Origina-se no proótico localizando-se medialmente ao Le2. Sua inserção idem Springer e Johnson (2004). 
Li3. Origina-se no proótico localizando-se medialmente ao Le2 e Li2. Sua inserção idem Springer e Johnson (2004). Apresenta um ventre muscular bem desenvolvido em relação aos ventres musculares dos outros músculos levantadores.

Od3. Idem Springer e Johnson (2004).

Od4. Idem Springer e Johnson (2004).

Od4'. Ausente.

OP. Origina-se na margem posterior do Eb4 e insere-se na rafe do esôfago posteriormente. Suas fibras musculares são de difícil distinção com o SO, idem Springer e Johnson (2004).

Ad4. Idem Springer e Johnson (2004).

Ad5. Idem Springer e Johnson (2004).

SO. Idem Springer e Johnson (2004).

TEb2. Liga-se medialmente a extremidade cartilaginosa do processo uncinado do Eb2 esquerdo e conecta-se à mesma estrutura no lado direito, o Od3 limita ventralmente esse músculo.

TPb3. Liga-se dorsalmente na região óssea do Pb3 esquerdo. Conecta-se na mesma estrutura no lado direito. $\mathrm{O} \mathrm{Od} 3$ está localizado dorsalmente ao $\mathrm{TPb} 3$.

$\mathrm{TPb} 4$. Liga-se na margem medial do $\mathrm{Pb} 4$ esquerdo e conecta-se na mesma estrutura no lado direito. Esse músculo é formado por uma fina camada de fibras musculares limitadas posteriormente pelas fibras do TEb4. 
TEb4. Liga-se medialmente às origens dos músculos LE4 e Od4 no Eb4 esquerdo e conecta-se nas mesmas estruturas no lado direito. Músculo em forma de fuso, com as fibras ligeiramente mais desenvolvidas que as do $\mathrm{TPb} 4$.

\section{Bryconamericus turiuba.}

Le1. Origina-se no proótico na incisura do proótico dorsalmente a articulação do $\mathrm{Pb} 1$ com o crânio. Insere-se na margem anterior do processo uncinado do Eb1.

Le2. Origina-se no proótico medialmente a origem do Li1. Insere-se na margem lateral do processo uncinado do Eb2. Músculo em forma de fita.

Le3. Originar-se no proótico medialmente a origem do Li2 e Li3. Insere-se na margem anterior do processo uncinado do Eb3. Músculo em forma de fita.

Le4. Origina-se no proótico medialmente a origem do Le3. Insere-se na extremidade dorsal na margem anterior do processo levantador do Eb4. Músculo em forma de fita.

LP. Origina-se na margem ventral do pterótico medialmente a origem do PP. Insere-se na extremidade dorsal do processo levantador do Eb4. Músculo em forma de fita.

Li1. Origina-se no proótico dorsalmente a origem do Le1. Insere-se na superfície dorsal do $\mathrm{Pb} 2$. Músculo em forma de leque.

Li2. Origina-se no proótico dorsalmente a origem do Le2. Insere-se na superfície dorsal do Pb3. Músculo em forma de fita.

Li3. Origina-se no proótico dorsalmente a origem do Li2. Insere-se na superfície dorsal do $\mathrm{Pb} 4$. Músculo em forma de fita. 
Od3. Origina-se anteriormente na extremidade anterior óssea do $\mathrm{Pb} 3$ ventralmente ao TEb2. Insere-se na extremidade dorsal cartilaginosa do processo uncinado do Eb3. Músculo em forma de fita.

Od4. Origina-se anteriormente no $\mathrm{Pb} 4$ e insere-se na face lateral e margem anterior do processo levantador do Eb4. Músculo em forma de leque.

Od4'. Presente. Origina-se anteriormente no $\mathrm{Pb} 3$ e insere-se na margem anterior e na face lateral do processo levantador do Eb4. Músculo em forma de fita.

OP. Origina-se na margem medial do Eb4, próximo às fibras do TEb4 e termina na rafe do esôfago.

Ad4. Na face medial do processo levantador do Eb4 e na margem dorsal da extremidade posterior do $\mathrm{Cb} 4$, medialmente ao ângulo interno da articulação Eb4-Cb4.

Ad5. Na margem posterior do Eb5 (cartilagem) e na extremidade posterior do Cb5.

SO. Camada de músculo que circunda o esôfago, com aumento no tamanho das fibras dorsalmente, delgado em outras partes, anteriormente suas fibras apresentam projeção conspícua, ventralmente ao TEb4.

TEb2. Liga-se medialmente a extremidade cartilaginosa do processo uncinado do Eb2 esquerdo e conecta-se a mesma estrutura do lado direito. Localiza-se dorsalmente ao Od3.

$\mathrm{TPb} 3$. Liga-se na face médio dorsal do Pb3 esquerdo e conecta-se na mesma estrutura no lado esquerdo. Está localizado ventralmente ao TEb2. É limitado posteriormente pelas fibras do $\mathrm{TPb} 4$. 
TPb4. Liga-se ao longo da margem medial do Pb4 esquerdo e conecta-se na mesma região do lado direito. É limitado posteriormente pelas fibras do TEb4.

TEb4. Liga-se na face medial ventral do Eb4 esquerdo e insere-se na mesma estrutura do lado direito. Anteriormente limita-se pelas fibras do TPb4. Músculo delgado.

\section{Charax pauciradiatus.}

Le1. Origina-se no proótico através de tendão e na extremidade dorsal do Pb1. Insere-se na face lateral do processo uncinado do Eb1. Músculo fusiforme, com uma cabeça e duas caudas. A cauda medial é o Li1.

Le2. Origina-se no proótico medialmente a origem do Li1. Insere-se na extremidade dorsal do processo uncinado do Eb2. Músculo em forma de fita.

Le3. Origina-se medialmente no proótico ventralmente a origem LE1, Le2, Li1, Li2 e

Li3. Insere-se na extremidade dorsal do processo uncinado do Eb3. Músculo em forma de fita.

Le4. Origina-se no proótico medialmente a origem do Le3. Insere-se na extremidade dorsal na margem anterior do processo levantador do Eb4. Músculo em forma de fita.

LP. Origina-se na margem ventral do pterótico. Insere-se na extremidade dorsal do processo levantador do Eb4. Músculo em forma de fita.

Li1. Cauda medial do Le1.

Li2. Origina-se no proótico dorsalmente a origem do Le2. Insere-se na superfície dorsal do Pb3. Músculo em forma de fita. 
Li3. Origina-se no proótico dorsalmente a origem do Li2. Insere-se na superfície dorsal do $\mathrm{Pb} 4$. Músculo em forma de fita.

Od3. Origina-se anteriormente na extremidade anterior do $\mathrm{Pb} 3$ ventralmente ao TEb2. Insere-se na extremidade dorsal do processo uncinado do Eb3 (osso). Músculo em forma de fita.

Od4. Origina-se anteriormente no $\mathrm{Pb} 4$. Insere-se na face lateral do processo levantador do Eb4. Músculo em forma de leque.

Od4'. Ausente.

OP. Origina-se na margem medial do Eb4, próximo às fibras do TEb4 e termina na rafe do esôfago.

Ad4. Na face medial do processo levantador do Eb4 e na margem dorsal da extremidade posterior do $\mathrm{Cb} 4$, medialmente ao ângulo interno da articulação Eb4-Cb4.

Ad5. Na margem posterior do Eb5 (cartilagem) e na extremidade posterior do Cb5.

SO. Camada de músculo que circunda o esôfago, com aumento no tamanho das fibras dorsalmente, delgado em outras partes, anteriormente suas fibras se projetam ventralmente ao TEb4.

TEb2. Liga-se medialmente a extremidade cartilaginosa do processo uncinado do Eb2 esquerdo e conecta-se a mesma estrutura do lado direito. Localiza-se dorsalmente ao Od3.

TPb3. Liga-se na face médio dorsal do Pb3 esquerdo e conecta-se na mesma estrutura no lado esquerdo. Está localizado ventralmente ao TEb2. É limitado posteriormente pelas fibras do $\mathrm{TPb} 4$. 
TPb4. Liga-se ao longo da margem medial do Pb4 esquerdo e conecta-se na mesma região do lado direito. É limitado posteriormente pelas fibras do TEb4.

TEb4. Liga-se na face medial ventral do Eb4 esquerdo e insere-se na mesma estrutura do lado direito. Anteriormente limita-se pelas fibras do TPb4.

\section{Cheirodon interruptus.}

Le1. Origina-se no proótico dorsalmente a articulação do Pb1 com o crânio. Insere-se no processo uncinado do Eb1. Músculo em forma de fita.

Le2. Origina-se no proótico dorsalmente a origem do Li1. Insere-se no processo uncinado do Eb2. Músculo em forma de fita.

Le3. Origina-se no proótico medialmente a origem do Li2 e Li3. Insere-se na extremidade dorsal (osso) do processo uncinado do Eb3. Músculo em forma de fita.

Le4. Origina-se no proótico medialmente a origem do Le3. Insere-se na extremidade dorsal da margem anterior do processo levantador do Eb4. Músculo em forma de fita.

LP. Origina-se na margem ventral do pterótico medialmente ao PP. Insere-se na extremidade dorsal (cartilagem) do processo levantador do Eb4.

Li1. Origina-se no proótico medialmente a origem do Le1. Insere-se na superfície dorsal do $\mathrm{Pb} 2$. Músculo em forma de fita.

Li2. Origina-se no proótico dorsalmente a origem do Le2. Insere-se na superfície dorsal do Pb3. Músculo em forma de fita. 
Li3. Origina-se no proótico dorsalmente a origem do Li2. Insere-se na superfície dorsal do Pb4.

Od3. Origina-se anteriormente na extremidade anterior do $\mathrm{Pb} 3$ (osso) ventralmente ao TEb2. Insere-se na margem anterior do processo uncinado do Eb3 (osso). Músculo fusiforme com dois ventres.

Od4. Origina-se anteriormente no $\mathrm{Pb}$ 4. Insere-se na superfície lateral do processo levantador do Eb4. Músculo em leque.

Od4'. Presente. Esse músculo está localizado lateralmente ao Od4 e insere-se na face lateral do processo levantador do Eb4. Sua origem ocorre na parte óssea posterior do Pb3. O limite das fibras entre o Od4 e Od4' não é claro podendo esse ser confundido com o Od4 ou classificado como um ventre do Od4 que apresenta origem de suas fibras no $\mathrm{Pb} 3$.

OP. Origina-se na margem medial do Eb4, próximo às fibras do TEb4 e termina na rafe do esôfago.

Ad4. Na face medial do processo levantador do Eb4 e na margem dorsal da extremidade posterior do $\mathrm{Cb} 4$, medialmente ao ângulo interno da articulação Eb4-Cb4.

Ad5. Na margem posterior do Eb5 (cartilagem) e na extremidade posterior do Cb5.

SO. Camada de músculo que circunda o esôfago, com aumento no tamanho das fibras dorsalmente, delgado em outras partes, anteriormente suas fibras apresentam projeção conspícua, ventralmente ao TEb4. 
TEb2. Liga-se medialmente a extremidade cartilaginosa do processo uncinado do Eb2 esquerdo e conecta-se a mesma estrutura do lado direito. Localiza-se dorsalmente ao Od3.

TPb3. Liga-se na face médio dorsal do Pb3 esquerdo e conecta-se na mesma estrutura no lado esquerdo. Está localizado ventralmente ao TEb2. É limitado posteriormente pelas fibras do $\mathrm{TPb} 4$.

$\mathrm{TPb} 4$. Liga-se ao longo da margem medial do $\mathrm{Pb} 4$ esquerdo e conecta-se na mesma região do lado direito. É limitado posteriormente pelas fibras do TEb4.

TEb4. Liga-se na face medial ventral do Eb4 esquerdo e insere-se na mesma estrutura do lado direito. Anteriormente limita-se pelas fibras do TPb4. Músculo delgado.

\section{Cynopotamus kincaidi.}

Le1. Origina-se na extremidade dorsal na face posterior do $\mathrm{Pb} 1$ e na incisura do proótico através de tendão dorsalmente a articulação do $\mathrm{Pb} 1$ com o crânio Insere-se na extremidade dorsal na face anterior do processo uncinado do Eb1. Músculo em forma de fita, com duas cabeças. Na origem esse músculo está localizado juntamente com outros músculos levantadores na incisura do proótico.

Le2. Origina-se na incisura do proótico dorsalmente a origem do Le1. Origem tendínea. Insere-se na face anterior do processo uncinado do Eb2. Músculo em forma de fita.

Le3. Origina-se no proótico medialmente a incisura do proótico. Insere-se na face anterior do processo uncinado do Eb3 ventralmente a inserção do Od3. Músculo em forma de fita. 
Le4. Origina-se no proótico medialmente a origem do Le3. Insere-se na extremidade dorsal do processo levantador do Eb4. Músculo em forma de fita.

LP. Origina-se na extremidade posterior na margem ventral do pterótico juntamente com o PP. Origem tendínea. Insere-se na extremidade dorsal na superfície medial do processo levantador do Eb4. Músculo fusiforme.

Li1. Origina-se na incisura proótico medialmente a origem do Le1. Insere-se na superfície dorsal do $\mathrm{Pb} 2$. Músculo em forma de fita

Li2. Origina-se na incisura do proótico medialmente a origem do Le2. Insere-se na superfície dorsal do $\mathrm{Pb} 3$. Músculo em forma de fita.

Li3. Origina-se na incisura do proótico dorsalmente a origem do Li2. Insere-se na superfície dorsal do $\mathrm{Pb} 4$. Músculo em forma de fita.

Od3. Origina-se anteriormente na extremidade anterior óssea do $\mathrm{Pb} 3$ ventralmente ao TEb2. Insere-se na extremidade dorsal (cartilagem) do processo uncinado do Eb3. Músculo fusiforme.

Od4. Origina-se anteriormente no $\mathrm{Pb} 4$ (cartilagem). Insere-se na face lateral do processo levantador do Eb4. Músculo largo.

Od4'. Presente. Esse músculo está localizado lateralmente ao Od4 e insere-se na face lateral do processo levantador do Eb4. Sua origem ocorre na parte óssea posterior do Pb3. O limite das fibras entre o Od4 e Od4' não é claro podendo esse ser confundido com o Od4 ou classificado como um ventre do Od4 que apresenta origem de suas fibras no $\mathrm{Pb} 3$. 
OP. Origina-se na margem medial do Eb4, próximo às fibras do TEb4 e termina na rafe do esôfago.

Ad4. Na face medial do processo levantador do Eb4 e na margem dorsal da extremidade posterior do $\mathrm{Cb} 4$, medialmente ao ângulo interno da articulação Eb4-Cb4.

Ad5. Na margem posterior do Eb5 (cartilagem) e na extremidade posterior do Cb5.

SO. Camada de músculo que circunda o esôfago, com aumento no tamanho das fibras dorsalmente, delgado em outras partes, suas fibras são limitadas anteriormente pelo TEb4.

TEb2. Liga-se medialmente a extremidade cartilaginosa do processo uncinado do Eb2 esquerdo e conecta-se a mesma estrutura do lado direito. Localiza-se dorsalmente ao Od3.

$\mathrm{TPb} 3-\mathrm{TPb} 4$. Liga-se na face médio dorsal do $\mathrm{Pb} 3$ e $\mathrm{Pb} 4$ esquerdos e conecta-se nas mesmas estruturas no lado esquerdo. Está localizado ventralmente ao TEb2. É limitado posteriormente pelas fibras do TEb4.

TEb4. Liga-se na face medial ventral do Eb4 esquerdo e insere-se na mesma estrutura do lado direito. Anteriormente limita-se pelas fibras do TPb3-TPb4.

\section{Exodon paradoxus}

Le1. Origina-se no proótico dorsalmente a articulação do $\mathrm{Pb} 1$ com o crânio, origem muscular. Insere-se na margem dorsal do processo uncinado do Eb1. Músculo fusiforme. $\mathrm{Na}$ origem esse músculo está localizado juntamente com outros músculos levantadores na incisura do proótico. 
Le2. Origina-se no proótico medialmente a origem do Le1. Origem muscular. Insere-se na face lateral do processo uncinado do Eb2. Músculo em forma de fita.

Le3. Origina-se no proótico medialmente a incisura do proótico. Origem muscular. Insere-se na face anterior do processo uncinado do Eb3 dorsalmente a inserção do Od3. Músculo em forma de fita.

Le4. Origina-se no proótico medialmente a origem do Le3. Origem muscular. Insere-se na extremidade dorsal do processo levantador do Eb4. Músculo em forma de fita.

LP. Origina-se na extremidade posterior na margem ventral do pterótico juntamente com o PP. Origem tendínea. Insere-se na extremidade dorsal do processo levantador do Eb4. Músculo em forma de fita.

Li1. Origina-se no proótico medialmente a origem do Le1. Origem muscular. Insere-se na superfície dorsal do Pb2. Músculo fusiforme.

Li2-Li3. Origina-se no proótico medialmente a origem do Le2. Origem muscular. Insere-se na parte posterior do $\mathrm{Pb} 3$ e na parte anterior do Pb4. Músculo em forma de fita. Nota: não foi possível evidenciar no exemplar dissecado separação nítida entre os ventres musculares do Li2 e do Li3.

Od3. Origina-se anteriormente na porção média do $\mathrm{Pb} 3$ ventralmente ao TEb2 e inserese na extremidade dorsal do processo uncinado do Eb3, medialmente a origem do Le3. Músculo fusiforme.

Od4. Origina-se anteriormente na extremidade anterior do $\mathrm{Pb} 4$ e insere-se ao longo de toda margem anterior do processo levantador do Eb4. Músculo em forma de leque. 
Od4'. Presente. Esse músculo está localizado lateralmente ao OD4 e insere-se na face lateral do processo levantador do Eb4. Sua origem ocorre na parte óssea posterior do Pb3. O limite das fibras entre o Od4 e Od4' não é claro podendo esse ser confundido com o Od4 ou classificado como um ventre do od4 que apresenta origem de suas fibras no $\mathrm{Pb} 3$.

OP. Origina-se na margem medial do Eb4, próximo às fibras do TEb4 e termina na rafe do esôfago.

Ad4. Na face medial do processo levantador do Eb4 e na margem dorsal da extremidade posterior do $\mathrm{Cb} 4$, medialmente ao ângulo interno da articulação Eb4-Cb4.

Ad5. Na margem posterior do Eb5 (cartilagem) e na extremidade posterior do $\mathrm{Cb} 5$.

SO. Camada de músculo que circunda o esôfago, com aumento no tamanho das fibras dorsalmente, delgado em outras partes, anteriormente suas fibras se projetam ventralmente ao TEb4.

TEb2. Liga-se medialmente a extremidade cartilaginosa do processo uncinado do Eb2 esquerdo e conecta-se a mesma estrutura do lado direito. Músculo delgado localizado dorsalmente ao Od3.

TPb3. Liga-se na face médio dorsal do Pb3 esquerdo e conecta-se na mesma estrutura no lado esquerdo. Está localizado ventralmente ao TEb2. É limitado posteriormente pelas fibras do $\mathrm{TPb} 4$.

TPb4. Liga-se ao longo da margem medial do $\mathrm{Pb} 4$ esquerdo e conecta-se na mesma região do lado direito. É limitado posteriormente pelas fibras do TEb4. 
TEb4. Liga-se na face medial ventral do Eb4 esquerdo e insere-se na mesma estrutura do lado direito. Anteriormente suas fibras se projetam ventralmente ao TEb4.

Nota: As origens do Le1, Le2, Li1, Li2-Li3 estão localizadas na incisura do proótico, mas devido a sua origem carnosa é possível distinguir pontos de origens separados nessa região.

Gnathocharax steindachneri.

Le1. Origina-se no proótico dorsalmente a articulação do Pb1 com o crânio. Insere-se no processo uncinado do Eb1. Músculo fusiforme.

Le2. Origina-se no proótico dorsalmente a origem do Le1. Insere-se no processo uncinado do Eb2. Músculo em forma de fita.

Le3. Origina-se no proótico medialmente as origens do Li2-Li3. Insere-se no processo uncinado do Eb3. Músculo em forma de leque.

Le4. Origina-se no proótico medialmente a origem do Le3. Insere-se na extremidade dorsal na margem anterior do processo levantador do Eb4. Músculo em forma de fita.

LP. Origina-se no pterótico. Insere-se na extremidade dorsal do processo levantador do Eb4 (cartilagem). Músculo em forma de fita.

Li1. Origina-se no proótico medialmente a origem do Le2. Insere-se na superfície dorsal do $\mathrm{Pb} 2$. Músculo em forma de fita.

Li2. Origina-se no proótico dorsalmente a origem do Le2. Insere-se na superfície dorsal do Pb3. Músculo em forma de fita. 
Li3. Origina-se no proótico dorsalmente a origem do Li2. Insere-se na superfície dorsal do Pb4. Músculo em forma de fita.

Od3. Origina-se anteriormente na extremidade posterior do Pb3. Insere-se na extremidade dorsal na margem anterior do processo uncinado do Eb3. Músculo em forma de fita.

Od4. Origina-se anteriormente no $\mathrm{Pb} 4$ (cartilagem). Insere-se na margem anterior e na face lateral do processo levantador do Eb4. Músculo em leque.

Od4'. Presente idem anterior.

OP. Não observado.

Ad4. Na face medial do processo levantador do Eb4 e na margem dorsal da extremidade posterior do $\mathrm{Cb} 4$, medialmente ao ângulo interno da articulação Eb4-Cb4.

Ad5. Na margem posterior do Eb5 (cartilagem) e na extremidade posterior do Cb5.

SO. Camada de músculo que circunda o esôfago, com aumento no tamanho das fibras dorsalmente, delgado em outras partes, anteriormente suas fibras se projetam ventralmente ao TEb4.

TEb2. Liga-se medialmente a extremidade cartilaginosa do processo uncinado do Eb2 esquerdo e conecta-se a mesma estrutura do lado direito. Localiza-se dorsalmente ao Od3.

$\mathrm{TPb} 3$. Liga-se na face médio dorsal do $\mathrm{Pb} 3$ esquerdo e conecta-se na mesma estrutura no lado esquerdo. Está localizado ventralmente ao TEb2. É limitado posteriormente pelas fibras do $\mathrm{TPb} 4$. 
TPb4. Liga-se ao longo da margem medial do Pb4 esquerdo e conecta-se na mesma região do lado direito. É limitado posteriormente pelas fibras do TEb4.

TEb4. Liga-se na face medial ventral do Eb4 esquerdo e insere-se na mesma estrutura do lado direito. Anteriormente limita-se pelas fibras do TPb4.

\section{Hemigrammus coeruleus.}

Le1. Origina-se no proótico dorsalmente a articulação do $\mathrm{Pb} 1$ com o crânio. Insere-se dorsalmente na face lateral do processo uncinado do Eb1. Músculo fusiforme.

Le2. Origina-se no proótico ventro medialmente a origem do Li1. Insere-se na face lateral do processo uncinado do Eb2. Músculo fusiforme.

Le3. Origina-se no proótico medialmente a origem do Li2-Li3. Insere-se na margem anterior do processo uncinado do Eb3 lateralmente a origem do Od3. Músculo em forma de fita.

Le4. Origina-se no proótico medialmente a origem do Le3. Insere-se na extremidade dorsal na margem anterior do processo levantador do Eb4, dorsalmente a inserção do Od4. Músculo em forma de fita.

LP. Origina-se na margem ventral do pterótico. Insere-se na extremidade dorsal (cartilagem) do processo levantador do Eb4. Músculo delgado em forma de fita.

Li1. Origina-se no proótico medialmente a origem do Le1. Insere-se na região de articulação entre o $\mathrm{Pb} 2-\mathrm{Eb} 1$ na superfície dorsal do $\mathrm{Pb}$ 2. Músculo em forma de fita. 
Li2. Origina-se no proótico dorsalmente a origem do Le2. Insere-se na superfície dorsal do Pb3. Músculo em forma de fita.

Li3. Origina-se no proótico dorsalmente a origem do Li2. Insere-se na superfície dorsal do Pb4. Músculo em forma de fita.

Od3. Origina-se anteriormente no $\mathrm{Pb} 3$ (osso) ventralmente ao TEb2. Insere-se na extremidade dorsal na margem anterior do processo uncinado do Eb3 (osso e cartilagem). Músculo em forma de fita.

Od4. Origina-se anteriormente no $\mathrm{Pb} 4$ (cartilagem). Insere-se na face lateral do processo levantador do Eb4 (osso). Músculo em forma de leque.

Od4'. Origina-se na extremidade posterior óssea do $\mathrm{Pb} 3$ anteriormente. Insere-se no processo levantador do Eb4. Esse músculo está localizado dorsalmente ao Od4.

OP. Não observado.

Ad4. Na face medial do processo levantador do Eb4 e na margem dorsal da extremidade posterior do $\mathrm{Cb} 4$, medialmente ao ângulo interno da articulação Eb4-Cb4.

Ad5. Na margem posterior do Eb5 (cartilagem) e na extremidade posterior do Cb5.

SO. Camada de músculo que circunda o esôfago, com aumento no tamanho das fibras dorsalmente, delgado em outras partes, anteriormente suas fibras apresentam projeção conspícua, ventralmente ao TEb4.

TEb2. Liga-se medialmente a extremidade cartilaginosa do processo uncinado do Eb2 esquerdo e conecta-se a mesma estrutura do lado direito. Localiza-se dorsalmente ao Od3. 
TPb3. Liga-se na face médio dorsal do Pb3 esquerdo e conecta-se na mesma estrutura no lado esquerdo. Está localizado ventralmente ao TEb2. É limitado posteriormente pelas fibras do $\mathrm{TPb} 4$.

$\mathrm{TPb} 4$. Liga-se ao longo da margem medial do Pb4 esquerdo e conecta-se na mesma região do lado direito. É limitado posteriormente pelas fibras do TEb4.

TEb4. Liga-se na face medial ventral do Eb4 esquerdo e insere-se na mesma estrutura do lado direito. Anteriormente limita-se pelas fibras do TPb4.

\section{Hyphessobrycon luetkenii.}

Le1. Origina-se no proótico dorsalmente a articulação do $\mathrm{Pb} 1$ com o crânio. Insere-se dorsalmente na face lateral do processo uncinado do Eb1. Músculo largo com dois ventres.

Le2. Origina-se no proótico medialmente a origem do Le1. Insere-se na margem anterior do processo uncinado do Eb2 (cartilagem e osso). Músculo em forma de fita. Le3. Origina-se no proótico medialmente a origem do Li2-Li3. Insere-se na margem anterior do processo uncinado do Eb3 (osso). Músculo em forma de fita.

Le4. Origina-se no proótico medialmente a origem do Le3. Insere-se na extremidade dorsal na margem anterior do processo levantador do Eb4. Músculo em forma de leque.

LP. Origina-se na margem ventral do pterótico. Insere-se na extremidade dorsal (cartilagem) do processo levantador do Eb4. Músculo delgado em forma de fita.

Li1. Origina-se no proótico medialmente a origem do Le1. Insere-se na região de articulação entre o $\mathrm{Pb} 2-\mathrm{Eb} 1$ na superfície dorsal do $\mathrm{Pb} 2$. Músculo em forma de fita. 
Li2. Origina-se no proótico dorsalmente a origem do Le2. Insere-se na superfície dorsal do Pb3. Músculo em forma de fita.

Li3. Origina-se no proótico dorsalmente a origem do Li2. Insere-se na superfície dorsal do Pb4. Músculo em forma de fita.

Od3. Origina-se anteriormente no $\mathrm{Pb} 3$ (osso) ventralmente ao TEb2. Insere-se na extremidade dorsal na margem anterior do processo uncinado do Eb3 (osso e cartilagem). Músculo em forma de fita.

Od4. Origina-se anteriormente no $\mathrm{Pb} 4$ (cartilagem). Insere-se na face lateral do processo levantador do Eb4 (osso). Músculo em forma de leque.

Od4'. Presente. Idem Cynopotamus.

OP. Não observado.

Ad3. Na foto do arco em vista lateral é possível verificar a presença do Ad3 entre o ângulo interno formado pela articulação do Eb3- Cb3.

Ad4. Na face medial do processo levantador do Eb4 e na margem dorsal da extremidade posterior do $\mathrm{Cb} 4$, medialmente ao ângulo interno da articulação Eb4-Cb4.

Ad5. Na margem posterior do Eb5 (cartilagem) e na extremidade posterior do Cb5.

SO. Camada de músculo que circunda o esôfago, com aumento no tamanho das fibras dorsalmente, delgado em outras partes, anteriormente suas fibras apresentam projeção conspícua, ventralmente ao TEb4. 
TEb2. Liga-se medialmente a extremidade cartilaginosa do processo uncinado do Eb2 esquerdo e conecta-se a mesma estrutura do lado direito. Localiza-se dorsalmente ao Od3.

$\mathrm{TPb} 3$. Liga-se na face médio dorsal do Pb3 esquerdo e conecta-se na mesma estrutura no lado esquerdo. Está localizado ventralmente ao TEb2. É limitado posteriormente pelas fibras do $\mathrm{TPb} 4$.

$\mathrm{TPb} 4$. Liga-se ao longo da margem medial do $\mathrm{Pb} 4$ esquerdo e conecta-se na mesma região do lado direito. É limitado posteriormente pelas fibras do TEb4.

TEb4. Liga-se na face medial ventral do Eb4 esquerdo e insere-se na mesma estrutura do lado direito. Anteriormente limita-se pelas fibras do TPb4.

Iguanodectes spilurus.

Le1. Origina-se no proótico dorsalmente a articulação do Pb1 com o crânio. Insere-se na extremidade dorsal cartilaginosa do processo uncinado do Eb1. Músculo curto.

Le2. Origina-se no proótico medialmente a origem do Li1. Insere-se na extremidade dorsal cartilaginosa do processo uncinado do Eb2. Músculo em forma de fita.

Le3. Origina-se no proótico medialmente a origem do Li2-Li3. Insere-se na extremidade dorsal na margem anterior do processo uncinado do Eb3. Músculo em forma de fita.

Le4. Origina-se no proótico medialmente a origem do Le3. Insere-se na extremidade dorsal na margem anterior do processo levantador do Eb4. Músculo em forma de fita. 
LP. Origina-se na margem ventral do pterótico. Insere-se na extremidade dorsal cartilaginosa do processo levantador do Eb4. Músculo em forma de fita.

Li1. Origina-se no proótico medialmente a origem do Le1. Insere-se na superfície dorsal do $\mathrm{Pb} 2$ medialmente a articulação entre o Pb2 e Eb1. Músculo delgado em forma de fita dividido em dois ventres.

Li2. Origina-se no proótico dorsalmente a origem do Li1. Insere-se na superfície dorsal do Pb3. Músculo em forma de fita.

Li3. Origina-se no proótico dorsalmente a origem do Li2. Insere-se na superfície dorsal do Pb4. Músculo em forma de fita.

Od3. Origina-se na extremidade anterior cartilaginosa do $\mathrm{Pb} 3$ ventralmente ao TEb2. Insere-se na margem anterior do processo uncinado do Eb3 (parte óssea). Músculo em forma de fita.

Od4. Origina-se no $\mathrm{Pb} 4$ (cartilagem) anteriormente. Insere-se na face lateral do processo levantador do Eb4. Músculo em forma de leque.

Od4'. Ausente.

OP. Origina-se na margem medial do Eb4, próximo às fibras do TEb4 e termina na rafe do esôfago.

Ad4. Na face medial do processo levantador do Eb4 e na margem dorsal da extremidade posterior do $\mathrm{Cb} 4$, medialmente ao ângulo interno da articulação Eb4-Cb4.

Ad5. Na margem posterior do Eb5 (cartilagem) e na extremidade posterior do Cb5. 
SO. Camada de músculo que circunda o esôfago, com aumento no tamanho das fibras dorsalmente, delgado em outras partes, anteriormente suas fibras se projetam ventralmente ao TEb4.

TEb2. Liga-se medialmente a extremidade cartilaginosa do processo uncinado do Eb2 esquerdo e conecta-se a mesma estrutura do lado direito. Localiza-se dorsalmente ao Od3.

$\mathrm{TPb} 3$. Liga-se na face médio dorsal do $\mathrm{Pb} 3$ esquerdo e conecta-se na mesma estrutura no lado esquerdo. Está localizado ventralmente ao TEb2. É limitado posteriormente pelas fibras do $\mathrm{TPb} 4$.

$\mathrm{TPb} 4$. Liga-se ao longo da margem medial do $\mathrm{Pb} 4$ esquerdo e conecta-se na mesma região do lado direito. É limitado posteriormente pelas fibras do TEb4.

TEb4. Liga-se na face medial ventral do Eb4 esquerdo e insere-se na mesma estrutura do lado direito. Anteriormente limita-se pelas fibras do TPb4.

\section{Lonchogenys ilisha}

Le1. Origina-se no proótico dorsalmente a articulação do Pb1 com o crânio. Insere-se na extremidade dorsal cartilaginosa do processo uncinado do Eb1. Músculo delgado em forma de fita.

Le2. Origina-se no proótico medialmente a origem do Li1. Insere-se na extremidade dorsal cartilaginosa do processo uncinado do Eb2. Músculo em forma de fita. 
Le3. Origina-se no proótico medialmente a origem do Li2-Li3. Insere-se na extremidade dorsal óssea na face lateral do processo uncinado do Eb3, lateralmente a origem do Od3. Músculo em forma de fita.

Le4. Origina-se no proótico medialmente a origem do Le3. Insere-se na extremidade dorsal na margem anterior do processo levantador do Eb4. Músculo em forma de fita.

LP. Origina-se na margem ventral do pterótico. Insere-se na extremidade dorsal cartilaginosa do processo levantador do Eb4. Músculo em forma de fita.

Li1. Origina-se no proótico medialmente a origem do Le1. Insere-se na superfície dorsal do $\mathrm{Pb} 2$ medialmente a articulação entre o $\mathrm{Pb} 2$ e Eb1. Músculo delgado em forma de fita.

Li2. Origina-se no proótico dorsalmente a origem do Li1. Insere-se na superfície dorsal do Pb3. Músculo em forma de fita.

Li3. Origina-se no proótico dorsalmente a origem do Li2. Insere-se na superfície dorsal do Pb4. Músculo em forma de fita.

Od3. Origina-se na extremidade anterior cartilaginosa do $\mathrm{Pb} 3$ ventralmente ao TEb2. Insere-se na extremidade dorsal da margem anterior do processo uncinado do Eb3 (parte óssea e cartilaginosa), medialmente a origem do Le3. Músculo em forma de fita.

Od4. Origina-se no $\mathrm{Pb} 4$ (cartilagem) anteriormente. Insere-se na face lateral do processo levantador do Eb4. Músculo em forma de leque.

Od4'. Ausente.

OP. Origina-se na margem medial do Eb4, próximo às fibras do TEb4 e termina na rafe do esôfago. 
Ad4. Na face medial do processo levantador do Eb4 e na margem dorsal da extremidade posterior do $\mathrm{Cb} 4$, medialmente ao ângulo interno da articulação Eb4-Cb4.

Ad5. Na margem posterior do Eb5 (cartilagem) e na extremidade posterior do Cb5.

SO. Camada de músculo que circunda o esôfago, com aumento no tamanho das fibras dorsalmente, delgado em outras partes, anteriormente suas fibras se projetam ventralmente ao TEb4.

TEb2. Liga-se medialmente a extremidade cartilaginosa do processo uncinado do Eb2 esquerdo e conecta-se a mesma estrutura do lado direito. Localiza-se dorsalmente ao Od3.

TPb3. Liga-se na face médio dorsal do Pb3 esquerdo e conecta-se na mesma estrutura no lado esquerdo. Está localizado ventralmente ao TEb2. É limitado posteriormente pelas fibras do $\mathrm{TPb} 4$.

$\mathrm{TPb} 4$. Liga-se ao longo da margem medial do $\mathrm{Pb} 4$ esquerdo e conecta-se na mesma região do lado direito. É limitado posteriormente pelas fibras do TEb4.

TEb4. Liga-se na face medial ventral do Eb4 esquerdo e insere-se na mesma estrutura do lado direito. Anteriormente limita-se pelas fibras do TPb4.

\section{Mimagoniates microlepis}

Le1. Origina-se no proótico dorsalmente a articulação do $\mathrm{Pb} 1$ com o crânio. Origem carnosa. Insere-se na margem anterior do processo uncinado do Eb1. Músculo em forma de fita. Na origem esse músculo está localizado juntamente com outros músculos levantadores na incisura do proótico. 
Le2. Origina-se no proótico medialmente a origem do Li1. Insere-se na extremidade dorsal na margem anterior do processo uncinado do Eb2. Músculo em forma de fita.

Le3. Origina-se no proótico medialmente a origem do Li2-Li3. Insere-se na extremidade dorsal na margem anterior do processo uncinado do Eb3 ventralmente a inserção do Od3. Músculo em forma de fita.

Le4. Origina-se no proótico medialmente a origem do Le3. Insere-se na extremidade dorsal na margem anterior do processo levantador do Eb4 dorsalmente a origem do Od4. Músculo em forma de fita.

LP. Origina-se na margem ventral do pterótico juntamente com o PP. Origem tendínea. Insere-se na extremidade dorsal cartilaginosa do processo levantador do Eb4. Músculo em forma de fita.

Li1. Origina-se no proótico dorso medialmente a origem do Le1. Insere-se na superfície dorsal do $\mathrm{Pb} 2$ medialmente a articulação entre o Pb2 e Eb1. Músculo delgado em forma de fita.

Li2. Origina-se no proótico dorsalmente a origem do Li1. Insere-se na superfície dorsal do Pb3. Músculo em forma de fita.

Li3. Origina-se no proótico dorsalmente a origem do Li2. Insere-se na superfície dorsal do Pb4. Músculo em forma de fita.

Od3. Origina-se na extremidade anterior cartilaginosa do $\mathrm{Pb} 3$ ventralmente ao TEb2. Insere-se na margem anterior do processo uncinado do Eb3 (parte óssea). Músculo em forma de fita. 
Od4. Origina-se no $\mathrm{Pb} 4$ (cartilagem) anteriormente. Insere-se na face lateral do processo levantador do Eb4. Músculo em forma de leque.

Od4'. Origina-se na extremidade posterior óssea do $\mathrm{Pb} 3$ anteriormente. Insere-se no processo levantador do Eb4. Esse músculo está localizado dorsalmente ao Od4.

OP. Origina-se na margem medial do Eb4, próximo às fibras do TEb4 e termina na rafe do esôfago.

Ad4. Na face medial do processo levantador do Eb4 e na margem dorsal da extremidade posterior do $\mathrm{Cb} 4$, medialmente ao ângulo interno da articulação Eb4-Cb4.

Ad5. Na margem posterior do Eb5 (cartilagem) e na extremidade posterior do Cb5.

SO. Camada de músculo que circunda o esôfago, com aumento no tamanho das fibras dorsalmente, delgado em outras partes, anteriormente suas fibras se projetam ventralmente ao TEb4.

TEb2. Liga-se medialmente a extremidade cartilaginosa do processo uncinado do Eb2 esquerdo e conecta-se a mesma estrutura do lado direito. Localiza-se dorsalmente ao Od3.

$\mathrm{TPb} 3$. Liga-se na face médio dorsal do Pb3 esquerdo e conecta-se na mesma estrutura no lado esquerdo. Está localizado ventralmente ao TEb2. É limitado posteriormente pelas fibras do $\mathrm{TPb} 4$.

$\mathrm{TPb} 4$. Liga-se ao longo da margem medial do Pb4 esquerdo e conecta-se na mesma região do lado direito. É limitado posteriormente pelas fibras do TEb4.

TEb4. Liga-se na face medial ventral do Eb4 esquerdo e insere-se na mesma estrutura do lado direito. Anteriormente limita-se pelas fibras do TPb4. 


\section{Moenkhausia tergimacula.}

Le1. Origina-se no proótico dorsalmente a articulação do Pb1 com o crânio. Insere-se na extremidade dorsal e na face medial do processo uncinado do Eb1. Músculo fusiforme e bicaudado.

Le2. Origina-se no proótico medialmente a origem do Li1. Insere-se na margem anterior do processo uncinado do Eb2. Músculo em forma de fita.

Le3. Origina-se no proótico ventralmente a origem do Li2 e Li3. Insere-se na margem anterior do processo uncinado do Eb3. Músculo em forma de leque.

Le4. Origina-se no proótico medialmente a origem do Le3. Insere-se na extremidade dorsal da margem anterior (osso e cartilagem) do processo levantador do Eb4. Músculo em forma de fita.

LP. Insere-se na extremidade dorsal cartilaginosa do processo levantador do Eb4.

Li1. Origina-se no proótico juntamente com a origem do Le1. Insere-se na superfície dorsal do $\mathrm{Pb} 2$. Músculo fusiforme e bicaudado. Li2. Origina-se no proótico dorsalmente a origem do Li1. Insere-se na superfície dorsal do Pb3. Músculo em forma de fita.

\section{Li3. Ausente.}

Od3. Origina-se anteriormente no Pb3ventralmente ao TEb2. Insere-se na extremidade dorsal cartilaginosa do processo uncinado do Eb3.

Od4. Origina-se anteriormente no $\mathrm{Pb} 4$. Insere-se na margem anterior e na face lateral do processo levantador do Eb4. Músculo em forma de leque. 
Od4'. Presente. Com ventre muscular bem evidente do Od4 lateralmente e ventralmente. Origina-se na margem medial óssea do $\mathrm{Pb} 3$ anteriormente e insere-se no Eb4 posteriormente.

OP. Origina-se na margem medial do Eb4, próximo às fibras do TEb4 e termina na rafe do esôfago.

Ad4. Na face medial do processo levantador do Eb4 e na margem dorsal da extremidade posterior do $\mathrm{Cb} 4$, medialmente ao ângulo interno da articulação Eb4-Cb4.

Ad5. Na margem posterior do Eb5 (cartilagem) e na extremidade posterior do Cb5.

SO. Camada de músculo que circunda o esôfago, com aumento no tamanho das fibras dorsalmente, delgado em outras partes, anteriormente suas fibras se projetam ventralmente ao TEb4.

TEb2. Liga-se medialmente a extremidade cartilaginosa do processo uncinado do Eb2 esquerdo e conecta-se a mesma estrutura do lado direito. Localiza-se dorsalmente ao Od3.

TPb3. Liga-se na face médio dorsal do Pb3 esquerdo e conecta-se na mesma estrutura no lado esquerdo. Está localizado ventralmente ao TEb2. É limitado posteriormente pelas fibras do $\mathrm{TPb} 4$.

$\mathrm{TPb} 4$. Liga-se ao longo da margem medial do $\mathrm{Pb} 4$ esquerdo e conecta-se na mesma região do lado direito. É limitado posteriormente pelas fibras do TEb4.

TEb4. Liga-se na face medial ventral do Eb4 esquerdo e insere-se na mesma estrutura do lado direito. Anteriormente limita-se pelas fibras do TPb4. 
Nota: Os músculos Le1, Le2, Le3, Li1, Li2 e Li3 parecem se originar na mesma região no proótico, indicando a presença de uma incisura.

\section{Metynnis sp.}

Le1. Origina-se na extremidade dorsal da margem posterior do $\mathrm{Pb} 1$ e no proótico através de tendão delgado. Insere-se na margem anterior do processo uncinado do Eb1. Músculo fusiforme, dividido em dois ventres: ventral (origem no $\mathrm{Pb} 1$ ) e dorsal (origem tendínea no proótico). Músculo bíceps.

Le2. Origem tendínea no proótico medialmente as origens do Le1 e Li1. Insere-se na margem anterior do processo uncinado do Eb2 (osso e cartilagem). Músculo fusiforme dividido em dois ventres.

Le3. Origem tendínea no proótico medialmente as origens do Li2 e Li3. Insere-se na extremidade dorsal do processo uncinado do Eb3. Músculo em forma de fita.

Le4. Origina-se no proótico medialmente a origem do Le3. Insere-se na extremidade dorsal na margem anterior do processo levantador do Eb4. Músculo em forma de leque, com divisão em dois ventres: lateral e medial. Na inserção fibras musculares do Le4 estão conectadas a fibras do LP por fáscia musculares.

LP. Origina-se na margem ventral do pterótico, medialmente ao PP. Insere-se na extremidade dorsal do processo levantador do Eb4.

Li1. Origina-se na extremidade dorsal da margem medial do $\mathrm{Pb} 1$. Insere-se na superfície dorsal do Pb2. Músculo fusiforme. 
Li2. Origina-se no proótico dorsalmente a origem do Le2. Insere-se na superfície dorsal do Pb3. Músculo em forma de fita.

Li3. Origina-se no proótico dorsalmente a origem do Li2. Insere-se na superfície dorsal do Pb4. Músculo em forma de fita.

Od3. Origina-se anteriormente na extremidade anterior do $\mathrm{Pb} 2$ ventralmente ao $\mathrm{TEb} 2$. Insere-se na margem anterior do processo uncinado do Eb3. Músculo em forma de fita.

Od4. Origina-se anteriormente no $\mathrm{Pb} 4$. Insere-se na margem anterior óssea e na face lateral do processo levantador do Eb4.

Od4'. ausente.

OP. Origina-se na margem medial do Eb4, próximo às fibras do TEb4 e termina na rafe do esôfago.

Ad4. Na face medial do processo levantador do Eb4 e na margem dorsal da extremidade posterior do $\mathrm{Cb} 4$, medialmente ao ângulo interno da articulação Eb4-Cb4.

Ad5. Na margem posterior do Eb5 (cartilagem) e na extremidade posterior do Cb5.

SO. Camada de músculo que circunda o esôfago, com aumento no tamanho das fibras dorsalmente, delgado em outras partes, anteriormente suas fibras apresenta projeção conspícua, ventralmente ao TEb4.

TEb2. Liga-se medialmente a extremidade cartilaginosa do processo uncinado do Eb2 esquerdo e conecta-se a mesma estrutura do lado direito. Localiza-se dorsalmente ao Od3.

$\mathrm{TPb} 3-\mathrm{TPb} 4$. Idem Myleus setiger. 
TEb4. Idem Myleus setiger

Myleus setiger.

Le1. Origina-se na margem lateral do $\mathrm{Pb} 1$ (osso e cartilagem). Insere-se na superfície lateral e medial do processo uncinado do Eb1. Entre o $\mathrm{Pb} 1$ e o proótico existe um pequeno ligamento. Músculo fusiforme e bicaudado.

Le2. Origina-se na extremidade dorsal cartilaginosa do $\mathrm{Pb} 1$ e no proótico, músculo bíceps Insere-se na margem anterior do processo uncinado do Eb2 (osso e cartilagem). Músculo em forma de fita.

Le3. Origina-se no proótico medialmente a origem do Li3. Insere-se na margem anterior do processo uncinado do Eb3. Músculo em forma de fita. Presença de incisura no proótico

Le4. Origina-se no proótico dorsalmente a origem do Le3. Insere-se na margem anterior da extremidade dorsal do processo levantador do Eb4. Músculo em forma de fita com dois ventres musculares Presença de incisura no proótico. O Le4 está dividido em parte ventral e dorsal.

LP. Origem não observada. Inserção na extremidade dorsal cartilaginosa do processo levantador do Eb4. Músculo em forma de fita.

Li1. Origina-se na margem medial do $\mathrm{Pb} 1$. Insere-se na superfície dorsal do $\mathrm{Pb} 2 . \mathrm{Na}$ região de inserção é possível verificar uma divisão dorsal e ventral. Músculo largo e bicaudado. 
Li2. Origina-se no proótico medialmente a origem do Le2. Insere-se na extremidade posterior do Pb3. Músculo em forma de fita.

Li3. Origina-se no proótico dorsalmente a origem do Li2. Insere-se na superfície dorsal do Pb4. Músculo em forma de fita.

Od3. Origina-se anteriormente na extremidade anterior do $\mathrm{Pb} 3$ ventralmente ao $\mathrm{TEb} 2$, que parece estar ligada a extremidade anterior do $\mathrm{Pb} 2$ por um ligamento. Insere-se na margem anterior óssea do processo uncinado do Eb3. Músculo em forma de fita.

Od4. Origina-se anteriormente no $\mathrm{Pb}$ 4. Insere-se na face lateral do processo levantador do Eb4. Músculo em forma de leque.

Od4'. Não observado.

OP. Não observado.

Ad4. Na face medial do processo levantador do Eb4 e na margem dorsal da extremidade posterior do Cb4, medialmente ao ângulo interno da articulação Eb4-Cb4.

Ad5. Na margem posterior do Eb5 (cartilagem) e na extremidade posterior do Cb5.

SO. Camada de músculo que circunda o esôfago, com aumento no tamanho das fibras dorsalmente, delgado em outras partes, suas fibras são limitadas anteriormente pelo TEb4.

TEb2. Liga-se medialmente a extremidade cartilaginosa do processo uncinado do Eb2 esquerdo e conecta-se a mesma estrutura do lado direito. Localizando-se dorsalmente ao Od3. 
TPb3-TPb4. Liga-se na face médio dorsal do Pb3 e Pb4 esquerdos e conecta-se nas mesmas estruturas no lado esquerdo. Está localizado ventralmente ao TEb2. É limitado posteriormente pelas fibras do TEb4.

TEb4. Liga-se na face medial ventral do Eb4 esquerdo e insere-se na mesma estrutura do lado direito. Anteriormente limita-se pelas fibras do TPb3-TPb4.

\section{Oligosarcus hepsetus.}

Le1. Origina-se no proótico dorsalmente a articulação do Pb1 com o crânio. Insere-se na margem anterior do processo uncinado do Eb1 (osso e cartilagem). Músculo fusiforme.

Le2. Origina-se no proótico medialmente a origem do Li1. Insere-se no processo uncinado do Eb2. Músculo em forma de fita.

Le3. Origina-se no proótico medialmente a origem do Li3. Insere-se na margem anterior do processo uncinado do Eb3. Músculo em forma de fita.

Le4. Origina-se no proótico medialmente a origem do Le3. Insere-se na extremidade dorsal do processo levantador do Eb4 (cartilagem) através de uma fáscia muscular também associada ao LP. Músculo em forma de fita.

LP. Origina-se na margem ventral do pterótico anteriormente a origem do PP. Insere-se na extremidade dorsal do processo levantador do Eb4 através de fáscia tendinosa compartilhada com o Le4. Músculo em forma de fita.

Li1. Origina-se no proótico dorsalmente a origem do Le1. Insere-se na superfície dorsal do Pb2. Músculo fusiforme. 
Li2. Origina-se no proótico medialmente a origem do Li1. Insere-se na face dorsal da extremidade posterior do $\mathrm{Pb} 3$. Músculo em forma de fita.

Li3. Origina-se no proótico dorsalmente a origem do Li2. Insere-se na face dorsal da extremidade anterior do $\mathrm{Pb} 4$.

Od3. Origina-se anteriormente na extremidade anterior do $\mathrm{Pb} 3$ ventralmente ao $\mathrm{TEb} 2$. Insere-se na extremidade dorsal cartilaginosa do processo uncinado do Eb3. Músculo fusiforme.

Od4. Origina-se anteriormente no $\mathrm{Pb} 4$ e insere-se na face lateral (óssea) do processo levantador do Eb4. Músculo em forma de leque. Músculo com dois ventres.

Od4'. Ausente.

OP. Origina-se na margem medial do Eb4, próximo às fibras do TEb4 e termina na rafe do esôfago.

Ad4. Na face medial do processo levantador do Eb4 e na margem dorsal da extremidade posterior do $\mathrm{Cb} 4$, medialmente ao ângulo interno da articulação Eb4-Cb4.

Ad5. Na margem posterior do Eb5 (cartilagem) e na extremidade posterior do Cb5.

SO. Camada de músculo que circunda o esôfago, com aumento no tamanho das fibras dorsalmente, delgado em outras partes, anteriormente suas fibras se projetam ventralmente ao TEb4.

TEb2. Liga-se medialmente a extremidade cartilaginosa do processo uncinado do Eb2 esquerdo e conecta-se a mesma estrutura do lado direito. Localiza-se dorsalmente ao Od3. 
TPb3. Liga-se na face médio dorsal do Pb3 esquerdo e conecta-se na mesma estrutura no lado esquerdo. Está localizado ventralmente ao TEb2. É limitado posteriormente pelas fibras do $\mathrm{TPb} 4$.

TPb4. Liga-se ao longo da margem medial do Pb4 esquerdo e conecta-se na mesma região do lado direito. É limitado posteriormente pelas fibras do TEb4.

TEb4. Liga-se na face medial ventral do Eb4 esquerdo e insere-se na mesma estrutura do lado direito. Anteriormente limita-se pelas fibras do TPb4.

\section{Poptella paraguayensis.}

Le1. Apresenta dois pontos de origem: fibras ventrais na extremidade dorsal do $\mathrm{Pb} 1 \mathrm{e}$ as fibras dorsais na incisura do proótico, dorsal a articulação do Pb1 com o crânio. Origem carnosa. Insere-se na face lateral do processo uncinado do Eb1. Músculo fusiforme.

Le2. Origina-se na incisura do proótico medialmente a origem do Li1. Insere-se na margem anterior do processo uncinado do Eb2 (osso e cartilagem). Músculo em forma de fita.

Le3. Origina-se no proótico medialmente as origens dos músculos Li2 e Li3. Insere-se na margem anterior do processo uncinado do Eb3 (osso e cartilagem). Músculo em forma de fita.

Le4. Origina-se no proótico dorsalmente a origem do Le3. Insere-se na extremidade dorsal da margem anterior do processo levantador Eb4. Músculo em forma de fita.

LP. Origina-se no pterótico. Insere-se na extremidade dorsal do processo levantador do Eb4. Músculo em forma de fita. 
Li1. Origina-se na incisura do proótico medialmente a origem do Le1. As origens desses músculos estão muito próximas podendo causar falsas interpretações de músculos com uma única origem e duas inserções. Insere-se na superfície dorsal do Pb2.

Li2-Li3. Origina-se na incisura do proótico dorsalmente a origem do Le2. Insere-se na superfície dorsal do Pb3. Músculo em forma de fita.

Od3. Origina-se anteriormente na extremidade anterior do $\mathrm{Pb} 3$ ventralmente ao TEb2. Insere-se na extremidade dorsal cartilaginosa do processo levantador do Eb3. Músculo fusiforme.

Od4. Origina-se anteriormente no $\mathrm{Pb} 4$. Insere-se na face lateral do processo levantador do Eb4. Músculo em forma de leque.

Od4'. Presente. Com ventre muscular bem evidente do Od4 lateralmente e ventralmente. Origina-se na margem medial óssea do $\mathrm{Pb} 3$ anteriormente e insere-se no Eb4 posteriormente.

OP. Origina-se na margem medial do Eb4, próximo às fibras do TEb4 e termina na rafe do esôfago.

Ad4. Na face lateral do processo levantador do Eb4 e na margem dorsal da extremidade posterior do $\mathrm{Cb} 4$, medialmente ao ângulo interno da articulação Eb4-Cb4.

Ad5. Na margem posterior do Eb5 (cartilagem) e na extremidade posterior do Cb5.

SO. Camada de músculo que circunda o esôfago, com aumento no tamanho das fibras dorsalmente, delgado em outras partes, anteriormente suas fibras se projetam ventralmente ao TEb4. 
TEb2. Liga-se medialmente a extremidade cartilaginosa do processo uncinado do Eb2 esquerdo e conecta-se a mesma estrutura do lado direito. Músculo delgado localizado dorsalmente ao Od3.

$\mathrm{TPb} 3$. Liga-se na face médio dorsal do Pb3 esquerdo e conecta-se na mesma estrutura no lado esquerdo. Está localizado ventralmente ao TEb2. É limitado posteriormente pelas fibras do $\mathrm{TPb} 4$.

$\mathrm{TPb} 4$. Liga-se ao longo da margem medial do $\mathrm{Pb} 4$ esquerdo e conecta-se na mesma região do lado direito. É limitado posteriormente pelas fibras do TEb4.

TEb4. Liga-se na face medial ventral do Eb4 esquerdo e insere-se na mesma estrutura do lado direito. Anteriormente limita-se pelas fibras do TPb4.

Nota: As origens do Le1, Le2, Li1, Li2-Li3 estão localizadas na incisura do proótico, mas devido a sua origem carnosa é possível distinguir pontos de origens separados nessa região.

\section{Roeboexodon guyanensis}

Le1. Origina-se no proótico dorsalmente a articulação do $\mathrm{Pb} 1$ com o crânio, origem muscular. Insere-se na face lateral óssea do processo uncinado do Eb1. Músculo fusiforme.

Le2. Origina-se na incisura do proótico medialmente a origem do Li1. Origem muscular. Insere-se na face lateral do processo uncinado do Eb2. Músculo em forma de fita. 
Le3. Origina-se no proótico medialmente a origem dos Li1-Li2. Origem muscular. Insere-se na face anterior do processo uncinado do Eb3 dorsalmente a inserção do Od3. Músculo em forma de fita.

Le4. Origina-se no proótico medialmente a origem do Le3. Origem muscular. Insere-se na extremidade dorsal do processo levantador do Eb4. Músculo em forma de fita.

LP. Origina-se na extremidade posterior na margem ventral do pterótico juntamente com o PP. Origem tendínea. Insere-se na extremidade dorsal do processo levantador do Eb4. Músculo em forma de fita.

Li1. Origina-se no proótico medialmente a origem do Le1. Origem muscular. Insere-se na superfície dorsal do Pb2. Músculo fusiforme.

Li2-Li3. Origina-se no proótico medialmente a origem do Le2. Origem muscular. Insere-se na parte posterior do $\mathrm{Pb} 3$ e na parte anterior do $\mathrm{Pb} 4$. Músculo em forma de fita. Nota: não foi possível evidenciar no exemplar dissecado separação nítida entre os ventres musculares do Li2 e do Li3.

Od3. Origina-se anteriormente na extremidade posterior do $\mathrm{Pb} 3$ ventralmente ao $\mathrm{TEb} 2 \mathrm{e}$ insere-se na extremidade dorsal do processo uncinado do Eb3, medialmente a origem do Le3. Músculo em forme de leque.

Od4. Origina-se anteriormente na extremidade posterior do $\mathrm{Pb} 4$ e insere-se ao longo de toda margem anterior do processo levantador do Eb4. Músculo em forma de leque.

Od4'. Presente. Esse músculo está localizado lateralmente ao OD4 e insere-se na face lateral do processo levantador do Eb4. Sua origem ocorre na parte óssea posterior do Pb3. O limite das fibras entre o Od4 e Od4' não é claro podendo esse ser confundido 
com o Od4 ou classificado como um ventre do Od4 que apresenta origem de suas fibras no $\mathrm{Pb} 3$.

OP. Origina-se na margem medial do Eb4, próximo às fibras do TEb4 e termina na rafe do esôfago.

Ad4. Na face medial do processo levantador do Eb4 e na margem dorsal da extremidade posterior do $\mathrm{Cb} 4$, medialmente ao ângulo interno da articulação Eb4-Cb4.

Ad5. Na margem posterior do Eb5 (cartilagem) e na extremidade posterior do Cb5.

SO. Camada de músculo que circunda o esôfago, com aumento no tamanho das fibras dorsalmente, delgado em outras partes, anteriormente suas fibras se projetam ventralmente ao TEb4.

TEb2. Liga-se medialmente a extremidade cartilaginosa do processo uncinado do Eb2 esquerdo e conecta-se a mesma estrutura do lado direito. Músculo delgado localizado dorsalmente ao Od3.

$\mathrm{TPb} 3$. Liga-se na face médio dorsal do $\mathrm{Pb} 3$ esquerdo e conecta-se na mesma estrutura no lado esquerdo. Está localizado ventralmente ao TEb2. É limitado posteriormente pelas fibras do $\mathrm{TPb} 4$.

$\mathrm{TPb} 4$. Liga-se ao longo da margem medial do Pb4 esquerdo e conecta-se na mesma região do lado direito. É limitado posteriormente pelas fibras do TEb4.

TEb4. Liga-se na face medial ventral do Eb4 esquerdo e insere-se na mesma estrutura do lado direito. Anteriormente limita-se pelas fibras do TPb4. 
Nota: As origens do Le1, Le2, Li1, Li2-Li3 estão localizadas na incisura do proótico, mas devido a sua origem carnosa é possível distinguir pontos de origens separados nessa região.

\section{Serrasalmus brandtii.}

Le1. Origina-se no na margem posterior do $\mathrm{Pb} 1$. Insere-se na margem anterior do processo uncinado do Eb1. Músculo fusiforme. $\mathrm{O} \mathrm{Pb} 1$ está articulado ao proótico e apresenta ligamentos para estabilizar essa articulação.

Le2. Origina-se na extremidade dorsal do $\mathrm{Pb} 1$ próximo a cartilagem articular. Origem tendínea. Insere-se na margem anterior do processo uncinado do Eb2. Músculo em forma de fita.

Le3. Origina-se no proótico dorsalmente a origem do Li2-Li3. Insere-se na margem anterior do processo uncinado do Eb3. Músculo em forma de fita.

Le4. Origina-se no proótico medialmente a origem do Le3. Insere-se na extremidade dorsal na margem anterior do processo levantador do Eb4. Músculo em forma de fita.

LP. Origina-se na margem ventral do pterótico, medialmente a origem do PP. Insere-se na extremidade dorsal do processo levantador do Eb4. Músculo em forma de fita.

Li1. Origina-se na extremidade dorsal na margem medial do Pb1. Insere-se na superfície dorsal do Pb2. Músculo fusiforme.

Li2. Origina-se na extremidade dorsal na margem posterior do $\mathrm{Pb} 1$. Apresenta a mesma origem com o Li3, músculo bicaudado. Insere-se na superfície dorsal do Pb3. Músculo em forma de fita. 
Li3. Origem idem Li2. Insere-se na superfície dorsal do Pb4. Músculo em forma de fita.

Od3. Origina-se anteriormente na extremidade posterior do $\mathrm{Pb} 3$ ventralmente ao $\mathrm{TPb} 2$. Insere-se na extremidade dorsal cartilaginosa na margem medial do processo uncinado do Eb3. Músculo fusiforme.

Od4. Origina-se anteriormente no $\mathrm{Pb} 4$. Insere-se na margem anterior e na face lateral do processo levantador do Eb4. Músculo em forma de leque. Apresenta dois ventres musculares.

Od4'. ausente.

OP. Ad4. Na face medial do processo levantador do Eb4 e na margem dorsal da extremidade posterior do $\mathrm{Cb} 4$, medialmente ao ângulo interno da articulação Eb4-Cb4.

Ad5. Na margem posterior do Eb5 (cartilagem) e na extremidade posterior do $\mathrm{Cb} 5$.

SO. Camada de músculo que circunda o esôfago, com aumento no tamanho das fibras dorsalmente, delgado em outras partes, suas fibras são limitadas anteriormente pelo TEb4. (Idem Myleus setiger)

TEb2. Liga-se medialmente a extremidade cartilaginosa do processo uncinado do Eb2 esquerdo e conecta-se a mesma estrutura do lado direito. Localiza-se dorsalmente ao Od3.

$\mathrm{TPb} 3-\mathrm{TPb} 4$. Idem Myleus setiger.

TEb4. Idem Myleus setiger

Nota:

. O músculo Le3, Li2 e Li3 apresentam a mesma origem tendínea no proótico. 
.Os músculos Le1, Le2, Li1, Li2, Li3 e Le3 estão conectados por uma grande fáscia tendinosa de tecido conjuntivo na sua região de origem, seja no proótico ou no $\mathrm{Pb} 1$. Olha Brycon falcatus

\section{Triportheus auritus}

Le1. Origina-se na incisura do proótico dorsalmente a articulação do Pb1 com o crânio. Origem tendínea. Insere-se na parede medial do Eb1. Ausência de processo uncinado do Eb1. Músculo fusiforme.

Le2. Origina-se na incisura do proótico medialmente a origem do Li1. Origem tendínea. Insere-se na margem anterior do processo uncinado do Eb2 (osso e cartilagem). Músculo em forma de fita.

Le3. Origina-se no proótico medialmente as origens dos músculos Le1, Le2, Li1, Li2 e Li3. Insere-se na margem anterior do processo uncinado do Eb3 (osso e cartilagem). Músculo em forma de fita.

Le4. Origina-se no proótico medialmente a origem do Le3. Insere-se na margem anterior do processo levantador do Eb4 (osso e cartilagem). Músculo em forma de leque.

LP. Origina-se na margem ventral do pterótico. Insere-se na face medial do processo levantador do Eb4.

Li1. Origina-se no proótico medialmente a origem do Le1. Origem tendínea. Não foi possível verificar sua inserção. 
Li2. Origina-se no proótico medialmente a origem do Le2. Origem tendínea. Insere-se no Pb3. Músculo em forma de fita.

Li3. Origina-se no proótico no mesmo ponto de origem do Le2. Insere-se no $\mathrm{Pb} 4$. Músculo em forma de fita. Os músculos Li2-Li3 apresentam uma cabeça de origem e duas caudas, sendo caracterizado como um músculo bicaudado.

Od3. Não observado.

Od4. Origina-se anteriormente no $\mathrm{Pb}$ 4. Insere-se na face lateral do processo levantador do Eb4. Músculo em forma de leque.

Od4'. ausente

OP. Não observado.

Ad4. Na margem ventral da extremidade posterior do Eb4 e na margem dorsal da extremidade posterior do $\mathrm{Cb} 4$, medialmente ao ângulo interno da articulação Eb4-Cb4.

Ad5. Na margem posterior do Eb5 (cartilagem) e na extremidade posterior do Cb5.

SO. Camada de músculo que circunda o esôfago, com aumento no tamanho das fibras dorsalmente, delgado em outras partes, suas fibras são limitadas anteriormente pelo TEb4. Na sua região média suas fibras direcionam-se anteriormente ventralmente ao TEb4.

TEb2. Liga-se medialmente a extremidade cartilaginosa do processo uncinado do Eb2 esquerdo e conecta-se a mesma estrutura do lado direito. Localiza-se dorsalmente ao Od3. 
TPb3. Liga-se na face médio dorsal do Pb3 esquerdo e conecta-se na mesma estrutura no lado esquerdo. Está localizado ventralmente ao TEb2. É limitado posteriormente pelas fibras do $\mathrm{TPb} 4$.

$\mathrm{TPb} 4$. Liga-se ao longo da margem medial do Pb4 esquerdo e conecta-se na mesma região do lado direito. É limitado posteriormente pelas fibras do TEb4.

TEb4. Liga-se na face medial ventral do Eb4 esquerdo e insere-se na mesma estrutura do lado direito. Anteriormente limita-se pelas fibras do TPb4.

Notas:

.Existe uma convergência nas origens dos músculos Le1, Le2, Li1, Li2 e Li3, mas a incisura do proótico não é tão evidente quanto nas outras espécies examinadas. Os músculos na origem parecem estar envolvidos por uma fáscia muscular, mas com uma dissecção mais cuidadosa é possível distinguir individualmente a origem de cada um dos músculos.

. $\mathrm{Pb1}$ : apresenta ligamento com o proótico

Triportheus signatus.

Le1. Origina-se na incisura do proótico dorsalmente a articulação do Pb1 com o crânio. Origem tendínea. Insere-se na extremidade dorsal do processo uncinado do Eb1. Músculo fusiforme. 
Le2. Origina-se na incisura do proótico dorsalmente as origens do Le1 e Li1. Origem tendínea. Insere-se na margem anterior (óssea e cartilaginosa) do processo uncinado do Eb2. Músculo em forma de fita.

Le3. Origina-se na incisura do proótico medialmente as origens do Le1, Le2, Li1, Li2 e Li3. Insere-se na margem anterior do processo uncinado do Eb3. Músculo em forma de leque.

Le4. Origina-se na incisura proótico medialmente a origem do Le3. Insere-se na face medial do processo levantador do Eb4. Suas fibras musculares estão conectadas através de fáscias tendíneas às fibras do LP. Músculo em forma de fita.

LP. Origina-se no pterótico. Insere-se através de fáscias tendíneas na face medial do processo levantador do Eb4. Músculo largo.

Li1. Origina-se na incisura proótico juntamente com o Le1. Origem tendínea. Insere-se na superfície dorsal do $\mathrm{Pb} 2$. Músculo fusiforme.

Li2. Origina-se na incisura do proótico medialmente a origem do Le2. Origem tendínea. Insere-se no Pb3. Músculo em forma de fita.

Li3. Origina-se na incisura do proótico dorsalmente a origem do Li2. Origem tendínea. Insere-se no Pb4. Músculo em forma de fita.

Od3. Origina-se anteriormente na extremidade anterior do $\mathrm{Pb} 3$ ventralmente ao TEb2. Insere-se na extremidade dorsal (osso e cartilagem) do processo uncinado do Eb3. Músculo em forma de fita.

Od4. Origina-se anteriormente no $\mathrm{Pb} 4$. Insere-se na face medial do processo levantador do Eb4. Músculo em forma de leque. 
Od4'. ausente.

OP. Origina-se na margem medial do Eb4, próximo às fibras do TEb4 e termina na rafe do esôfago.

Ad4. Na margem ventral da extremidade posterior do Eb4 e na margem dorsal da extremidade posterior do $\mathrm{Cb} 4$, medialmente ao ângulo interno da articulação Eb4-Cb4.

Ad5. Na margem posterior do Eb5 (cartilagem) e na extremidade posterior do Cb5.

SO. Camada de músculo que circunda o esôfago, com aumento no tamanho das fibras dorsalmente, delgado em outras partes, anteriormente suas fibras apresentam projeção conspícua, ventralmente ao TEb4.

TEb2. Liga-se medialmente a extremidade cartilaginosa do processo uncinado do Eb2 esquerdo e conecta-se a mesma estrutura do lado direito. Músculo delgado localizado dorsalmente ao $\mathrm{Od} 3$.

TPb3. Liga-se na face médio dorsal do Pb3 esquerdo e conecta-se na mesma estrutura no lado esquerdo. Está localizado ventralmente ao TEb2. É limitado posteriormente pelas fibras do $\mathrm{TPb} 4$.

TPb4. Liga-se ao longo da margem medial do $\mathrm{Pb} 4$ esquerdo e conecta-se na mesma região do lado direito. É limitado posteriormente pelas fibras do TEb4.

TEb4. Liga-se na face medial ventral do Eb4 esquerdo e insere-se na mesma estrutura do lado direito. Anteriormente limita-se pelas fibras do TPb4.

Notas: 
. As origens dos músculos Le1, Li1, Le2, Li2 e Li3 no proótico estão limitadas a uma incisura óssea no proótico. Essa peculiaridade topográfica torna os tendões de origem desses músculos muito próximos e de difícil distinção. Existe uma grande fáscia muscular recobrindo esses músculos na região de origem e mesmo após sua remoção não é possível separar os mesmos na origem, pois suas fibras musculares terminam em um tendão comum ao Le1, Li1, Le2 e Le3, que se conecta na incisura do proótico. A separação topográfica dos músculos é possível até o limite entre as fibras e o tendão de origem. Esse complexo muscular é denominado músculo policaudado.

. $\mathrm{Pb} 1$ articula-se diretamente com o proótico sem a presença de ligamento.

\section{Triportheus pantanensis.}

Le1. Origina-se na incisura do proótico dorsalmente a articulação do Pb1 com o crânio. Origem tendínea. Insere-se ao longo da face medial do processo uncinado do Eb1. Músculo fusiforme.

Le2. Origina-se na incisura do proótico dorsalmente as origens do Le1 e do Li1. Inserese na margem anterior do processo uncinado (óssea e cartilaginosa) do Eb2. Músculo fusiforme.

Le3. Origina-se no proótico medialmente as origens do Le1, Le2, Li1, Li2 e Li3. Na origem suas fibras estão localizadas lateralmente as fibras do Le4. Insere-se ao longo da superfície anterior do processo uncinado do Eb3. Músculo largo.

Le4. Origina-se no proótico mediamente a origem do Le3. Insere-se na margem anterior do processo levantador do Eb4. Músculo largo. 
LP. Origina-se na margem ventral do pterótico, medialmente a origem do PP. Insere-se medialmente na extremidade dorsal do processo levantador do Eb4.

Li1. Origina-se na incisura do proótico medialmente a origem do Le1. Origem tendínea. Insere-se na superfície dorsal do $\mathrm{Pb} 2$. Músculo fusiforme.

Li2. Origina-se na incisura do proótico dorsalmente a origem do Li1. Origem tendínea. Insere-se no Pb3. Músculo em forma de fita.

Li3. Origina-se na incisura do proótico dorsalmente a origem do Li2. Origem tendínea. Insere-se no $\mathrm{Pb} 4$. Músculo em forma de fita.

Od3. Origina-se anteriormente na extremidade anterior do $\mathrm{Pb}$, ventralmente ao $\mathrm{TEb} 2$. Insere-se posteriormente na extremidade dorsal do processo uncinado do Eb4. Músculo em forma de fita.

Od4. Origina-se no $\mathrm{Pb} 4$ anteriormente. Insere-se na margem lateral do processo levantador do Eb4. Músculo em forma de leque.

Od4'. Ausente.

OP. Origina-se na margem medial do Eb4, próximo às fibras do TEb4 e termina na rafe do esôfago.

Ad4. Na margem ventral da extremidade posterior do Eb4 e na margem dorsal da extremidade posterior do Cb4, medialmente ao ângulo interno da articulação Eb4-Cb4.

Ad5. Na margem posterior do Eb5 (cartilagem) e na extremidade posterior do Cb5. 
SO. Camada de músculo que circunda o esôfago, com aumento no tamanho das fibras dorsalmente, delgado em outras partes, anteriormente suas fibras se projetam ventralmente ao TEb4.

TEb2. Liga-se medialmente a extremidade cartilaginosa do processo uncinado do Eb2 esquerdo e conecta-se a mesma estrutura do lado direito. Músculo delgado localizado dorsalmente ao Od3.

TPb3. Liga-se na face médio dorsal do Pb3 esquerdo e conecta-se na mesma estrutura no lado esquerdo. Está localizado ventralmente ao TEb2. É limitado posteriormente pelas fibras do $\mathrm{TPb} 4$.

$\mathrm{TPb} 4$. Liga-se ao longo da margem medial do $\mathrm{Pb} 4$ esquerdo e conecta-se na mesma região do lado direito. É limitado posteriormente pelas fibras do TEb4.

TEb4. Liga-se na face medial ventral do Eb4 esquerdo e insere-se na mesma estrutura do lado direito. Anteriormente limita-se pelas fibras do TPb4.

Nota:

. As origens dos músculos Le1, Li1, Le2, Li2 e Li3 no proótico estão limitadas a uma incisura óssea no proótico. Essa peculiaridade topográfica torna os tendões de origem desses músculos muito próximos e de difícil distinção. Existe uma grande fáscia muscular recobrindo esses músculos na região de origem e mesmo após sua remoção não é possível separar os mesmos na origem, pois suas fibras musculares terminam em um tendão comum ao Le1, Li1, Le2 e Le3, que se conecta na incisura do proótico. A separação topográfica dos músculos é possível até o limite entre as fibras e o tendão de origem. Esse complexo muscular é denominado músculo policaudado. 
. $\mathrm{Pb} 1$ articula-se diretamente com o proótico sem a presença de ligamento

\section{Tetragonopterus spp}

Le1. Origina-se no proótico dorsalmente a articulação do $\mathrm{Pb} 1$ com o crânio. Origem muscular. Insere-se ao longo da face medial do processo uncinado do Eb1. Músculo fusiforme.

Le2. Origina-se no proótico medialmente a origem do Li1. Insere-se na margem anterior do processo uncinado (óssea e cartilaginosa) do Eb2. Músculo fusiforme.

Le3. Origina-se no proótico medialmente as origens do Le1, Le2, Li1, Li2 e Li3. Na origem suas fibras estão localizadas lateralmente as fibras do Le4. Insere-se na margem anterior do processo uncinado do Eb3. Músculo em forma de fita.

Le4. Origina-se no proótico medialmente a origem do Le3. Insere-se na face medial do processo levantador do Eb4. Músculo em forma de fita.

LP. Origina-se na margem ventral do pterótico, medialmente a origem do PP. Insere-se medialmente na extremidade dorsal do processo levantador do Eb4.

Li1. Origina-se no proótico medialmente a origem do Le1. Origem muscular. Insere-se na superfície dorsal do $\mathrm{Pb} 2$. Músculo em forma de fita.

Li2. Origina-se no proótico dorsalmente a origem do Li1. Origem muscular. Insere-se no $\mathrm{Pb} 3$. Músculo em forma de fita.

Li3. Origina-se no proótico dorsalmente a origem do Li2. Origem muscular. Insere-se no $\mathrm{Pb} 4$. Músculo em forma de fita. 
Od3. Origina-se anteriormente na extremidade anterior do $\mathrm{Pb} 3$, ventralmente ao TEb2. Insere-se posteriormente na extremidade dorsal do processo uncinado do Eb3 medialmente a origem do Le3. Músculo fusiforme.

Od4. Origina-se no $\mathrm{Pb} 4$ anteriormente. Insere-se na face lateral do processo levantador do Eb4. Músculo em forma de leque.

Od4'. Ausente.

OP. Origina-se na margem medial do Eb4, próximo às fibras do TEb4 e termina na rafe do esôfago.

Ad4. Na margem ventral da extremidade posterior do Eb4 e na margem dorsal da extremidade posterior do $\mathrm{Cb} 4$, medialmente ao ângulo interno da articulação Eb4-Cb4.

Ad5. Na margem posterior do Eb5 (cartilagem) e na extremidade posterior do Cb5.

SO. Camada de músculo que circunda o esôfago, com aumento no tamanho das fibras dorsalmente, delgado em outras partes, anteriormente suas fibras se projetam ventralmente ao TEb4.

TEb2. Liga-se medialmente a extremidade cartilaginosa do processo uncinado do Eb2 esquerdo e conecta-se a mesma estrutura do lado direito. Músculo delgado localizado dorsalmente ao Od3.

TPb3. Liga-se na face médio dorsal do Pb3 esquerdo e conecta-se na mesma estrutura no lado esquerdo. Está localizado ventralmente ao TEb2. É limitado posteriormente pelas fibras do $\mathrm{TPb} 4$.

$\mathrm{TPb} 4$. Liga-se ao longo da margem medial do $\mathrm{Pb} 4$ esquerdo e conecta-se na mesma região do lado direito. É limitado posteriormente pelas fibras do TEb4. 
TEb4. Liga-se na face medial ventral do Eb4 esquerdo e insere-se na mesma estrutura do lado direito. Anteriormente limita-se pelas fibras do TPb4.

\subsubsection{Família Chilodontidae.}

\section{Chilodus punctatus.}

Le1. Origina-se no proótico na região de articulação do Pb1 com o crânio. Insere-se no Eb1.

Le2. Origina-se no proótico medialmente à origem do Le1. Insere-se no Eb2.

Le3. Origina-se no proótico medialmente a origem dos músculos Li2-Li3. Insere-se na extremidade anterior do Eb3. O músculo parece estar dividido em dois ventres.

LP. Origina-se no pterótico e insere-se na margem dorsal do processo levantador do Eb4.

Li1. Não observado.

Li2-Li3. Origina-se no proótico, apresentando forma de leque.

Od3. Origina-se anteriormente na superfície dorsal do $\mathrm{Pb} 3$ dorsalmente ao TEb2 e insere-se na extremidade dorsal do processo uncinado do Eb3, medialmente a origem do Le3. Músculo fusiforme. Nota: Esse músculo apresenta um tamanho muito maior se comparado com outras espécies e suas fibras estão localizadas dorsalmente as fibras do Od4.

Od4. Origina-se anteriormente na superfície dorsal do $\mathrm{Pb} 4$ e insere-se ao longo da margem anterior do processo levantador do Eb4. Músculo em forma de leque. 
Od4'. Ausente.

OP. Não observado.

Ad4. Na margem ventral da extremidade posterior do Eb4 e na margem dorsal da extremidade posterior do Cb4, medialmente ao ângulo interno da articulação Eb4-Cb4.

Ad5. Conecta a face posterior da cartilagem Eb5 a margem dorsal do Cb5. Esse músculo forma uma estrutura bulbosa que parece representar um órgão epibranquial.

SO. Camada de músculo que circunda o esôfago, com aumento no tamanho das fibras dorsalmente, delgado em outras partes, anteriormente suas fibras apresentam projeção conspícua, estão limitadas pelo TEb4.

TEb2. Liga-se no processo uncinado do Eb2 esquerdo e conecta-se na estrutura correspondente no lado direito. Feixes de fibras associados ao TEb2 ligam-se também ligam-se na margem medial do $\mathrm{Pb} 3$ esquerdo e conectam-se ao seus correspondentes no lado direito.

$\mathrm{TPb} 3$. Liga-se na face médio dorsal do $\mathrm{Pb} 3$ esquerdo e conecta-se na mesma estrutura no lado esquerdo. É limitado posteriormente pelas fibras do TPb4.

$\mathrm{TPb} 4$. Liga-se ao longo da margem medial do $\mathrm{Pb} 4$ esquerdo e conecta-se na mesma região do lado direito. É limitado posteriormente pelas fibras do TEb4.

TEb4. Liga-se na face medial ventral do Eb4 esquerdo e insere-se na mesma estrutura do lado direito. Anteriormente limita-se pelas fibras do TPb4.

Família Citharinidae 


\section{Citharinus latus}

Le1. Origina-se no proótico. Origem tendínea. Insere-se na face lateral do processo uncinado do Eb1. Músculo em forma de fita dividido em duas partes.

Le2. Origina-se no proótico dorso medialmente a origem do Le1-Li1. Origem muscular. Insere-se na face lateral do processo uncinado do Eb2. Músculo fusiforme dividido em duas partes.

Le3. Origina-se no proótico medialmente a origem do Li3. Insere-se na extremidade dorsal do processo uncinado do Eb3. Músculo em forma de fita dividido em duas partes.

Le4. Origina-se no proótico medialmente a origem do Le3. Insere-se na extremidade dorsal e na margem anterior do processo levantador do Eb4. Músculo em forma de fita.

LP. Origem não observada. Insere-se na extremidade dorsal na face medial do processo levantador do Eb4. Músculo em forma de fita.

Li1. Origina-se no proótico ventralmente a origem do Le1. Origem muscular. Insere-se na superfície dorsal do $\mathrm{Pb}$. Músculo em forma de fita.

Li2. Origina-se no proótico dorsalmente a origem do Le2. Insere-se na superfície dorsal do Pb3. Músculo em forma de fita.

Li3. Origina-se no proótico em uma incisura própria (incisura do Li3). Insere-se na superfície dorsal do $\mathrm{Pb} 4$. Músculo em forma de fita.

Od3. Origina-se anteriormente na extremidade posterior do $\mathrm{Pb}$. Insere-se na margem anterior óssea do processo uncinado do Eb3, ventralmente a origem do Le3. Músculo fusiforme. 
Od4. Origina-se no $\mathrm{Pb} 4$ anteriormente. Insere-se na face lateral do processo levantador do Eb4. Músculo em forma de leque.

Od4'. Ausente.

OP. Origina-se na margem medial do Eb4, próximo às fibras do TEb4 e termina na rafe do esôfago.

Ad4. Não observado.

Ad5. Na margem posterior do Eb5 (cartilagem) e na extremidade posterior do Cb5. Esse músculo forma um grande bulbo folhoso o órgão epibranquial.

SO. Camada de músculo que circunda o esôfago, com aumento no tamanho das fibras dorsalmente, delgado em outras partes, anteriormente suas fibras se projetam ventralmente ao TEb4.

TEb2. Liga-se medialmente a extremidade cartilaginosa do processo uncinado do Eb2 esquerdo e conecta-se a mesma estrutura do lado direito. Localiza-se dorsalmente ao Od3.

$\mathrm{TPb} 3$. Liga-se na face médio dorsal do Pb3 esquerdo e conecta-se na mesma estrutura no lado esquerdo. Está localizado ventralmente ao TEb2. É limitado posteriormente pelas fibras do $\mathrm{TPb} 4$.

TEb4. Liga-se na face medial ventral do Eb4 esquerdo e insere-se na mesma estrutura do lado direito. Anteriormente limita-se pelas fibras do TPb4. 


\subsubsection{Família Crenuchidae.}

Crenuchus spilurus.

Le1. Origina-se ventralmente a extremidade articular do $\mathrm{Pb} 1$, na sua margem posterior. Insere-se medialmente à lâmina lateral do Eb1. Músculo em forma de fita.

Le2. Origina-se no proótico dorsalmente à articulação do Pb1 com o crânio. Insere-se no processo uncinado do Eb2. Músculo em forma de fita.

Le3. Origina-se no proótico dorsalmente a origem do Li3. Insere-se na margem anterior do processo uncinado do Eb3. Músculo em forma de fita.

Le4. Origina-se no proótico, medialmente a origem dos músculos Le1, Le2, Le3, Li1 e Li3. Insere-se na margem anterior do processo levantador do Eb4.

LP. Origina-se no pterótico, medialmente à origem do protractor pectoralis. Insere-se na extremidade dorsal do processo levantador do Eb4.

Li1. Origina-se no proótico medialmente a origem do Le1. Insere-se na superfície dorsal da margem medial do $\mathrm{Pb} 2$. Músculo em forma de fita.

\section{Li2. Ausente.}

Li3. Origina-se no proótico ventralmente a origem do Le3. Insere-se no $\mathrm{Pb} 4$. Músculo em forma de fita.

Od3. Origina-se no $\mathrm{Pb} 3$ anteriormente, ventralmente ao TEb2. Insere-se na extremidade dorsal do processo uncinado do Eb3. Músculo em forma de fita. 
Od4. Origina-se anteriormente no $\mathrm{Pb} 4$. Insere-se na margem lateral do processo levantador do Eb4. Músculo em forma de fita na origem e em forma de leque na inserção.

Od4'. Ausente.

OP. Faixa muscular larga que se estende do TEb4, anteriormente, até o Ad5 posteriormente.

Ad4. Na superfície medial do Eb4 da extremidade dorsal do processo levantador do Eb4 até a superfície dorsal do $\mathrm{Cb} 4$, medialmente ao ângulo interno da articulação do Eb4$\mathrm{Cb} 4$.

Ad5. Na margem posterior do Eb5 (cartilagem) e no Cb5.

SO. Camada circular de músculos que circunda o esôfago. Dorsalmente as fibras musculares são mais espessas.

TEb2. Liga-se medialmente ao processo uncinado do Eb2 esquerdo e conecta-se na mesma estrutura no lado direito.

$\mathrm{TPb} 3$. Liga-se na face médio dorsal do $\mathrm{Pb} 3$ esquerdo e conecta-se na mesma estrutura no lado esquerdo. Está localizado ventralmente ao TEb2 e na região do seu limite posterior suas fibras confundem-se com as do TPb4.

$\mathrm{TPb} 4$. Liga-se ao longo da margem medial do $\mathrm{Pb} 4$ esquerdo e insere-se na mesma região do lado direito. Anteriormente seu limite não é bem definido, pois suas fibras musculares se confundem com as fibras do $\mathrm{TPb} 3$. Seu limite posterior é bem estabelecido pelo músculo TEb4. 
TEb4. Liga-se medialmente no Eb4 esquerdo e conecta-se nas mesmas estruturas no lado direito. Músculo em forma de fita, com as fibras ligeiramente mais desenvolvidas que as do $\mathrm{TPb} 4$.

\section{Characidium oiticicai.}

Le1. Origina-se na região de articulação do Pb1 com o crânio Idem Crenuchus spilurus. Insere-se no Eb1. Músculo em forma de fita.

Le2. Origina-se no proótico medialmente a origem do Li1. Insere-se no processo uncinado do Eb2.

Le3. Origina-se no proótico medialmente a origem do Li3. Insere-se na extremidade dorsal do processo uncinado do Le3.

Le4. Origina-se no proótico, medialmente a origem do Le3. Insere-se na extremidade dorsal do processo levantador do Eb4.

LP. Origina-se no pterótico, medialmente a origem do protractor pectoralis. Insere-se na margem posterior do processo levantador do Eb4.

Li1. Origina-se no proótico, dorsalmente a origem do Le1. Insere-se na superfície dorsal do $\mathrm{Pb} 2$.

Li2. Ausente

Li3. Origina-se no proótico dorsalmente ao Le2 e medialmente ao Li1. Insere-se no $\mathrm{Pb} 4$. Músculo em forma de fita. 
Od3. Origina-se anteriormente $\mathrm{Pb}$. Insere-se na extremidade dorsal do processo uncinado do Eb3. Músculo fusiforme. O Od3 é muito menor do que o Od4.

Od4. Origina-se no $\mathrm{Pb} 4$ anteriormente. Insere-se na superfície lateral do processo levantador do Eb4, adquirindo a forma de leque.

Od4'. Idem Crenuchus spilurus.

OP. Faixa muscular estreita que se estende do TEb4 até a rafe do esôfago.

Ad4. Idem Crenuchus spilurus.

Ad5. Idem Crenuchus spilurus

SO. Idem Crenuchus spilurus.

TEb2-TPb3-TPb4. As fibras musculares do que são três músculos distintos em Crenuchus spilurus não são diferenciáveis nos exemplares examinados. Topograficamente as relações se mantêm em relação ao TEb2, TPb3 e TPb4 de Crenuchus spilurus.

TEb4. Idem Crenuchus spilurus.

4.1.7 Família Cynodontidae.

Hydrolycus tatauaia.

Le1. Origina-se no proótico ventralmente à articulação do $\mathrm{Pb} 1$ com o crânio. Insere-se na margem posterior do processo uncinado do Eb1. Compartilha a mesma origem com o Li1. Músculo fusiforme. 
Nota: As origens do Le2 e do Li2/Li3 localizam-se dorsalmente à origem do Le1.

Le2. Origina-se no proótico dorsalmente à origem do Le1, na mesma altura da articulação do Pb1 com o crânio. Insere-se na margem anterior do processo uncinado do Eb2. Músculo fusiforme.

Le3. Origina-se no proótico ventro medialmente à origem do Li2/Li3 e lateralmente à origem do Le4. Insere-se na margem lateral do processo uncinado do Eb3. Músculo fusiforme.

Le4. Origina-se no proótico ventro medialmente à origem do Le3. Insere-se amplamente na margem medial do processo levantador do Eb4. Músculo em forma de fita.

LP. Origina-se no pterótico através de um tendão delgado e largo. Compartilha a mesma origem com o protractor pectoralis que localiza-se medialmente ao primeiro. Insere-se na extremidade dorsal do processo levantador do Eb4.

Li1. Origina-se no proótico, no mesmo ponto de origem do Le1. Insere-se no $\mathrm{Pb} 2$. Músculo em forma de fita. O complexo Le1-Li1 é descrito como um músculo bicaudado.

Li2. Origina-se no proótico dorsalmente à articulação do $\mathrm{Pb} 1$ com o crânio. Insere-se no $\mathrm{Pb} 3$. Músculo em forma de fita.

Li3. Origina-se no proótico no mesmo ponto de origem do Li2. Insere-se no $\mathrm{Pb} 4$. Seu ventre muscular está localizado dorsalmente ao Li2. Músculo em forma de fita. 
Od3. Origina-se no Pb3 ventralmente ao músculo TEb2 e insere-se na extremidade cartilaginosa do processo uncinado do Eb3, que apresenta-se deslocado medialmente. Músculo fusiforme.

Od4. Origina-se no $\mathrm{Pb} 4$ e insere-se amplamente na margem lateral do processo levantador do Eb4. Na região de inserção apresenta a forma de leque. A distância entre a origem e a inserção é menor comparativamente à origem e inserção do Od3. Topograficamente, em vista dorsal, o Od4 aparenta estar bastante reduzido em relação às outras espécies observadas.

Od4'. Ausente.

OP. Origina-se no Eb4 posteriormente. Estende-se lateralmente até a rafe do esôfago e posteriormente até o Ad5.

Ad4. Encontra-se sobre a margem médio posterior do processo levantador do Eb4. Nessa região apresenta a forma de leque. Insere-se no Cb4.

Ad5. Origina-se no Eb5 e insere-se no Cb5.

SO. Idem Springer e Johnson (2004).

TEb2. Grande parte do conjunto das fibras liga o processo uncinado do Eb2 esquerdo ao seu correspondente do lado direito. Fibras musculares assimétricas estão associadas ao TEb2 e também conectam-se anteriormente a margem medial do $\mathrm{Pb} 2$.

$\mathrm{TPb} 3-\mathrm{TPb} 4$. Liga-se na margem medial do $\mathrm{Pb} 3$ e $\mathrm{Pb} 4$ esquerdos e conecta-se aos seus correspondentes no lado direito. Fibras dispostas paralelamente em uma camada bem delgada. Seu limite anterior é bem estabelecido pelo TEb2, assim como seu limite caudal pelo TEb4. 
TEb4. Liga-se na margem medial do Eb4 esquerdo, medialmente à origem do LP e do Le4 e conecta-se na mesma estrutura no lado direito. Não é possível delimitar claramente seu limite anterior com o $\mathrm{TPb} 4$ e seu limite posterior com o $\mathrm{SO}$.

Cynodon gibbus.

Le1. Origina-se no proótico medialmente à articulação do $\mathrm{Pb} 1$ com o crânio. Insere-se lateralmente ao processo uncinado do Eb1. Músculo fusiforme.

Le2. Origina-se no proótico medialmente à origem do Le1. Insere-se na extremidade cartilaginosa do processo uncinado do Eb2. Músculo fusiforme.

Le3. Origina-se no proótico medialmente à origem do Li2/Li3. Insere-se na extremidade cartilaginosa do processo uncinado do Eb3, lateralmente a inserção do Od3. Músculo fusiforme.

Le4. Origina-se no proótico ventro medialmente à origem do Le3, lateralmente ao plexo branquial do nervo $\mathrm{X}$. Insere-se na margem medial do processo levantador do Eb4. Músculo em forma de fita.

LP. Origina-se no pterótico através de um tendão delgado, compartilhando a mesma origem do protractor pectoralis. Topograficamente o ventre fusiforme do LP localiza-se medialmente ao ventre muscular do protractor pectoralis. Insere-se na margem dorsal do processo levantador do Eb4.

Li1. Origina-se no proótico juntamente com o Le1. Insere-se no $\mathrm{Pb}$, passando pela margem medial do processo uncinado do Eb1. O complexo Le1-Li1 é descrito como um músculo bicaudado. 
Li2. Origina-se no proótico medialmente à origem do Le2. Apresenta grande área de superfície de contato com o crânio na região da origem. Insere-se na margem posterior do $\mathrm{Pb} 3$, anteriormente ao $\mathrm{Pb} 4$. Músculo em forma de fita.

\section{Li3. Idem H. tatauaia.}

Od3. Origina-se no $\mathrm{Pb} 3$, ventralmente ao músculo $\mathrm{TPb} 3-\mathrm{Eb} 2$. Insere-se medialmente à inserção do Le3 na margem medial do processo uncinado do Eb3. Músculo fusiforme.

Od4. Origina-se no $\mathrm{Pb} 4$ e insere-se amplamente na face lateral do processo levantador do Eb4. Músculo em forma de leque. Comparativamente com o Od3, o Od4 apresenta um ventre muscular mais robusto e evidente em relação ao primeiro.

Od4'. Ausente.

OP. Idem Springer e Johnson (2004).

Ad4. Origina-se na margem posterior do processo levantador do Eb4. Sua inserção ocorre no $\mathrm{Cb} 4$.

Ad5. Origina-se no Eb5 e insere-se no Cb5.

SO. Idem H. tatauaia.

TEb2. Idem H. tatauaia.

TPb3-TPb4. Idem H. tatauaia.

TEb4. Liga-se na parte medial do Eb4 esquerdo, e conecta-se no seu correspondente do lado direito. As fibras musculares são delgadas, tornando sua identificação difícil em relação as fibras do $\mathrm{TPb} 3-\mathrm{TPb} 4$ e $\mathrm{SO}$. 
Nota: Os músculos levantadores, com exceção dos músculos Le4 e LP, originam-se no proótico em linha, da região da articulação do $\mathrm{Pb} 1$ com o crânio.

\section{Rhaphiodon vulpinus.}

Le1. Origina-se no proótico medialmente à articulação do $\mathrm{Pb} 1$ ao crânio. Insere-se lateralmente no processo uncinado do Eb1. Músculo fusiforme.

Le2. Origina-se no proótico dorsalmente à origem do Le1. Insere-se no processo uncinado do Eb2. Músculo em forma de fita. Compartilha a mesma origem com o Li3.

Le3. Origina-se no proótico ventro medialmente à origem do Le2 e do Li3. Insere-se na margem anterior da extremidade cartilaginosa do processo uncinado do Eb3. Músculo em forma de fita.

Le4. Origina-se no proótico medialmente à origem do Le3. Apresenta grande superfície de contato entre o ventre muscular e o osso na região da origem. Insere-se na margem medial do processo levantador do Eb4 dorsalmente ao Od4.

LP. Origina-se no pterótico, compartilhando o tendão de inserção com o músculo protractor pectoralis. Topograficamente o LP está localizado medialmente ao PP. Insere-se na extremidade cartilaginosa do processo levantador do Eb4. Músculo fusiforme.

Li1. Origina-se no proótico juntamente com o Le1. Insere-se no $\mathrm{Pb} 2$, passando medialmente ao processo uncinado do Eb1. O complexo Le1-Li1 é descrito como um músculo bicaudado.

\section{Li2. Ausente.}


Li3. Apresenta a origem compartilhada com o Le2, no proótico. Insere-se no $\mathrm{Pb} 4$. Músculo em forma de fita. O complexo Le2-Li3 é descrito como um músculo bicaudado.

Od3. Idem C. gibbus.

Od4. Idem H.tatauaia

Od4'. Ausente.

OP. Origina-se na margem médio posterior do Eb4. Insere-se idem Springer e Johnson (2004).

Ad4. Origina-se no Eb4 e insere-se no Cb4 medial ao ângulo interno entre a articulação do $\mathrm{Eb} 4$ e do $\mathrm{Cb} 4$.

Ad5. Idem C. gibbus

SO. Idem Springer e Johnson (2004).

TEb2. Idem H. tatauaia.

$\mathrm{TPb} 3-\mathrm{TPb} 4$. Liga-se na margem medial do $\mathrm{Pb} 3$ e $\mathrm{Pb} 4$ esquerdos e conecta-se aos seus correspondentes no lado direito. Fibras dispostas paralelamente em uma camada bem delgada. Seu limite anterior é bem estabelecido pelo TEb2, assim como seu limite caudal pelo TEb4.

TEb4. Liga-se na margem medial do Eb4 esquerdo, medialmente à origem do LP e do Le4 e conecta-se na mesma estrutura no lado direito. Não é possível delimitar claramente seu limite anterior com o $\mathrm{TPb} 4$ e seu limite posterior com o SO. 
Nota: As origens dos músculos Le1, Le2 e Li2/Li3 estão topograficamente muito próximas.

\section{Gilbertolus alatus}

Le1. Origina-se no proótico dorsalmente a articulação do $\mathrm{Pb} 1$ com o crânio, origem muscular. Insere-se na face lateral óssea do processo uncinado do Eb1. Músculo em forma de fita.

Le2. Origina-se no proótico medialmente a origem do Li1. Origem muscular. Insere-se na face lateral do processo uncinado do Eb2. Músculo em forma de fita.

Le3. Origina-se no proótico medialmente a origem dos Li1-Li2. Origem muscular. Insere-se na face anterior da extremidade dorsal do processo uncinado do Eb3 dorsalmente a inserção do Od3. Músculo em forma de fita.

Le4. Origina-se no proótico medialmente a origem do Le3. Origem muscular. Insere-se na extremidade dorsal do processo levantador do Eb4. Músculo em forma de fita.

LP. Origina-se na extremidade posterior na margem ventral do pterótico medialmente ao PP. Origem muscular. Insere-se na extremidade dorsal do processo levantador do Eb4. Músculo em forma de fita.

Li1. Origina-se no proótico medialmente a origem do Le1. Origem muscular. Insere-se na superfície dorsal do $\mathrm{Pb} 2$. Músculo fusiforme.

Li2-Li3. Origina-se no proótico medialmente a origem do Le2. Origem muscular. Insere-se na parte posterior do $\mathrm{Pb} 3$ e na parte anterior do Pb4. Músculo em forma de 
fita. Nota: não foi possível evidenciar no exemplar dissecado separação nítida entre os ventres musculares do Li2 e do Li3.

Od3. Origina-se anteriormente na extremidade anterior do $\mathrm{Pb} 3$ ventralmente ao $\mathrm{TEb} 2 \mathrm{e}$ insere-se na extremidade dorsal do processo uncinado do Eb3, ventralmente a origem do Le3. Músculo fusiforme.

Od4. Origina-se anteriormente na extremidade anterior do $\mathrm{Pb} 4$ e insere-se na face lateral do processo levantador do Eb4. Músculo em forma de leque.

Od4'. Presente. Esse músculo está localizado lateralmente ao OD4 e insere-se na face lateral do processo levantador do Eb4. Sua origem ocorre na parte óssea posterior do $\mathrm{Pb} 3$. Músculo em forma de fita.

OP. Origina-se na margem medial do Eb4, próximo às fibras do TEb4 e termina na rafe do esôfago.

Ad4. Na face medial do processo levantador do Eb4 e na margem dorsal da extremidade posterior do $\mathrm{Cb} 4$, medialmente ao ângulo interno da articulação Eb4-Cb4.

Ad5. Na margem posterior do Eb5 (cartilagem) e na extremidade posterior do Cb5.

SO. Camada de músculo que circunda o esôfago, com aumento no tamanho das fibras dorsalmente, delgado em outras partes.

TEb2. Liga-se medialmente a extremidade cartilaginosa do processo uncinado do Eb2 esquerdo e conecta-se a mesma estrutura do lado direito. Músculo delgado localizado dorsalmente ao Od3. 
TPb3. Liga-se na face médio dorsal do Pb3 esquerdo e conecta-se na mesma estrutura no lado esquerdo. Está localizado ventralmente ao TEb2. É limitado posteriormente pelas fibras do $\mathrm{TPb} 4$.

$\mathrm{TPb} 4$. Liga-se ao longo da margem medial do $\mathrm{Pb} 4$ esquerdo e conecta-se na mesma região do lado direito. É limitado posteriormente pelas fibras do TEb4.

TEb4. Liga-se na face medial ventral do Eb4 esquerdo e insere-se na mesma estrutura do lado direito. Anteriormente limita-se pelas fibras do TPb4.

Nota: As origens do Le1, Le2, Li1, Li2-Li3 estão localizadas na incisura do proótico, mas devido a sua origem carnosa é possível distinguir pontos de origens separados nessa região.

\subsubsection{Família Ctenoluciidae}

\section{Boulengerella cuvieri.}

Le1. Origina-se no proótico dorsalmente à articulação do $\mathrm{Pb} 1$ e o crânio, lateralmente à origem do Li1. O ventre muscular apresenta-se alargado na região de origem. Insere-se no processo uncinado do Eb1, idem Springer e Johnson (2004). Músculo em forma de fita.

Le2. Origina-se no proótico medialmente às origens de Le1 e Li1. Insere-se na extremidade dorsal do processo uncinado do Eb2. Músculo fusiforme. 
Le3. Insere-se na extremidade dorsal do processo uncinado do Eb3. Músculo fusiforme. Devido a dissecação não foi possível observar a origem desse músculo.

Le4. Origina-se no proótico ventro medialmente às origens dos levantadores externos e internos. Insere-se na margem anterior do processo levantador do Eb4. Músculo em forma de fita.

LP. Origina-se na margem anterior do pterótico. Não compartilha a origem com o músculo protractor pectoralis. Insere-se na extremidade dorsal do processo levantador do Eb4. Músculo em forma de fita.

Li1. Origina-se no proótico dorso medialmente à origem do Le1 e lateralmente à origem do Le2. Apresenta na região da origem a forma de leque. Insere-se no $\mathrm{Pb} 2$.

Li2. Insere-se na região dorsal do Pb3. Músculo em forma de fita. Devido a dissecação não foi possível observar a origem desse músculo.

Li3. Insere-se no Pb4. Músculo em forma de fita. Devido a dissecação não foi possível observar a origem desse músculo.

Od3. Origina-se anteriormente no $\mathrm{Pb} 3$ ventralmente ao $\mathrm{TPb} 3-\mathrm{Eb} 2$. Insere-se na margem medial do processo uncinado do Eb3. Músculo fusiforme.

Od4. Origina-se no $\mathrm{Pb} 4$ e insere-se amplamente na margem medial do processo levantador do Eb4. Músculo em forma de fita.

Od4'. Ausente.

OP. Origina-se na margem póstero medial do Eb4 estendendo suas fibras posteriormente até o Ad5 e lateralmente até a rafe do esôfago. Suas fibras não se confundem com as do SO. 
Ad4. Ausente.

Ad5. Idem Springer e Johnson (2004).

SO. Idem Springer e Johnson (2004).

TEb2. Idem Springer e Johnson (2004).

$\mathrm{TPb} 3$. Liga-se na margem medial do $\mathrm{Pb} 3$ esquerdo e conecta-se a mesma estrutura no lado direito. Suas fibras musculares confundem-se com as fibras do TPb4 que liga-se no $\mathrm{Pb} 3$ esquerdo anteriormente e insere-se no $\mathrm{Pb} 4$ posteriormente. Esse músculo transverso apresenta um correspondente simétrico bilateralmente.

$\mathrm{TPb} 4-E b 4$. Liga o $\mathrm{Pb} 4$ e a parte medial do Eb4 esquerdos aos seus correspondentes estruturais no lado direito.

\subsubsection{Família Curimatidae.}

\section{Curimatopsis myersi.}

Le1. Origina-se no proótico na região de articulação do $\mathrm{Pb} 1$ com o crânio através de um tendão delgado. Na região de inserção apresenta duas partes distintas: inserindo-se na extremidade dorsal do processo uncinado do Eb1 e látero posteriormente ao processo uncinado do Eb1. Músculo fusiforme.

Le2. Origina-se no proótico medialmente a origem do Le1. Insere-se na extremidade dorsal do processo uncinado do Eb2. Músculo fusiforme.

Le3. Origina-se no proótico medialmente a origem do Li2-Li3. Insere-se na extremidade dorsal do processo uncinado do Eb3. Músculo fusiforme. 
Le4. Origina-se no proótico, medialmente a origem do Le3. Insere-se na margem anterior do processo levantador do Eb4.

LP. Origina-se no pterótico. Insere-se na margem dorsal do processo levantador do Eb4. Músculo em forma de fita. (Parece não haver um músculo protractor pectoralis associado topograficamente ao LP).

Li1. Origina-se no proótico medialmente a origem do Le1. Inserção em dois pontos distintos do $\mathrm{Pb} 2$, caracterizando um músculo bicaudado.

Li2. Origina-se no proótico medialmente a origem do Le2. Insere-se na superfície dorsal do $\mathrm{Pb} 3$

Li3. Origina-se no proótico dorsalmente a origem do Li2. Insere-se na extremidade posterior do $\mathrm{Pb} 3$ e na extremidade anterior na superfície dorsal do $\mathrm{Pb} 4$.

Od3. Origina-se anteriormente no $\mathrm{Pb} 3$ e insere-se na extremidade cartilaginosa do processo uncinado do Eb3.

Od4. Origina-se anteriormente no $\mathrm{Pb} 4$ e insere-se na margem anterior do processo levantador do Eb4.

Od4'. Ausente.

OP. Origina-se posteriormente no Eb4 e insere-se posteriormente próximo a rafe do esôfago juntamente com fibras do Ad4.

Ad4. Origina-se na extremidade posterior do Eb4 em sua margem ventral. Suas fibras na região da origem confundem-se com as fibras do SO e do OP.

Ad5. Não observado. 
SO. Camada de fibras musculares que circundam o esôfago, posterior aos órgãos epibranquiais.

TEb2. Liga-se no processo uncinado do Eb2 esquerdo e conecta-se na estrutura correspondente no lado direito. Feixes de fibras associadas ao TEb2 ligam-se também ligam-se na margem medial do $\mathrm{Pb} 3$ esquerdo e conectam-se ao seus correspondentes no lado direito.

$\mathrm{TPb} 4$. Ausente.

TEb4. Liga a extremidade posterior da margem medial do Eb4 esquerdo e conecta-se a mesma estrutura no lado direito.

Nota: O TEb4 apresenta um grande espessamento nas suas fibras dorsais e ventrais na região de conexão com o Eb4. As fibras mais posteriores se tornam mais delgadas e elásticas estendendo-se da região dorsal e da região ventral em direção aos órgãos epibranquiais posteriormente, formando um saco de fundo cego, na região mediana, entre os órgãos epibranquiais.

Curimata vittata.

Le1. Idem Curimatopsis myersi

Le2. Origina-se no proótico medialmente a origem do Le1. Insere-se na margem dorsal do $\mathrm{Eb} 2$.

Le3. Origina-se no proótico medialmente a origem do Le2. Insere-se na margem dorsal do Eb3. 
Le4. Origina-se no proótico medialmente a origem do Le3. Insere-se na extremidade dorsal cartilaginosa do processo levantador do Eb4.

LP. Origina-se no pterótico, medialmente à origem do protractor pectoralis. Insere-se na margem dorsal do Eb4. Músculo em forma de fita.

Li1. Origina-se no proótico medialmente ao Le1. Insere-se na superfície dorsal do $\mathrm{Pb} 2$.

Li2. Idem Curimatopsis myersi. Insere-se na porção óssea do $\mathrm{Pb} 3$, posteriormente. $\mathrm{O}$ ventre muscular do Li2 é menor se comparado ao do Li3.

Li3. Idem Curimatopsis myersi. Insere-se na porção cartilaginosa do $\mathrm{Pb} 4$ anteriormente, lateralmente a origem do Od4. Apresenta ventre muscular maior que o Li2.

Od3. Origina-se no $\mathrm{Pb} 3$ anteriormente. Insere-se na margem anterior do processo uncinado do Eb3 através de um tendão afilado.

Od4. Origina-se no $\mathrm{Pb} 4$ anteriormente através de um tendão delgado. Insere-se na face medial da lâmina óssea do Eb4.

Od4'. Ausente.

OP. Não observado.

Ad4. No Eb4 posteriormente até a superfície dorsal do Cb4, medialmente ao ângulo interno da articulação do Eb4-Cb4.

Ad5. Não observado.

SO. Idem Curimatopsis myersi.

TEb2. Idem Curimatopsis myersi. 
$\mathrm{TPb} 4$. Ausente.

TEb4. Idem Curimatopsis myersi.

Nota: Em Curimatopsis myersi os órgãos epibranquiais não apresentam ligação dorsal em sua extremidade posterior. Em Curimata vittata os órgãos epibranquiais são contínuos posteriormente ligados dorsalmente por fibras musculares.

\subsubsection{Família Distichodontidae}

Distichodus sp.

Le1. Originam-se no proótico dorsalmente a articulação do $\mathrm{Pb} 1$ com o crânio. Origem tendínea. Insere-se ao longo da parede medial do Eb1, lateralmente ao processo uncinado do Eb1. Músculo fusiforme.

Le2. Origina-se no proótico juntamente com a origem do Le1. Origem tendínea. Inserese na margem anterior, na face lateral e medial óssea do processo uncinado do Eb2. Músculo em forma de fita.

Le3. Originam-se no proótico medialmente as origens dos músculosLi2 e Li3. Insere-se na margem anterior da extremidade dorsal do processo uncinado do Eb3 (osso e cartilagem). Músculo em forma de fita.

Le4. Origina-se no proótico medialmente a origem do Le3. Insere-se na extremidade dorsal cartilaginosa do processo levantador do Eb4. Músculo em forma fita.

LP. Origina-se na margem ventral do pterótico. Insere-se na extremidade dorsal na face medial do processo levantador do Eb4. Músculo em forma de fita. O PP está ausente 
Li1. Origina-se no proótico juntamente com a origem do Le1. Origem tendínea. Inserese na superfície dorsal óssea do $\mathrm{Pb} 2$ até a região de articulação com o Eb2. Músculo em forma de fita.

Li2. Origina-se no proótico medialmente a origem do Le1-Li1-Le2 e ventralmente a origem do Li3. Insere-se no Pb3. Músculo em forma de fita.

Li3. Origina-se no proótico dorsalmente a origem do Li2. Insere-se no Pb4. Músculo em forma de fita

Od3. Origina-se anteriormente na extremidade anterior do $\mathrm{Pb} 3$, lateralmente a origem do Od4', ventralmente ao TEb2. Insere-se na extremidade dorsal cartilaginosa do processo uncinado do Eb3 medialmente a inserção do Le3. Músculo em forma de fita. (reduzido)

Od4. Origina-se anteriormente no $\mathrm{Pb} 4$. Insere-se na face lateral do processo levantador do Eb4. Músculo em forma de leque.

Od4'. Origina-se anteriormente no $\mathrm{Pb} 3$, medialmente a origem do Od3. Insere-se na extremidade dorsal cartilaginosa do processo levantador do Eb4. Músculo em forma de fita, localizado dorsalmente ao Od4.

OP. Origina-se na margem medial do Eb4, próximo às fibras do TEb4 e termina na rafe do esôfago.

Ad4. Na margem ventral da porção média até a extremidade posterior do Eb4 e na margem dorsal da porção média até a extremidade posterior do $\mathrm{Cb} 4$, medialmente ao ângulo interno da articulação Eb4-Cb4. (Músculo bem desenvolvido se comparado com outros táxons examinados). 
Ad5. Na margem posterior do Eb5 (cartilagem) e na extremidade posterior do Cb5.

SO. Camada de músculo que circunda o esôfago, com aumento no tamanho das fibras dorsalmente, com uma projeção anterior mediana de fibras que se estendem ventralmente ao TEb4.

TEb2. Liga-se medialmente a extremidade cartilaginosa do processo uncinado do Eb2 esquerdo e conecta-se na mesma estrutura no lado direito.

TPb3. Liga-se na face médio dorsal do Pb3 esquerdo e conecta-se na mesma estrutura no lado esquerdo. Está localizado ventralmente ao TEb2. Seu limite posterior são as fibras do $\mathrm{TPb} 4$.

TPb4. Liga-se ao longo da margem medial do Pb4 esquerdo e insere-se na mesma região do lado direito. Anteriormente seu limite são fibras musculares se do TPb3. Seu limite posterior é bem estabelecido pelo músculo TEb4.

TEb4. Liga-se medialmente no Eb4 esquerdo e conecta-se nas mesmas estruturas no lado direito. Músculo em forma de fuso, com as fibras ligeiramente mais desenvolvidas que as do $\mathrm{TPb} 4$.

Nota: O complexo muscular formado pelo Le1, Le2 e Li1 é caracterizado como um músculo policaudado, apresentando origem única e três inserções distintas.

\section{Eugnathichthys sp.}

Le1. Originam-se no proótico medialmente a articulação do Pb1 com o crânio. Origem tendínea. Insere-se na face lateral óssea do processo uncinado do Eb1. Músculo fusiforme. 
Le2. Origina-se no proótico medialmente a origem do Le1. Origem tendínea. Insere-se na margem anterior, na face lateral e medial óssea do processo uncinado do Eb2. Músculo fusiforme.

Le3. Originam-se no proótico medialmente as origens dos músculos Li2 e Li3. Insere-se na margem anterior da extremidade dorsal do processo uncinado do Eb3 (osso e cartilagem). Músculo em forma de fita.

Le4. Origina-se no proótico medialmente a origem do Le3. Insere-se na extremidade dorsal cartilaginosa do processo levantador do Eb4. Músculo em forma fita.

LP. Origina-se na margem ventral do pterótico juntamente com o PP. Insere-se na extremidade dorsal na face medial do processo levantador do Eb4. Músculo em forma de fita. PP reduzido. Na região de inserção o PP e o Le4 estão unidos por fáscia muscular.

Li1. Origina-se no proótico juntamente com a origem do Le1. Origem tendínea. Inserese na superfície dorsal óssea do $\mathrm{Pb} 2$ até a região de articulação com o Eb2. Músculo em forma de fita.

Li2. Origina-se no proótico medialmente a origem do Le1-Li1-Le2 e ventralmente a origem do Li3. Insere-se no Pb3. Músculo em forma de fita.

Li3. Origina-se no proótico dorsalmente a origem do Li2. Insere-se no $\mathrm{Pb}$ 4. Músculo em forma de fita

Od3. Ausente.

Od4. Origina-se anteriormente no $\mathrm{Pb} 4$. Insere-se na face lateral do processo levantador do Eb4. Músculo em forma de leque. 
Od4'. Origina-se anteriormente no $\mathrm{Pb} 3$, medialmente a origem do Od3. Insere-se na extremidade dorsal cartilaginosa do processo levantador do Eb4. Músculo em forma de fita, localizado dorsalmente ao Od4.

OP. Origina-se na margem medial do Eb4, próximo às fibras do TEb4 e termina na rafe do esôfago.

Ad4. Ausente

Ad5. Na margem posterior do Eb5 (cartilagem) e na extremidade posterior do Cb5.

SO. Camada de músculo que circunda o esôfago, com aumento no tamanho das fibras dorsalmente, com uma projeção anterior mediana de fibras que se estendem ventralmente ao TEb4.

TEb2. Liga-se medialmente ao processo uncinado do Eb2 esquerdo e conecta-se na mesma estrutura no lado direito.

$\mathrm{TPb} 3$. Liga-se na face medial óssea do $\mathrm{Pb} 3$ esquerdo e conecta-se na mesma estrutura no lado esquerdo. Está localizado ventralmente ao TEb2 e na região do seu limite posterior suas fibras confundem-se com as do $\mathrm{TPb} 4$.

$\mathrm{TPb} 4$. Liga-se ao longo da margem medial do Pb4 esquerdo e insere-se na mesma região do lado direito. Anteriormente seu limite não é bem definido, pois suas fibras musculares se confundem com as fibras do $\mathrm{TPb} 3$. Seu limite posterior é bem estabelecido pelo músculo TEb4.

TEb4. Liga-se medialmente no Eb4 esquerdo e conecta-se nas mesmas estruturas no lado direito. Músculo em forma de fuso, com as fibras ligeiramente mais desenvolvidas que as do $\mathrm{TPb} 4$. 
Hemigrammocharax multifasciatus.

Le1. Originam-se no proótico dorsalmente a articulação do Pb1 com o crânio. Origem tendínea. Inserção Idem Nannocharax sp.

Le2. Idem Nannocharax sp.

Le3. Idem Nannocharax sp.

Le4. Idem Nannocharax sp.

LP. Idem Nannocharax sp.

Li1. Idem Nannocharax sp.

Li2. Idem Nannocharax sp.

Li3. Idem Nannocharax spOd3. Idem Nannocharax sp. Od4. Idem Nannocharax sp. Od4'. Idem Nannocharax sp.

OP. Idem Nannocharax sp.

Ad4. Idem Nannocharax sp.

Ad5. Na margem posterior do Eb5 (cartilagem) e na extremidade posterior do Cb5.

SO. Camada de músculo que circunda o esôfago, com aumento no tamanho das fibras dorsalmente.

TEb2. Liga o Eb2 esquerdo ao seu correspondente no lado direito. O limite posterior desse músculo não é claro, pois suas fibras se confundem com as fibras do $\mathrm{TPb} 3$. 
TPb3-TPb4-TEb4. Uma camada fina de músculos que liga-se ao Pb3, Pb4 e o TEb4 esquerdos e conectam-se as mesmas estruturas no lado direito. Não é possível distinguir o limite posterior com as fibras do SO.

\section{Nannocharax sp.}

Le1. Origina-se no proótico dorsalmente a articulação do Pb1 com o crânio. Insere-se ao longo da parede medial do Eb1, lateralmente ao processo uncinado do Eb1. Músculo fusiforme.

Le2. Origina-se no proótico medialmente a origem do Le1- Li1. Insere-se na margem anterior, na face lateral óssea do processo uncinado do Eb2. Músculo em forma de fita.

Le3. Origina-se no proótico medialmente as origens dos músculos Li2 e Li3. Insere-se na margem anterior da extremidade dorsal do processo uncinado do Eb3 (osso e cartilagem). Músculo em forma de fita.

Le4. Origina-se no proótico medialmente a origem do Le3. Insere-se na extremidade dorsal cartilaginosa do processo levantador do Eb4. Músculo em forma fita.

LP. Origina-se na margem ventral do pterótico. Insere-se na extremidade dorsal na face medial do processo levantador do Eb4. Músculo em forma de fita. O PP está ausente Li1. Origina-se no proótico ventralmente a origem do Le1. Insere-se na margem lateral óssea do Pb2 até a região de articulação com o Eb2. Músculo em forma de fita.

Li2. Origina-se no proótico medialmente a origem do Le2 e ventralmente a origem do Li3. Insere-se no Pb3. Músculo em forma de fita. 
Li3. Origina-se no proótico dorsalmente a origem do Li2. Insere-se no Pb4. Músculo em forma de fita

Od3. Origina-se anteriormente na extremidade anterior do Pb3ventralmente ao TEb2. Insere-se na extremidade dorsal cartilaginosa do processo uncinado do Eb3. Músculo em forma de fita.

Od4. Origina-se anteriormente no $\mathrm{Pb}$ 4. Insere-se na face lateral do processo levantador do Eb4. Músculo em forma de leque.

Od4'. Ausente

OP. Origina-se na margem medial do Eb4, próximo às fibras do TEb4 e termina na rafe do esôfago.

Ad4. Na margem ventral da porção média até a extremidade posterior do Eb4 e na margem dorsal da porção média até a extremidade posterior do $\mathrm{Cb} 4$, medialmente ao ângulo interno da articulação Eb4-Cb4. (Músculo bem desenvolvido se comparado com outros táxons examinados).

Ad5. Na margem posterior do Eb5 (cartilagem) e na extremidade posterior do Cb5.

SO. Camada de músculo que circunda o esôfago, com aumento no tamanho das fibras dorsalmente.

TEb2. Liga o Eb2 esquerdo ao seu correspondente no lado direito. O limite posterior desse músculo não é claro, pois suas fibras se confundem com as fibras do TPb3.

TPb3-TPb4-TEb4. Uma camada fina de músculos que liga-se ao Pb3, Pb4 e o TEb4 esquerdos e conectam-se as mesmas estruturas no lado direito. Não é possível distinguir o limite posterior com as fibras do SO. 


\section{Neolebias trilineatus.}

Le1. Origina-se no proótico dorso medialmente a articulação do Pb1 com o crânio. Origem tendínea. Insere-se na face lateral óssea do processo uncinado do Eb1. Músculo fusiforme.

Le2. Origina-se no proótico juntamente com a origem do Le1. Origem tendínea. Inserese na margem anterior, na face lateral e medial óssea do processo uncinado do Eb2. Músculo em forma de fita.

Le3. Origina-se no proótico medialmente as origens dos músculos Li2 e Li3. Insere-se na margem anterior da extremidade dorsal do processo uncinado do Eb3 (osso e cartilagem). Músculo em forma de fita.

Le4. Origina-se no proótico medialmente a origem do Le3. Insere-se na extremidade dorsal cartilaginosa do processo levantador do Eb4. Músculo em forma fita.

LP. Origina-se na margem ventral do pterótico. Insere-se na extremidade dorsal na face medial do processo levantador do Eb4. Músculo em forma de fita. O PP está ausente.

Li1. Origina-se no proótico juntamente a origem do Le1. Origem tendínea. Insere-se na superfície dorsal óssea do $\mathrm{Pb} 2$ até a região de articulação com o Eb2. Músculo em forma de fita.

Li2. Origina-se no proótico medialmente a origem do Le1-Li1-Le2 e ventralmente a origem do Li3. Insere-se no Pb3. Músculo em forma de fita.

Li3. Origina-se no proótico dorsalmente a origem do Li2. Insere-se no Pb4. Músculo em forma de fita 
Od3. Origina-se anteriormente na extremidade anterior do $\mathrm{Pb} 3$, lateralmente a origem do Od4', ventralmente ao TEb2. Insere-se na extremidade dorsal do processo uncinado do Eb3. Músculo em forma de fita.

Od4. Origina-se anteriormente no $\mathrm{Pb} 4$. Insere-se na face lateral do processo levantador do Eb4. Músculo em forma de leque.

Od4'. Origina-se anteriormente no $\mathrm{Pb} 3$, medialmente a origem do Od3. Insere-se na extremidade dorsal cartilaginosa do processo levantador do Eb4. Músculo em forma de fita, localizado dorsalmente ao Od4.

OP. Origina-se na margem medial do Eb4, próximo às fibras do TEb4 e termina na rafe do esôfago.

Ad4. Na margem ventral da porção média até a extremidade posterior do Eb4 e na margem dorsal da porção média até a extremidade posterior do $\mathrm{Cb} 4$, medialmente ao ângulo interno da articulação Eb4-Cb4. (Músculo bem desenvolvido se comparado com outros táxons examinados). Ad5. Na margem posterior do Eb5 (cartilagem) e na extremidade posterior do $\mathrm{Cb} 5$.

SO. Camada de músculo que circunda o esôfago, com aumento no tamanho das fibras dorsalmente, com uma projeção anterior mediana de fibras que se estendem ventralmente ao TEb4.

TEb2. Liga-se medialmente ao processo uncinado do Eb2 esquerdo e conecta-se na mesma estrutura no lado direito. 
$\mathrm{TPb} 3$. Liga-se na face medial óssea do Pb3 esquerdo e conecta-se na mesma estrutura no lado esquerdo. Está localizado ventralmente ao TEb2 e na região do seu limite posterior suas fibras confundem-se com as do $\mathrm{TPb} 4$.

TPb4. Liga-se ao longo da margem medial do Pb4 esquerdo e insere-se na mesma região do lado direito. Anteriormente seu limite não é bem definido, pois suas fibras musculares se confundem com as fibras do $\mathrm{TPb} 3$. Seu limite posterior é bem estabelecido pelo músculo TEb4.

TEb4. Liga-se medialmente no Eb4 esquerdo e conecta-se nas mesmas estruturas no lado direito. Músculo em forma de fuso, com as fibras ligeiramente mais desenvolvidas que as do $\mathrm{TPb} 4$.

Nota: O complexo muscular formado pelo Le1, Le2 e Li1 é caracterizado como um músculo policaudado, apresentando uma origem única e três inserções distintas.

Phago intermedius.

Le1. Idem Eugnathichthys sp.

Le2.Idem Eugnathichthys sp.

Le3. Idem Eugnathichthys sp.

Le4. Idem Eugnathichthys sp.

LP. Idem Eugnathichthys sp.

Li1. Idem Eugnathichthys sp.

Li2. Idem Eugnathichthys sp. 


\section{Li3. Idem Eugnathichthys sp.}

Od3. Idem Eugnathichthys sp.

Od4. Origina-se anteriormente no $\mathrm{Pb} 4$. Insere-se na face lateral do processo levantador do Eb4. Músculo em forma de leque.

Od4'. Origina-se anteriormente no $\mathrm{Pb} 3$, medialmente a origem do $\mathrm{Od} 3$. Insere-se na extremidade dorsal cartilaginosa do processo levantador do Eb4. Músculo em forma de fita, localizado dorsalmente ao Od4.

OP. Origina-se na margem medial do Eb4, próximo às fibras do TEb4 e termina na rafe do esôfago.

Ad4. Na margem ventral da porção média até a extremidade posterior do Eb4 e na margem dorsal da porção média até a extremidade posterior do $\mathrm{Cb} 4$, medialmente ao ângulo interno da articulação Eb4-Cb4. (Músculo bem desenvolvido se comparado com outros táxons examinados).

Ad5. Na margem posterior do Eb5 (cartilagem) e na extremidade posterior do Cb5.

SO. Camada de músculo que circunda o esôfago, com aumento no tamanho das fibras dorsalmente, com uma projeção anterior mediana de fibras que se estendem ventralmente ao TEb4.

TEb2. Liga-se medialmente ao processo uncinado do Eb2 esquerdo e conecta-se na mesma estrutura no lado direito.

$\mathrm{TPb} 3$. Liga-se na face medial óssea do $\mathrm{Pb} 3$ esquerdo e conecta-se na mesma estrutura no lado esquerdo. Está localizado ventralmente ao $\mathrm{TEb} 2$ e na região do seu limite posterior suas fibras confundem-se com as do $\mathrm{TPb} 4$. 
TPb4. Liga-se ao longo da margem medial do Pb4 esquerdo e insere-se na mesma região do lado direito. Anteriormente seu limite não é bem definido, pois suas fibras musculares se confundem com as fibras do $\mathrm{TPb} 3$. Seu limite posterior é bem estabelecido pelo músculo TEb4.

TEb4. Liga-se medialmente no Eb4 esquerdo e conecta-se nas mesmas estruturas no lado direito. Músculo em forma de fuso, com as fibras ligeiramente mais desenvolvidas que as do $\mathrm{TPb} 4$.

\subsubsection{Família Erythrinidae}

\section{Hoplias malabaricus.}

Le1. Origina-se no proótico dorsalmente à articulação do $\mathrm{Pbl}$ com o crânio e lateralmente à origem do Li1. Insere-se lateralmente ao processo uncinado do Eb1. Músculo em forme de fita.

Le2. Origina-se no proótico medialmente à origem do Li1 e lateralmente à origem do Li2 e Li3. Na região da origem esse músculo está próximo ao Li1, tornando a distinção dos mesmos difícil. Insere-se na margem anterior do processo uncinado do Eb2. Músculo em forma de fita.

Le3. Origina-se no proótico medialmente às origens do Le1, Le2 e Li1 e lateralmente à origem do Le4. Insere-se na margem anterior do processo uncinado do Eb3. Músculo fusiforme. 
Le4. Origina-se no proótico medialmente à origem do Le3 e lateralmente os ramos do nervo X (plexo branquial). Insere-se no processo levantador do Eb4, dorsalmente à inserção do músculo Od4. Músculo fusiforme.

LP. Origina-se na margem anterior do pterótico através de um tendão delgado. Não compartilha a mesma origem com o protractor pectoralis. Na região da origem esse músculo pode ser classificado como fusiforme, porém na região de inserção passa a apresentar o formato de fita. Insere-se no processo levantador do Eb4 medialmente.

Li1. Origina-se no proótico medialmente à origem do Le1 e lateralmente à origem do Le2. Insere-se na superfície dorsal Pb2. Músculo em forma de fita.

Li2. Origina-se no proótico medialmente a emergência do nervo IX. Apresenta ampla área de superfície de contato com o crânio na região da origem. Insere-se na superfície dorsal do Pb3. Músculo em forma de fita.

Li3. Compartilha a mesma origem do músculo Li2. Insere-se na superfície dorsal do $\mathrm{Pb} 4$. O ventre muscular do Li3 é mais desenvolvido que o ventre muscular do Li2 que está localizado ventralmente ao primeiro.

Od3. Origina-se no $\mathrm{Pb} 3$, ventralmente ao TPb2-Eb2. Insere-se na margem medial do processo uncinado do Eb3. Músculo fusiforme (idem B. cuvieri).

Od4. Origina-se no $\mathrm{Pb} 4$, com superfície de contato amplamente maior se comparado à origem do Od3. Insere-se amplamente na face medial do processo levantador do Eb4. Músculo em forma de fita.

Od4'. Ausente. 
OP. Origina-se na margem médio posterior do Eb4 estendendo suas fibras caudalmente até o Ad5 e medialmente até a rafe do esôfago, entrando em contato com as fibras do SO.

Ad4. Origina-se amplamente na margem medial do processo levantador do Eb4, apresentando forma de leque e insere-se no $\mathrm{Cb} 4$.

Ad5. Origina-se no Eb5 e insere-se no Cb5.

SO. Idem Springer e Johnson (2004).

TEb2. Idem Springer e Johnson (2004).

$\mathrm{TPb} 3-\mathrm{TPb} 4$. Liga-se na margem medial do $\mathrm{Pb} 3$ e $\mathrm{Pb} 4$ esquerdos e conecta-se às mesmas estruturas no lado direito. Fibras dispostas paralelamente em uma camada bem delgada. Seu limite anterior é bem estabelecido pelo TEb2, assim como seu limite posterior pelo TEb4. O limite entre os músculos TPb3 e TPb4 não é claro.

TEb4. Liga-se na margem medial do Eb4 esquerdo, medialmente à origem do LP e do Le4 e conecta-se na mesma estrutura no lado direito. É delimitado posteriormente pelo SO.

Erythrinus erythrinus.

Le1. Origina-se no proótico dorsalmente à articulação do $\mathrm{Pb} 1$ com o crânio. Insere-se na extremidade dorsal do processo uncinado do Eb1. Músculo fusiforme.

Le2. Origina-se no proótico medialmente à origem do Le1 e do Li1 e lateralmente à origem do Li2 e Li3. Insere-se na margem anterior do processo uncinado do Eb2. Músculo em forma de fita. 
Le3. Origina-se no proótico ventro medialmente à origem do Li2/Li3 e lateralmente à origem do Le4. Insere-se na extremidade dorsal do processo uncinado do Eb3. Músculo fusiforme.

Le4. Origina-se no proótico medialmente à origem do Le3. Insere-se no processo levantador do Eb4 dorsalmente à inserção do Od4. Músculo em forma de fita.

LP. Origina-se no pterótico através de um tendão delgado. Compartilha a mesma origem com o protractor pectoralis. Insere-se na margem medial do processo levantador do Eb4. Músculo fusiforme.

Li1. Origina-se no proótico medialmente à origem do Le1 e ventralmente à origem do Le2. Insere-se na superfície dorsal do Pb2. Músculo em forma de fita.

Li2. Origina-se no proótico dorsalmente às origens dos músculos Le1, Li1 e Le2. Na região da origem apresenta a forma de um leque, o que confere uma grande superfície de contato entre o músculo e o crânio. Insere-se ao Pb3.

Li3. Origina-se juntamente com o Li2 e insere-se no $\mathrm{Pb} 4$. O ventre muscular do Li3 está localizado dorsalmente ao ventre muscular do Li2.

Od3. Idem H. malabaricus.

Od4. Idem H. malabaricus.

Od4'. Idem H. malabaricus.

OP. Idem H. malabaricus.

Ad4. Idem H. malabaricus.

Ad5. Idem H. malabaricus. 
SO. Idem H. malabaricus

TEb2. Idem H. malabaricus.

TPb3-TPb4. Idem H. malabaricus.

TEb4. Idem H. malabaricus.

4.1.12. Família Gasteropelecidae.

Gasteropelecus sternicla.

Le1. Origina-se no proótico na região de articulação do Pb1 com o crânio. Insere-se na face lateral do processo uncinado do Eb1. Músculo em forma de fita.

Le2. Origina-se no proótico, dorsalmente a origem do Le1. Insere-se na face lateral do processo uncinado do Eb2

Le3. Origina-se no proótico dorsalmente ao Li3. Insere-se na margem anterior do processo uncinado do Eb3.

Le4. Origina-se no proótico medialmente a origem do Le3. Insere-se na extremidade dorsal do processo levantador do Eb4, anteriormente a extremidade cartilaginosa. Músculo em forma de fita.

LP. Origina-se através de tendão no pterótico lateralmente a origem do músculo protractor pectoralis. Insere-se no processo levantador do Eb4, posteriormente a inserção do Le4.

Li1. Origina-se no proótico medialmente a origem do Le1. Insere-se na superfície dorsal do $\mathrm{Pb} 2$. 
Li2. Origina-se no proótico medialmente a origem do Le2 e ventralmente a origem do Li3. Insere-se anteriormente na superfície dorsal do Pb3. As fibras musculares do Li2 e do Li3 estão muito próximas sendo difícil a sua separação.

Li3. Origina-se no proótico medialmente a origem do Le2 e dorsalmente a origem do Li2. Insere-se na extremidade anterior do $\mathrm{Pb} 4$.

Od3. Origina-se anteriormente na extremidade anterior do Pb3. Insere-se na margem anterior do processo uncinado do Eb3.

Od4. Origina-se anteriormente no $\mathrm{Pb}$ 4. Insere-se na superfície lateral do processo levantador do Eb4. Músculo em forma de leque na região da origem e da inserção.

Od4'. Ausente.

OP. Faixa muscular estreita que se estende do TEb4 até o Cb5.

Ad4. Origina-se na superfície póstero medial do Eb4 pouco separada do SO, terminando ventralmente na rafe do esôfago.

Ad5. Na margem posterior do Eb5 (cartilagem) e na margem posterior do Cb5.

SO. Camada de músculo que circunda o esôfago, com aumento no tamanho das fibras dorsalmente, com uma projeção anterior mediana conspícua de fibras que se estendem ventralmente ao TEb4.

TEb2. Liga-se medialmente ao processo uncinado do Eb2 esquerdo e conecta-se na mesma estrutura no lado direito. 
TPb3. Liga-se na face médio dorsal do Pb3 esquerdo e conecta-se na mesma estrutura no lado esquerdo. Está localizado ventralmente ao TEb2 e na região do seu limite posterior suas fibras confundem-se com as do $\mathrm{TPb} 4$.

$\mathrm{TPb} 4$. Liga-se ao longo da margem medial do $\mathrm{Pb} 4$ esquerdo e insere-se na mesma região do lado direito. Anteriormente seu limite não é bem definido, pois suas fibras musculares se confundem com as fibras do $\mathrm{TPb} 3$. Seu limite posterior é bem estabelecido pelo músculo TEb4.

TEb4. Liga-se medialmente no Eb4 esquerdo e conecta-se na mesma estrutura no lado direito. Músculo em forma de fica com uma projeção mediana localizada ventralmente ao TPb4.

Thoracocharax stellatus.

Le1. Origina-se na incisura do proótico dorsalmente a articulação do Pb1 com o crânio. Inserção tendínea. Insere-se na face lateral do processo uncinado do Eb1. Apresenta dois ventres musculares. Músculo em forma de fita.

Le2. Origina-se na incisura do proótico medialmente a origem do Li1. Insere-se completamente no corpo do processo uncinado do Eb2. Músculo em forma de fita.

Le3. Origina-se no proótico medialmente aos músculos que se originam na incisura do proótico. Insere-se na margem anterior do processo uncinado do Eb3. Músculo em forma de fita.

Le4. Origina-se no proótico dorsalmente a origem do Le3. Insere-se na margem anterior do processo levantador do Eb4 (osso e cartilagem). Músculo em forma de fita. 
LP. Origina-se na margem ventral do pterótico, medialmente a origem do PP. Insere-se na extremidade dorsal e margem posterior do processo levantador do Eb4 (osso e cartilagem). Músculo em forma de fita.

Li1. Origina-se na incisura do proótico. Insere-se na superfície dorsal do $\mathrm{Pb} 2$ e na margem lateral posterior ao processo articular do $\mathrm{Pb} 2-\mathrm{Eb} 1$. Músculo em forma de fita.

Li2. Origina-se na incisura do proótico medialmente a origem do Le2. Insere-se no $\mathrm{Pb} 3$. Músculo em forma de fita.

Li3. Origina-se na incisura do proótico medialmente a origem do Li2. Insere-se no Pb4. Músculo em forma de fita. O ventre muscular do Li3 é muito maior do que o ventre muscular do Li2.

Od3. Origina-se anteriormente na extremidade anterior do Pb3 ventralmente ao TEb2$\mathrm{TPb} 3$. Insere-se posteriormente na margem anterior do processo uncinado do Eb3. Músculo em forma de fita.

Od4. Origina-se anteriormente no $\mathrm{Pb} 4$. Insere-se na face lateral do processo levantador do Eb4. Músculo em forma de leque.

Od4'. ausente.

OP. Origina-se na margem medial do Eb4, próximo às fibras do TEb4 e termina na rafe do esôfago.

Ad4. Na margem ventral da extremidade posterior do Eb4 e na margem dorsal da extremidade posterior do $\mathrm{Cb} 4$, medialmente ao ângulo interno da articulação Eb4-Cb4.

Ad5. Na margem posterior do Eb5 (cartilagem) e na extremidade posterior do $\mathrm{Cb} 5$. 
SO. Camada de músculo que circunda o esôfago, com aumento no tamanho das fibras dorsalmente, delgado em outras partes, anteriormente suas fibras apresentam projeção conspícua, ventralmente ao TEb4.

TEb2. Liga-se medialmente no processo uncinado do Eb2 e na margem medial do Pb3 e conecta-se aos seus correspondentes no lado direito.

$\mathrm{TPb} 4$. Liga-se ao longo da margem medial do Pb4 esquerdo e conecta-se na mesma região do lado direito. É limitado posteriormente pelas fibras do TEb4.

TEb4. Liga-se na face medial ventral do Eb4 esquerdo e insere-se na mesma estrutura do lado direito. Anteriormente limita-se pelas fibras do TPb4.

Nota:

. As origens dos músculos Le1, Li1, Le2, Li2 e Li3 no proótico estão limitadas a uma incisura óssea no proótico. Essa peculiaridade topográfica torna os tendões de origem desses músculos muito próximos e de difícil distinção. Existe uma grande fáscia muscular recobrindo esses músculos na região de origem e mesmo após sua remoção não é possível separar os mesmos na origem, pois suas fibras musculares terminam em um tendão comum ao Le1, Li1, Le2 e Le3, que se conecta na incisura do proótico. A separação topográfica dos músculos é possível até o limite entre as fibras e o tendão de origem. Esse complexo muscular é denominado músculo policaudado.

\subsubsection{Família Hemiodontidae.}

Bivibranchia velox. 
Le1. Origina-se no proótico lateralmente à origem do Li1. Insere-se em duas partes do processo uncinado do Eb1. O músculo largo dividido em duas porções caracterizando um músculo bicaudado.

Le2. Origina-se no proótico medialmente à origem do Le1. Insere-se na lateral do processo uncinado do Eb2.

Le3. Origina-se no proótico dorsalmente à origem dos Le1, Le2 e Li1. Insere-se na base do processo uncinado do Eb3. Músculo fusiforme

Le4. Origina-se no proótico dorso lateralmente à origem do Le3. Insere-se na extremidade dorsal do processo levantador do Eb4. Músculo fusiforme.

LP. Não foi possível observar a origem desse músculo. Insere-se na margem dorsal do processo levantador do Eb4.

Li1. Origina-se no proótico medialmente ao Le1. Insere-se na superfície dorsal do $\mathrm{Pb} 2$. Músculo largo.

Li2. Origina-se no proótico ventralmente a origem do Li3. Insere-se na superfície dorsal do Pb3. Músculo largo.

Li3. Origina-se no proótico dorsalmente a origem do Li2. Insere-se na superfície dorsal do Pb4. Músculo largo. Os músculos Li3 e Li2 não parecem estar separados na origem, porem essa separação torna-se evidente na região de inserção.

Od3. Origina-se anteriormente no $\mathrm{Pb} 3$ e insere-se no processo uncinado do Eb3. Músculo em forma de fita. 
Od4. Origina-se na parte anterior do $\mathrm{Pb} 4 \mathrm{e}$ insere-se na face lateral do processo levantador do Eb4. Músculo em forma de fita anteriormente e na inserção um músculo em forma de leque.

Od4'. Ausente.

OP. Origina-se na superfície póstero medial do Eb4 pouco separada do SO, terminando ventralmente na rafe do esôfago. As fibras musculares continuam ventralmente a partir da rafe do esôfago incluindo o Ad5 e o SO, idem Springer e Johnson (2004).

Ad4. No Eb4 dorso posteriormente e na superfície dorsal do $\mathrm{Cb} 4$, medialmente ao ângulo interno da articulação do Eb4-Cb4. Suas fibras estão localizadas ventralmente ao OP e lateralmente as fibras do SO.

Ad5. No Eb5 posteriormente e Cb5 posteriormente.

SO. Camada de músculo que circunda o esôfago, com aumento no tamanho das fibras dorsalmente, com uma projeção anterior mediana conspícua de fibras, até o TEb4.

TEb2. Liga-se medialmente ao processo uncinado do Eb2 esquerdo e conecta-se na mesma estrutura no lado direito.

TPb4a. Liga-se anteriormente no Pb4 esquerdo e conecta-se através de duas divisões na mesma estrutura do lado direito. Está localizado posteriormente ao TEb2.

$\mathrm{TPb} 4 p$. Liga-se ao longo da margem médio posterior do $\mathrm{Pb} 4$ esquerdo e insere-se na mesma região do lado direito. Anteriormente limita-se por tecido cartilaginoso e posteriormente limita-se ao TEb4. Não há sobreposição de fibras entre o TPb4a e $\mathrm{TPb} 4 \mathrm{p}$. 
TEb4. Liga-se na face medial do Eb4 esquerdo e insere-se na mesma estrutura do lado direito. Anteriormente limita-se pelas fibras do $\mathrm{TPb} 4 \mathrm{p}$.

\section{Hemiodus argenteus.}

Le1. Origina-se no proótico medialmente à articulação do $\mathrm{Pb} 1$ com o crânio, Insere-se no processo uncinado do Eb1. Esse músculo apresenta duas porções caracterizando um músculo bicaudado (Idem Bivibranchia velox).

Le2. Origina-se no proótico, medialmente a origem do Le1. Insere-se no processo uncinado do Eb2.

Le3. Origina-se no proótico posteriormente a origem do Li3 Insere-se na margem anterior do processo uncinado do Eb3. Apresenta a forma de um cone (amplo na origem e afilado na inserção).

Le4. Origina-se no proótico posteriormente à origem do Le3. Insere-se na margem anterior do processo levantador do Eb4.

LP. Não foi possível verificar a origem desse músculo. Sua inserção ocorre na extremidade cartilaginosa do processo levantador do Eb4.

Li1. Origina-se no proótico medialmente à origem do Le1. Insere-se na superfície dorsal e na margem lateral do $\mathrm{Pb} 2$.

Li2. Origina-se no proótico e insere-se na face dorsal do $\mathrm{Pb} 4$.

Li3. Origina-se no proótico dorsalmente às origens do Le1, Le2 e Li1. Insere-se na face dorsal do $\mathrm{Pb} 4$. 
Od3. Origina-se no $\mathrm{Pb} 3$ anteriormente, ventralmente ao músculo TEb2. Insere-se na extremidade do processo uncinado do Eb3.

Od4. Origina-se no $\mathrm{Pb} 4$ anteriormente e insere-se na face lateral do processo levantador do Eb4. Músculo em forma de leque (Idem Bivibranchia velox)

Od4'. Presente. dorsal ao od4 na inserção e origem tendínea no $\mathrm{Pb} 3$ posteriormente osso OP. Origina-se na superfície medial do Eb4, ventralmente às fibras do TEb4 e termina ventralmente na rafe do esôfago.

Ad4. Na margem medial do Eb4 da extremidade dorsal do processo levantador do Eb4 até a superfície dorsal do $\mathrm{Cb} 4$, medialmente ao ângulo interno da articulação do Eb4Cb4.

Ad5. No Eb5 (cartilagem) posteriormente e no Cb5.

SO. Camada de músculo que circunda o esôfago, com aumento no tamanho das fibras dorsalmente, com uma projeção anterior mediana conspícua de fibras, até o TEb4.

TEb2. Liga-se medialmente ao processo uncinado do Eb2 esquerdo e conecta-se na mesma estrutura no lado direito (Idem Bivibranchia velox)

TPb3. Liga-se na face médio dorsal do Pb3 esquerdo e conecta-se na mesma estrutura no lado esquerdo. Está localizado ventralmente ao TEb2 e na região do seu limite posterior suas fibras confundem-se com as do $\mathrm{TPb} 4$.

$\mathrm{TPb} 4$. Um conjunto de músculos medianos que se ligam anteriormente no $\mathrm{Pb} 4$ esquerdo e conectam-se através na mesma estrutura do lado direito. Está localizado posteriormente ao TEb2 e anteriormente ao TEb4. 
TEb4. Liga-se na face medial do Eb4 esquerdo e insere-se na mesma estrutura do lado direito. Anteriormente limita-se pelas fibras do $\mathrm{TPb} 4$.

\subsubsection{Família Hepsetidae}

I. Hepsetus odoe (SAIAB 80799).

Le1. Origina-se no proótico medialmente a articulação do Pb1 com o crânio. Insere-se na face lateral óssea do processo uncinado do Eb1. Músculo em forma de fita.

Le2. Origina-se ventralmente a origem do Le1, medialmente ao Li1. Insere-se na extremidade dorsal cartilaginosa do processo uncinado do Eb2. Músculo em forma de fita.

Le3. Origina-se no proótico medialmente a origem do Li2-Li3. Insere-se na margem anterior da extremidade dorsal cartilaginosa do processo uncinado do Eb3. Músculo em forma de fita.

Le4. Origina-se no proótico dorsalmente a origem do Le3. Insere-se na margem anterior da extremidade dorsal do processo levantador do Le4. Músculo em forma de fita.

LP. Origina-se na margem ventral do Pterótico, lateralmente a origem do PP. Origem tendínea. Insere-se na margem medial da extremidade dorsal do processo levantador do Eb4. Músculo em forma de fita.

Li1. Origina-se no proótico lateralmente a origem do Le1. Insere-se na margem medial do $\mathrm{Pb} 2$. Músculo com dois ventres musculares, largo e delgado.

Li2. Origina-se no proótico lateralmente a origem do Le2. Insere-se na superfície dorsal do Pb3. Músculo em forma de fita. 
Li3. Origina-se no proótico dorsalmente a origem do Li2. Insere-se na superfície dorsal do Pb4. Músculo em forma de leque.

Od3. Não observado.

Od4. Origina-se anteriormente no $\mathrm{Pb}$ 4. Insere-se na face lateral do processo levantador do Eb4. Músculo em forma de leque, com dois ventres musculares.

Od4'. Origina-se no $\mathrm{Pb} 3$ anteriormente e insere-se no processo levantador do Eb4.

OP. Origina-se na margem medial do Eb4, próximo às fibras do TEb4 e termina na rafe do esôfago.

Ad4. Na margem ventral da extremidade posterior do Eb4 e na margem dorsal da extremidade posterior do $\mathrm{Cb} 4$, medialmente ao ângulo interno da articulação Eb4-Cb4.

Ad5. Na margem posterior do Eb5 (cartilagem) e na extremidade posterior do Cb5.

SO. Camada de músculo que circunda o esôfago, com aumento no tamanho das fibras dorsalmente, com uma projeção anterior mediana de fibras que se estendem ventralmente ao TEb4.

TEb2. Liga-se medialmente ao processo uncinado do Eb2 esquerdo e conecta-se na mesma estrutura no lado direito.

$\mathrm{TPb} 3$. Liga-se na face medial óssea do $\mathrm{Pb} 3$ esquerdo e conecta-se na mesma estrutura no lado esquerdo. Está localizado ventralmente ao TEb2 e na região do seu limite posterior suas fibras confundem-se com as do $\mathrm{TPb} 4$.

$\mathrm{TPb} 4$. Liga-se ao longo da margem medial do $\mathrm{Pb} 4$ esquerdo e insere-se na mesma região do lado direito. Anteriormente seu limite não é bem definido, pois suas fibras 
musculares se confundem com as fibras do $\mathrm{TPb} 3$. Seu limite posterior é bem estabelecido pelo músculo TEb4.

TEb4. Liga-se medialmente no Eb4 esquerdo e conecta-se nas mesmas estruturas no lado direito. Músculo em forma de fuso, com as fibras ligeiramente mais desenvolvidas que as do $\mathrm{TPb} 4$.

Nota: Os músculos $\mathrm{TPb} 3, \mathrm{TPb} 4, \mathrm{TEb} 4$ e $\mathrm{SO}$ apresentam nas suas fibras projeção mediana anterior.

Nota: A asa do pterótico está em formato de teto.

II. Hepsetus odoe (SAIAB 72802).

Le1. Origina-se no proótico medialmente a articulação do Pb1 com o crânio. Insere-se na face lateral óssea e na extremidade dorsal cartilaginosa do processo uncinado do Eb1. Músculo em forma de fita.

Le2. Origina-se ventralmente a origem do Le1, medialmente ao Li1. Insere-se na extremidade dorsal cartilaginosa do processo uncinado do Eb2. Músculo em forma de fita. (Idem H.odoe I)

Le3. Origina-se no proótico medialmente a origem do Li2-Li3. Insere-se na margem anterior da extremidade dorsal cartilaginosa do processo uncinado do Eb3. Músculo em forma de fita. Músculo com dois ventres na inserção.

Le4. Origina-se no proótico dorsalmente a origem do Le3. Insere-se na margem anterior da extremidade dorsal do processo levantador do Le4. Músculo em forma de fita. 
LP. Origina-se na margem ventral do pterótico, juntamente com o PP. Origem tendínea. Insere-se na margem medial da extremidade dorsal do processo levantador do Eb4. Músculo em forma de fita.

Li1. Origina-se no proótico lateralmente a origem do Le1. Insere-se na margem medial do Pb2. Músculo com dois ventres musculares, largo e delgado. (Idem H.odoe I).

Li2. Origina-se no proótico lateralmente a origem do Le2. Insere-se na superfície dorsal do Pb3. Músculo em forma de fita.

Li3. Origina-se no proótico dorsalmente a origem do Li2. Insere-se na superfície dorsal do $\mathrm{Pb} 4$. Músculo em forma de leque.

Od3. Não observado.

Od4. Origina-se anteriormente no $\mathrm{Pb}$ 4. Insere-se na face lateral do processo levantador do Eb4. Músculo em forma de leque.

Od4'. Ausente. (Variação intraespecífica).

OP. Origina-se na margem medial do Eb4, próximo às fibras do TEb4 e termina na rafe do esôfago.

Ad4. Na margem ventral da extremidade posterior do Eb4 e na margem dorsal da extremidade posterior do $\mathrm{Cb} 4$, medialmente ao ângulo interno da articulação Eb4-Cb4. Ausência da projeção do A4 no processo levantador do Eb4.

Ad5. Na margem posterior do Eb5 (cartilagem) e na extremidade posterior do Cb5. 
SO. Camada de músculo que circunda o esôfago, com aumento no tamanho das fibras dorsalmente, com uma projeção anterior mediana de fibras que se estendem ventralmente ao TEb4.

TEb2. Liga-se medialmente ao processo uncinado do Eb2 esquerdo e conecta-se na mesma estrutura no lado direito.

$\mathrm{TPb} 3$. Liga-se na face medial óssea do $\mathrm{Pb} 3$ esquerdo e conecta-se na mesma estrutura no lado esquerdo. Está localizado ventralmente ao TEb2 e na região do seu limite posterior suas fibras confundem-se com as do $\mathrm{TPb} 4$.

$\mathrm{TPb} 4$. Liga-se ao longo da margem medial do $\mathrm{Pb} 4$ esquerdo e insere-se na mesma região do lado direito. Anteriormente seu limite não é bem definido, pois suas fibras musculares se confundem com as fibras do $\mathrm{TPb} 3$. Seu limite posterior é bem estabelecido pelo músculo TEb4.

TEb4. Liga-se medialmente no Eb4 esquerdo e conecta-se nas mesmas estruturas no lado direito. Músculo em forma de fuso, com as fibras ligeiramente mais desenvolvidas que as do $\mathrm{TPb} 4$.

Nota: Os músculos TPb3, TPb4, TEb4 e SO apresentam nas suas fibras projeção mediana anterior.

Nota:

. A asa do pterótico apresenta formato triangular pontiagudo.

A ponta do $\mathrm{Pb} 2$ cartilaginosa está direcionada para a direita 


\subsubsection{Família Lebiasinidae.}

Copeina sp.

Le1. Origina-se medialmente ao $\mathrm{Pb} 1$ no proótico. Insere-se no processo uncinado do Eb1.

Le2. Origina-se no proótico medialmente a origem do Li1. Insere-se no processo uncinado do Eb2.

Le3. Origina-se no proótico medialmente ao Li2-Li3. Insere-se na margem anterior do processo uncinado do Eb3.

Le4. Origina-se no proótico dorsalmente a origem do Le3. Insere-se na extremidade anterior do processo levantador do Eb4.

LP. Origina-se no pterótico juntamente com o protractor pectoralis. Insere-se na extremidade dorsal cartilaginosa do processo levantador do Le4.

Li1. Origina-se no proótico medialmente a origem do Le1. Insere-se em dois pontos distintos do $\mathrm{Pb} 2$, caracterizando um músculo bicaudado. Na origem apresenta forma de leque.

Li2. Origina-se no proótico medialmente ao Le2. Na origem suas fibras estão muito próximas das fibras do Li3. Insere-se na margem dorsal do $\mathrm{Pb} 3$.

Li3. Origina-se dorsalmente a origem do Li2. Insere-se anteriormente na superfície dorsal do $\mathrm{Pb} 4$. 
Od3. Origina-se anteriormente no $\mathrm{Pb} 3$. Insere-se na margem medial da extremidade dorsal do processo uncinado do Eb3.

Od4. Origina-se anteriormente no $\mathrm{Pb} 4$. Insere-se lateralmente ao processo levantador do Eb4. Na região de inserção o músculo apresenta forma de leque. Músculo dividido em dois ventres: lateral e medial.

Od4'. Ausente.

OP. Origina-se na margem médio posterior do Eb4 estendendo suas fibras posteriormente até o Ad5 e medialmente até a rafe do esôfago, entrando em contato com as fibras do SO.

Ad4. Origina-se amplamente na margem medial do processo levantador do Eb4, apresentando forma de leque e insere-se no $\mathrm{Cb} 4$.

Ad5. Origina-se no Eb5 e insere-se no Cb5.

SO. Camada de músculo que circunda o esôfago, com aumento no tamanho das fibras dorsalmente, delgado em outras partes, idem Springer e Johnson (2004).

TEb2. Idem Springer e Johnson (2004).

$\mathrm{TPb} 3-\mathrm{TPb} 4$. Liga-se na margem medial do $\mathrm{Pb} 3$ e $\mathrm{Pb} 4$ esquerdos e conecta-se às mesmas estruturas no lado direito. Fibras dispostas paralelamente em uma camada bem delgada. Seu limite anterior é bem estabelecido pelo $\mathrm{TPb} 3-\mathrm{Eb} 2$, assim como seu limite posterior pelo TEb4.

TEb4. Liga-se na margem medial do Eb4 esquerdo, medialmente à origem do LP e do Le4 e conecta-se na mesma estrutura no lado direito. É delimitado posteriormente pelo SO. 
II. Nannostomus trifasciatus.

Le1. Idem Copeina sp.

Le2. Idem Copeina sp.

Le3. Idem Copeina sp.

Le4. Idem Copeina sp.

LP. Origem não observada. Insere-se na extremidade dorsal cartilaginosa do processo levantador do Eb4.

Li1. Idem Copeina sp.

Li2. Idem Copeina sp.

Li3. Idem Copeina sp.

Od3. Origina-se anteriormente no $\mathrm{Pb} 3$. Insere-se na extremidade dorsal do processo uncinado do Eb3. Está localizado dorsalmente ao Od4 e suas fibras são de difícil separação.

Od4. Origina-se anteriormente no $\mathrm{Pb} 4$. Insere-se na superfície medial do processo levantador do Eb4. Músculo em forma de leque.

Od4'. Ausente.

OP. Origina-se na margem médio posterior do Eb4 estendendo suas fibras posteriormente até a rafe do esôfago medialmente, entrando em contato com as fibras do $\mathrm{SO}$, posteriormente. 
Ad4. Origina-se na margem posterior da extremidade dorsal do processo levantador do Eb4. Insere-se no Cb4 ventralmente. Músculo largo.

Ad5. Origina-se na margem posterior do Eb5 cartilaginoso. Insere-se na superfície dorsal do Cb5. Suas fibras estão localizadas dorsalmente as fibras posteriores do SO.

SO. Camada de músculo que circunda o esôfago, com aumento no tamanho das fibras dorsalmente, delgado em outras partes, anteriormente suas fibras se projetam ventralmente ao TEb4.

TEb2. Idem Copeina.

$\mathrm{TPb} 3-\mathrm{TPb} 4$. Idem Copeina sp.

TEb4. Idem Copeina sp.

\subsubsection{Família Parodontidae.}

Apareiodon affinis

Le1. Origina-se no proótico medialmente ao $\mathrm{Pb} 2$. Origem tendínea. Insere-se no $\mathrm{Eb} 1 \mathrm{em}$ duas partes distintas: no processo uncinado do Eb1 e na extremidade anterior do Eb1. Músculo fusiforme.

Le2. Origina-se no proótico medialmente a origem do Li1. Origem muscular. Insere-se na face lateral do processo uncinado do Eb2. Músculo fusiforme. Na região de inserção o músculo este dividido em duas partes 
Le3. Origina-se no proótico medialmente às origens do Li2-Li3. Insere-se na extremidade dorsal da margem anterior do processo uncinado do Eb3. Músculo em forma de fita.

Le4. Origina-se no proótico medialmente a origem do Le3. Origem tendínea. Insere-se dorsalmente na margem anterior e na face medial do processo levantador do Eb4.

LP. Origem não observada. Insere-se na margem dorsal do processo levantador do Eb4.

Li1. Origina-se no proótico medialmente a origem do Le1. Origem muscular. Insere-se na superfície dorsal do $\mathrm{Pb} 2$. Músculo em forma de fita

Li2. Origina-se no proótico medialmente a origem do Le2. Origem muscular. Insere-se na superfície dorsal do $\mathrm{Pb} 3$.

Li3. Origina-se dorsalmente ao Li2. Origem muscular. Insere-se na extremidade anterior do $\mathrm{Pb} 4$.

Od3. Origina-se anteriormente na superfície dorsal do $\mathrm{Pb} 2$ ventralmente ao TEb2. Insere-se ao na margem anterior do processo uncinado do Eb3 ventralmente a origem do Le3.

Od4. Origina-se anteriormente na superfície dorsal do $\mathrm{Pb} 4$. Insere-se ao longo da margem anterior e da face lateral do processo levantador do Eb4. Músculo em forma de leque.

Od4'. Ausente.

OP. Origina-se na superfície póstero medial do Eb4 pouco separada do $\mathrm{SO}$, terminando ventralmente na rafe do esôfago. As fibras musculares continuam ventralmente a partir da rafe do esôfago incluindo o Ad5 e o SO, idem Springer e Johnson (2004). 
Ad4. Ao longo da margem posterior do processo levantador do Eb4 até a superfície dorsal do Cb4, medialmente ao ângulo interno da articulação do Eb4-Cb4.

Ad5. Ver nota de Paradon nasus.

SO. Camada de músculo que circunda o esôfago, com aumento no tamanho das fibras dorsalmente, delgado em outras partes, idem Springer e Johnson (2004).

TEb2. Liga-se medialmente a extremidade cartilaginosa do processo uncinado do Eb2 esquerdo e conecta-se a mesma estrutura do lado direito. Localizando-se dorsalmente ao Od3.

TPb3. Liga-se na face médio dorsal do Pb3 esquerdo e conecta-se na mesma estrutura no lado esquerdo. Está localizado ventralmente ao TEb2. É limitado posteriormente pelas fibras do $\mathrm{TPb} 4$.

$\mathrm{TPb} 4$. Liga-se ao longo da margem medial do $\mathrm{Pb} 4$ esquerdo e conecta-se na mesma região do lado direito. É limitado posteriormente pelas fibras do TEb4.

TEb4. Liga a extremidade posterior da margem medial do Eb4 esquerdo e conecta-se a mesma estrutura no lado direito. Músculo em forma de fita com fibras bem delgadas.

Parodon nasus.

Le1. Origina-se no proótico medialmente ao $\mathrm{Pb} 2$. Insere-se no Eb1 em duas partes distintas: no processo uncinado do Eb1 e na extremidade anterior do Eb1.

Le2. Origina-se no proótico lateralmente ao Li. Insere-se no processo uncinado do Eb2. 
Le3. Origina-se no proótico medialmente às origens do Li2-Li3. Insere-se no processo uncinado do Eb3.

Le4. Origina-se no proótico medialmente a origem do Le3. Insere-se dorsalmente na margem anterior do processo levantador do Eb4.

LP. Origem não observada. Insere-se na margem dorsal do processo levantador do Eb4.

Li1. Origina-se no proótico medialmente a origem do Le1. Insere-se na superfície dorsal do $\mathrm{Pb} 2$.

Li2. Origina-se no proótico medialmente a origem do Le2. Insere-se na superfície dorsal do $\mathrm{Pb} 3$.

Li3. Origina-se dorsalmente ao Li2. Insere-se na extremidade anterior do $\mathrm{Pb} 4$.

Od3. Origina-se anteriormente no $\mathrm{Pb}$. Insere-se na margem anterior da extremidade dorsal do processo uncinado do Eb3.

Od4. Ausente.

Od4'. Ausente.

OP. Não observado.

Ad4. Ver nota.

Ad5. Ver nota.

SO. Camada de músculo que circunda o esôfago, com aumento no tamanho das fibras dorsalmente, delgado em outras partes, idem Springer e Johnson (2004). 
TEb2. Liga-se medialmente a extremidade cartilaginosa do processo uncinado do Eb2 esquerdo e conecta-se a mesma estrutura do lado direito. Localizando-se dorsalmente ao Od3. .

$\mathrm{TPb} 3-\mathrm{TPb} 4$. Liga-se anteriormente na margem medial do $\mathrm{Pb} 3$ e posteriormente na margem medial do $\mathrm{Pb} 4$. Conecta-se aos seus correspondentes no lado direito. Está limitado posteriormente pelo TEb4.

TEb4. Liga a extremidade posterior da margem medial do Eb4 esquerdo e conecta-se a mesma estrutura no lado direito. Músculo em forma de fita com fibras bem delgadas.

Nota: Essa espécie parece apresentar modificações nos músculos Adutores e OP. Esses músculos parecem formar uma estrutura sacular localizada lateralmente ao SO muito semelhantes a órgãos epibranquiais, como os observados em Semaprochilodus taeniurus.

\subsubsection{Família Prochilodontidae.}

\section{Semaprochilodus taeniurus.}

Le1. Origina-se no proótico na região de articulação do Pb1 com o crânio através de um tendão delgado. Na região de inserção apresenta duas partes distintas: inserindo-se na extremidade dorsal do processo uncinado do Eb1 e látero posteriormente ao processo uncinado do Eb1. Músculo fusiforme.

Le2. Origina-se no proótico dorsalmente a articulação do Le1 através de um tendão delgado. Insere-se na margem anterior do processo uncinado do Eb2. Músculo fusiforme. 
Le3. Origina-se no proótico medialmente a origem do Li3. Insere-se na margem anterior do processo uncinado do Eb3.

Le4. Origina-se no proótico medialmente a origem do Le3. Insere-se na margem anterior cartilaginosa do processo levantador do Eb4. Músculo fusiforme.

LP. Origina-se no pterótico medialmente a origem do músculo protractor pectoralis. Insere-se na extremidade dorsal do processo levantador do Eb4. Músculo em forma de fita.

Li1. Origina-se no proótico medialmente a origem do Lel e insere-se na superfície dorsal do $\mathrm{Pb} 2 \mathrm{Na}$ região de inserção ocorre uma divisão no ventre muscular.

Li2. Origina-se no proótico, medialmente a origem do Le2. Insere-se no Pb3. Músculo em forma de fita.

Li3. Origina-se no proótico, medialmente a origem do Li2. Insere-se no Pb4. Músculo em forma de fita.

Od3. Origina-se no $\mathrm{Pb} 3$ anteriormente, através de um tendão delgado. Insere-se na extremidade anterior do processo uncinado do Eb3.

Od4. Origina-se no $\mathrm{Pb} 4$ anteriormente. Insere-se na borda anterior do Eb4, ventralmente a inserção do Le4. Músculo em forma de leque.

Od4'. Ausente.

OP. Não observado.

Ad4. Entre o ângulo formado pelo Eb4 ventralmente e Cb5 dorsalmente.

Ad5. Ver nota. 
SO. Camada de fibras musculares que circundam o esôfago, posterior aos órgãos epibranquiais.

TEb2. Liga-se no processo uncinado do Eb2 esquerdo e conecta-se na estrutura correspondente no lado direito. Feixes de fibras associados ao TEb2 ligam-se também ligam-se na margem medial do $\mathrm{Pb} 3$ esquerdo e conectam-se ao seus correspondentes no lado direito.

$\mathrm{TPb} 4$. Ausente.

TEb4. Liga a extremidade posterior da margem medial do Eb4 esquerdo e conecta-se a mesma estrutura no lado direito.

Nota: Os órgãos epibranquiais assemelham-se aos de Curimatopsis myersi. Entre os dois sacos convolutos musculares há uma camada muscular que forma um saco de fundo cego. Anteriormente as fibras do TEb4 são bem desenvolvidas. A posição dos órgãos epibranquiais impossibilitou a visualização dos músculos OP.

4.2. Generalizações sobre os músculos dorsais dos arcos branquiais em Characiformes.

Os músculos dorsais dos arcos branquiais dos Characiformes são em sua maioria músculos exclusivamente cefálicos originando-se e inserindo-se em estruturas anatômicas pertencentes à cabeça, com exceção do músculo protractor pectoralis, que se origina no pterótico e se insere no cleitro, um osso da cintura peitoral. Esses músculos podem ser claramente distinguidos em dois grupos: os músculos extrínsecos e os músculos intrínsecos. 
Os primeiros possuem origem no crânio e inserem-se aos elementos esqueléticos dos arcos branquiais e são denominados músculos levantadores, que podem ser diferenciados topograficamente quanto a sua inserção em músculos levantadores externos e internos. Os músculos levantadores externos 1-4 conectam o proótico aos processos uncinados dos epibranquiais 1,2 e 3 e ao processo levantador do epibranquial 4, respectivamente. Essas estruturas são projeções dorsais ósseas que apresentam geralmente uma cartilagem em sua extremidade dorsal, localizadas no terço proximal dos epibranquiais. O músculo levator posterioris nos Characiformes é também um músculo levantador externo, pois se insere no processo levantador do Eb4, mesmo que sua origem ocorra no pterótico e não no proótico, diferenciando-o dos outros músculos levantadores externos.

O segundo conjunto de músculos levantadores apresenta origem no proótico e inserção na face dorsal dos elementos faringobranquiais. São denominados músculos levantadores internos, pois sua inserção sempre ocorre medialmente às inserções dos músculos levantadores externos. Nos Characiformes existem entre dois ou três músculos levantadores internos.

Em Serrasalmidae e Crenuchus o ponto de origem do Le1 não ocorre no proótico (ver discussão do caráter 2) como nos outros Characiformes examinados, mas sim no faringobranquial 1 . Nesse caso específico o músculo levantador externo 1 deixa de ser um músculo extrínseco e por definição passa a ser um músculo intrínseco, pois apresente origem e inserção exclusivamente em elementos esqueléticos dos arcos branquiais.

Nos Characiformes os músculos intrínsecos são representados pelos músculos oblíquos, adutores, transversos e esfíncter do esôfago. Esse conjunto de músculos 
apresenta origem e inserção exclusivamente em elementos esqueléticos dos arcos branquiais. Os músculos oblíquos conectam o epibranquial de um arco ao faringobranquial anterior, a essa estrutura podendo haver até 4 músculos oblíquos nos Characiformes O Od3 origina-se no faringobranquial 3 e insere-se no epibranquial 3, o Od4 origina-se no faringobranquial 4 e insere-se no processo levantador do epibranquial 4. Alguns Characiformes apresentam mais um músculo obliquo dorsal adicional aos Od3 e 4, denominado obliquo dorsal 4', que se origina na extremidade posterior do faringobranquial 3, anteriormente ao epibranquial 4, seu ponto de inserção. Esse músculo está presente apenas em espécie, entre os Disthicodontidae examinados e em XX dos Characidae examinados (cite o local onde o leitor pode encontrar essa informação.

Os músculos adutores então presentes na grande maioria dos Characiformes e são representados pelos adutores 4 e 5 . Esses músculos conectam o epibranquial ao ceratobranquial correspondente na região da articulação entre essas estruturas. Os Alestidae examinados apresentam o ventre muscular do adutor 4 mais próximo da articulação entre o ceratobranquial 4 e o epibranquial 4 em relação aos outros exemplares de Characiformes examinados que apresentam o ventre muscular desse músculo mais afastado dessa articulação. Em exemplares de Curimatidae, Prochilodontidae e Citharinidae é possível reconhecer na região do adutor 5 uma estrutura muscular sacular, os órgãos epibranquiais. Em Parodontidae, Chilodontidae e Anostomidae o tamanho relativo do adutor 5 é muito maior se comparado com os outros Characiformes examinados no presente estudo.

De uma maneira geral os músculos transversos conectam os faringobranquiais, os epibranquiais ou epibranquiais e faringobranquiais do mesmo arco através da linha 
longitudinal mediana. Em alguns casos o conjunto das fibras musculares que delimitam o músculo não segue um padrão bem definido como observado nos outros músculos dorsais dos arcos branquiais, levando a descrições com certo grau de subjetividade. Esse problema também foi observado por Springer e Johnson (2004) na descrição dos músculos transversos dos Actinopterygii. Nos Characiformes é possível reconhecer entre 3 e 4 músculos transversos.

O músculo esfíncter do esôfago está presente em todos os exemplares examinados e consiste em um conjunto orbicular de fibras musculares que circundam o esôfago.

\subsection{Descrição dos caracteres.}

As designações numéricas associadas ao termo "estado" são empregadas apenas para a organização das descrições das diferentes condições observadas de um determinado caráter, e não tem a priori nenhum significado filogenético.

Os táxons que não foram listados na descrição de um caráter não tiveram os seus estados de caráter codificados, devido a impossibilidade da descrição e ou exame da musculatura.

\section{MÚSCULO LEVATOR EXTERNUS 1}

1. Tipo da origem do Levator externus 1: (0) origem muscular; (1) origem tendínea.

Na maioria dos Characiformes examinados a conexão muscular na região de origem do Levator externus 1 com o crânio ocorre diretamente entre o conjunto de feixe de fibras musculares e o proótico não havendo uma estrutura tendínea entre os mesmos (estado 0) 
(Figs.33A e 34A ). Essa condição já havia sido previamente descrita para Brycon guatemalensis (Winterbottom, 1974: 253). O tipo de origem no proótico através de um tendão (estado 1) ocorre em Alestes, Astyanax, Brycinus, Brycon falcatus, Bryconaethiops, Chalceus, Charax, Citharinus, Cynopotamus, Distichodus, Eugnathichthys, Hemigrammocharax, Hydrocynus, Leporinus, Neolebias, Phago, Rhaphiodon, Semaprochilodus, Thoracocharax e Triportheus (Figs. 39A ) É possível notar que o estado 1 é variável em Brycon.

2. Local de origem do Levator externus 1: (0) exclusivamente no proótico; (1) no proótico e no faringobranquial 1; (2) exclusivamente no faringobranquial 1.

Na maioria dos Characiformes examinados é possível reconhecer a origem do músculo Levator externus 1 exclusivamente no proótico (Fig.35A), tal como descrito por Winterbottom (1974) para Brycon guatemalensis. Essa condição foi descrita nos Actinopterygii basais Accipenser sturio (= Acipenser oxyrinchus) por Vetter (1878:477) e Amia calva por Allis (1897:668). Nos Teleostei essa condição é amplamente distribuída entre os táxons (Winterbottom, 1974), mas alguns táxons examinados no presente estudo apresentaram a origem do no faringobranquial 1. Em Crenuchus, Myleus, Metynnis e Serrasalmus as fibras musculares do Levator externus 1 conectamse exclusivamente ao longo da margem posterior do faringobranquial 1 (estado 2) (Fig. 36A e 37B). Em Charax, Cynopotamus, e Poptella fibras laterais do Levator externus 1 conectam-se ao longo da margem posterior do faringobranquial 1 e as fibras mediais desse músculo conectam-se ao proótico através de um pequeno tendão (estado 1) (Fig. 38B). A presença da origem do Levator externus 1 no faringobranquial 1 foi descrita em Osteoglossum (Springer e Johnson, 2004:31) e Galaxias (Springer e Johnson, 2004: 54) 
sugerindo que esse caráter evoluiu independentemente em diferentes linhagens de Teleostei.

3. Presença ou ausência da inserção do Levator externus 1 no processo uncinado do epibranquial 1: (0) presente; (1) ausente.

Na maioria dos táxons examinados a inserção do Levator externus 1 ocorre no processo uncinado do epibranquial 1 (estado 0). O processo uncinado é uma projeção óssea orientada dorsalmente a localizada na parte anterior dos epibranquiais. Essa estrutura apresenta em sua extremidade dorsal uma cartilagem que se articula com o processo articular do faringobranquial 2. A inserção do Levator externus 1 pode ocorrer tanto na parte óssea quanto na extremidade dorsal cartilaginosa do processo uncinado do epibranquial 1. Em Moenkhausia a inserção do Levator externus 1 ocorre em dois pontos distintos do processo uncinado do epibranquial 1, na extremidade dorsal cartilaginosa e na face medial da porção óssea. A ausência de inserção do Levator externus 1 no processo uncinado do epibranquial 1 (estado 1: Figs. 2, 8, 10, 11, 12, 21, 22, 30 e 32, ) foi observada em Brycon falcatus, Bivibranchia, Chalceus, Crenuchus, Curimata, Curimatopsis, Distichodus, Hemigrammocharax, Hemiodus, Leporinus, Nannocharax, Parodon, Semaprochilodus e Triportheus auritus. Nesses táxons as inserções musculares ocorrem na fase dorsal da diáfase do epibranquial 1. A inserção do Levator externus 1 no processo uncinado do epibranquial 1 foi descrita como um padrão geral para Teleostei por Winterbottom (1974) e Springer e Johnson (2004). Os últimos detalharam com maior precisão a posição de inserção do Levator externus 1, ressaltando a grande variação, ao longo dos táxons, das relações topográficas entre o Levator externus 1 e o processo uncinado do epibranquial 1 na região de inserção. 
4. Presença ou ausência de divisão do Levator externus 1 no local de inserção: (0) ausente; (1) presente.

Na maioria dos Characiformes examinados não existe subdivisão do Levator externus 1 na região de inserção (estado 0). . Em Apareiodon, Bivibranchia, Curimata, Curimatopsis, Hemiodus, Leporinus, Parodon e Semaprochilodus a inserção do Levator externus 1 ocorre em dois pontos distintos da superfície dorsal do epibranquial 1 (estado 1: Figs. 8, 12 e 22), o primeiro localizado anteriormente próximo a articulação do epibranquial 1 com o faringobranquial 1, e o segundo localizado posteriormente ao primeiro ponto de inserção do Levator externus 1 no epibranquial 1.

5. Proximidade das origens dos músculos Levator externus 1 e 2 e Levator internus 1 e 3 no proótico: (0) muito próximos; (1) afastados.

As origens dos músculos Levator externus 1 e 2 e Levator internus 1, 2 e 3 no proótico ocorrem na mesma região desse osso (estado 0) em Acestrorhynchus lacustris, Acestrocephalus, Agoniates, Alestes, Aphyocharax, Brycon, Bryconaethiops, Bryconamericus, Bryconops, Boulengerella, Chalceus, Characidium, Charax, Cheirodon, Citharinus, Copeina, Cynopotamus, Distichodus, Erythrinus, Eugnathichthys, Exodon, Gnathocharax, Gilbertolus, Hemigrammocharax, Hemiodus, Hepsetus, Hoplias, Hydrocynus, Hydrolycus, Hyphessobrycon, Iguanodectes, Lonchogenys, Metynnis, Moenkhausia, Myleus, Nannostomus, Nannocharax, Neolebias, Roeboexodon, Oligosarcus, Phago, Poptella, Serrasalmus, Tetragonopterus, Triportheus e Thoracocharax. Essa condição se destacada em Metynnis, Myleus, Rhaphiodon, Serrasalmus, Thoracocharax, e Triportheus (Fig.23A 24A 27B, 29B, 34A e 47B) espécies que apresentam incisura óssea na origem desses músculos. Essa condição também foi descrita para Brycon guatemalensis por Winterbottom (1974: 
253). Outra condição foi observada em Acestrorhynchus nasutus, Apareiodon, Bivibranchia, Chilodus, Crenuchus, Cynodon, Curimatopsis, Gasteropelecus, Hemiodus, Leporinus, Parodon e Semaprochilodus onde as origens do Levator externus 1 e 2 e Levator internus 1, 2 e 3 são claramente separadas em pontos distintos do proótico (estado 1), com os músculos Levator externus 2, Levator internus 1, 2 e 3 dispostos medialmente ao Levator externus 1, cada qual conectado a uma parte específica do proótico na região de origem (Fig. 33B). Nos Teleostei variações nesse caráter também foram observadas na literatura. A condição descrita para os táxons agrupados pelo estado (0) foi descrita em Argyropelecus (Stomiiformes) (Winterbottom, 1974:250) e Scianidae (Aguilera, 1987). Em Gasterosteiformes (Takata e Sasaki, 2004) e Cyprinidae (Takahasi, 1925, Winterbottom, 1974: 258 e Grey e Mabee, 2012) apresentam as origens do Levator externus 1 e 2 e Levator internus 1, 2, e 3 afastadas no proótico, tal como os táxons agrupados no estado (1) do caráter 5.

\section{MÚSCULO LEVATOR EXTERNUS 2}

O músculo Levator externus 2 origina-se no proótico e insere-se no processo uncinado do epibranquial 2. Esse padrão foi observado em todos os exemplares examinados, com exceção de Rhaphiodon vulpinus (Fig.40A) que apresenta o mesmo tendão de origem para os músculos Levator externus 2 e Levator internus 3. Esse tendão conecta-se ao proótico medialmente a origem do Levator externus 1.

\section{MÚSCULO LEVATOR EXTERNUS 3}

6. Presença ou ausência de inserção do Levator externus 3 no processo uncinado do epibranquial 3: (0) ausente; (1) presente. 
Na maioria dos Characiformes examinados a inserção do Levator externus 3 ocorre no processo uncinado do epibranquial 3 (Figs. 26 e 27 estado 0), com exceção de Bivibranchia e Chilodus que não apresentam a inserção desse músculo no processo uncinado do epibranquial 3 (estado 1: Fig. 8), mas sim na diáfise do epibranquial na sua superfície dorsal anteriormente ao processo uncinado.

7. Local de inserção do Levator externus 3 no processo uncinado do epibranquial 3: (0) inserção na margem anterior do processo uncinado do epibranquial 3; (1) inserção na extremidade dorsal do processo uncinado do epibranquial 3; (2) inserção na face lateral do processo uncinado do epibranquial 3.

Na maioria dos Characiformes examinados a inserção do Levator externus 3 ocorre ao longo da margem anterior do processo uncinado do epibranquial 3 (Fig. 29), descrito para Xenocharax spilurus por Springer e Johnson (2004:49) e também para Acestrocephalus, Agoniates, Alestes, Bryconamericus, Brycinus, Chalceus, Crenuchus, Cynopotamus, Chilodus, Distichodus, Eugnathichthys, Exodon, Gasteropelecus, Gilbertolus, Hemigrammocharax, Hemiodus, Hoplias, Hydrocynus, Hyphessobrycon, Moenkhausia, Myleus, Nannocharax, Neolebias, Oligosarcus, Phago, Poptella, Rhaphiodon, Roeboexodon, Semaprochilodus, Serrasalmus, Tetragonopterus, Triportheus e Thoracocharax examinados no presente estudo, podendo ser considerada a condição generalizada em Characiformes (estado 0). Em Brycon guatemalensis e Brycon. melanopterus (Springer e Johnson, 2004: 48) e Acestrorhynchus, Astyanax, Apareiodon, Bryconaethiops, Bryconops, Boulengerella, Charax, Cheirodon, Citharinus, Copeina, Cynodon, Curimata, Curimatopsis, Erythrinus, Gnathocharax, Hepsetus, Iguanodectes, Leporinus, Lonchogenys, Metynnis, Nannostomus e Parodon a inserção do levator externus 3 ocorre na extremidade dorsal cartilaginosa do processo 
uncinado do epibranquial 3 (estado 1: Figs. 21, 28 e 31). As descrições de Springer e Johnson (2004) para Brycon diferem da condição nos exemplares desse gênero examinados no presente estudo, que apresentam inserção na face lateral óssea do processo uncinado do epibranquial 3 (Fig. 2), descrita no estado 2. Essa condição também foi observada em Aphyocharax, Characidium e Hydrolycus.

\section{MÚSCULO LEVANTOR EXTERNUS 4.}

8. Local de inserção do Levator externus 4: (0) na margem anterior do processo levantador do epibranquial 4; (1) na extremidade dorsal do processo levantador do epibranquial 4; (2) na face medial do processo levantador do epibranquial 4; (3) na extremidade dorsal e na margem anterior do processo levantador do epibranquial 4.

A inserção do levator externus 4 de Rhaphiodon, Hydrolycus, Cynodon, Triportheus signatus e Tetragonopterus ocorre na face medial do processo levantador do epibranquial 4 (estado 2) (Figs. 13, 18 e 20) ventralmente a origem do Levator posterioris. Essa condição não foi descrita para Brycon e Xenocharax examinados por Springer e Johnson (2004) que apresentam na região de inserção conexão muscular na extremidade dorsal cartilaginosa do processo levantador do epibranquial 4, anteriormente a inserção do Levator posterioris. Essa condição (estado 1) foi observada em Acestrorhynchus, Aphyocharax, Bivibranchia, Boulengerella, Chalceus, Charax, Characidium, Cheirodon, Citharinus, Curimata, Curimatopsis, Distichodus Erythrinus, Eugnathichthys, Exodon, Hemigrammocharax, Gilbertolus, Hoplias, Nannocharax, Neolebias, Oligosarcus, Phago e Roeboexodon (Figs 1 e 12.). A maioria das espécies de Characiformes examinadas apresenta inserção do Levator externus 4 ao longo da margem anterior do processo levantador do epibranquial 4 dorsalmente a inserção do Obliquus dorsalis 4 (estado 0) (Figs. 2, 3 e 5). Essa condição foi observada em 
Acestrocephalus, Agoniates, Alestes, Brycon, Brycinus, Bryconaethiops, Bryconamericus, Bryconops, Crenuchus, Cynopotamus, Copeina, Gasteropelecus, Gnathocharax, Hemiodus, Hepsetus, Hydrocynus, Hyphessobrycon, Iguanodectes, Leporinus, Metynnis, Moenkhausia, Myleus, Nannostomus, Poptella, Semaprochilodus, Serrasalmus, Thoracocharax, Triportheus auritus e T.pantanensis. A inserção do Levator externus 4 em dois pontos distintos do processo levantador do epibranquial 4 foi observada em Astyanax, Hemigrammus, Mimagoniates, Parodon e Apareiodon.

\section{MÚSCULO LEVATOR POSTERIORIS.}

9. Tipo de origem do Levator posterioris: (0) origem muscular; (1) origem tendínea.

A conexão das fibras musculares diretamente no pterótico sem a presença de tendão de origem entre o osso e o ventre muscular foi observada na maioria dos exemplares de Characiformes examinados representando a condição generalizada para a ordem (estado 0) (Fig.41B) em Alestes, Aphyocharax, Bivibranchia, Brycinus, Bryconaethiops, Bryconamericus, Boulengerella, Charax, Chilodus, Cheirodon, Copeina, Curimatopsis, Eugnathichthys, Distichodus, Gnathocharax, Gilbertolus, Hemiodus, Hemigrammus Hemigrammocharax, Iguanodectes, Hyphessobrycon, Leporinus, Lonchogenys,Metynnis, Oligosarcus, Nannocharax , Neolebias , Phago, Poptella, Semaprochilodus, Serrasalmus, Thoracocharax, Triportheus e Tetragonopterus. Em Acestrorhynchus, Acestrocephalus, Agoniates, Brycon, Chalceus, Characidium, Crenuchus, Curimata, Cynodon, Cynopotamus, Erythrinus, Exodon, Gasteropelecus, Hepsetus, Hoplias, Hydrocynus Hydrolycus, Mimagoniates, Rhaphiodon e Roeboexodon a conexão do Levator posterioris no pterótico ocorre através de um tendão afilado que liga o ventre muscular ao osso (estado 1) (Fig. 42B). 
10. Presença ou ausência de origem compartilhada entre o Levator posterioris e o Protractor pectoralis: (0) ausente; (1) presente.

$\mathrm{Na}$ maioria dos Characiformes examinados as conexões dos músculos Levator posterioris e Protractor pectoralis na região de origem ocorrem em pontos distintos do pterótico (estado 0), o primeiro na asa do pterótico e o segundo medialmente ao último como observado em Chilodus, Curimata, Curimatopsis, Leporinus e Semaprochilodus , Boulengerella, Hoplias, Bivibranchia, Brycinus, Bryconaethiops, Bryconamericus, Cheirodon, Distichodus, Gnathocharax, Gilbertolus, Hemiodus, Hemigrammus, Hemigrammocharax, Hyphessobrycon, Iguanodectes, Lonchogenys Metynnis, Nannocharax, Neolebias, Oligosarcus, Serrasalmus, Thoracocharax, Triportheus e Tetragonopterus. Nos demais Characiformes examinados (Acestrorhynchus Acestrocephalus, Alestes Agoniates, Aphyocharax, Brycon, Bryconaethiops, Chalceus, Charax pauciradiatus, Characidium, Crenuchus, Copeina, Cynodon, Cynopotamus, Curimata, Erythrinus, Eugnathichthys, Exodon, Gasteropelecus, Hepsetus, Hydrolycus, Hydrocynus, Mimagoniates, Phago, Poptella, Rhaphiodon e Roeboexodon) existe um único ponto de origem no pterótico, localizado na extremidade posterior da asa do pterótico para os músculos Levator posterioris e Protractor pectoralis que se conectam ao osso através de um tendão delgado (estado 1). A presença de um único ponto de origem através de um tendão para dois ventres musculares distintos, caracteriza um complexo denominado músculo bicaudado (Fig. 43C).

\section{MÚSCULO LEVATOR INTERNUS I}

11. Tipo de origem do Levator internus 1: (0) origem muscular; (1) origem tendínea. 
$\mathrm{Na}$ maioria dos Characiformes examinados os músculos Levator externus 1 e Levator internus 1 originam-se em regiões distintas do proótico e a origem do Levator internus 1 é muscular (estado 0). Outra condição foi observada em Brycinus, Brycon falcatus, Bryconaethiops, Chalceus, Charax, Moenkhausia e Triportheus signatus, que apresentam o mesmo ponto de origem do Levator externus 1 e do Levator internus 1 no proótico (estado 1) (Fig. 44 B). Um mesmo tendão conecta os ventres musculares desses músculos a um único ponto de origem no proótico. Essa conformação anatômica é definida como músculo bicaudado: um único ponto de origem, para dois ventres distintos e com pontos de inserção em locais diferentes. O Levator internus 1 de Metynnis, Myleus e Serrasalmus apresenta origem muscular (estado 0), mas o local de origem desse músculo nessas espécies ocorre no faringobranquial 1.

12. Local de inserção do Levator internus 1: (0) inserção do Levator internus 1 no faringobranquial 2 em um único ponto; (1) inserção do Levator internus 1 em dois pontos distintos do faríngobranquial 2.

Na maioria dos Characiformes examinados a inserção do Levator internus 1 ocorre na face dorsal do diastema do faringobranquial 2 medialmente ao processo articular do faringobranquial 2 com o epibranquial 1 (estado 0: Figs. 1 e 2). Essa condição também foi descrita para Brycon e Xenocharax por Springer e Johnson (2004: 48-49) representando a condição generalizada para a ordem. Em Boulengerella, Copeina, Erythrinus, Hepsetus, Hoplias, Nannostomus, Acestrorhynchus, Iguanodectes, Thoracocharax, Semaprochilodus e Curimatopsis a inserção do músculo Levator internus 1 ocorre medialmente a base do processo articular do faringobranquial 2 com o epibranquial 1 (Figs., 9, 12, 14, 17 e 31) em dois pontos distintos do faringobranquial 2, 
sendo possível reconhecer dois ventres do Levator internus 1 na região de inserção: ventre anterior e posterior.

\section{MÚSCULO LEVATOR INTERNUS 2.}

13. Presença ou ausência do Levator internus 2: (0) presença em todos os táxons examinados exceto os listados sob o estado 1; (1) ausência em Characidium, Crenuchus, e Rhaphiodon (Figs. 11,e 20) .

\section{MÚSCULO LEVATOR INTERNUS 3.}

14. Presença ou ausência do levator internus 3:(0) presente em todos os táxons examinados exceto os listados sob o estado $1 ;$ (1) ausente em Moenkhausia e Poptella(.

15. Local de inserção do Levator internus 3: (0) inserção do Levator internus 3 no faringobranquial 4; (1) inserção do Levator internus 3 no faringobranquial 3 e 4.

A inserção do Levator internus 3 ocorre em dois pontos: na extremidade posterior da superfície dorsal do faringobranquial 3 e na extremidade anterior da superfície dorsal do faringobranquial 4 (estado 1) em Curimata e Curimatopsis (Fig.12). Essa condição difere da encontrada na maioria dos Characiformes examinados que apresentam a inserção do Levator internus 3 exclusivamente na região média da superfície dorsal do faringobranquial 4, tal condição também foi descrita para Brycon e Xenocharax por Springer e Johnson (2004: 48-49).

16. Presença ou ausência de origem compartilhada entre o Levator internus 3 e o Levator internus 2: (0) ausente; (1) presente.

A conexão na região de origem do Levator internus 3 e Levator internus 2 ocorre no mesmo local no proótico (estado 1) em Cynodon, Erythrinus, Exodon, Hoplias, 
Hydrolycus, Roeboexodon, Serrasalmus brandtii (Fig.37B) e Triportheus auritus examinados no presente estudo. Os músculos Levator internus 3 e Levator internus 2 representam cada qual um ventre de um complexo muscular denominado músculo policaudado: um único ponto de origem para dois ventres musculares distintos. Essa condição difere da encontrada na maioria dos Characiformes examinados que apresentam a conexão na região de origem do músculo Levator internus 3 e Levator internus 2 separadas em pontos distintos do proótico com a origem do Levator internus 3 localizada dorsalmente da origem do Levator internus 2.

17. Presença ou ausência da origem do Levator internus 3 compartilhada com o Levator externus 2: (0) ausente em todos os táxons examinados exceto o listado no estado 1 ; (1) presente em Rhaphiodon.

A conexão dos músculos Levator internus 3 e Levator externus 2 ocorre no mesmo ponto na região de origem no proótico através de um tendão afilado em Rhaphiodon (Fig.40B). O local de origem desses músculos está localizado medialmente ao Levator externus 1 e seus ventres musculares convergem para o mesmo tendão que os conecta ao osso na região de origem. Essa condição difere da encontrada em Cynodon e Hydrolycus e na maioria dos Characiformes examinados que apresentam origens do Levator internus 3 e Levator externus 2 separadas em pontos distintos do proótico com o primeiro localizado medialmente ao segundo.

MÚSCULO OBLIQUUS DORSALIS 3. 
18. Presença ou ausência do Obliquus dorsalis 3: (0) presente em todos os táxons examinados exceto os listados sob o estado 1; (1) ausente em Eugnathichthys e Phago.

19. Local de inserção do Obliquus dorsalis 3: (0) na extremidade dorsal do processo uncinado do epibranquial 3; (1) na margem anterior do processo uncinado do epibranquial 3 ; (2) na face medial do processo uncinado do epibranquial 3.

A inserção do Obliquus dorsalis 3 ocorre na extremidade cartilaginosa do processo uncinado do epibranquial 3 na maioria dos Characiformes examinados assim como em Brycon e Xenocharax examinados por Springer e Johnson (2004: 48-49) sendo esta a condição generalizada para a ordem (Fig. 2). Em Astyanax, Aphyocharax, Apareiodon, Citharinus, Cheirodon, Curimata, Gnathocharax, Hemigrammus, Hyphessobrycon, Iguanodectes, Leporinus, Lonchogeny, Metynnis, Mimagoniates, Myleus, Parodon, Semaprochilodus e Thoracocharax a conexão do Obliquus dorsalis 3 ocorre ao longo da margem anterior do processo uncinado do epibranquial 1 (estado 1: Figs: 25, 26 e 28). Outra condição (estado 2: Figs. 9, 14 e 17) foi verificada em Boulengerella, Hoplias, Erythrinus e Copeina onde o Obliquus dorsalis 3 se insere na face medial do processo uncinado do epibranquial 3 ventralmente a inserção do Levator externus 3.

\section{MÚSCULO OBLIQUUS DORSALIS 4.}

20. Presença ou ausência de dois ventres musculares no Obliquus dorsalis 4: (0) ausente; (1) presente.

Na maioria dos Characiformes examinados o Obliquus dorsalis 4 não apresenta divisão no ventre muscular desde sua origem no faringobranquial 4 até sua inserção no processo levantador do epibranquial 4. Springer e Johnson (2004: 48-49) descreveram essa condição para Brycon e Xenocharax examinados em seu estudo sendo este padrão 
anatômico a condição generalizada para a ordem. Em Boulengerella, Brycon falcatus, Bryconamericus, Charax, Copeina, Hepsetus, Leporinus, Oligosarcus e Serrasalmus o Obliquus dorsalis 4 é claramente dividido desde sua origem no faringobranquial 4 até a inserção no epibranquial 4 em dois ventres musculares: parte lateral e parte medial do Obliquus dorsalis 4 (Figs. 2, 9 e 21). Essa característica anatômica nesses táxons causou dúvidas quanto a correta identificação desse músculo, pois a parte medial do mesmo poderia ser definida topograficamente como o Obliquus dorsalis 4' segundo Springer e Johnson (2004). O exame preciso das origens e inserções do Obliquus dorsalis 4 provou que a parte medial desse músculo não se tratava do Obliquus dorsalis 4', mas sim de uma divisão do Obliquus dorsalis 4, pois esse ventre muscular apresenta origem no faringobranquial 4. O músculo Obliquus dorsalis 4' apresenta origem no faringobranquial 3. Springer e Johnson (2004) descreveram a presença de Obliquus dorsalis 4' para Brycon guatemalensis, tal condição não foi verificada nos exemplares desse gênero examinados no presente estudo, assim como em Brycon melanopterus (Springer e Johnson, 2004: 48) sugerindo que esse músculo deva ser melhor estudado nas espécies de Characiformes examinadas por Springer e Johnson (2004).

21. Local de inserção do Obliquus dorsalis 4: (0) na face lateral do processo levantador do epibranquial 4; (1) na face medial do processo levantador do epibranquial 4; (2) na margem anterior do processo levantador do epibranquial 4; (3) nas faces medial e lateral do processo levantador do epibranquial 4.

A maioria dos Characiformes examinados o Obliquus dorsalis 4 insere-se na face lateral do processo levantador do Eb4 através de uma extensa aponeurose (estado 0) (Fig.2 e 32). Condição descrita por Springer e Johnson (2004: 48-49) para Brycon guatemalensis e Xenocharax e observadas nas seguintes espécies examinadas: 
Acestrorhynchus, Acestrocephalus, Agoniates, Alestes, Aphyocharax, Apareiodon, Astyanax, Bivibranchia, Brycinus, Brycon, Bryconaethiops, Bryconamericus, Bryconops, Chalceus, Characidium, Charax, Crenuchus, Cheirodon, Citharinus, Copeina, Cynodon, Cynopotamus, Distichodus, Eugnathichthys, Gasteropelecus, Gnathocharax, Gilbertolus, Hepsetus, Hemigrammocharax, Hemiodus, Hemigrammus, Hydrocynus, Hydrolycus, Hyphessobrycon, Iguanodectes, Lonchogenys, Mimagoniates, Myleus, Moenkhausia, Metynnis, Nannocharax, Neolebias, Oligosarcus, Phago, Poptella, Rhaphiodon, Serrasalmus, Thoracocharax, Triportheus auritus, Triportheus pantanensis e Tetragonopterus. Outras condições foram observadas nos exemplares examinados quanto ao local de inserção do Obliquus dorsalis 4. Em Boulengerella, Curimata, Erythrinus, Hoplias, Nannostomus, e Triportheus signatus a inserção do Obliquus dorsalis 4 ocorre através de aponeurose na face medial do processo levantador do epibranquial 4 (estado 1) (Figs. 7 e 19). Em Chilodus, Curimatopsis, Exodon, Roeboexodon e Semaprochilodus a inserção do Obliquus dorsalis 4 ocorre na extremidade dorsal da margem anterior do processo levantador do epibranquial 4 (estado 2) (Fig. 12), diferentemente de Leporinus que apresenta a inserção do Obliquus dorsalis 4 na face medial e lateral do processo levantador do epibranquial 4, abraçando a margem anterior desse osso (estado 3) (Fig. 21).

\section{MÚSCULO OBLIQUUS DORSALIS 4'.}

22. Presença ou ausência do Obliquus dorsalis 4': (0) ausente; (1) presente.

A presença do Obliquus dorsalis 4' não foi observada nos exemplares de Brycon e na maioria dos Characiformes examinados no presente estudo (Fig. 2). Springer e Johnson (2004: 48) descrevem a presença do Obliquus dorsalis 4' para Brycon guatemalensis e ausência para Brycon melanopterus, o que sugere que o caráter possa variar em 
Bryconinae, ou que houve uma falha no reconhecimento de uma divisão medial do Obliquus dorsalis 4 (ver discussão do caráter 20). Os Distichodontidae examinados apresentaram Obliquus dorsalis 4' (Fig. 32), assim como Xenocharax (Springer e Johnson, 2004: 49), porém sua descrição determina a origem desse músculo no faringobranquial 4 nessa espécie, diferindo da definição da descrição da origem do Obliquus dorsalis 4' no faringobranquial 3 (Springer e Johnson, 2004). O Obliquus dorsalis 4' está presente (estado 1: Figs. 25, 26 e 27) em Acestrocephalus, Aphyocharax, Astyanax, Bryconamericus, Cheirodon Cynopotamus, Distichodus, Eugnathichthys, Exodon, Gnathocharax, Gilbertolus, Hemigrammus, Hyphessobrycon, Mimagoniates, Moenkhausia, Neolebias, Phago, Poptella e Roeboexodon examinados no presente estudo. Nessas espécies o Obliquus dorsalis 4' origina-se anteriormente na superfície dorsal média da diáfise do faringobranquial 3 tal como descrito para $B$. guatemalensis (Springer e Johnson, 2004: 48).

\section{MÚSCULO OBLIQUUS POSTERIORIS.}

23. Presença ou ausência do Obliquus posterioris: (0) presente em todos os táxons exceto o listado no estado 1; (1) ausente em Boulengerella (Fig. 9) .

24. Local de origem do Obliquus posterioris: (0) exclusivamente no epibranquial 4 em todos os táxons examinados exceto os listados sob o estado 1 e 2 ; (1) origem no epibranquial 4 e no transverso epibranquial 4 em Characidium e Crenuchus (2) origem no faringobranquial 4 em Gasteropelecus.

Nos táxons listados no estado 1 a origem do Obliquus posterioris ocorre no processo levantador do epibranquial 4 e nas fibras conjuntivas associadas ao músculo transverso epibranquial 4 (Fig. 11). Essa condição não foi observada na maioria dos Characiformes 
examinados assim como em Brycon e Xenocharax, descritos por Springer e Johnson (2004). Em Gasteropelecus a origem do Obliquus posterioris ocorre ventralmente ao transverso epibranquial 4 (Fig. 15) na superfície dorsal do faringobranquial 4 (estado 2).

\section{MÚSCULO ADDUCTOR 4.}

25. Proximidade do Adductor 4 da articulação formada pelo epibranquial 4 e ceratobranquial 4: (0) relativamente afastado em todos os táxons examinados exceto os listados sob o estado 1; (1) relativamente próximos em Alestes, Bathyaethiops, Brycinus, Bryconaethiops, Chalceus e Hydrocynus.

O Adductor 4 está localizado próximo ângulo da articulação do ceratobranquial 4 com o epibranquial 4 . Nos táxons listados no estado 1 o Adductor 4 apresenta o ventre muscular relativamente próximo à articulação entre os ceratobranquial 4 e 0 epibranquial 4 (Fig. 10).. Nos demais Characiformes examinados e descritos na literatura (Springer e Johnson, 2004: 48-49) o ventre muscular do Adductor 4 se estende anteriormente ao ângulo da articulação entre o ceratobranquial 4 e o epibranquial 4 estando relativamente afastado dessa juntura (estado 0) ( Fig. 7).

\section{MÚSCULO ADDUCTOR 5.}

26. Presença ou ausência do aumento relativo do tamanho do Adductor 5: (0) ausente na maioria dos táxons examinados exceto os listados sob o estado 1 ; (1) presente em Apareiodon, Chilodus, Hemigrammus, Leporinus e Parodon (Figs. 21, 22, 24 e 25).

O tamanho relativo do Adductor 5 nos táxons listados sob o estado 1 é muito maior do que o verificado na maioria dos Characiformes examinados assim como nos táxons dessa ordem examinados por Springer e Johnson (2004). 


\section{MÚSCULO TRANSVERSUS EPIBRANQUIALIS 4.}

27. Presença ou ausência de limite definido entre o Transversus epibranquialis 4, Sphicter oesophagus e Transversus pharingobranchialis 4: (0) presente em todos os táxons examinados exceto os listados sob o estado 1; (1) ausente em Cynodon, Hydrolycus, Hemigrammocharax, Nannocharax e Rhaphiodon (Figs. 45B e 46B) .

Na maioria dos Characiformes examinados é possível observar o conjunto de feixes de fibras musculares que conjuntamente formam a loja muscular definida topograficamente como o Transversus epibranquialis 4 e as fibras orbiculares do Sphincter oesophagus mesmo que alguns feixes de fibras desse conjunto estejam disposta de forma irregular, incongruente com a descrição topográfica de Brycon e Xenocharax de Springer e Johnson (2004), permitindo definir claramente a posição topográfica dos dois músculos. Nos táxons listados sob o estado 1 não é possível definir uma separação entre as fibras musculares do Transversus epibranquialis 4 e do Sphicter oesophagus.

\section{MÚSCULO TRANSVERSUS PHARYNGOBRANCHIALIS 2.}

28. Presença ou ausência do Transversus pharyngobranchialis 2: (0) ausente em todos os táxons examinados exceto os listados sob o estado 1; (1) presente em Cynodon, Hydrolycus e Rhaphiodon (Figs. 13, 18 e 20),

\section{MÚSCULO TRANSVERSUS PHARYNGOBRANCHIALIS 3.}

29. Presença ou ausência de limite definido entre o Transversus pharyngobranchialis 3

e Transversus pharyngobranchialis 4: (0) presente em todos os táxon examinados exceto os listados sob o estado 1; (1) ausente Cynodon, Hydrolycus, Raphiodon, 
Boulengerella, Hoplias, Erythrinus, Copeina, Nannostomus, Parodon, Cynopotamus, Metynnis, Myleus, Serrasalmus, Bryconaethiops, Hydrocynus, Acestrocephalus, Cynopotamus ,Hemigrammocharax, Nannocharax e Hepsetus (Figs. 13, 18 e 20).

Ver discussão do caráter 27.

\section{MÚSCULO TRANSVERSUS PHARYNGOBRANCHIALIS 4}

30. Presença ou ausência do Transversus pharyngobranchialis 4: (0) presente em todos os táxons examinados exceto os listados sob o estado 1; (1) ausente em Curimatopsis, Curimata, Leporinus e Semaprochilodus (Figs. 12, 21 e 30).

31.Presença ou ausência de dois ou mais ventres musculares no Transversus pharyngobranchialis 4: (0) ausente em todos os táxons examinados exceto os listados sob o estado 1; (1) presente em Bivibranquia e Hemiodus (Figs. 8 e 16).

\section{ÓRGÃO EPIBRANQUIAL.}

32. Presença ou ausência de Órgãos epibranquiais: (0) ausente na maioria dos táxons examinados exceto os listados sob o estado 1; (1) presente em Curimatopsis, Curimata, Semaprochilodus e Citharinus (Figs. 12, 28 e 30).

\section{MÚSCULO SPHINCTER ESOPHAGI.}

33. Presença ou ausência de projeção mediana anterior conspícua das fibras musculares do Sphincter esophagi: (0) ausente na maioria das espécies examinadas exceto as listadas sob o estado 1; (1) presente Cheirodon, Hyphessobrycon l, Metynnis, Triportheus, Thoracocharax, Bivibranchia, Hemiodus, Gasteropelecus, Chilodus, Hemigrammus e Bryconamericus. 
$\mathrm{Na}$ maioria das espécies examinadas as fibras orbiculares do Sphincter esophagi circundam exclusivamente a camada muscular lisa do esôfago, como em Brycon e Xenocharax descritos por Springer e Johnson (2004). Nas espécies listadas no estado 1 as fibras orbiculares dorsais do Sphincter esophagi projetam-se anteriormente a camada muscular do esôfago alcançando a região do faringobranquial 4, ventralmente ao Transversus epibranchialis 4 (Figs. 8, 16, 24, 25 e 27).

4.4. Discussão da variação dos caracteres em um contexto filogenético.

O número de caracteres é menor do que o número de táxons, e a grande quantidade de incongruências no conjunto de dados resultou em muitas homoplasias já indicando que as o resultado da análise seria de baixa resolução, como poderá ser verificado adiante.

A análise gerou um cladograma de baixa resolução (Anexo 2) para grande parte dos táxons terminais, com consenso estrito de 18829 árvores de 157 passos com índice de consistência (CI) 16 e índice de retenção (RI) 34, com a presença de "overflow". Diversas analises foram realizadas com diferentes parâmetros de busca a fím de estabilizar as mesmas e evitar o"overflow", porem mesmo com parâmetros de busca mais baixos os resultados reportavam "overflow" e o consenso estrito da análise mantinha-se inalterado quando comparado com buscas mais agressivas, como foi possível verificar comparativamente com análises de retenção de 500000 a 140 árvores. Em todas as análises realizadas nesse intervalo obteve-se o mesmo consenso estrito o que determinou que o resultado obtido é confiável e aceitável. A distribuição dos caracteres foi incongruente interferindo no, colapsamento de 45 nós gerados pelo consenso estrito. Apenas alguns poucos clados resultaram da análise e estão de acordo com hipóteses filogenéticas previamente propostas na literatura como, por exemplo, o 
clado 20 (formado por Boulengerella, Erythrinus, Hoplias, Hepsetus, Copeina e Nannostomus).

Outros clados mais inclusivos retrataram a relação entre espécies do mesmo gênero exemplificado pelo clado 9 (formado por Acestrorhynchus lacustris e A.nasutus) e entre espécies da mesma família exemplificado pelo clado 14 (formado por Rhaphiodon vulpinus, Cynodon gibbus e Hydrolycus tatauaia), lembrando que os clados formados serviram apenas para direcionar a discussão de poucos caracteres. A discusão dos resultados se baseou nas informações disponíveis na literatura sobre as relações de Characiformes a fim de se compreender o significado filogenético da variação encontrada.

\section{Discussão}

Os resultados do presente estudo demonstraram que os músculos dorsais dos arcos branquiais dos Characiformes apresentam relativamente pouca variação nas espécies examinadas, com a maioria dos caracteres amplamente distribuídos nos táxons. No entanto essa distribuição também permitiu reconhecer alguns caracteres exclusivos em certos agrupamentos taxonômicos. Para compreender o significado da ocorrência desses caracteres nas espécies examinadas os mesmos serão discutidos a seguir baseando-se nas hipóteses de relações filogenéticas propostas para os Characiformes disponíveis na literatura.

O músculo Adductor 4 fica relativamente mais próximo do ângulo interno da articulação epibranquial 4-ceratobranquial 4 (caráter 25) nos gêneros Alestes, Bathyaethiops, Brycinus, Bryconaethiops, Chalceus e Hydrocynus examinados no presente estudo. Esse músculo quando comparado com os outros gêneros de 
Characiformes examinados, é um caráter derivado exclusivo desses táxons. O conjunto de gêneros que compartilham o caráter 25 também foi objeto do estudo de Zanata e Vari (2005) que estabeleceram uma hipótese de monofiletismo para os mesmos determinando que o gênero Neotropical Chalceus seja relacionado aos gêneros africanos de alestídeos, e reunidos formam a família Alestidae. O estado de caráter observado nos Alestidae examinados no presente estudo pode ser sugerido como uma sinapomorfia adicional à hipótese de Zanata e Vari (2005). Os táxons Chalceus, Brycynus e Bryconaethiops aqui examinados compartilham a ausência de inserção do Levator externus 1 no processo uncinado do epibranquial 1 (caráter 3).

O músculo Transversus pharyngobranchialis 2 (caráter 28) está presente nos gêneros Rhaphiodon, Cynodon e Hydrolycus e entre todos os Characiformes examinados são os únicos táxons a apresentar esse caráter. Esses gêneros também foram objeto do estudo de Lucena e Menezes (1998) que propuseram uma hipótese de monofiletismo entre esses táxons, posteriormente corroborado por Toledo-Piza (2000), que passaram a ser reconhecidos como subfamília Cynodontinae. A presença do Transversus pharyngobranchialis 2 nos Cynodontinae examinados pode ser um caráter derivado desse táxon concordando com as hipóteses de Lucena e Menezes (1998) e Toledo-Piza (2000). A inserção do levator externus 4 ocorre na face medial do processo levantador do epibranquial 4 (caráter 8) nos Cynodontinae e nos gêneros Triportheus e Tetragonopterus e sua distribuição entre essas espécies reconhecidamente pouco relacionadas, segundo a hipótese de Mirande (2010), sugere que esse caráter evoluiu independentemente nesses táxons e que a condição reconhecida nos Cynodontinae examinados possa ser um caráter derivado compartilhado para esse táxon. 
A inserção do Obliquus dorsalis 3 na face medial do processo uncinado do epibranquial 3 (caráter 19) está presente nos gêneros Boulengerella, Erythrinus, Hoplias e Copeina e essa condição não foi verificada nos outros gêneros de Characiformes examinados, sendo exclusiva desses táxons. O monofiletismo das famílias que compreendem os gêneros examinados no presente estudo foi determinado por Vari (1995) que propôs o clado Erythrinidae, Ctenoluciidae, Lebiasinadea e Hepsetidae, posteriormente denominado Erythrinoidea por Buckup (1998). Os Erythrinoidea examinados no presente estudo compartilham a inserção do Obliquus dorsalis 3 na face medial do processo uncinado do epibranquial 3, apoiando a hipótese de Vari (1995) de monofiletismo entre as famílias, podendo ser uma sinapomorfia para os Erythrinoidea examinados.

Os representantes de Erythrinoidea examinados também compartilham outros caracteres, que não são exclusivos a esse táxon, como por exemplo, o local de inserção do Levator internus 1 em dois pontos distintos do faríngobranquial 2 (caráter 12) em todos os representantes de Erythrinoidea examinados e nos gêneros Acestrorhynchus, Iguanodectes, Thoracocharax, Semaprochilodus e Curimatopsis. A presença desse caráter no gênero Acestrorhynchus e nos demais sugere que o mesmo possa ter evoluído independentemente nos Characiformes examinados. Porém algumas hipóteses sugerem que os gêneros presentes em Erythrinoidea possam formar com Acestrorhynchus um táxon monofilético (Buckup, 1998 e Datovo, 2010). Diante dessas hipóteses a inserção do Levator internus 1 em dois pontos distintos do faríngobranquial 2 nos Erythrinoidea e Acestrorhynchus sugere que esse caráter possa ser uma sinapomorfia para esse táxon.

No presente estudo foi observado que o local de origem do Levator externus 1 ocorre exclusivamente no faringobranquial 1 (caráter 2) nos gêneros Crenuchus, 
Myleus, Metynnis e Serrasalmus, sendo essa uma condição exclusiva para esses táxons. Os gêneros Myleus, Metynnis e Serrassalmus são historicamente estabelecidos como proximamente relacionados (Jegu, 2003). Essa condição está de acordo com a hipótese de Serrasalmidae monofilético, proposta por Mirande (2010) sendo um caráter derivado que poderia ser uma sinapomorfia adicional à hipótese do autor. Essa condição também está presente no gênero Crenuchus. Essa distribuição sugere que essa condição evoluiu independentemente nos gêneros representantes de Serrasalmidae e Crenuchidae examinados no presente estudo.

O músculo Levator externus 1 apresentou variação quanto à presença de divisões no seu ventre no local de inserção. Nos gêneros Apareiodon, Bivibranchia, Curimata, Curimatopsis, Hemiodus, Leporinus, Parodon e Semaprochilodus examinados a inserção do Levator externus 1 ocorre em dois pontos distintos da superfície dorsal do epibranquial 1(caráter 4) sendo um caráter derivado exclusivo desses táxons. Os gêneros Curimata, Curimatopsis, Semaprochilodus e Leporinus foram considerados um grupo monofilético por Vari (1983) posteriormente corroborado por Buckup (1998) que nomeou esse táxon como superfamília Anostomoidea. O estado de caráter em questão, também está presente nos gêneros Apareiodon, Parodon, Bivibranchia e Hemiodus, os dois primeiros pertencentes à família Parodontidae e os últimos à família Hemiodontidae. A hipótese de Mirande (2010) determina que os gêneros Parodon, Apareiodon e Hemiodus formam um táxon monofilético, e que esse clado é grupo irmão dos Anostomoidea examinados em seu estudo. A presença da inserção do Levator externus 1 ocorrendo em dois pontos distintos da superfície dorsal do epibranquial 1(caráter 4) é um caráter derivado compartilhado pelos representantes de Anostomoidea, Parodontidae e Hemiodontidae examinados, sendo o mesmo exclusivo 
desses táxons, indicando que o caráter possa ser uma sinapomorfia para esse táxon concordando com a hipótese de monofiletismo de Mirande (2010).

A ausência do Transversus pharyngobranchialis 4 (caráter 30) é compartilhada exclusivamente nos gêneros Curimatopsis, Curimata, Leporinus e Semaprochilodus Os gêneros Curimatopsis, Curimata e Semaprochilodus representam as famílias Curimatidae e Prochilodontidae respectivamente, que segundo as hipóteses de Vari (1983 e 1989) formam um táxon monofilético. O autor ainda estabelece que Anostomidae é grupo irmão de Chilodontidae, que juntamente com Curimatidae e Prochilodontidae formam um táxon monofilético mais inclusivo. Diante dessa hipótese a distribuição do caráter ausência do Transversus pharyngobranchialis 4 (caráter 30) pode ser um caráter derivado dos representantes de Anostomidae, Curimatidae e Prochilodontidae examinados, ou poderia ter surgido independentemente no táxon formado pelos Curimatidae e Prochilodontidae e em Anostomidae. Já a presença de Órgãos epibranquiais (caráter 32) foi observada exclusivamente nos representantes de Curimatidae, Prochilodontidae e no gênero Citharinus da família africana Citharinidae. A presença dessas estruturas nas famílias Curimatidae e Prochilodontidae poderia ser um caráter derivado adicional à hipótese de Vari (1989) sugerindo que esse caráter evoluiu independentemente no representante de Citharinidae examinado no presente trabalho.

A inserção do músculo Levator externus 3 no processo uncinado do epibranquial 3 (caráter 6) está ausente em Bivibranchia e Chilodus examinados no presente estudo. Essa condição é restrita para esses gêneros e não está presente no gênero Hemiodus também examinado. Os gêneros Hemiodus e Bivibranchia fazem parte da família Hemiodontidae sensu Langeani (2003) e segundo as observações do presente estudo não 
compartilham o estado ausência de inserção do Levator externus 3 no processo uncinado do epibranquial 3. Esse caráter pode ser informativo em níveis taxonômicos menos inclusivos da família Hemiodontidae. A presença desse estado de caráter em Chilodus sugere que essa condição possa ter evoluído independentemente nos representantes de Chilodontidae e Hemiodintidae examinados no presente estudo.

A presença de dois ou mais ventres musculares no Transversus pharyngobranchialis 4 (caráter 31) é compartilhada exclusivamente por Bivibranchia e Hemiodus, representantes de Hemiodontidae examinados nesse estudo. Esse táxon está de acordo com a hipótese de monofiletismo de Hemiodontidae proposta por Langeani (2008).

Os gêneros Curimata e Curimatopsis examinados no presente estudo compartilham um caráter exclusivo: o local de inserção do Levator internus 3 no faringobranquial 3 e 4 (caráter 15) A presença dessa condição nesses gêneros está de acordo com a hipótese morfológica, amplamente baseada em osteologia, do monofiletismo de Curimatidae sensu Vari (1989), com Curimatopsis na base e Curimata em uma posição intermediária no cladograma (Vari, 1989: 50).

As famílias africanas Distichodontidae e Citharinidae foram propostas por Vari (1979) como um táxon monofilético, e posteriormente foram estabelecidas por Fink e Fink (1981) como o grupo irmão das demais famílias de Characiformes. O presente estudo examinou seis espécies de Distichodontidae (Distichodus sp, Eugnathichthys sp, Hemigrammocharax multifasciatus, Nannocharax sp, Neolebias trilineatus e Phago intermedius) e um caráter derivado exclusivo é compartilhado por Eugnathichthys e Phago: a ausência do Obliquus dorsalis 3 (caráter 18). Springer e Johnson (2004) descreveram esse músculo em Xenocharax com uma origem única no faringobranquial 3 e inserção 
no processo uncinado do epibranquial 3 e no processo levantador do epibranquial 4, caracterizando um músculo bicaudado. A condição descrita pelos autores não foi observada nos disticodontídeos examinados. O táxon formado pelos gêneros Eugnathichthys e Phago estão de acordo com a hipótese de Vari (1979) que estabelece um táxon monofilético formado pelos gêneros Eugnathichthys, Phago, Paraphago e Belonophago baseado em 10 sinapomorfias osteológicas provenientes do exame do neurocrânio, das maxilas e do suspensório (Vari, 1979: 336).

A ausência de limite definido entre o Transversus epibranquialis 4, Sphicter esophagus e Transversus pharingobranchialis 4 (caráter 27) nos gêneros Eugnathichthys e Phago examinados é compartilhada nos disticodontídeos Hemigrammocharax e Nannocharax, ocorrendo também nos Cynodontinae examinados no presente estudo. O táxon formado por Hemigrammocharax e Nannocharax corrobora a hipótese de Vari (1979) que estabelece os mesmos como grupos irmãos baseando-se em 12 sinapomorfias osteológicas provenientes em sua maioria da morfologia craniana Vari (1979: 331). O autor ainda propõe que esse clado é grupo irmão de Distichodus, que também foi examinado no presente estudo e apresentou outra condição para o caráter 27: presença de limite definido entre o Transversus epibranquialis 4, Sphicter esophagus e Transversus pharingobranchialis 4. A distribuição da condição ausência de limite definido entre o Transversus epibranquialis 4, Sphicter esophagus e Transversus pharingobranchialis 4 nos gêneros de disticodontídeos examinados, exceto Distichodus, parece indicar que esse caráter possa ser uma sinapomorfia para esses táxons. A presença da mesma condição nos gêneros representantes de Cynodontinae reforça a hipótese de monofiletismo de Toledo-Piza (2000) sugerindo que esse caráter possa ser uma sinapomorfia adicional para a subfamília e que devido aos gêneros de Cynodontinae e Distichodontidae serem pouco relacionados em hipóteses filogenéticas 
mais abrangentes (eg. Mirande 2010) esse caráter tenha evoluído independentemente nesses táxons.

Os órgãos epibranquiais (caráter 32) estão presentes no exemplar de Citharinus examinado no presente estudo e foram descritos por Vari (1979) para os gêneros Citharinus e Citharidium. O autor examinou essas estruturas em Hemigrammocharax e Nannaethiops, e cita a presença da mesma em Distichodus, Neolebias e Nannocharax com base nos estudos de Daget (1958: 1368) e Nelson (1967: 73). No presente estudo essas estruturas não foram observadas nos gêneros Distichodus, Neolebias, Nannocharax e Hemigrammocharax, sendo encontradas em exemplares de Curimatidae e Prochilodontidae neotropicais e Citharinidae africano. Com base na anatomia e na distribuição dos órgãos epibranquiais nas espécies examinadas sugere-se que os mesmos tenham evoluído independentemente nos Characiformes neotropicais e africanos.

Os caracteres dos músculos dorsais dos arcos branquiais nos Characidae (sensu Mirande, 2010) examinados no presente estudo estão distribuídos de forma incongruente nos táxons, sendo em sua grande maioria pouco informativos para se determinar agrupamentos entre os mesmos. A ausência do levator internus 3 (caráter14) é claramente uma exceção, pois é o único caráter derivado exclusivo do táxon formado pelos gêneros Moenkhausia e Poptella. Em sua análise Mirande (2010) inclui esses gêneros à subfamília Tetragonopterinae representada em sua análise por 20 gêneros. Os resultados reforçam a hipótese apresentada pelo autor, mesmo que os gêneros examinados no presente estudo não estejam proximamente relacionados, sugerindo que a ausência do levator internus 3 nesses táxons possam contribuir para o conhecimento das relações em Tetragonopterinae em análises mais amplas. 
O local de inserção do Obliquus dorsalis 4 na margem anterior do processo levantador do epibranquial 4 (caráter 21) está presente nos gêneros examinados Exodon e Roeboexodon, não sendo um caráter exclusivo, pois a mesma condição está presente em representantes dos gêneros Chilodus e Semaprochilodus. A hipótese morfológica de Mirande (2010) estabelece que os gêneros Exodon e Roeboexodon fazem parte de um táxon monofilético juntamente com Bryconexodon, não examinado no presente estudo. As observações do presente estudo sugerem que o local de inserção do Obliquus dorsalis 4 na margem anterior do processo levantador do epibranquial 4 pode ser um caráter derivado para Roestini, e como também está presente em Semaprochilodus evoluiu independentemente nos táxons examinados. A condição local de inserção do Obliquus dorsalis 4 nas faces medial e lateral do processo levantador do epibranquial 4 do caráter 21 ocorre exclusivamente no gênero Leporinus examinado, sugerindo que esse caráter possa ser uma autapomorfia para o gênero.

A distribuição da presença do Obliquus dorsalis 4' (caráter 22) nos Characiformes examinados é singular, pois ocorre em todos os Distichodontidae examinados e em algumas espécies de Characidae. Claramente a distribuição desse músculo sugere que o mesmo evoluiu independentemente em pelo menos duas famílias de Characiformes, fato observado anteriormente por Springer e Johnson (2004) que descreveu a presença desse músculo em Xenocharax e Brycon guatemalensis, mas a ausência do mesmo em Brycon melanopterus. Esse caráter não foi observado nos Bryconinae examinados no presente estudo ficando a presença do Obliquus dorsalis 4' restritas aos seguintes Characidae examinados: Acestrocephalus, Aphyocharax, Astyanax, Bryconamericus, Cheirodon, Cynopotamus, Exodon, Gnathocharax, Hemigrammus, Hyphessobrycon, Mimagoniates, Moenkhausia e Roeboexodon. Seguindo a distribuição do caráter nos táxons é possível reconhecer que alguns dos 
gêneros examinados no presente estudo coincidem com o táxon monofilético proposto por Malabarba e Weitzman (2003) suportado pela ausência do osso supraorbital compreendendo as subfamílias Cheirodontinae (sensu Malabarba, 1998), Characinae (sensu Lucena, 1998), Stethaprioninae (sensu Reis, 1989) e Aphyocharacinae, Rhoadsiinae, Tetragonopterinae mais insertae sedis genera e o clado A (sensu Malabarba e Weitzman, 2003). Porém a distribuição desse caráter é irregular nos táxons de Characidae mencionados acima. O Obliquus dorsalis 4' também está presente em todos os representantes de Distichodontidae,podendo ser considerado um caráter compartilhado pelos táxons examinados dessa família..

A presença da origem do Levator internus 3 compartilhada com o Levator externus 2 (caráter 17) foi observada apenas no gênero Rhaphiodon dentre todas as espécies examinadas no presente estudo, podendo ser considerada uma autapomorfia desse táxon. A ausência do Obliquus posterioris (caráter 23), só ocorre no gênero Boulengerella dentre todos os gêneros examinados no presente estudo podendo ser considerado uma autapomorfia para esse táxon. No gênero Gasteropelecus o local de origem do Obliquus posterioris ocorre no faringobranquial 4 (caráter 24), sendo essa condição exclusiva desse gênero podendo ser considerada uma autapomorfia de Gasteropelecus.

A discussão dos caracteres dos músculos dorsais dos $\operatorname{arcos}$ branquiais de Characiformes, embasada nas hipóteses de relacionamento filogenético disponíveis na literatura para a ordem demonstrou que mesmo com poucas variações nesse complexo de caracteres foi possível corroborar hipóteses prévias, amplamente baseadas na análise de caracteres osteológicos, em diversos níveis taxonômicos. Após a discussão é possível 
visualizar que os caracteres provenientes da musculatura dorsal dos arcos branquias possa ser analisada em futuros estudos de abrangência taxonômica mais restrita.

\section{Referências bibliográficas}

Aguilera, O. 1987. Musculatura de lós arcos branquiales, arco hioideo y opérculo em peces Sciaenidae del Atlantico Oeste y Rios de America. Revista Brasileira de Zoologia 4 (2): 89-103.

Allis, E. P. Jr, 1897. The cranial muscles and cranial and first spinal nerves in Amia calva. Journal of Morphology, 12(3): 487-772.

Buckup, P. A. 1998. Relationships of Characidiinae and phylogeny of characiform fishes (Teleostei: Ostariophysi), p. 123-144. In: L. R. Malabarba, R. E. Reis, R. P. Vari, Z. M. Lucena \& C. A. Lucena. (Ed.). Phylogeny and classification of Neotropical fishes. EDIPUCRS, Porto Alegre, 603 p.

Calcagnotto, D., S. A. Schaefer \& R. DeSalle. 2005. Relationships among characiform fishes inferred from analysis of nuclear and mitochondrial gene sequences. Molecular Phylogenetics and Evolution 36: 135-153.

Castro, R. M. C \& M. M. C. Castro. 1987. Proposta de uma nomenclatura osteológica para Characiformes (Pisces: Ostariophysi). Boletim do Museu Paraense Emílio Goeldi Série Zoologia 3 (1): 25-32.

Castro, R. M. C. \& R. P. Vari. 2004. Detritivores of the South American Fish Family Prochilodontidae (Teleostei: Ostariophysi: Characiformes): A Phylogenetic and Revisionary Study. Smithsonian Contributions to Zoology, 622: 1-189.

Datovo, A. 2010. Miologia cefálica de Characiformes com ênfase em Characidae (Teleostei: Ostariophysi) Tese de doutorado não publicada, Universidade de São Paulo, Ribeirão Preto, 298p.

Datovo, A. \& R. Castro. 2012. Anatomy and evolution of the mandibular, hyopalatine, and opercular muscles in characiform fishes (Teleostei: Ostariophysi). Zoology. 115: 84-116. 
Edgeworth, F. H. 1929. The development of some of the cranial muscles of ganoid fishes. Philosophical Transactions of the Royal Society of London. Series B, Conteining Papers of a Biological Character 217: 39-89.

Fink, S. V. \& W. L. Fink. 1981. Interrelationships of the Ostariophysan fishes (Teleostei). Zoological Journal of the Linnean Society 72: 297-353.

Fink, S. V. \& W. L. Fink. 1996. Interrelationships of Ostariophysan fishes (Teleostei), p. 209-249. In: M. L. J. Stiassny, Parenti, L. R., Johnson, G. D. (Ed.). Interrelationships of fishes. Academic Press, San Diego, 496p.

Gery, J. 1977. Characoids of the world. United States: T.F.H. Publications, Inc. Ltd. $672 \mathrm{p}$.

Grey, E. A \& P. M. Mabee. 2012. Gill-Arch Musculature of the Quillback Carpiodes cyprinus (Cypriniformes: Catostomidae) with a Comparison to Cyprinids. Journal of Morphology. 273: 909-918.

Goloboff, Farris e Nixon, 2008. Cladistics 24: 774-786.

Harder, W. 1975. Anatomy of Fishes. Stuttgart: E. Schweizerbart'sche Verlagsbuchhandlung. 612p. Vol.1

Ingenito, L. F. S. 2008. Análise filogenética da família Parodontidae (Teleostei: Characiformes). Tese de doutorado não publicada, Universidade Federal do Rio de Janeiro, Rio de Janeiro, 127p.

Javonillo R, L. R., Malabarba, S. H. Weitzman \& J. R. Burns. 2010. Relationships among major lineages of characid fishes (Teleostei: Ostariophysi:Characiformes), based on molecular sequence data. Mol Phylogenet Evol, 54:498-511.

Johnson, G. D. 1992. Monophyly of the euteleostean clades - Neoteleostei, Euripterygii e Ctenosquamata. Copeia 1: 8-25.

Lauder, G. V \& K. F. Liem. 1983.The evolution and relationships of the actinopterygian fishes. Bulletin of Museum of Comparative Zoology 150(3): 95-197. 
Langeani, F. 2003. Family Hemiodontidae (Hemiodontids). pp. 96-100. in: Reis, R.E., S.O. Kullander, \& C.J. Ferraris jr. (org.).Check List of The Freshwater of South and Central America. edipucrs, Porto Alegre, 729 p.

Lucena, C. A. 1993. Estudo filogenético da família Characidae com uma discussão dos grupos naturais propostos (Teleostei, Ostariophysi, Characiformes). Tese de doutorado não publicada, Universidade de São Paulo, São Paulo, 158p.

Lucena, C. A. \& N. A. Menezes. 1998. Phylogenetic analysis of Roestes Gunther and Gilbertolus Eigenmann, with a hypothesis on the relationships of the Cynodontidae and Acestrorhynchidae (Teleostei: Ostariophysi: Characiformes), p. 261-268. In: L. R. Malabarba, R. E. Reis, R. P. Vari, Z. M. Lucena \& C. A. Lucena. (Ed.). Phylogeny and classification of Neotropical fishes. EDIPUCRS, Porto Alegre, 603 p.

Malabarba L. R. \& S. H. Weitzman. 2003. Description of a new genus with six new species from Southern Brazil, Uruguay and Argentina, with a discussion of a putative characid clade (Teleostei: Characiformes: Characidae). Comunicações do Museu de Ciências e Tecnologia, PUCRS, Série Zoologia 16 (1): 67-151.

Mattox, G. T. \& M. Toledo-Piza. 2012. Phylogenetic study of the Characinae (Teleostei: Characiformes: Characidae). Zoological Journal of the Linnean Society, 165: 809-915.

Mirande, J. M. 2009. Weighted parsimony phylogeny of the family Characidae (Teleostei: Characiformes). Cladistics, 25(6): 574-613.

Mirande, J. M. 2010. Phylogeny of the family Characidae (Teleostei: Characiformes): from characters to taxonomy. Neotropical Ichthyology. 8(3): 385-568.

Moreira, C. R. 2002. Relações filogenéticas em Iguanodectinae (Characidae: Characiformes: Teleostei). Dissertação de mestrado não publicada, Universidade de São Paulo, São Paulo, 276p.

Moreira, C. R. 2007. Relações filogenéticas na ordem Characiformes (Teleostei: Ostariophysi). Tese de doutorado não publicada, Universidade de São Paulo, São Paulo, $468 \mathrm{p}$. 
Nakae, M \& K. Sasaki. 2008. Branchial arches muscle innervation by the glossopharyngeal (IX) and vagal (X) nerves in Tetraodontiformes, with special reference to muscle homology. Journal of Morphology 269: 674-690.

Nelson, G. J. 1967. Epibranchial organs in lower teleostean fishes, Zoology 53 (1): 71-89.

Nelson, G. J. 1968. Gill-Arch structures in Acanthodes. Nobel Symposium 4: 129-143.

Nelson, G. J. 1969. Gill Arches and the Phylogeny of Fishes, With Notes on the Classification of Vertebrates. Bulletin of the American Museum of Natural History 141 (4): 477-551.

Nelson, J. S. 2006. Fishes of the World. 4. ed. Hoboken: John Wiley \& Sons, Inc. 539p.

Netto-Ferreira, A. L. 2006. Relações filogenéticas dos gêneros de Lebiasinidae (Ostariophysi, Characiformes). Dissertação de mestrado não publicada, Universidade Federal do Rio de Janeiro/Museu Nacional, Rio de Janeiro, 375p.

Nixon, K. C. \& J. C. Carpenter. 1993. On outgroups. Cladistics 9:413-426.

Oliveira, C., G. S. Avelino, K. T. Abe, T. C. Mariguela, R. C. Benine, G. Ortí, R. P. Vari \& R. M. C. Castro. 2011. Phylogenetic relationships within the speciose family Characidae(Teleostei: Ostariophysi:Characiformes) based on multilocus analysis and extensive ingroup sampling. BMC Evolutionary Biology 11(275): 1-25.

Orti, G. \& A. Meyer. 1997. The Radiation of Characiform Fishes and the Limits of Resolution of the Mitochondrial Ribosomal DNA Sequences. Systematic Biology 346 (1): 75-100.

Oyakawa, O. T. 1998. Relações filogenéticas das famílias Pyrruhulinidae, Lebiasianidae e Erythrinidae (Osteichthyes: Characiformes). Tese de doutorado não publicada, Universidade de São Paulo, São Paulo, 200p.

Patterson, C. 1977. Cartilage bones, dermal bones and membrane bones, or the exoskeleton versus the endoskeleton. In: S. M. Adrews, R. S. Miles e A. D. Walker, p. 77-121, Problems in vertebrate evolution, Academic press. 
Reis, R. E, S .O. Kullander \& C. J. Ferraris-JR. 2003. Check list of the freshwater fishes of South and Central America. Porto Alegre: EDIPUCRS. 729p.

Roberts, T. R. 1969. Osteology and relationships of characoid fishes, particularly the genera Hepsetus, Salminus, Hoplias, Ctenolucius and Acestrorhynchus. Proceedings of the California Academy of Sciences 36: 391-500.

Rosen, D. E. 1973. Interrelationships of higher euteleostean fishes. p. 397-513. In: P. H. Greenwood, R. S. Miles e Patterson (eds.), Interrelationship of fishes. Academic Press, London.

Rosen, D. E, 1982. Teleostean Interrelationships, Morphological Function and Evolutionary Inference. American Zoologist 22: 261-273.

Sidlauskas, B. \& R. Vari 2008. Phylogenetic relationships within the South American fish family Anostomidae (Teleostei, Ostariophysi, Characiformes). Zoological Journal of Linnean Society 154 (1): 70-210.

Springer, V. G. \& G. D. Johnson. 2000. Use and Advantages of Ethanol Solution of Alizarin Red S Dye for Staining Bone in Fishes. Copeia 1: 300-301.

Springer, V. G. \& G. D. Johnson. 2004. Study of the dorsal gill-arch musculature of teleostomi fishes, with special reference to the Actinopterygii. Bulletin of the Biological Society of Washington 11: 1-236.

Springer, V. G. \& T. M. Orrell 2004. Phylogenetic analysis of the families of acanthomorph fishes based on dorsal gill arch muscles and skeleton. Bulletin of the Biological Society of Washington 11: 237-260.

Takahasi, N. 1925. On the Homology of The Cranial Muscles of The Cypriniform Fishes. Journal of Morphology 40 (1): 4-109.

Takata, Y \& K. Sasaki. 2004. Branchial structures in the Gasterosteiformes, with special reference to myology and phylogenetic implications. Ichthyological Research 52: 33-49.

Taylor, W. R. \& G. C. VanDyke. 1985. Revised procedures for staining and claering small fishes and other vertebrates for bone and cartilage study. Cybium 9(2): 107-119. 
Toledo-Piza, M. 2000. The Neotropical Fish Subfamily Cynodontinae (Teleostei: Ostariophysi: Characiformes): A Phylogenetic Study and a Revision of Cynodon and Rhaphiodon. American Museum Novitates 3286: 1-88.

Toledo-Piza, M. 2007. Phylogenetic relationship among Acestrorhynchus species (Ostariophysi: Characiformes: Acestrorhynchidae). Zoological Journal of Linnean Society 151: 691-757.

Vari, R. P. 1979. Anatomy, relationships and classification of the families Citharinidae and Distichodontidae (Pisces, Characoidea). Bulletin of British Museum of Natural History (Zoology) 36 (2): 261-344.

Vari, R. P. 1983. Phylogenetic Relationships of the Families Curimatidae, Prochilodontidae, Anostomidae and Chilodontidae (Pisces: Characiformes). Smithsonian Contributions to Zoology 378: 1-59.

Vari, R. P. 1995. The Neotropical fish family Ctenoluciidae (Teleostei: Ostariophysi: Characiformes): supra and intrafamilial phylogenetic relationships, with a revisionary study. Smithsonian Contributions to Zoology 564: 1-97.

Vari, R. P. 1998. Higher Level Phylogenetic Concepts within Characiforms (Ostariophysi), a Historical Review, p. 111-121. L. R. Malabarba, R. E. Reis, R. P. Vari, Z. M. Lucena \& C. A. Lucena. (Ed.). Phylogeny and classification of Neotropical fishes. EDIPUCRS, Porto Alegre, 603 p.

Vetter, B. 1878. Untersuchungen zur vergleichenden Anatomie der Kiemen- und Kiefermuskulatur der Fische. (ii) Theil,Jenaische Zeitscbr. f. Naturw, vol. 12. 550p.

Weitzman, S. H. 1954. The osteology and the relationships of the South American characid fishes of the subfamily Gasteropelecinae. Stanford Ichthyological Bulletin 4: 213-263.

Weitzman, S. H. 1962. The osteology of Brycon meeki, a generalized characid fish, with an osteological definition of the family. Stanford Ichthyological Bulletin 8: 1-77.

Weitzman, S. H. 1974. Osteology and Evolutionary Relantionships of the Sternoptychidae With a New Classification of Stomatoid Families. Bulletin of The American Museum of Natural History 153 (3): 329-478. 
Weitzman, M. \& S. H. Weitzman. 2003. Lebiasinidae (Pencil fishes). p. 241-251. In: Reis, R.E., S.O. Kullander, \& C.J. Ferraris Jr. (org.) .Check List of The Freshwater of South and Central America. edipucrs, Porto Alegre, 729 p.

Wiley, E. O. \& D. G. Johnson, 2010. A teleost classification based on monophyletic groups. In: J. S. Nelson, H-P. Schuktz e M. V. H. Wilson (eds), Origin and Phylogenetic Interrelationships of Teleosts, p. 123-182, Verlag.

Winterbottom, R. 1974. A descriptive synonymy of the striated muscles of the Teleostei. Proceedings of the Academy of Natural Sciences of Philadelphia 125 (12): 225-317.

Zanata, A. M. 2000. Estudo das relações filogenéticas do gênero Brycon Muller \& Troschel, 1844. (Characidae; Characiformes). Tese de doutorado não publicada, Universidade de São Paulo, São Paulo, 358p.

Zanata, A. M. \& R. P. Vari. 2005. The family Alestidae (Ostariophysi: Characiformes): a phylogenetic analysis of a Trans-Atlantic Clade. Zoological Journal of the Linnean Society 145: 1-144. 


\section{Figuras}

Le1

Eb1

Le2

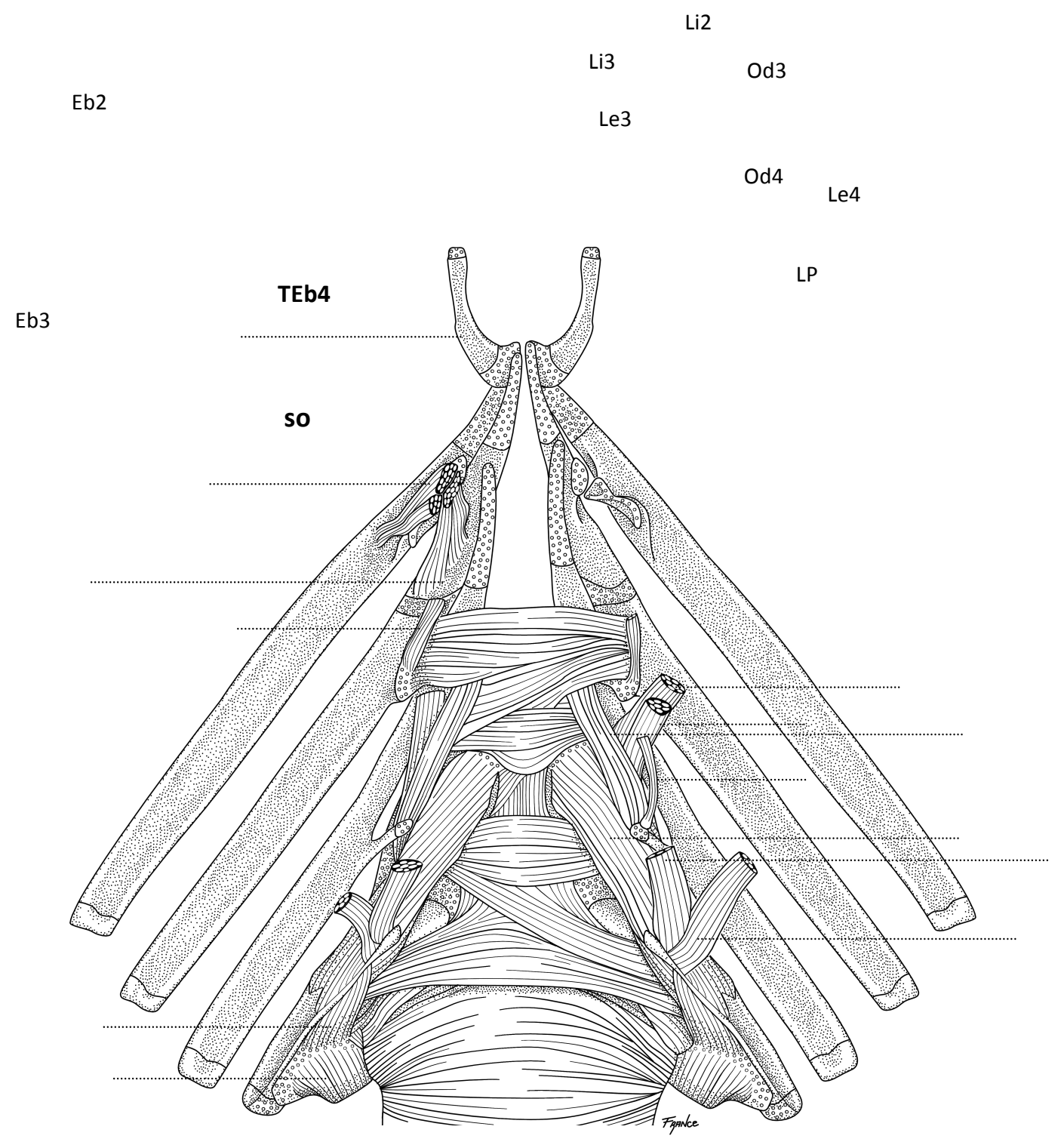

Figura1. Acestrorhynchus lacustris Não catalogado, 134,3 mm CP. Vista dorsal. 
Le2

Eb1

$$
{ }_{\text {Od3 }}^{\text {Li2 }}
$$

Eb2

Le3

Od4
Eb3

TEb4
Le4

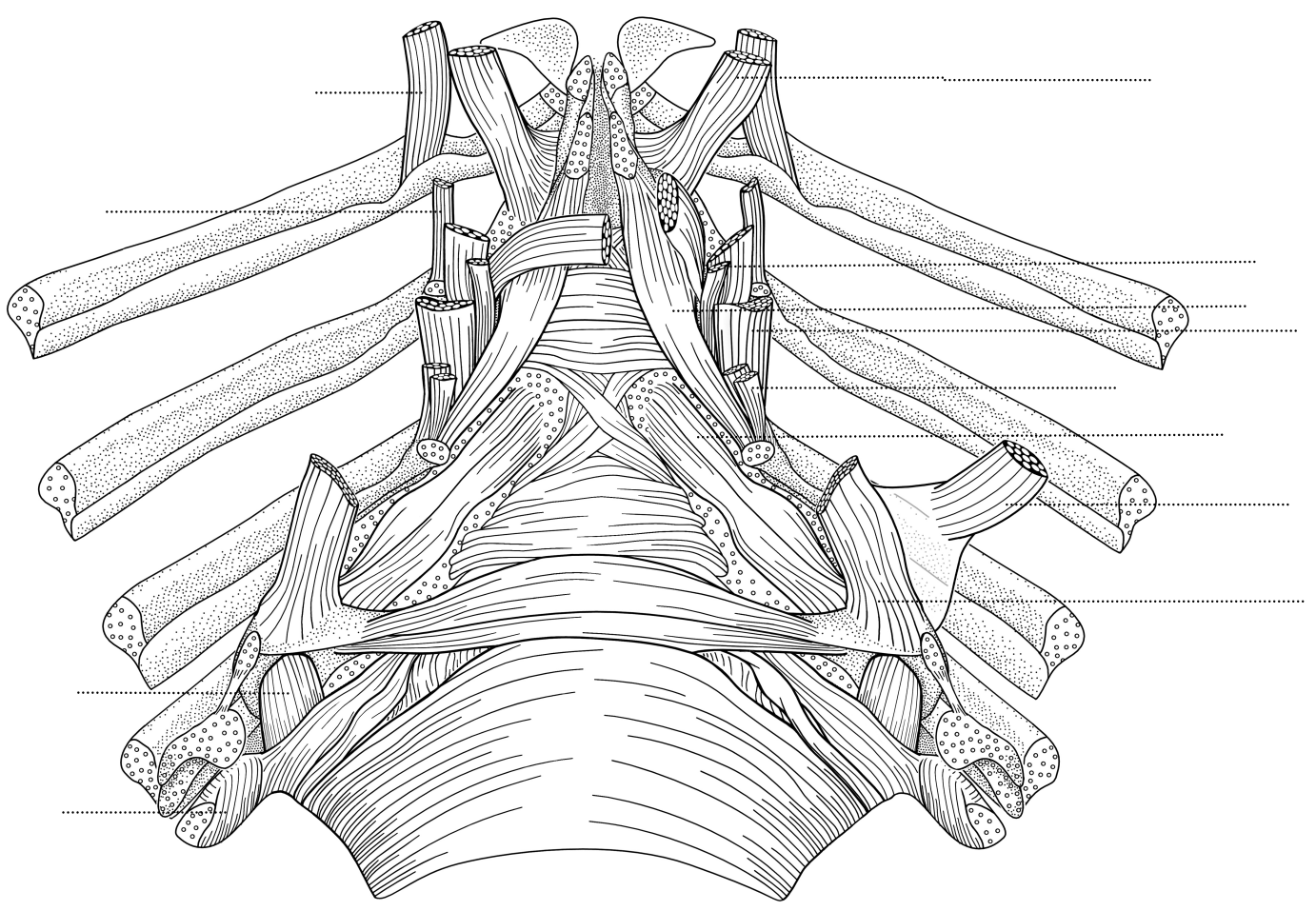

Figura 2. Brycon falcatus MZUSP 56945, 175,4 mm CP. Vista dorsal. 
Le1

Li1

Le2

Eb2

Eb1

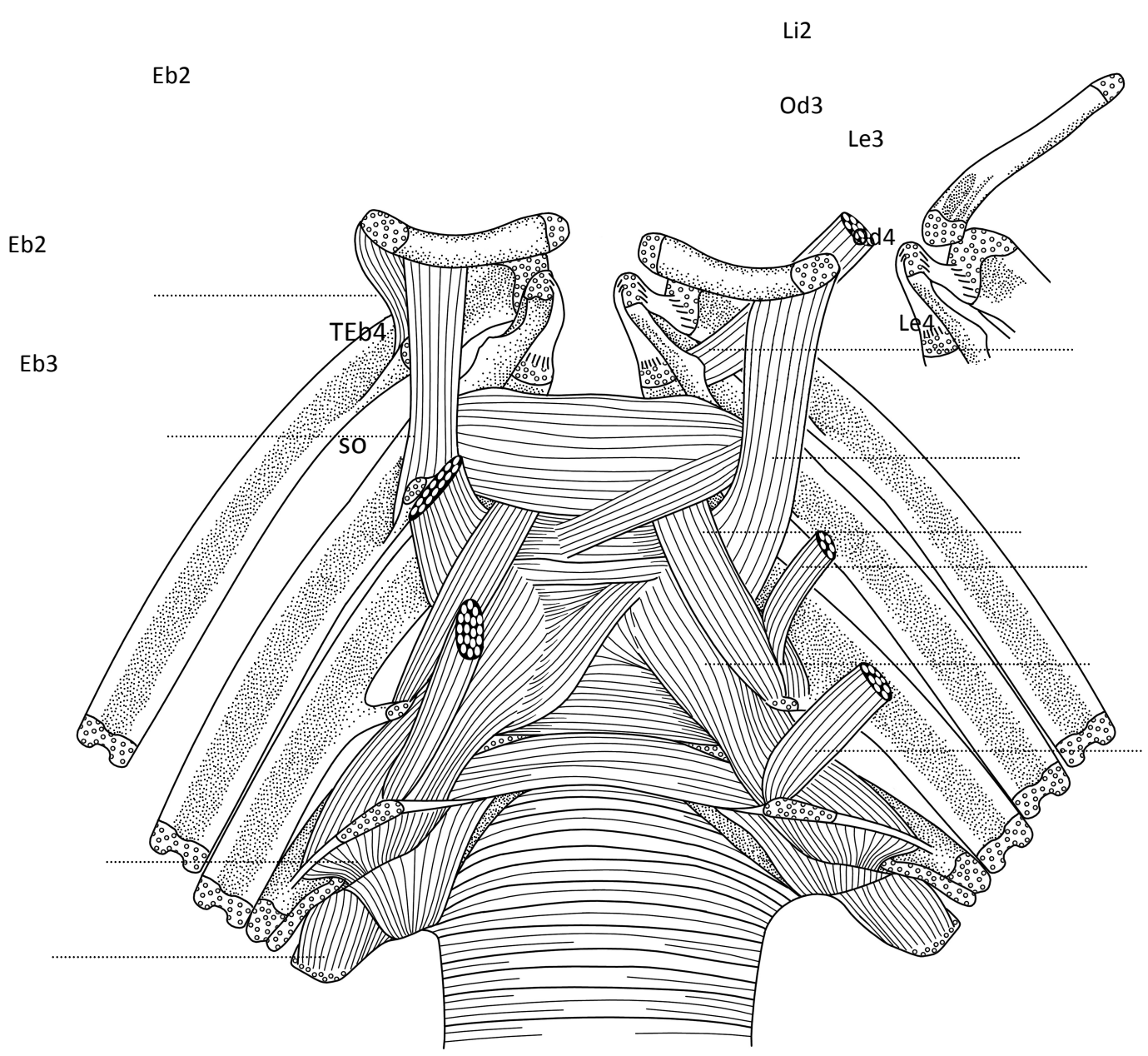

Figura 3. Cynopotamus kincaidi MZUSP 19987, 105,7 mm CP. Vista dorsal. 


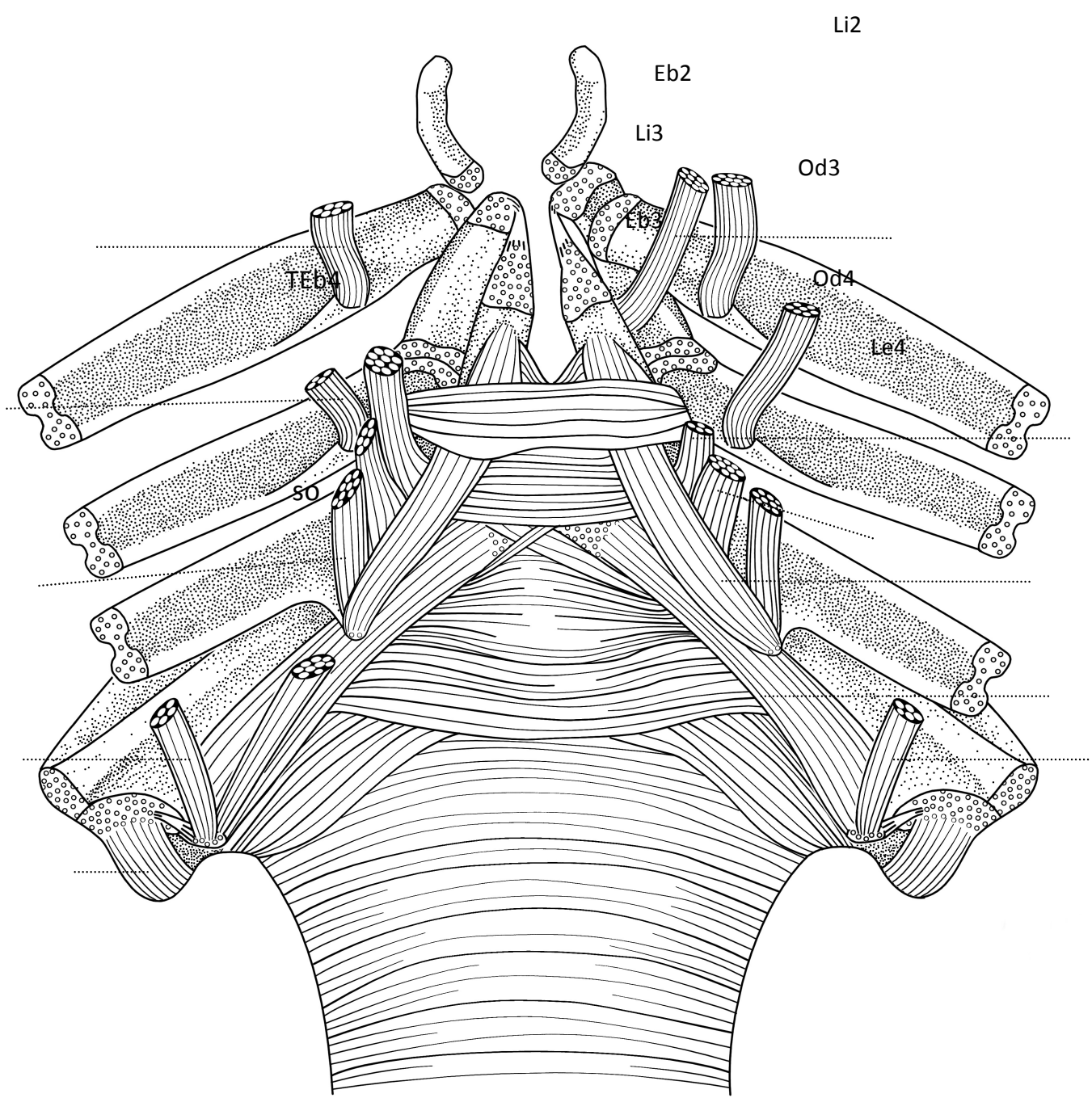

Figura 4. Mimagoniates microlepis MZUSP 72850, 45,9 mm CP. Vista dorsal. 
Le1

Od3

Eb1

Eb2

Eb3

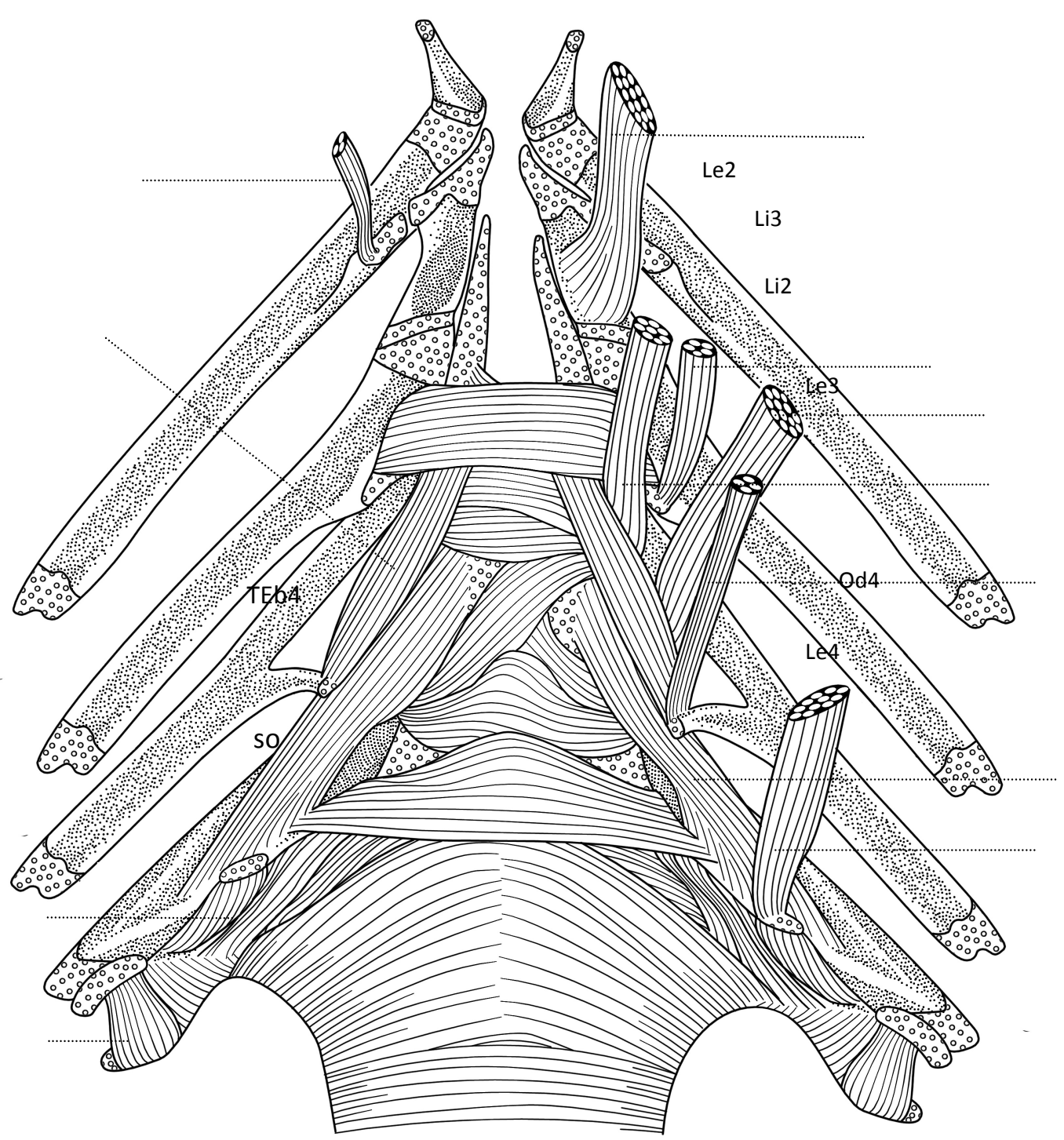

Figura 5. Oligosarcus hepsetus MZUSP 42890, 83,7 mm CP. Vista dorsal. 
Li3

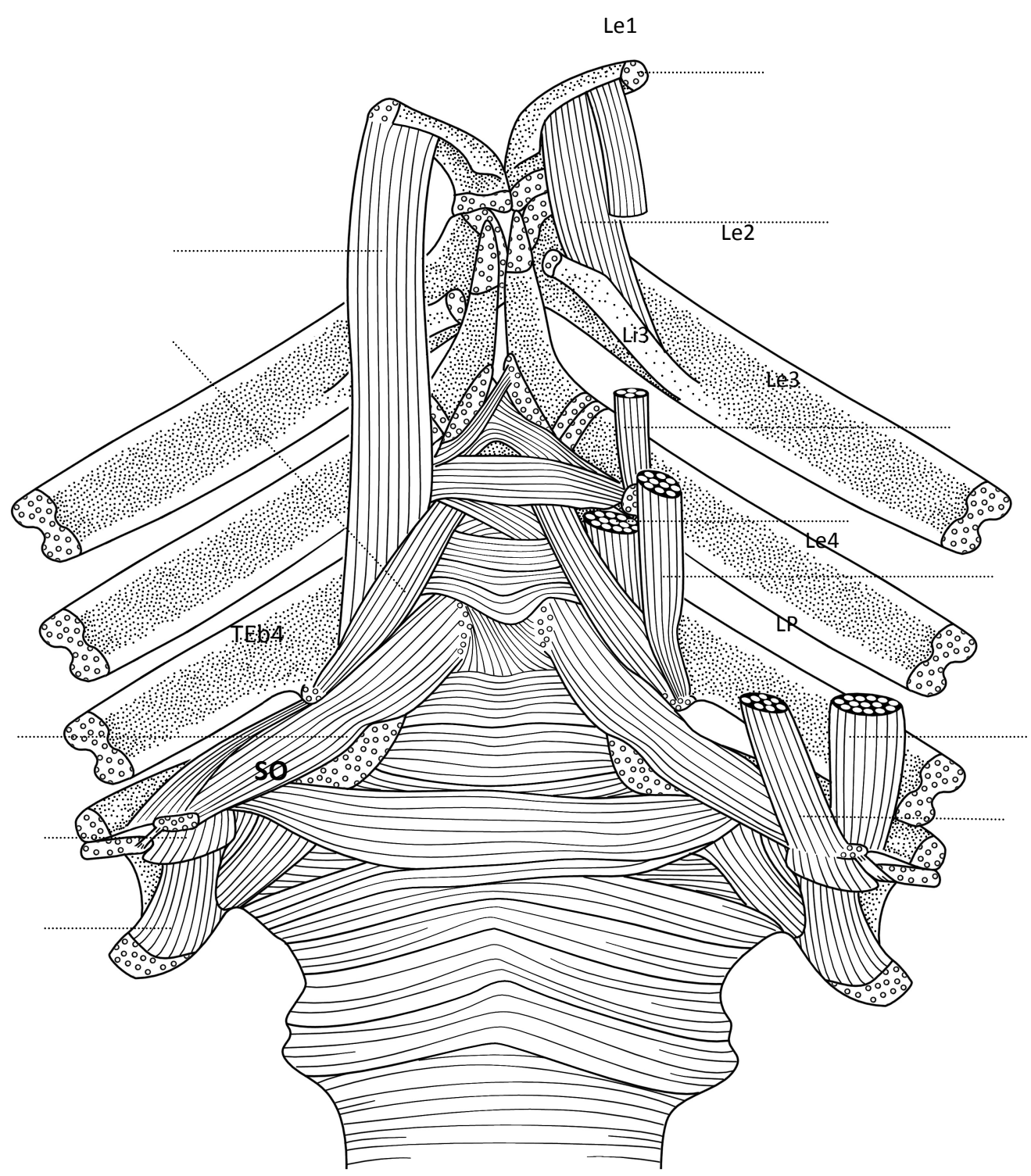

Figura 6. Serrasalmus brandtii MZUSP 57550, 92,3 mm CP. Vista dorsal. 


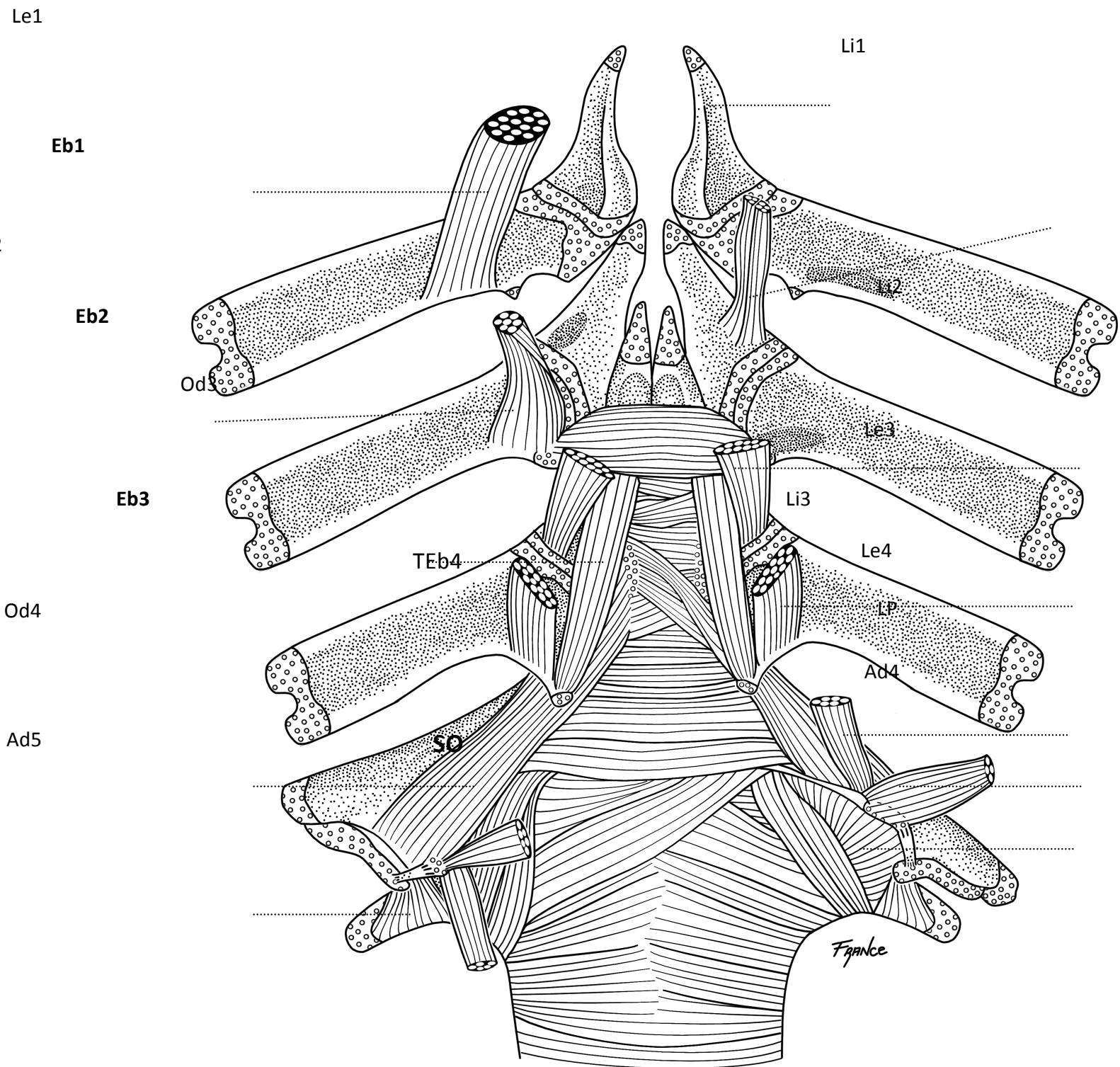

Figura 7. Triportheus pantanensis MZUSP 54147, 83,3 mm CP. Vista dorsal. 


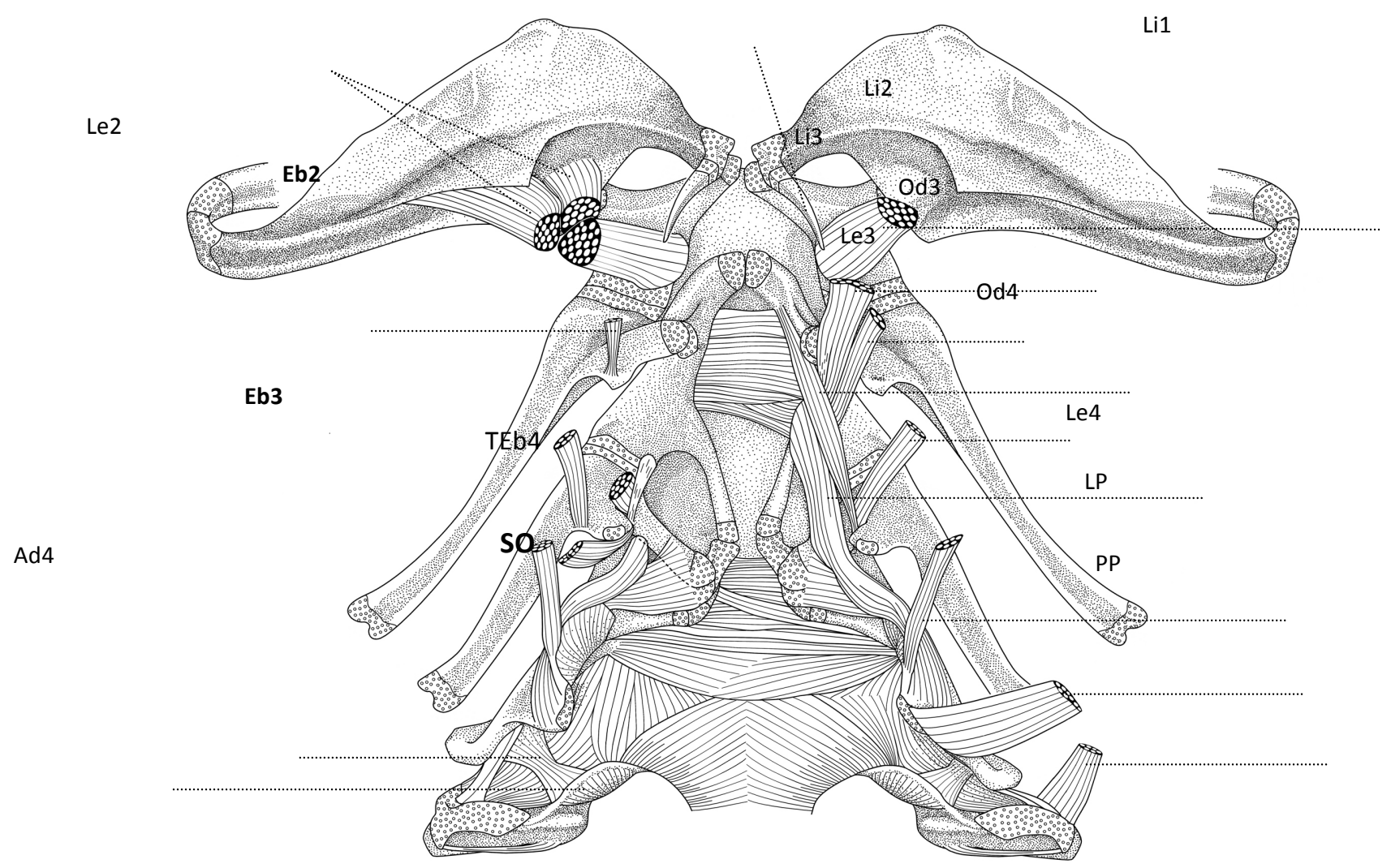

Figura 8. Bivibranchia velox MZUSP 97228, 134,8 mm CP. Vista dorsal. 
$\mathrm{Pb} 2$

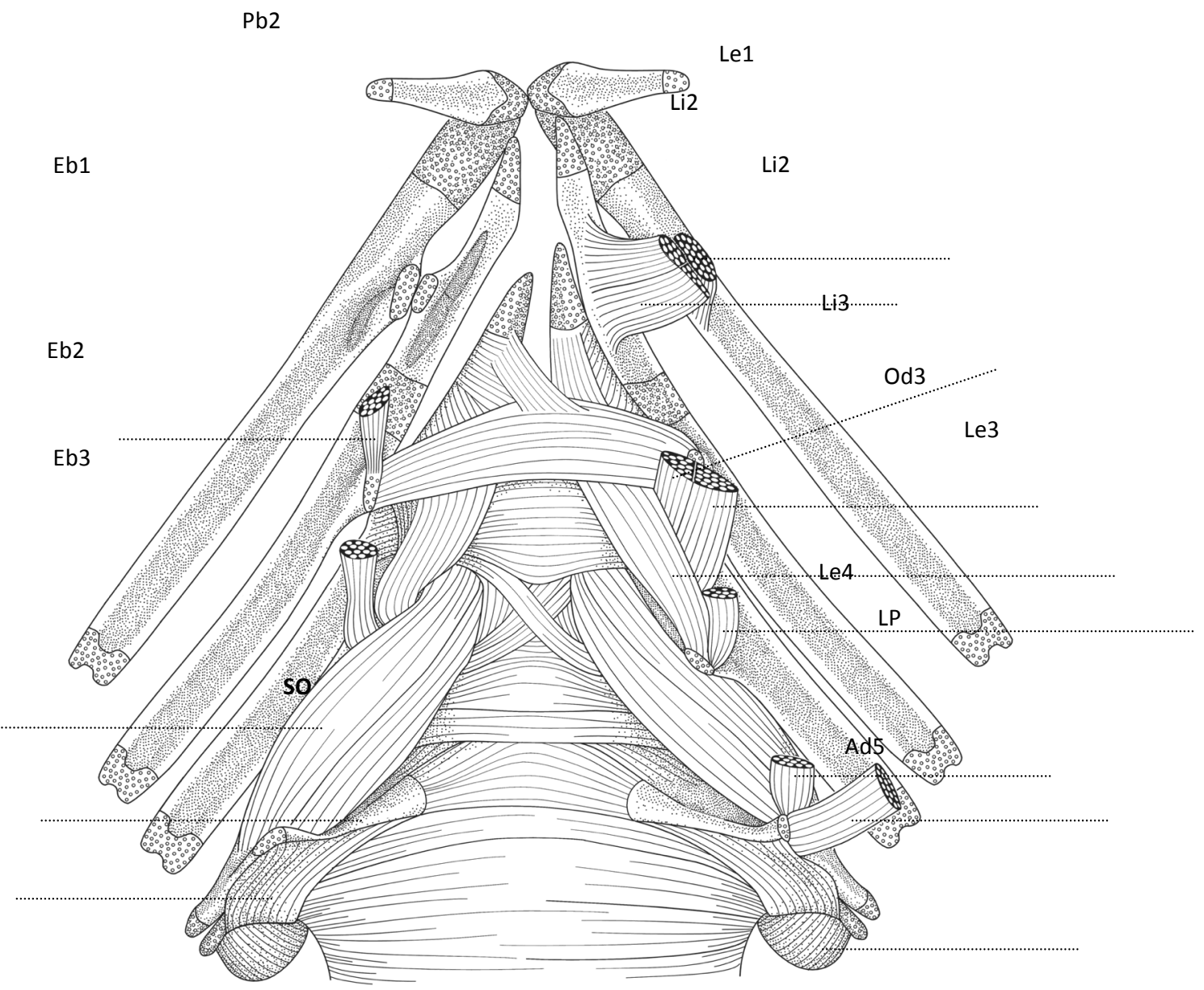

Figura 9. Boulengerella cuvieri MZUSP 101733, 248,1 mm CP. Vista dorsal. 
$\mathrm{Pb} 1$

Le1 Le2

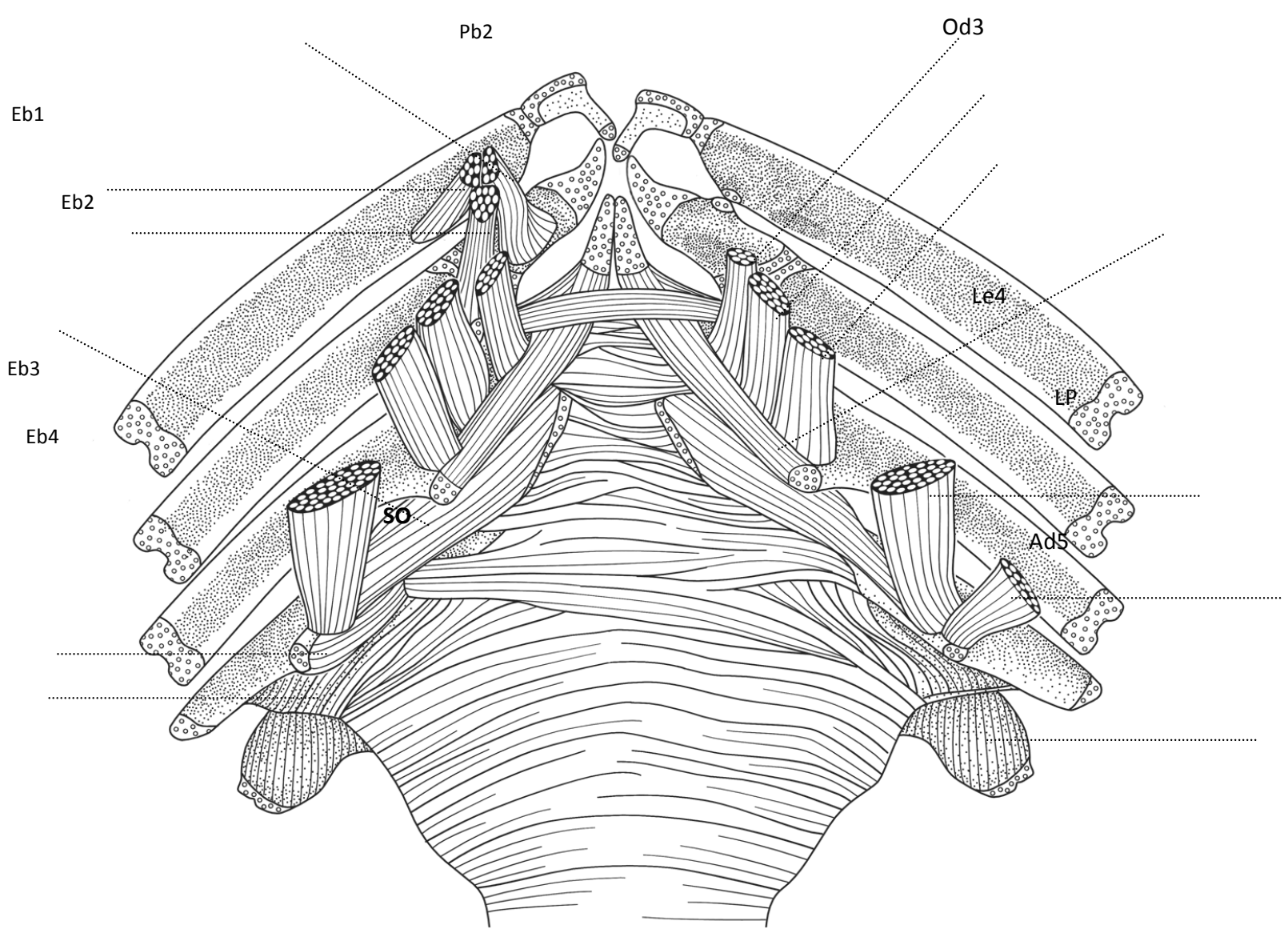

Figura 10. Chalceus spilogyros MZUSP 19698, 152,1 mm CP. Vista dorsal. 


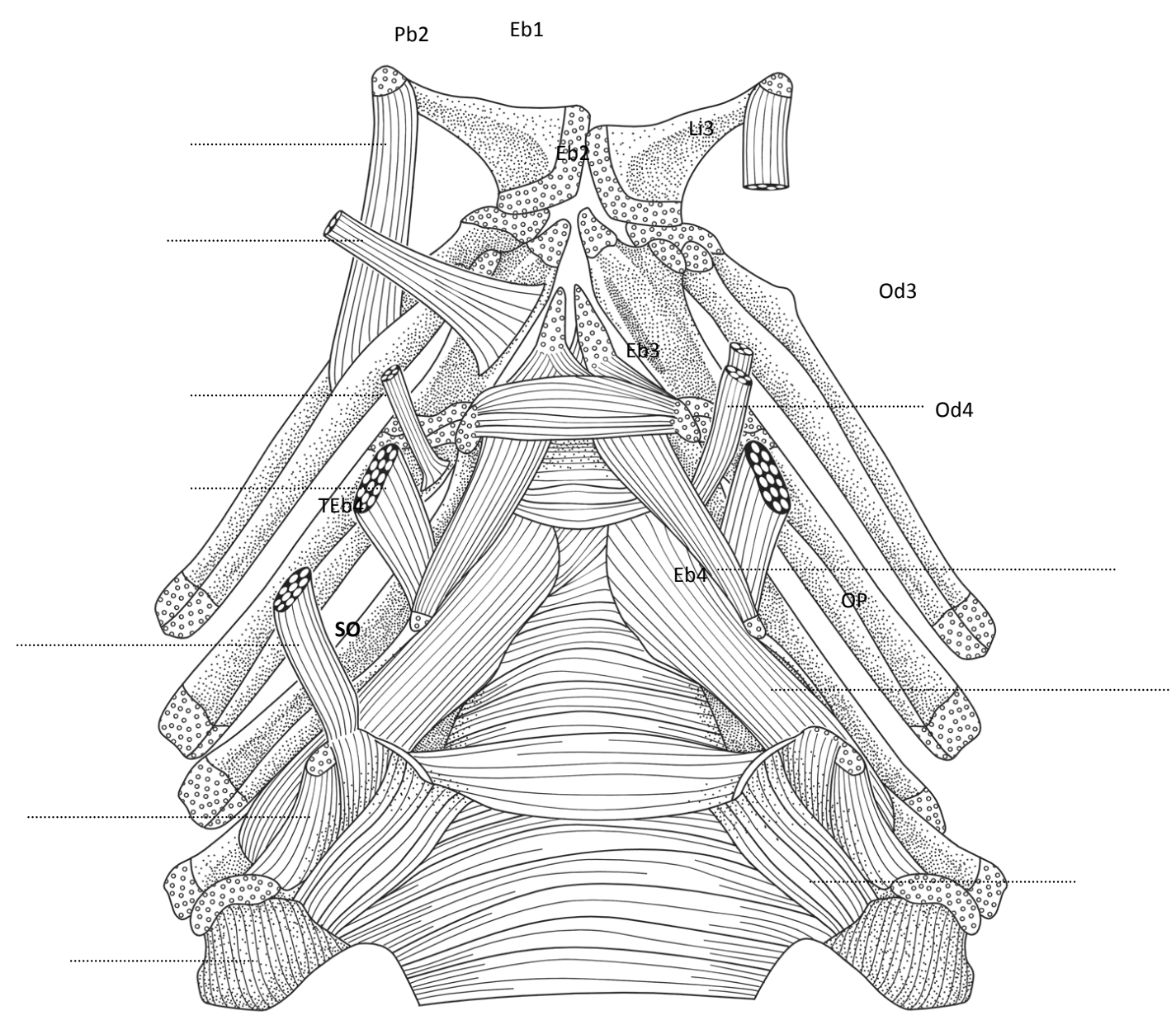

Figura 11. Crenuchus spilurus MZUSP 85582, 33,9 mm CP. Vista dorsal. 
Le1

$\mathrm{Pb} 2$

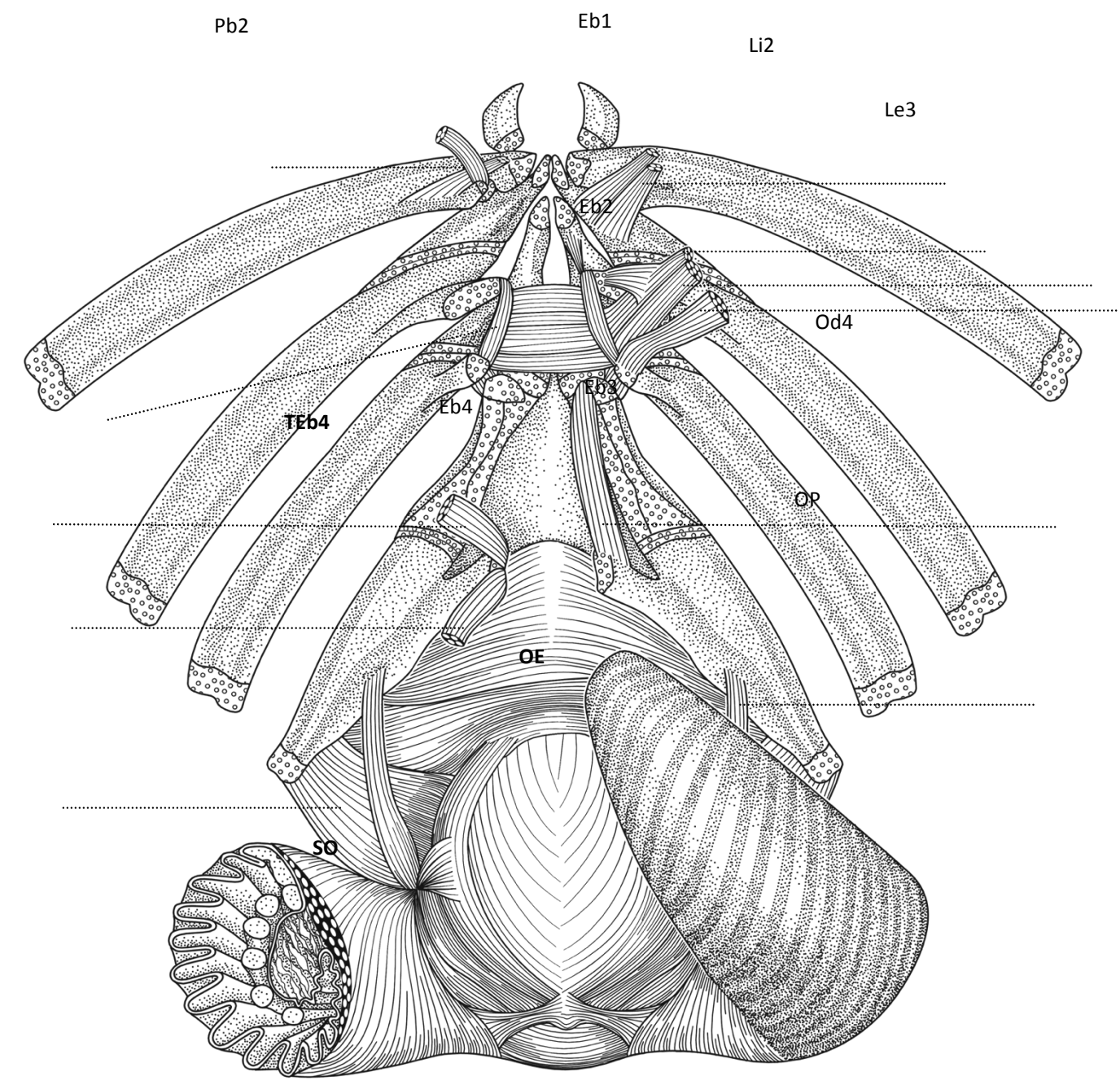

Figura 12. Curimatopsis myersi MZUSP 74778, 191,9 mm CP. Vista dorsal. 


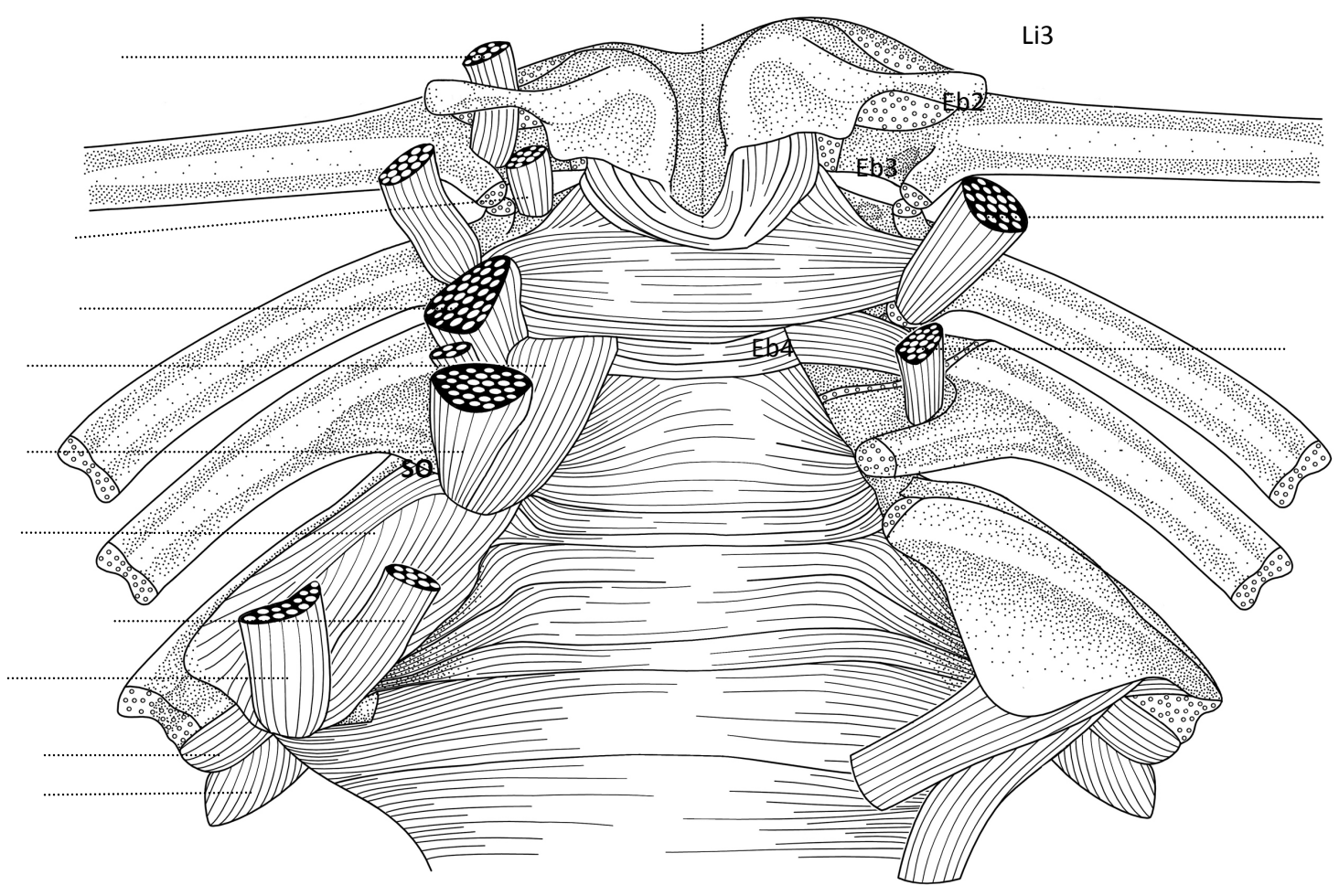

Figura 13. Cynodon gibbus. MZUSP 89905, 231,1 mm CP. Vista dorsal. 
Eb2

Figura 14. Erythrinus erythrinus MZUSP 34351, 97,7 mm CP. Vista dorsal. 
UP Ad5 Li3 Li1 SO Eb3 Eb2 Le3 Od3

Eb4 Le1 Eb1 Od4

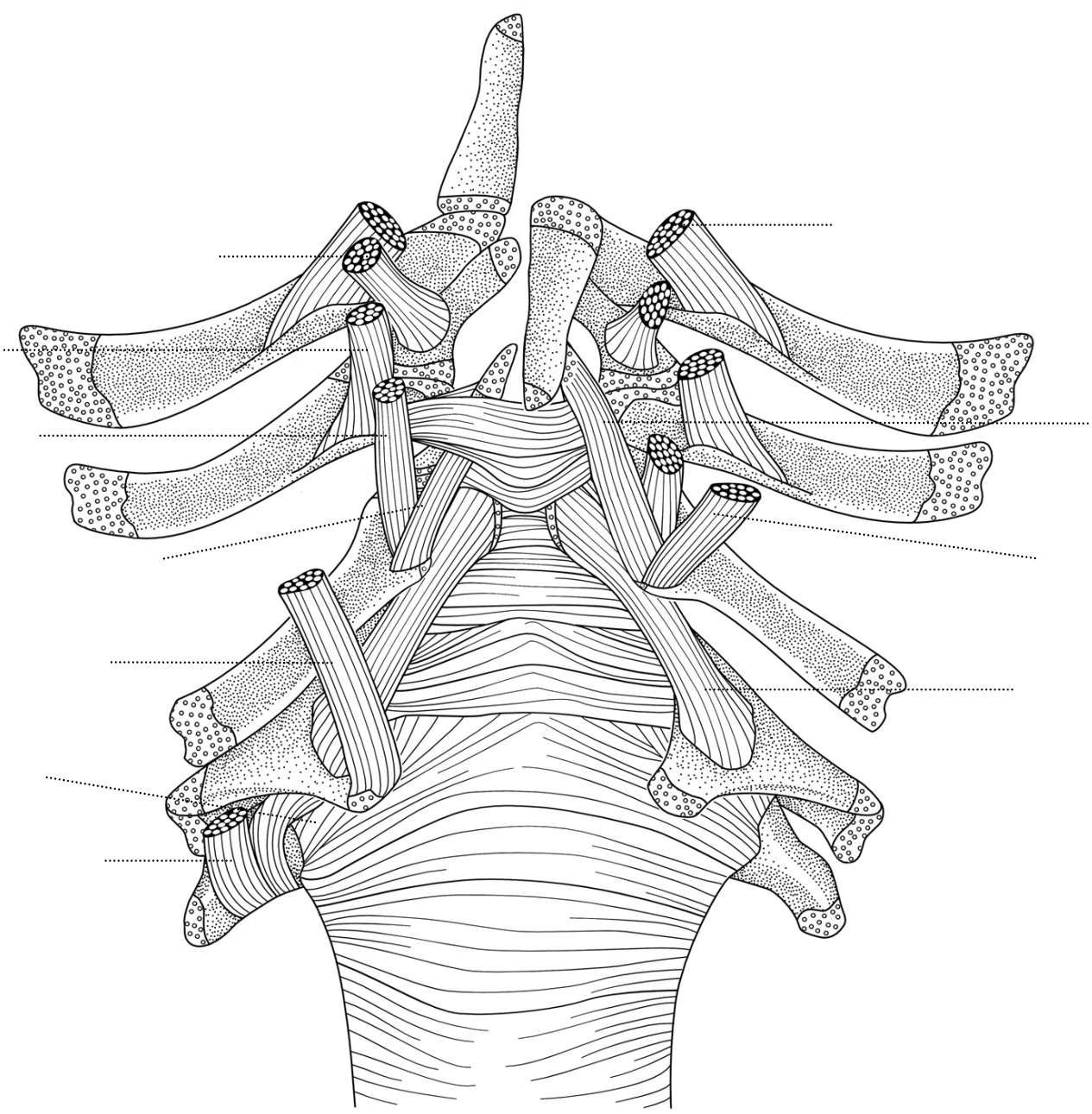

Figura 15. Gasteropelecus sternicla MZUSP 38238, 41,1 mm CP. Vista dorsal. 


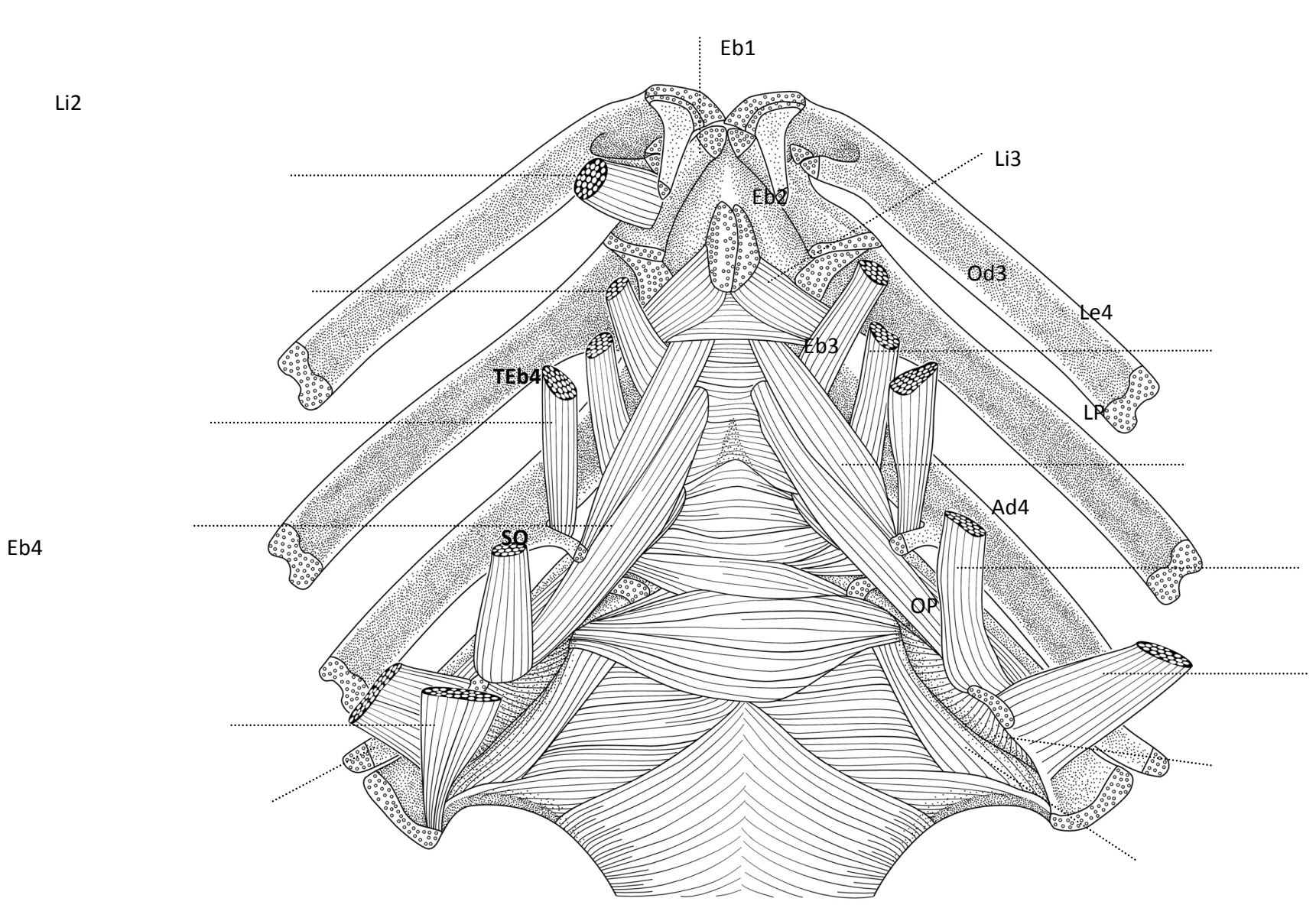

Figura 16. Hemiodus argenteus MZUSP 95721, 108,9 mm CP. Vista dorsal. 
$\mathrm{Pb} 1$

Li1

Le2

Eb2

Eb3

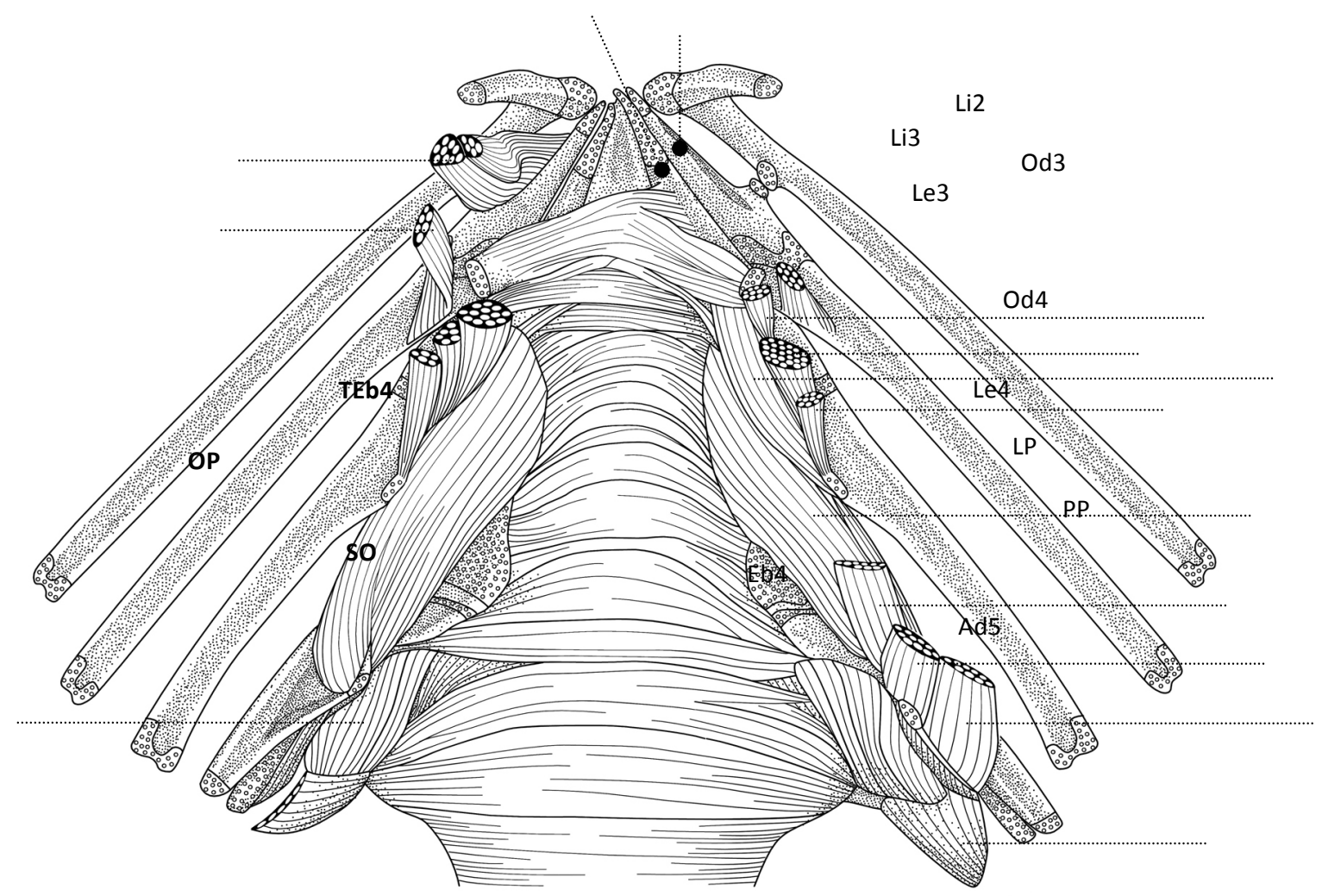

Figura 17. Hoplias malabaricus MZUSP 97913, 164,5 mm CP. Vista dorsal. 


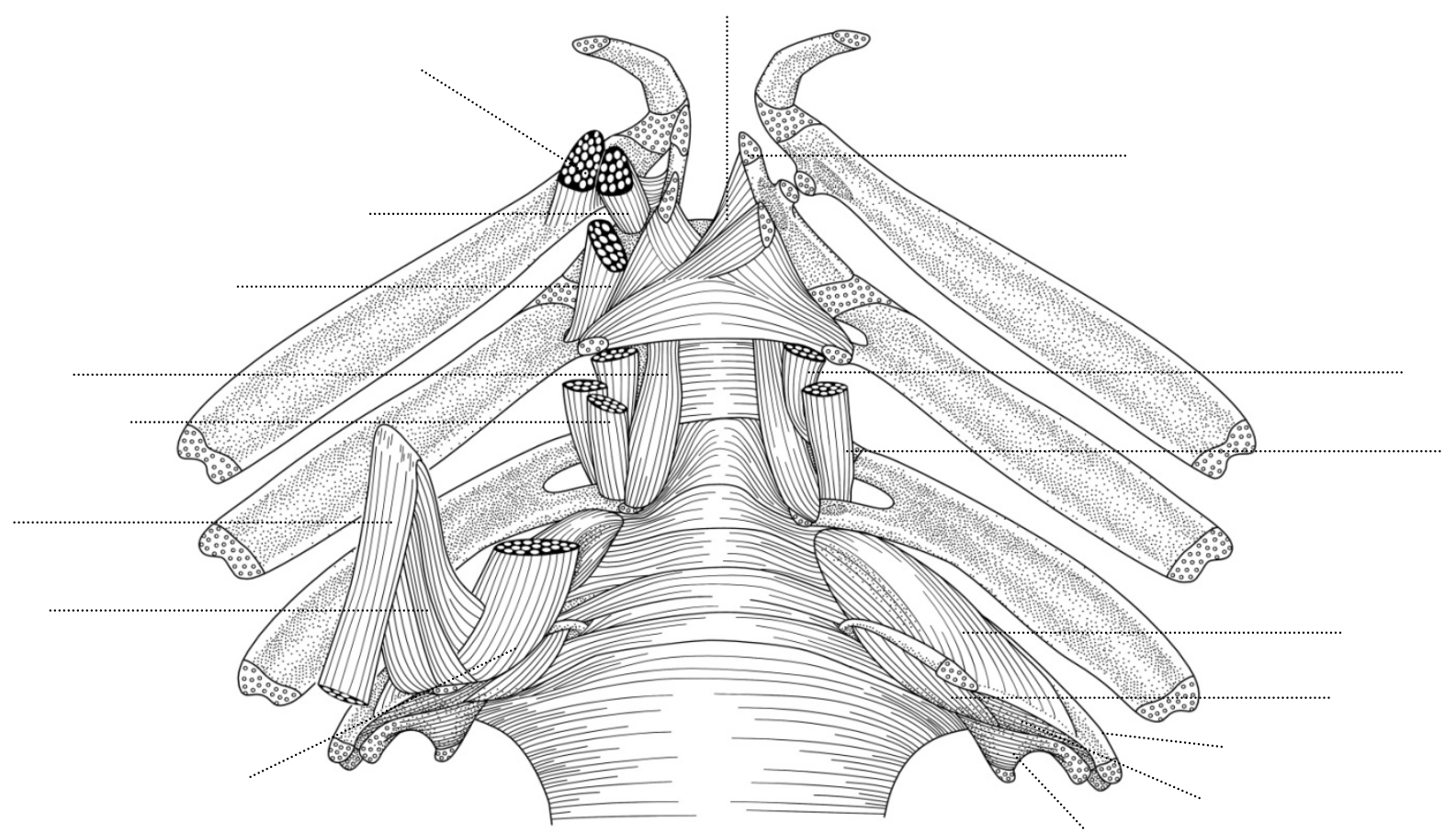

Figura 18. Hydrolycus tatauaia MZUSP 99870, 129,1 mm CP. Vista dorsal. 


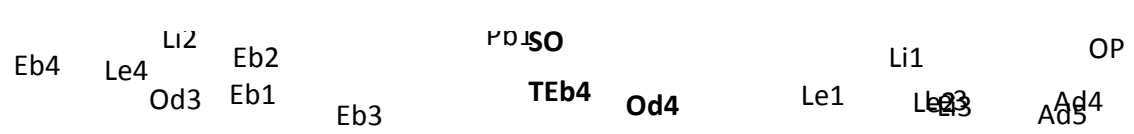

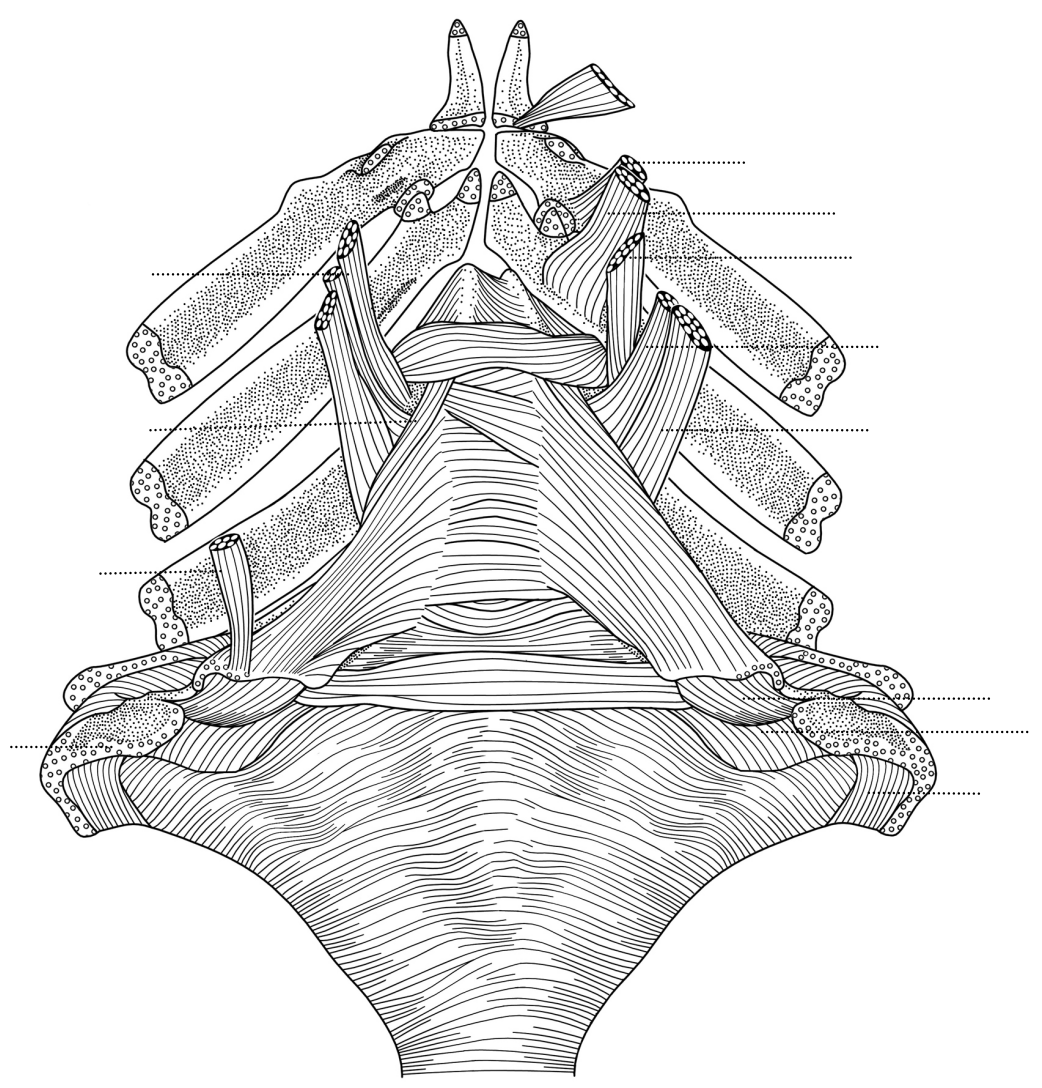

Figura 19. Nannostomus trifasciatus MZUSP 29296, 25,5 mm CP. Vista dorsal. 


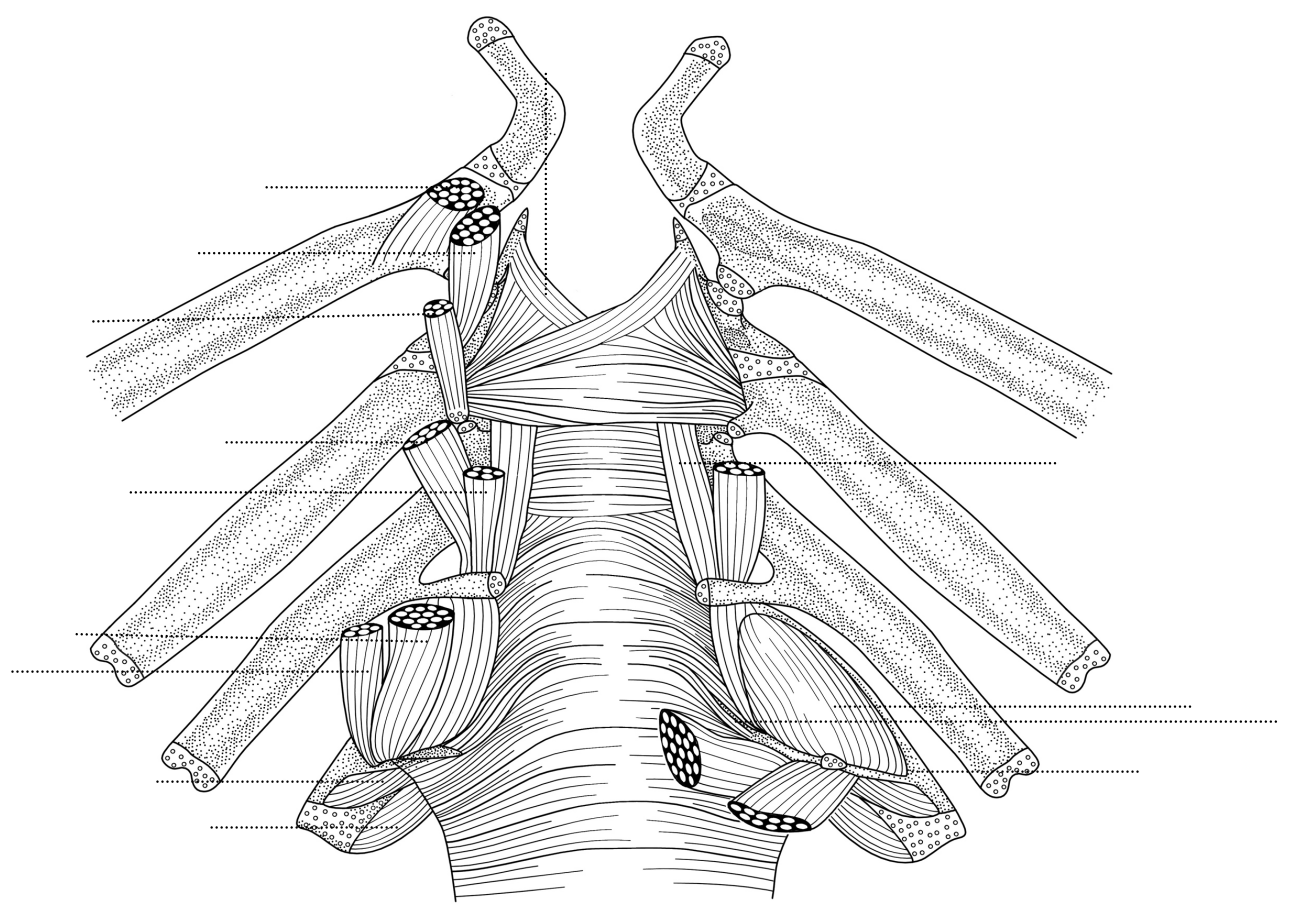

Figura 20. Rhaphiodon vulpinus MZUSP 15219, 126,7 mm CP. Vista dorsal. 
$\mathrm{Li} 2$

$\mathrm{Li3}$

LP

Ad4

Ad5

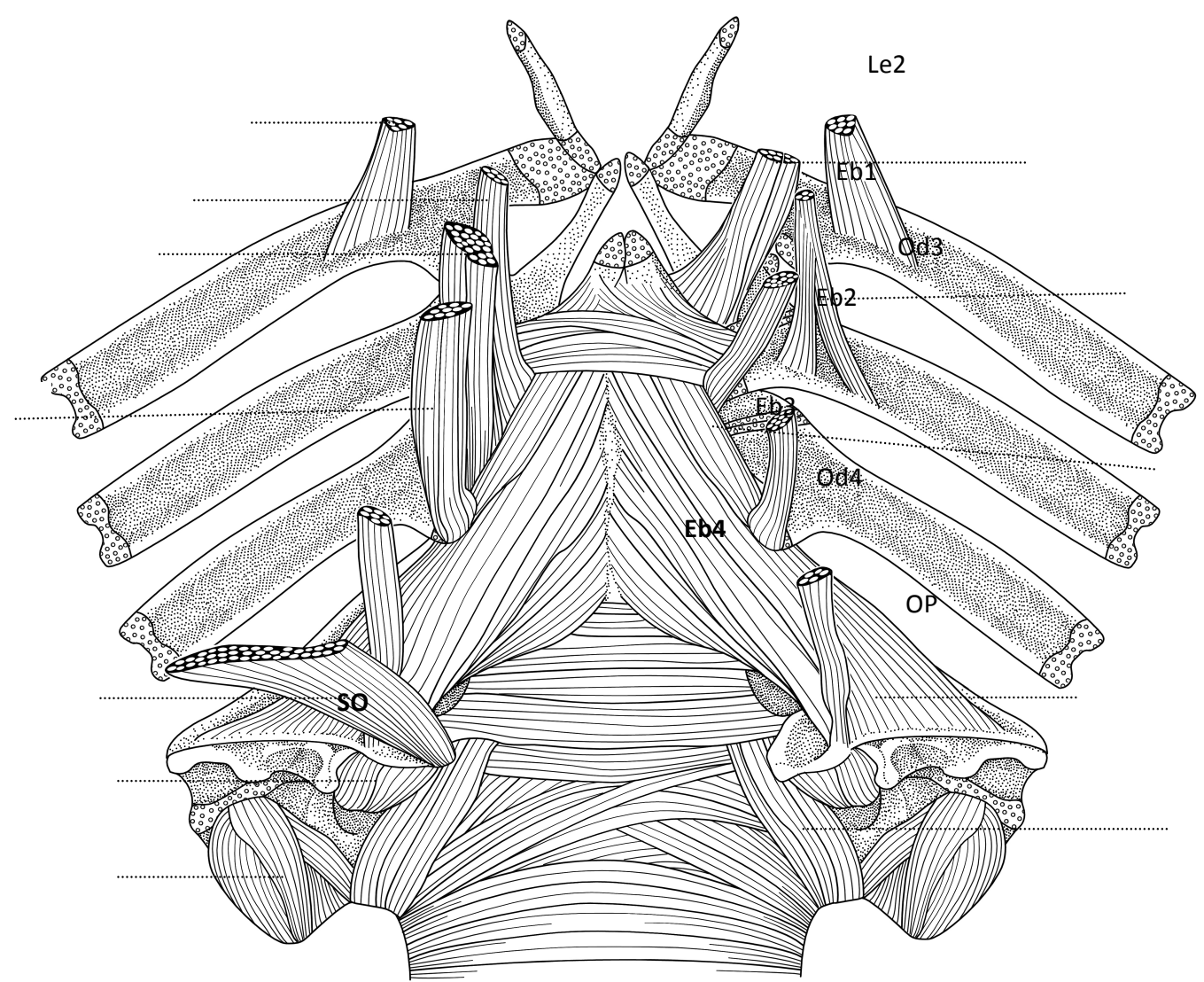

Figura 21. Leporinus octofasciatus MZUSP 73226, 243,3 mm CP. Vista dorsal. 
Le1

Li2

Le3

Od4

Le4

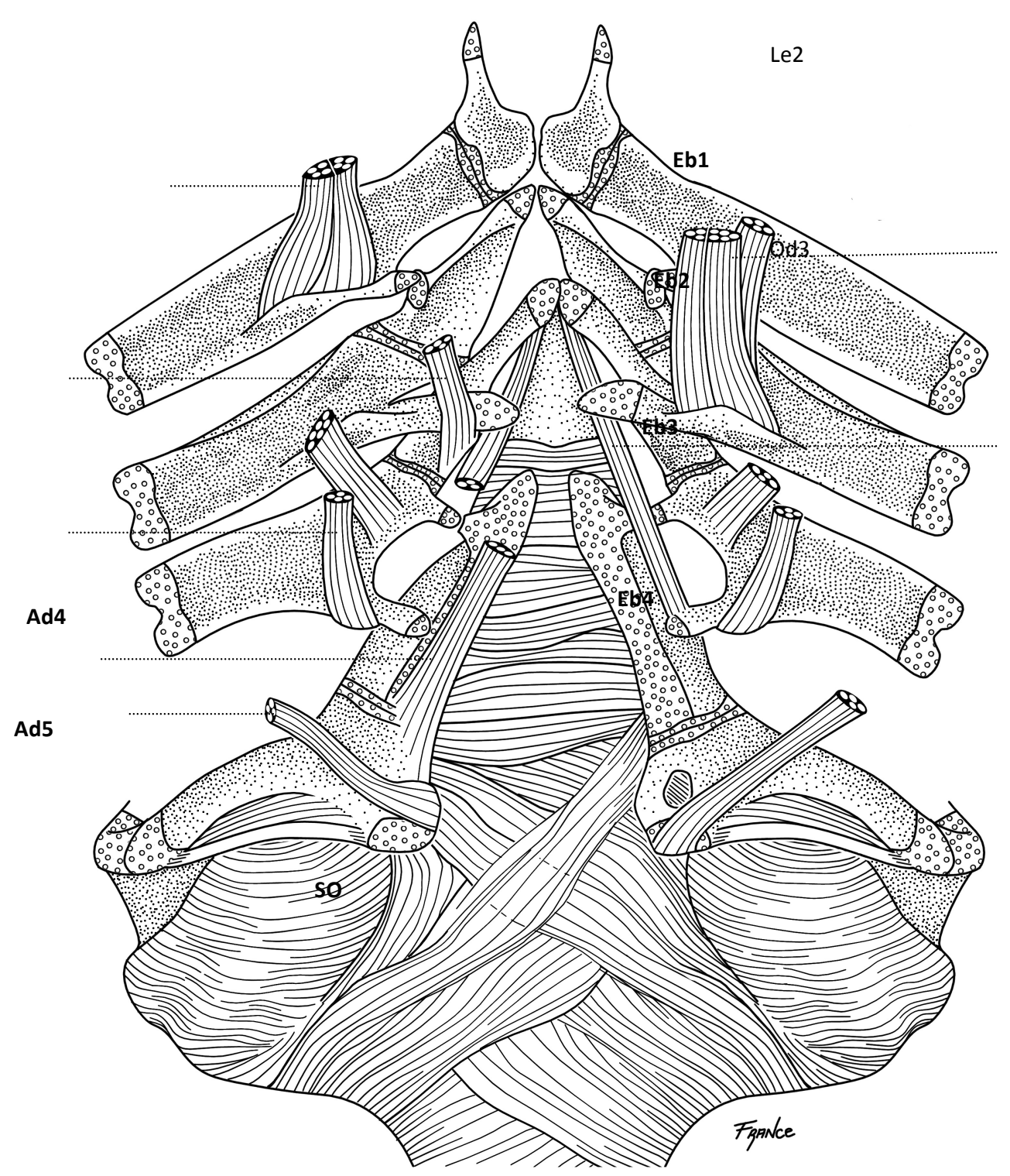

Figura 22. Paradon nasus MZUSP 19345, 105,4 mm CP. Vista dorsal. 


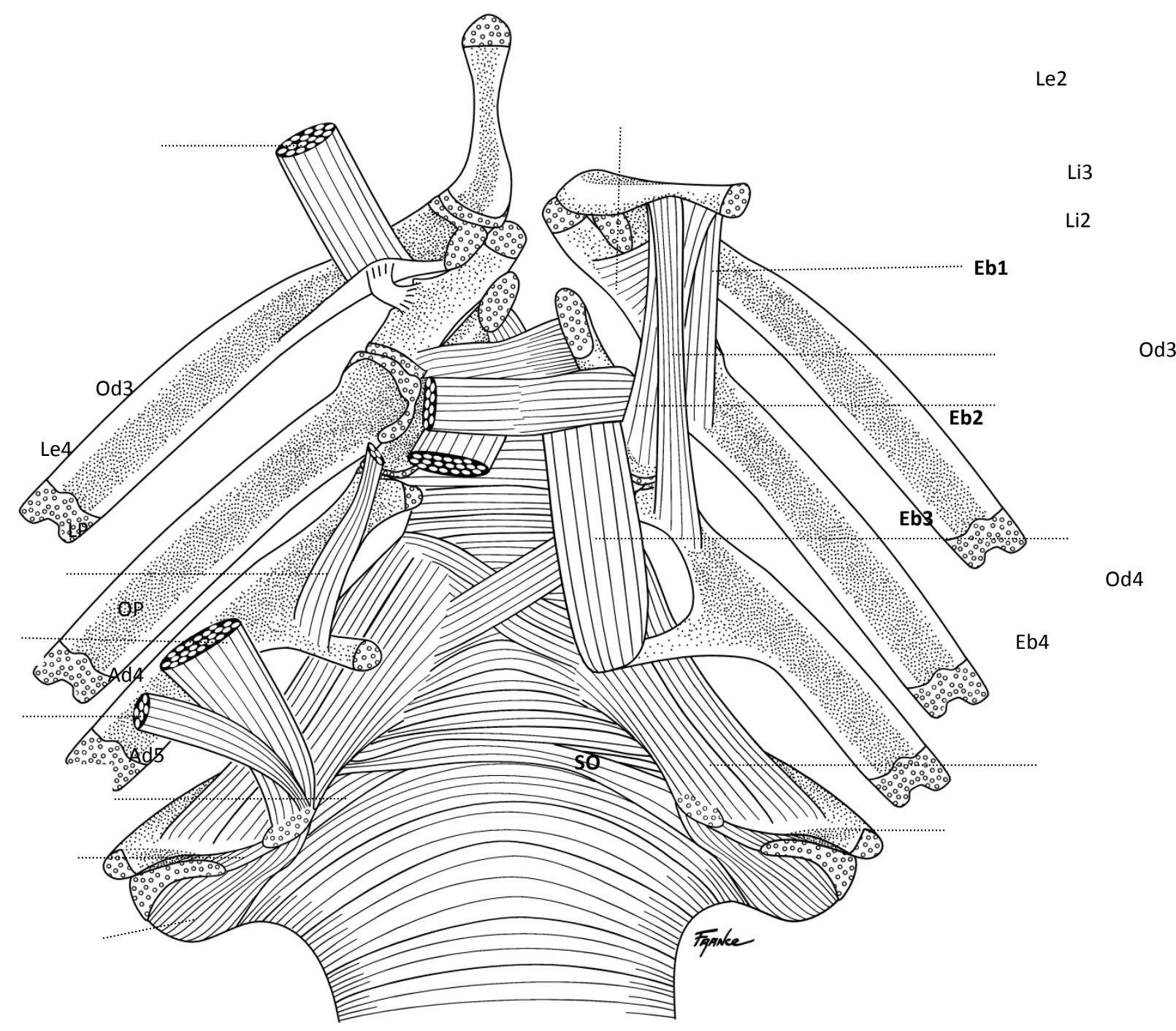

Figura 23. Charax pauciradiatus, MZUSP 20291, 91,5 mm CP. Vista dorsal. 


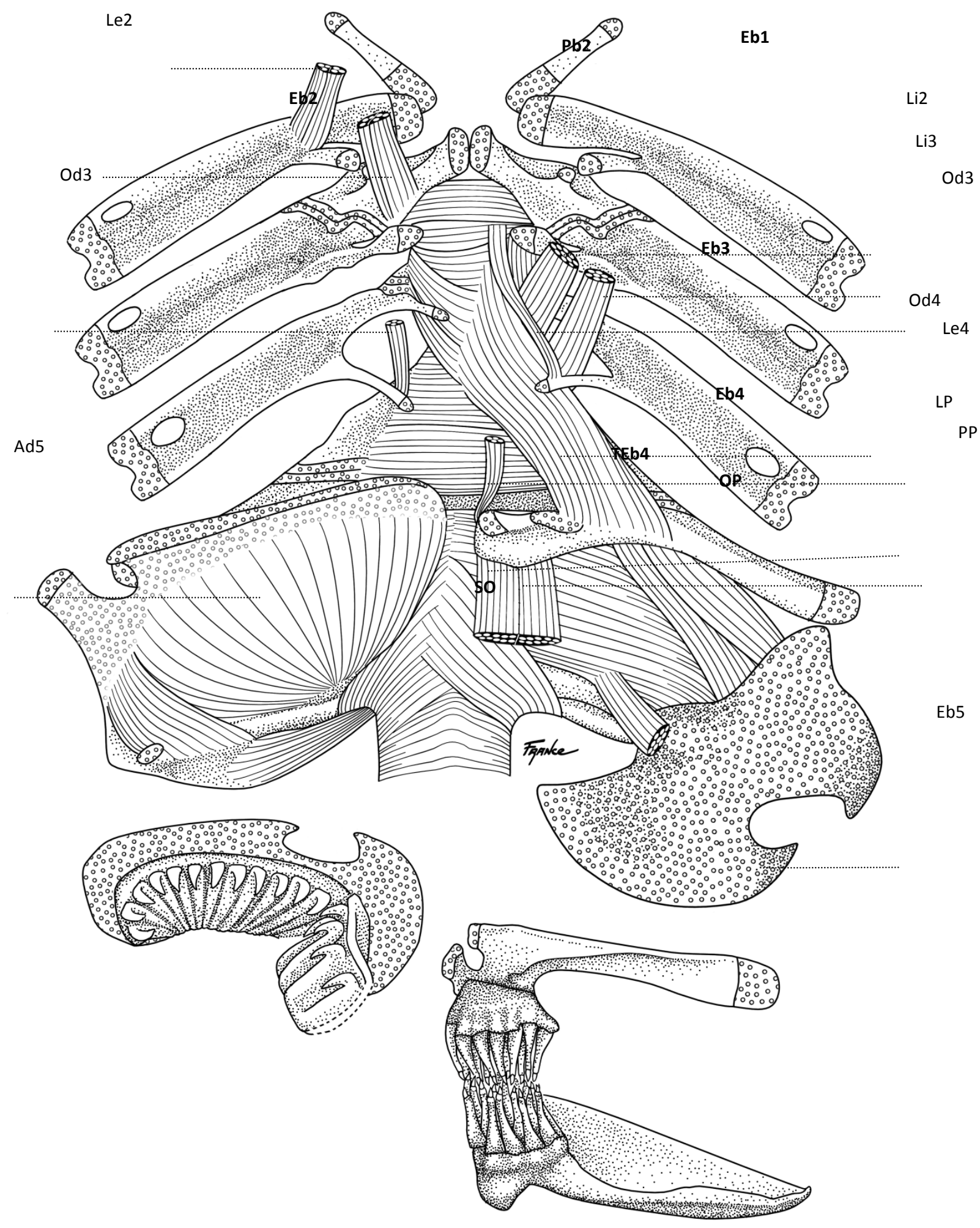

Figura 24. Chilodus puntactus MZUSP 89116, 49,7 mm CP. Vista dorsal. 


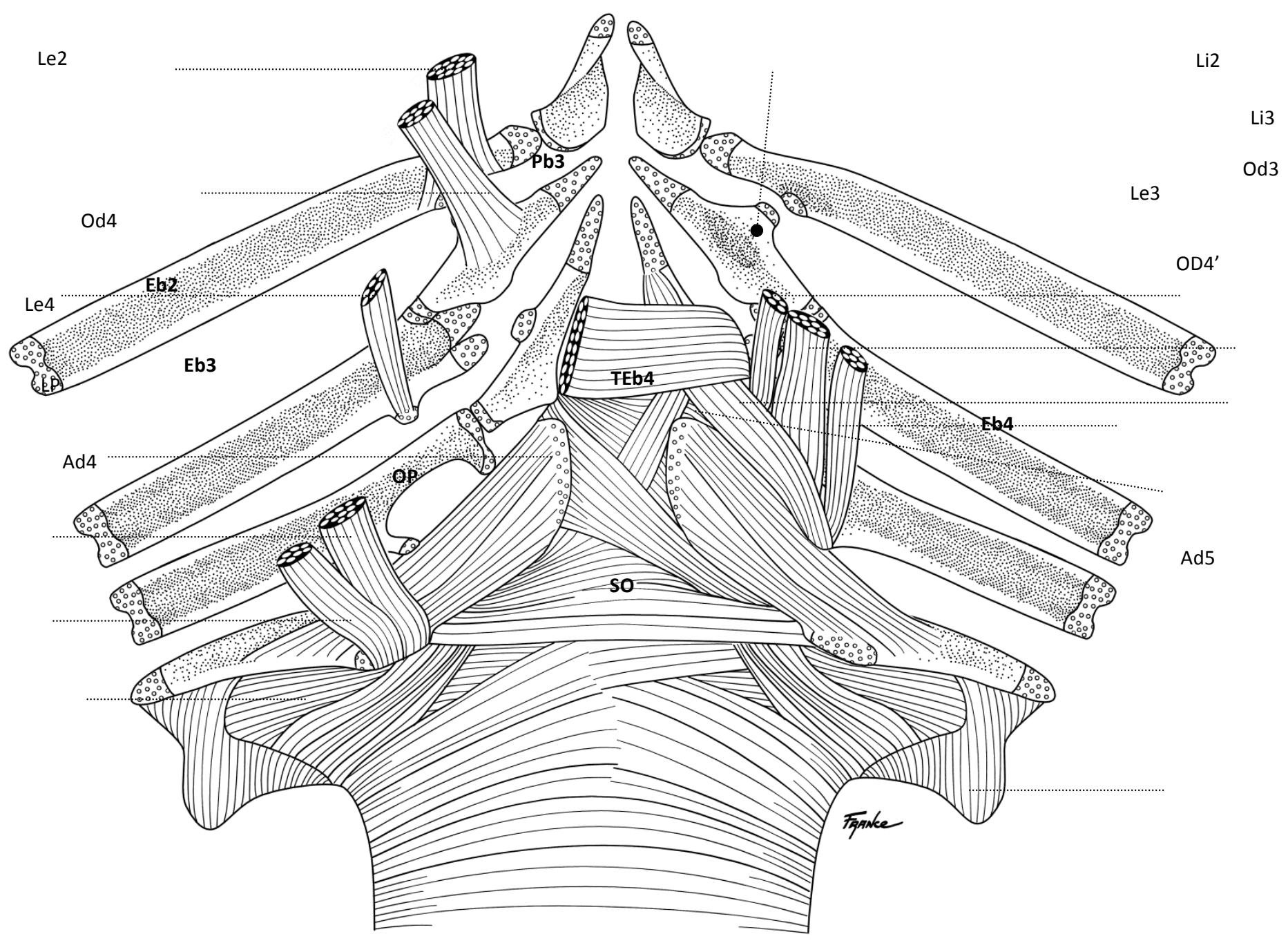

Figura 25. Hemigrammus coeruleus MZUSP 75437, 41,9 mm CP. Vista dorsal. 
Le1

$\mathrm{Pb} 2$

$$
\text { Le2 }
$$

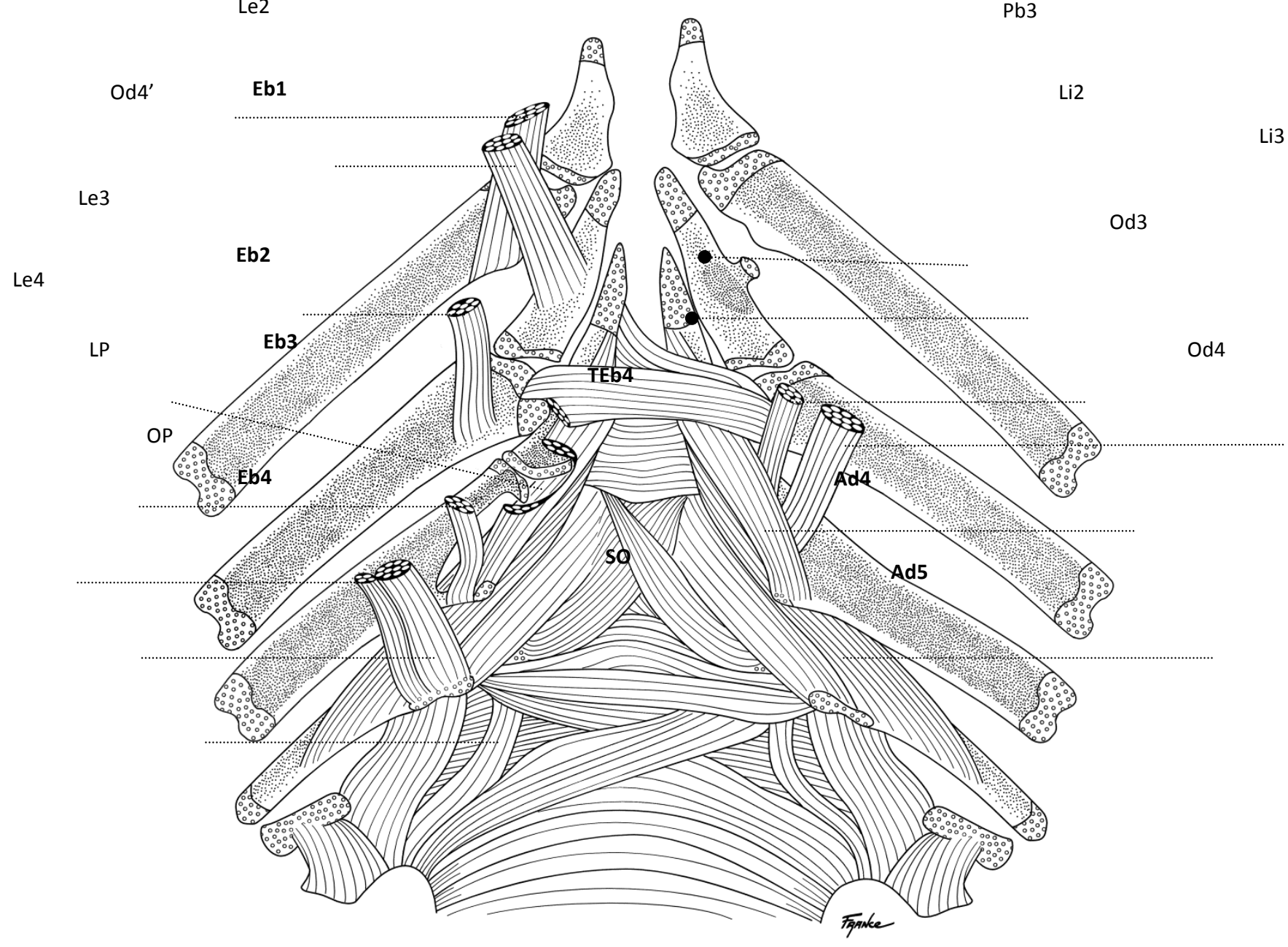

Figura 26. Aphyocharax dentatus MZUSP 4015, 46,1 mm CP. Vista dorsal. 
Le1

Li1

$\mathrm{Pb} 2$

Pb3

Le2

Eb1

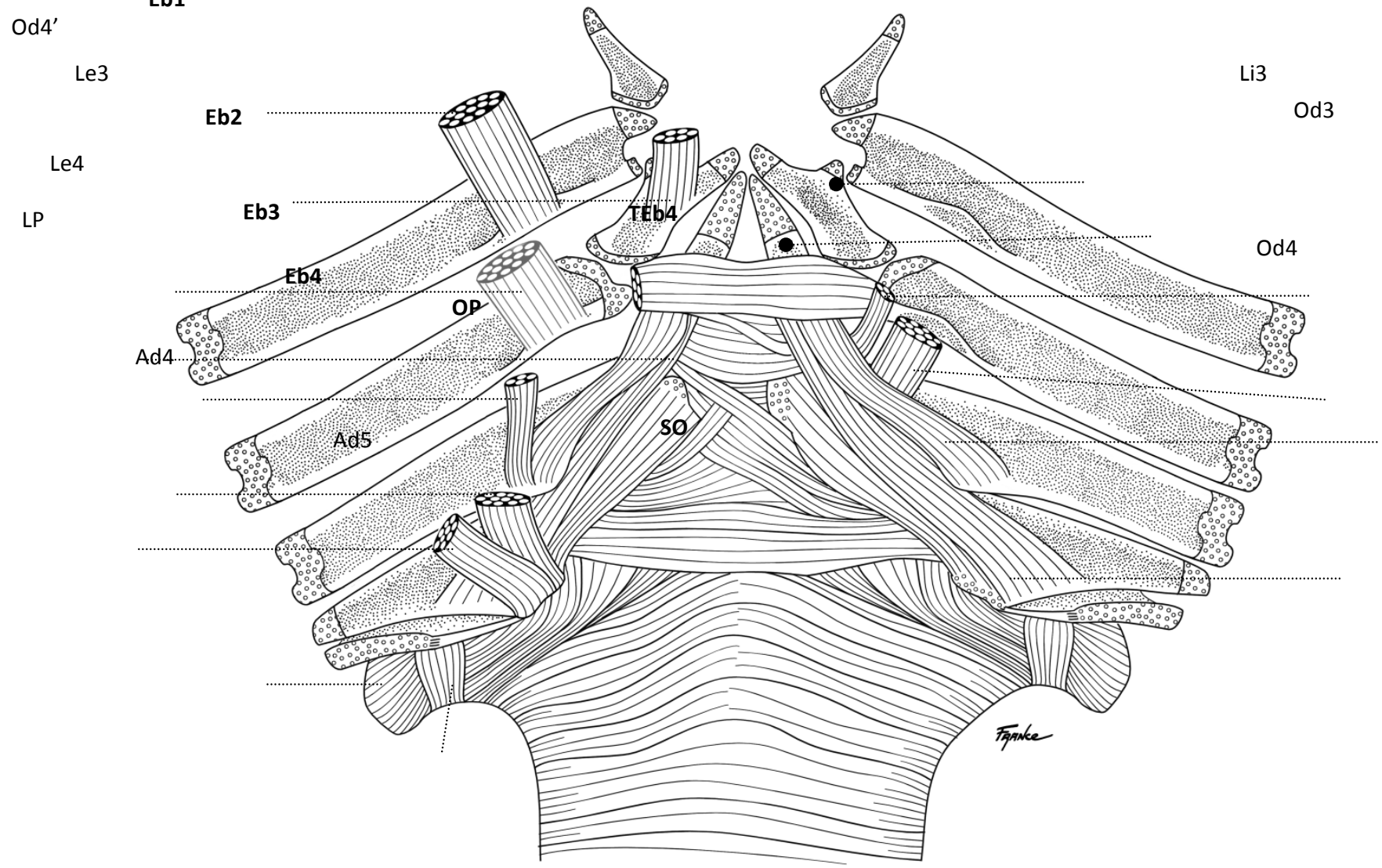

Figura 27. Bryconamericus turiuba MZUSP 79799, 56,5 mm CP. Vista dorsal. 


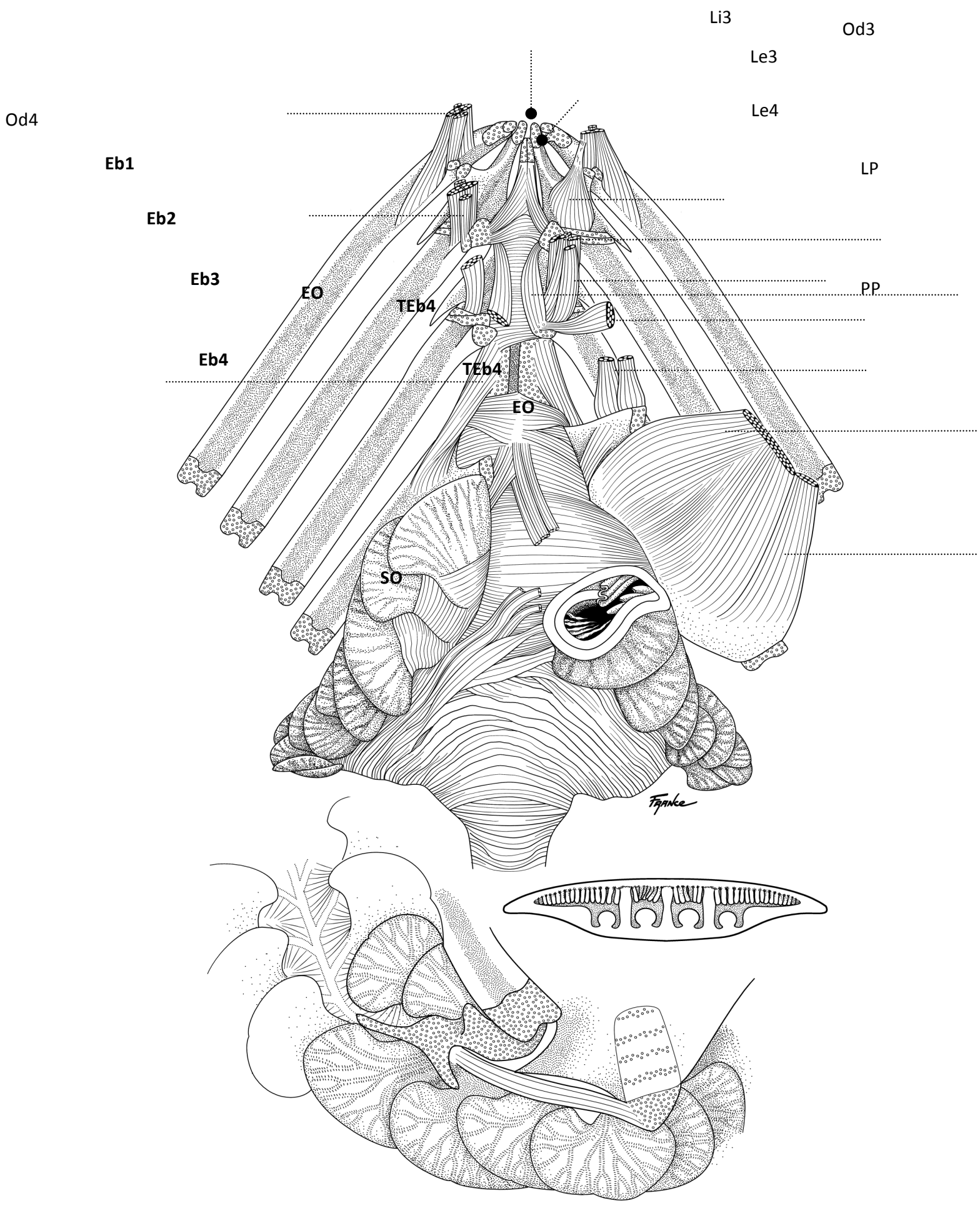

Figura 28. Citharinus latus MZUSP 84480,117,6 mm CP. Vista dorsal. 


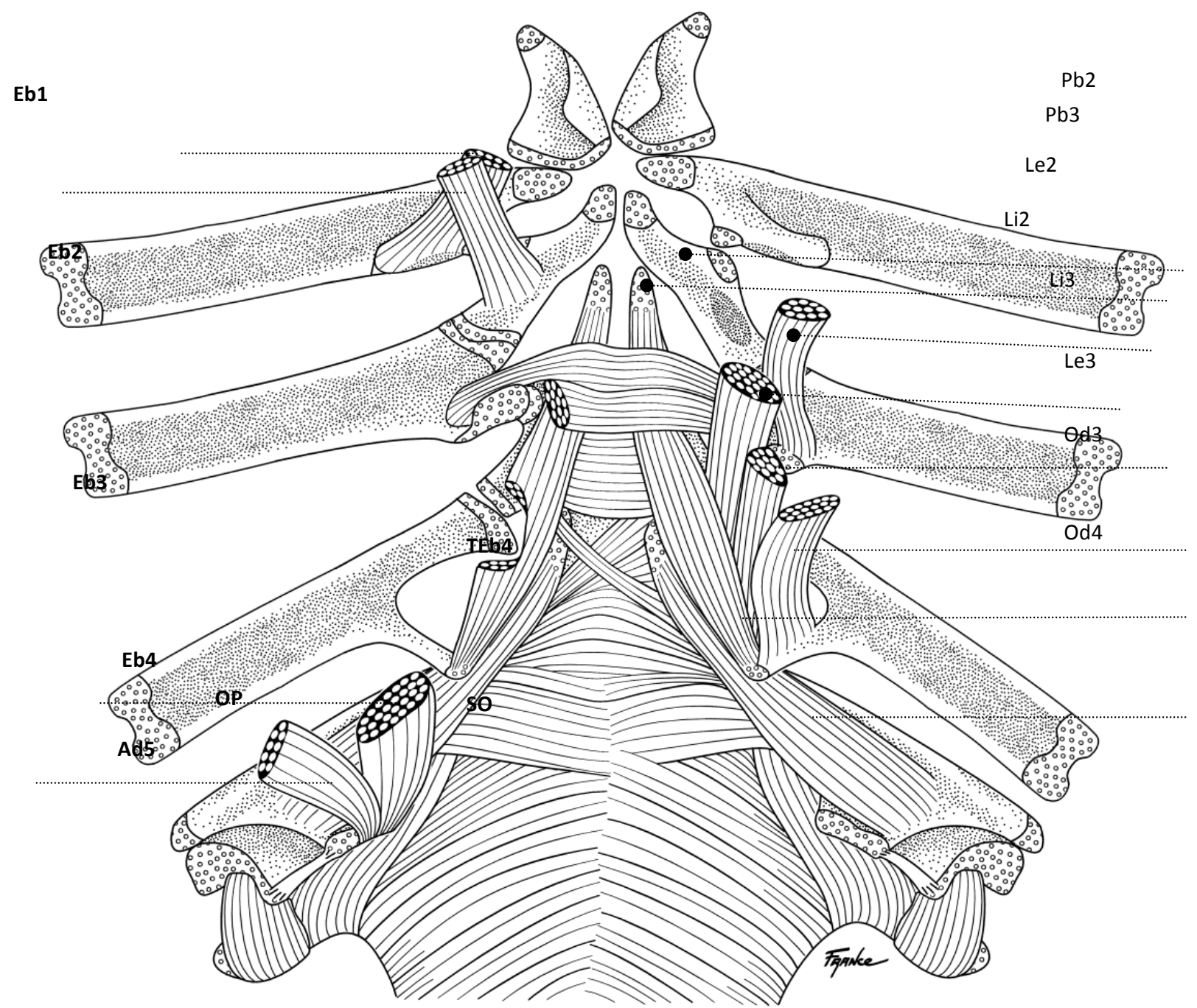

Figura 29. Tetragonopterus argenteus MZUSP 27756,97,9 mm CP. Vista dorsal. 


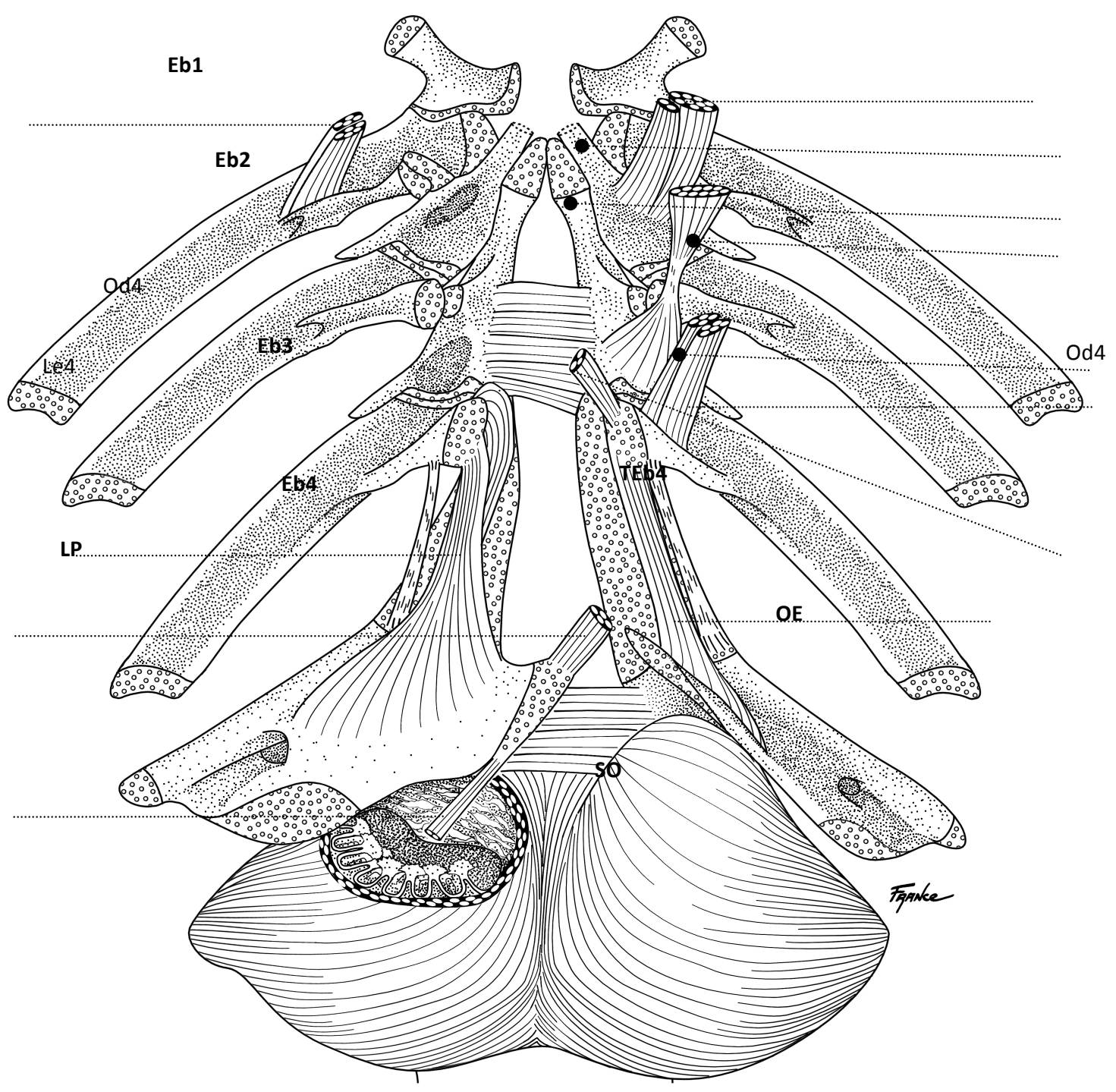

Figura 30. Semaprochilodus taeniurus MZUSP 35767, 143,6 mm CP.Vista dorsal. 


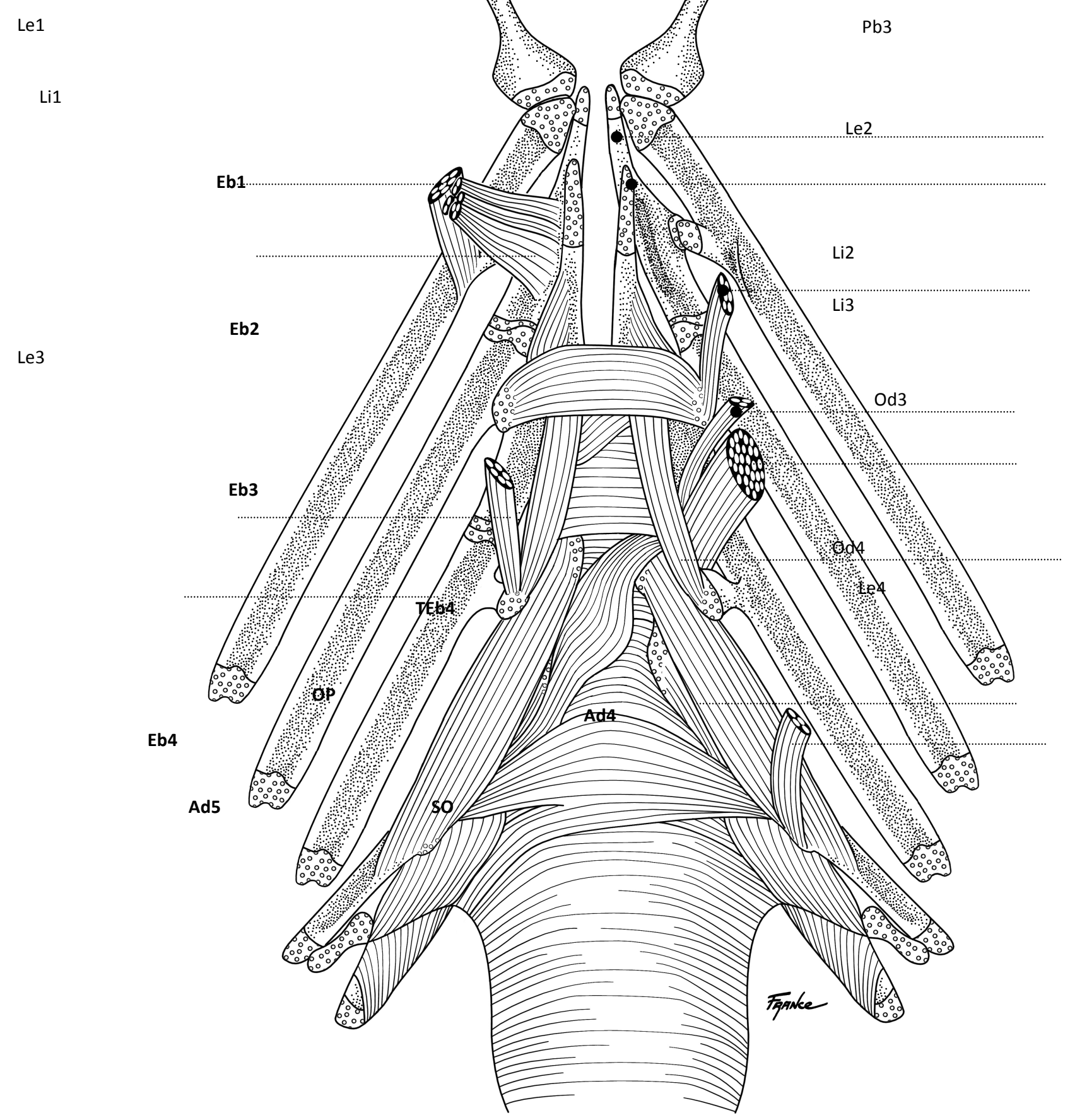

Figura 31. Hepsetus odoe, SAIAB 72802, 154,1 mm CP. Vista dorsal. 
$\mathrm{Pb} 2$

$\mathrm{Pb} 3$

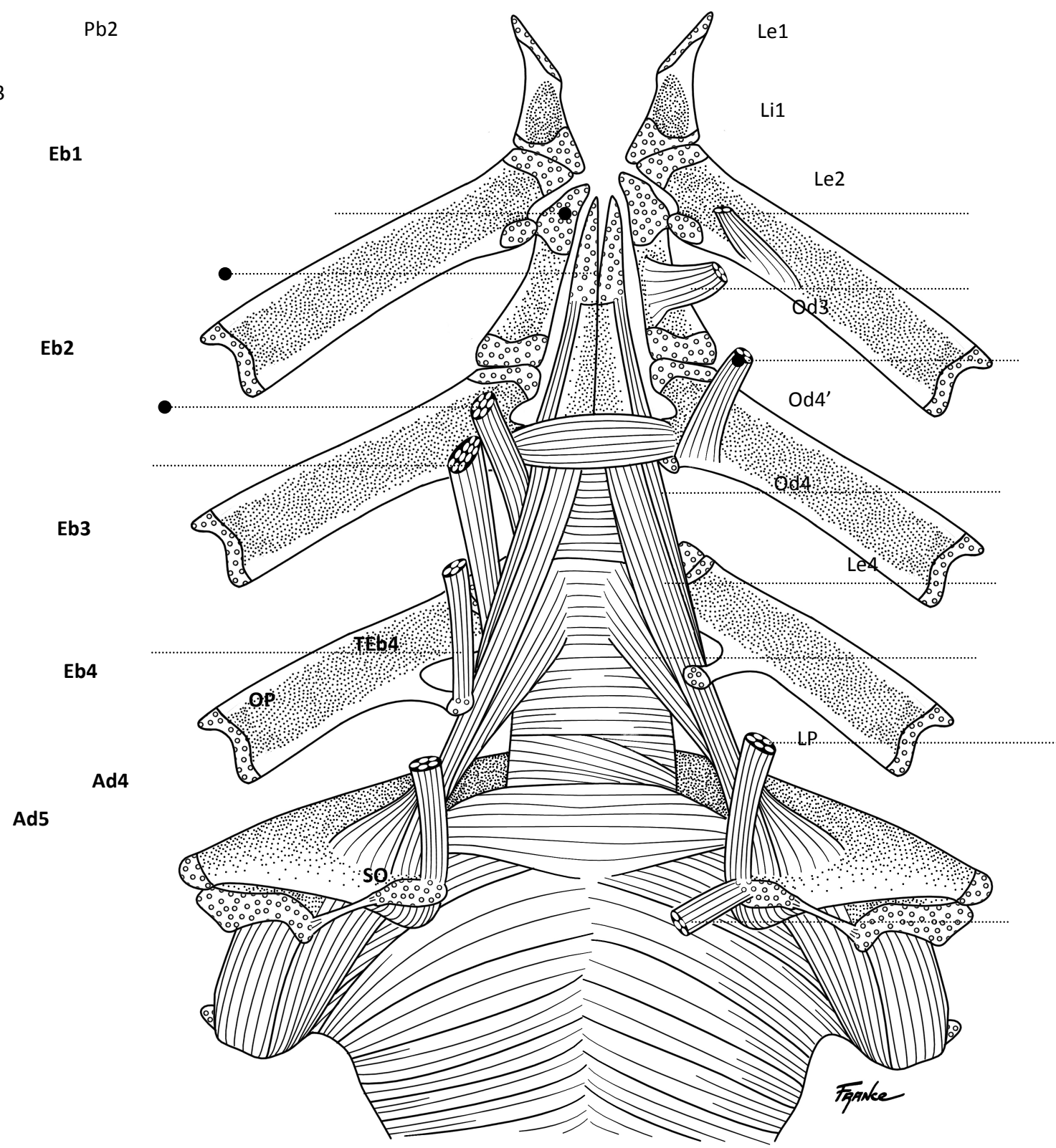

Figura 32. Distichodus sp SAIAB 78008, 64,3 mm CP. Vista dorsal. 

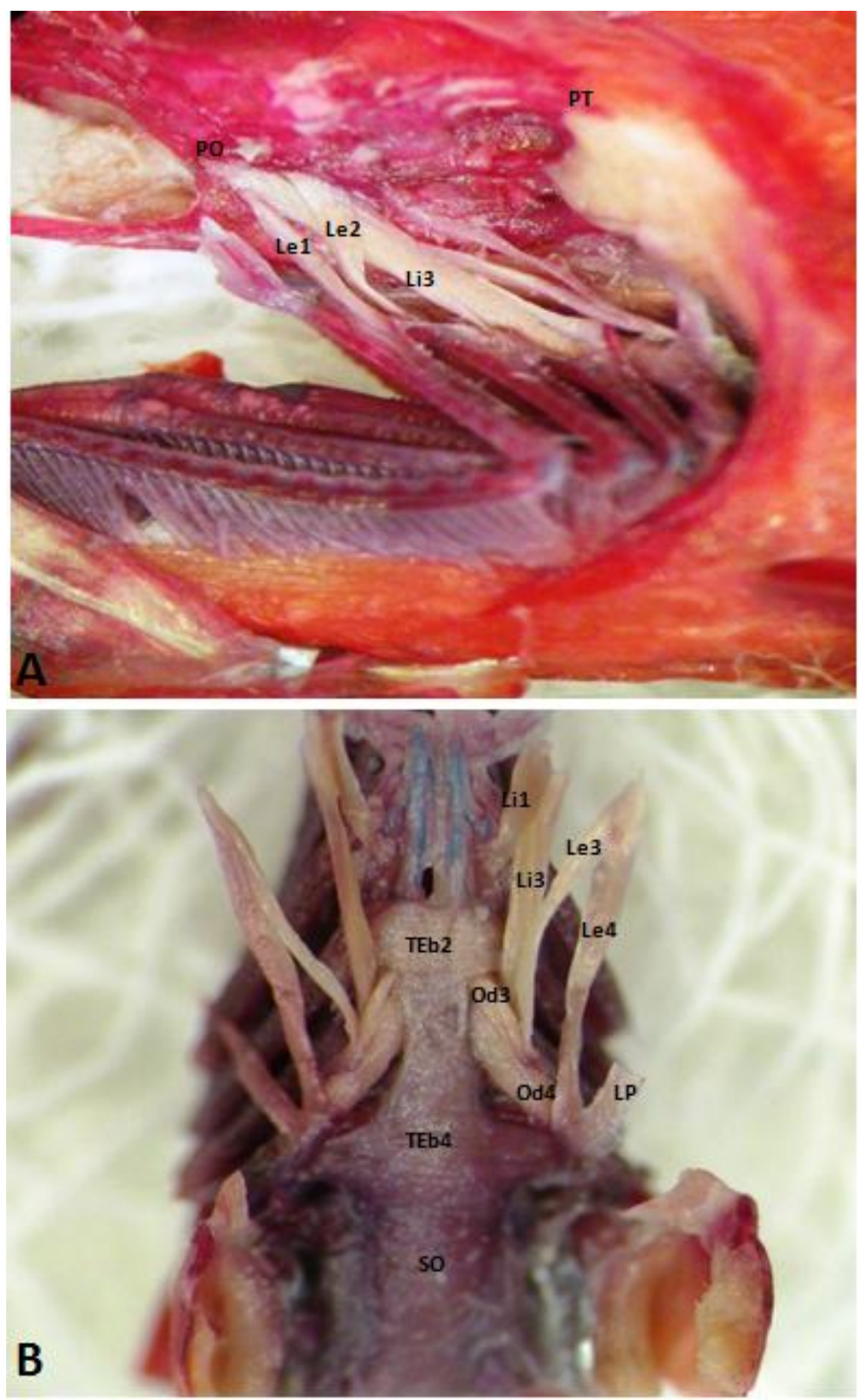

Fig.33. Acestrorhynchus nasutus (Não catalogado CP: 85,1 mm). A: vista lateral esquerda. B: vista dorsal. 


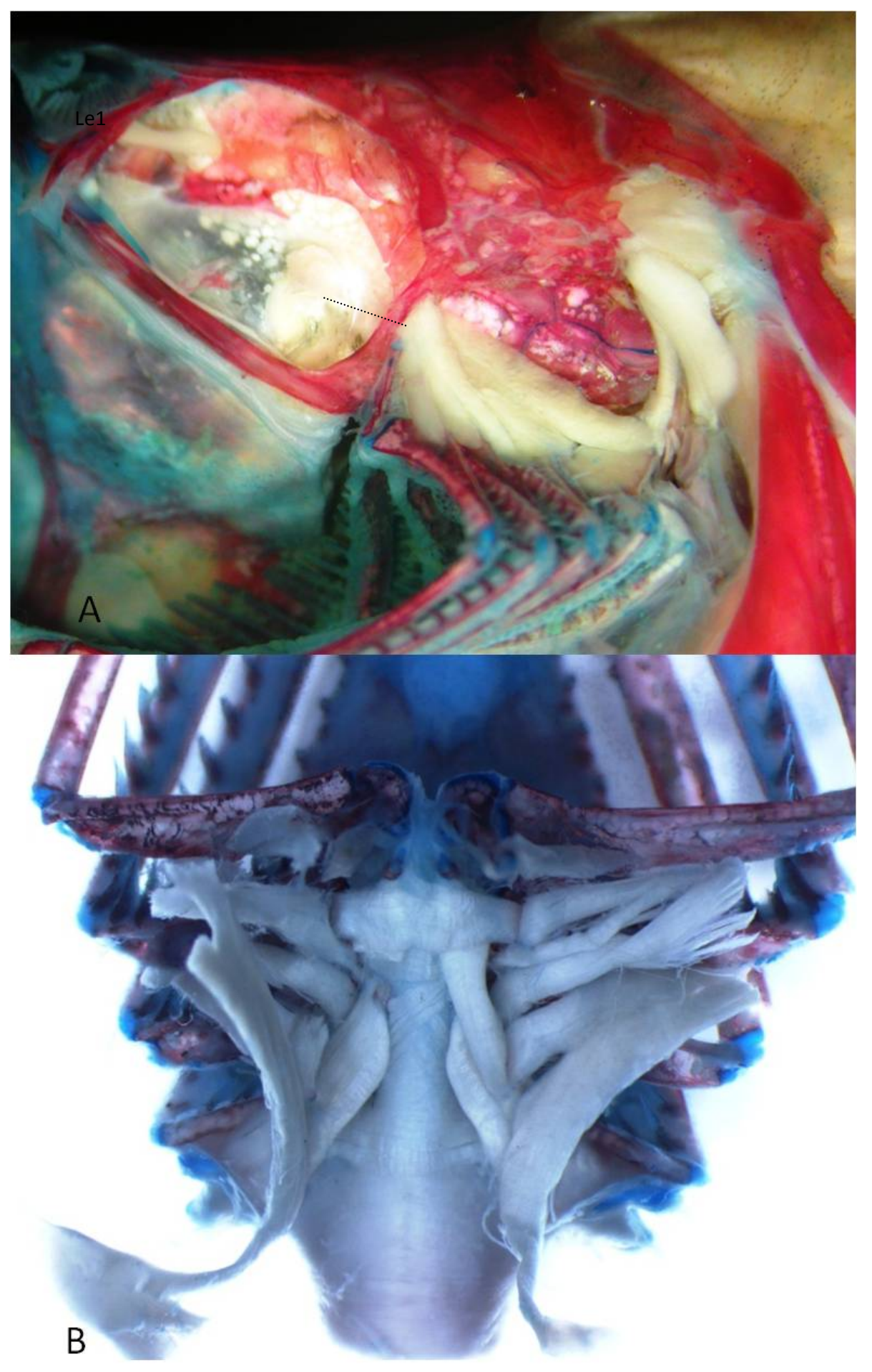

Fig.34. Gilbertolus alatus (MCNG 56104, 92,7 mm CP). A e B vistas lateral e dorsal. 

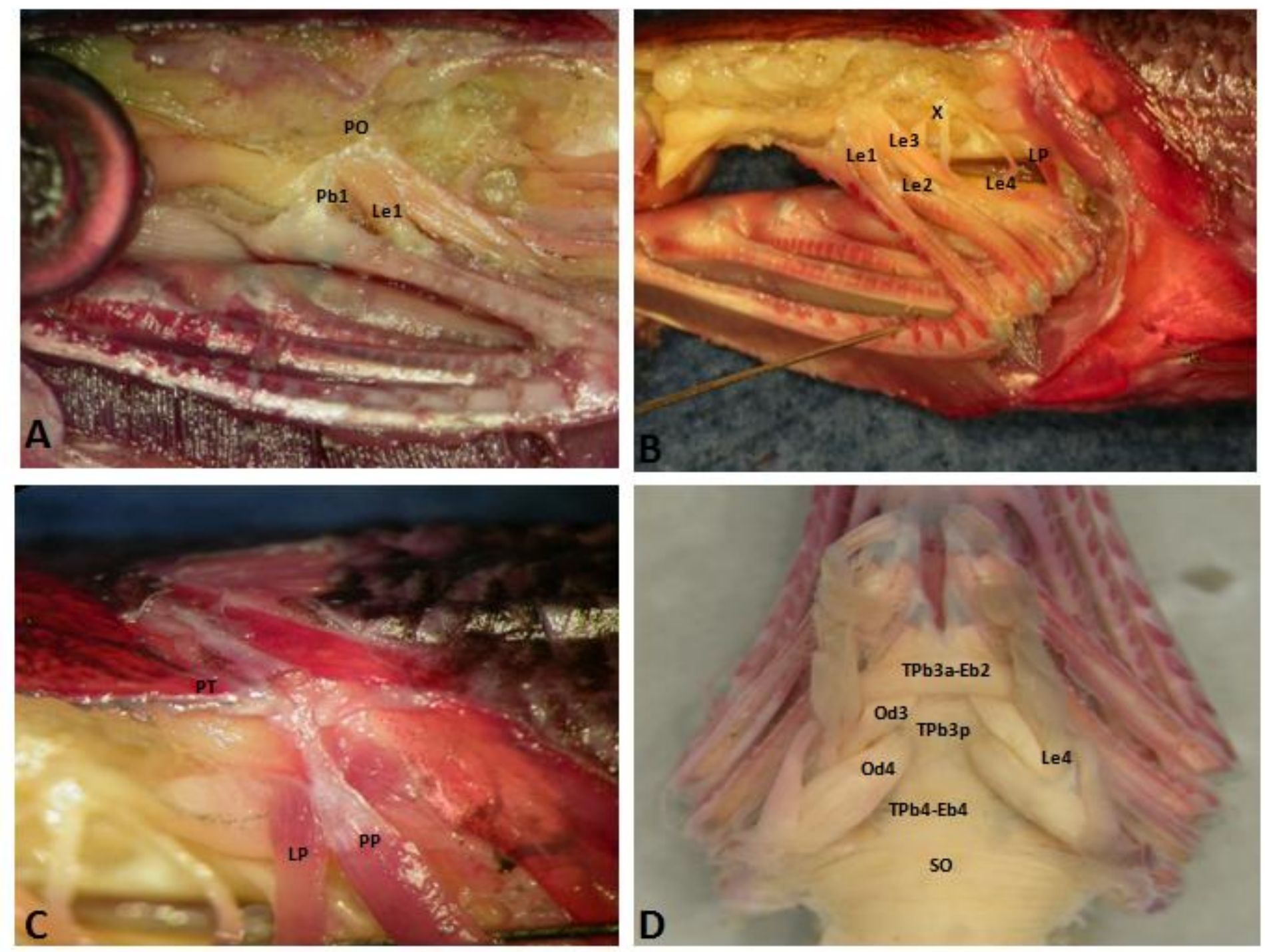

Fig.35. Boulengerella cuvieri (MZUSP 101733 248,1 mm CP). A, B e C: vista lateral esquerda. D: vista dorsal. 

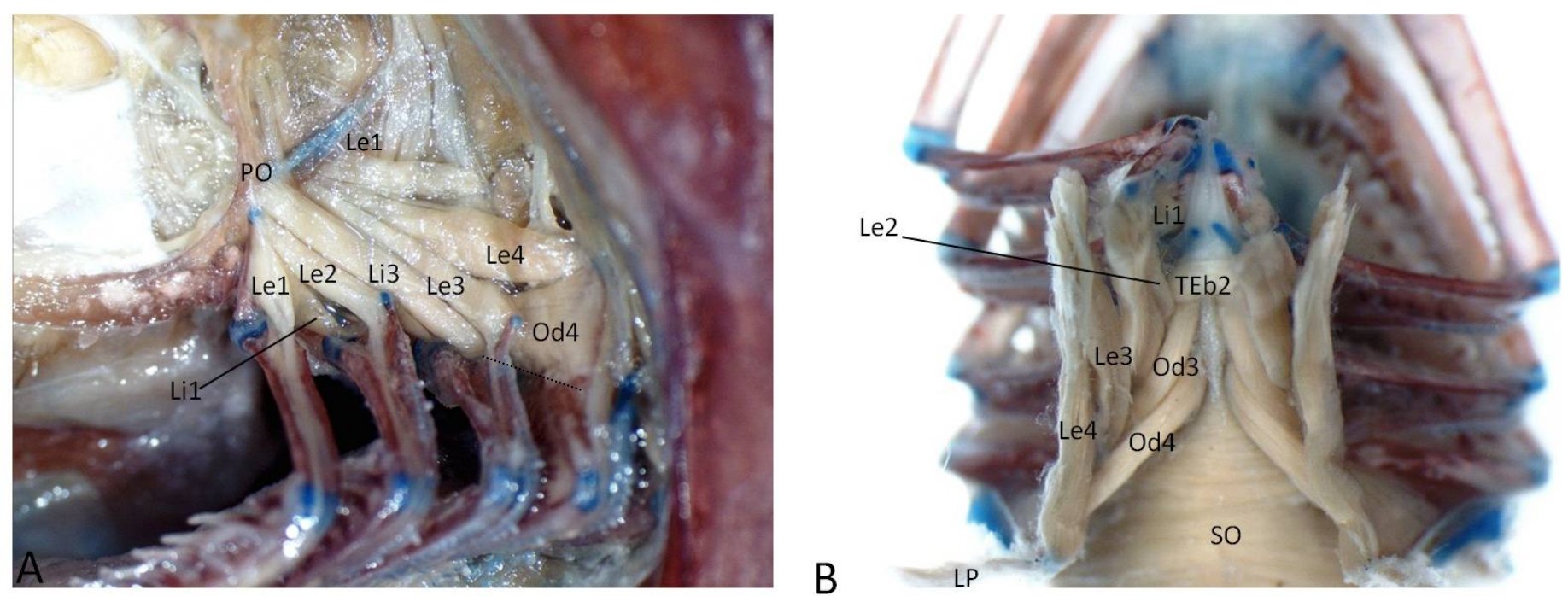

Fig.36. Myleus setiger (MZUSP 15809 128,1 mm CP). Vista lateral dos músculos dorsais dos arcos branquiais (A). Vista dorsal dos músculos dorsais dos arcos branquiais (B). 

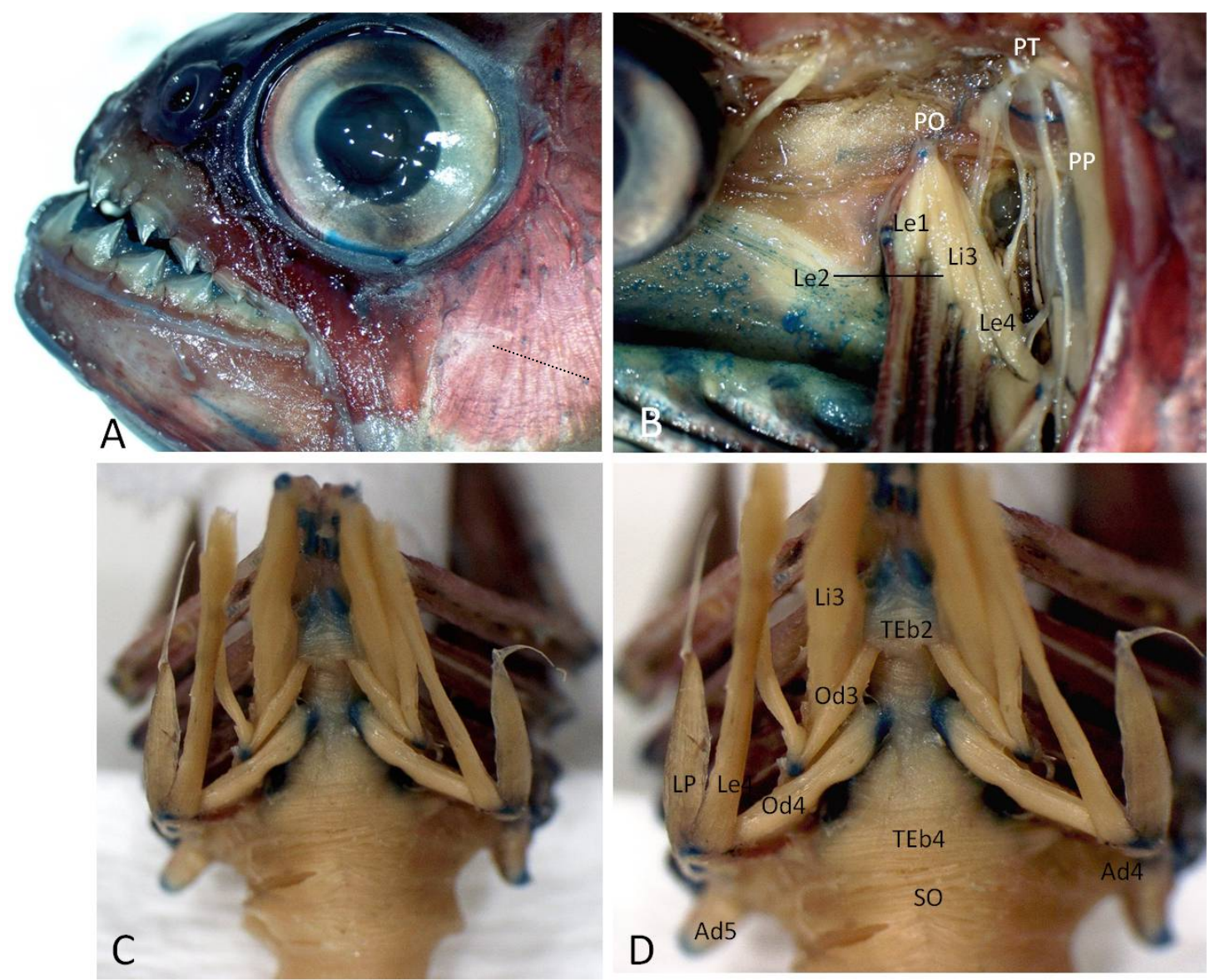

Fig.37. Serrasalmus brandtii (MZUSP 57550 92,3 mm CP). Vista lateral dos músculos dorsais dos ar branquiais (A e B). Vista dorsal dos músculos dorsais dos arcos branquiais (C e D). 

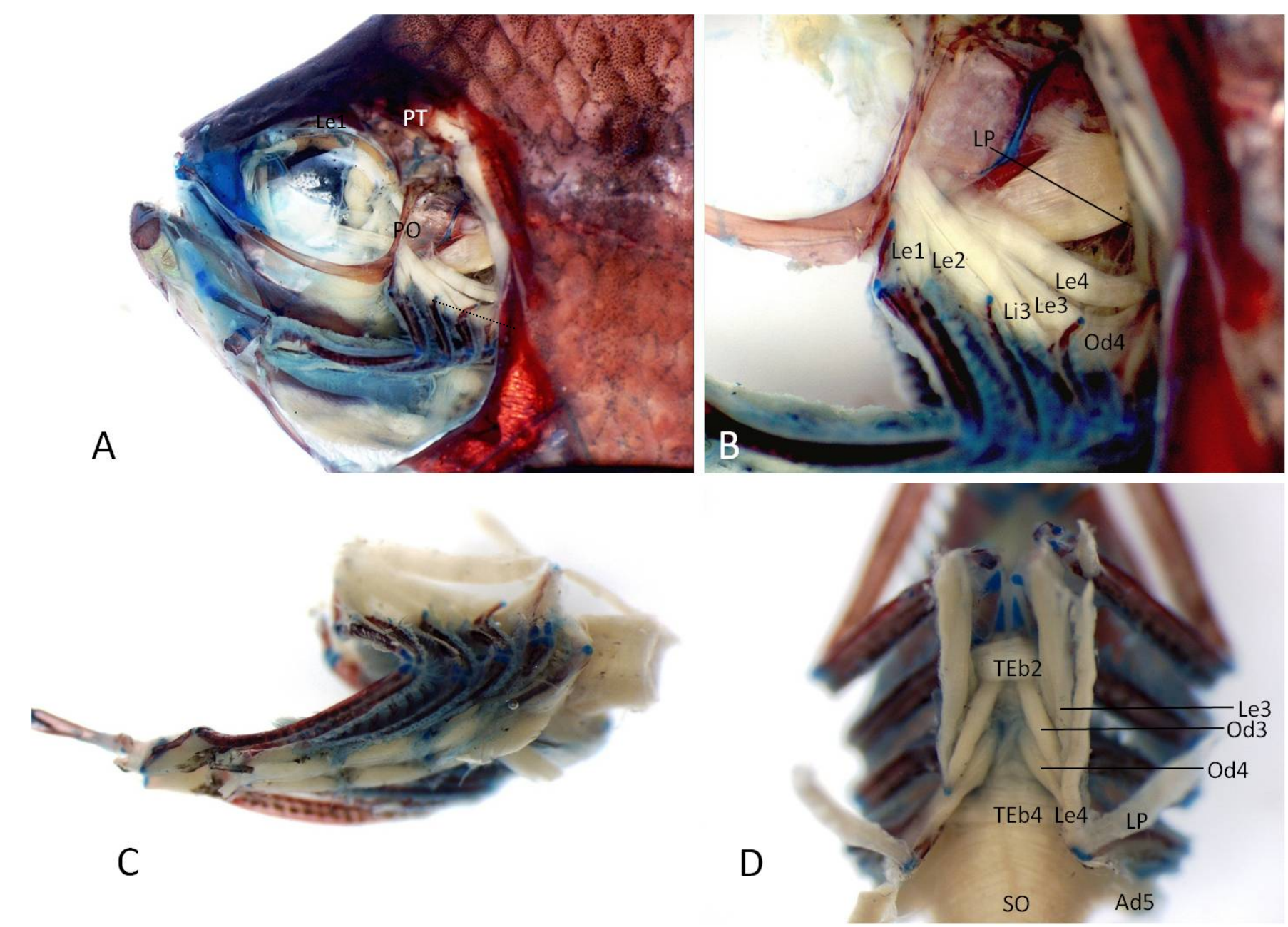

Fig.38. Poptella paraguayensis (MZUSP 59914 56,1 mm CP). Vista lateral dos músculos dorsais dos arcos branquiais (A e B). Vista dorsal dos músculos dorsais dos arcos branquiais $(\mathrm{C}$ e $\mathrm{D})$. 

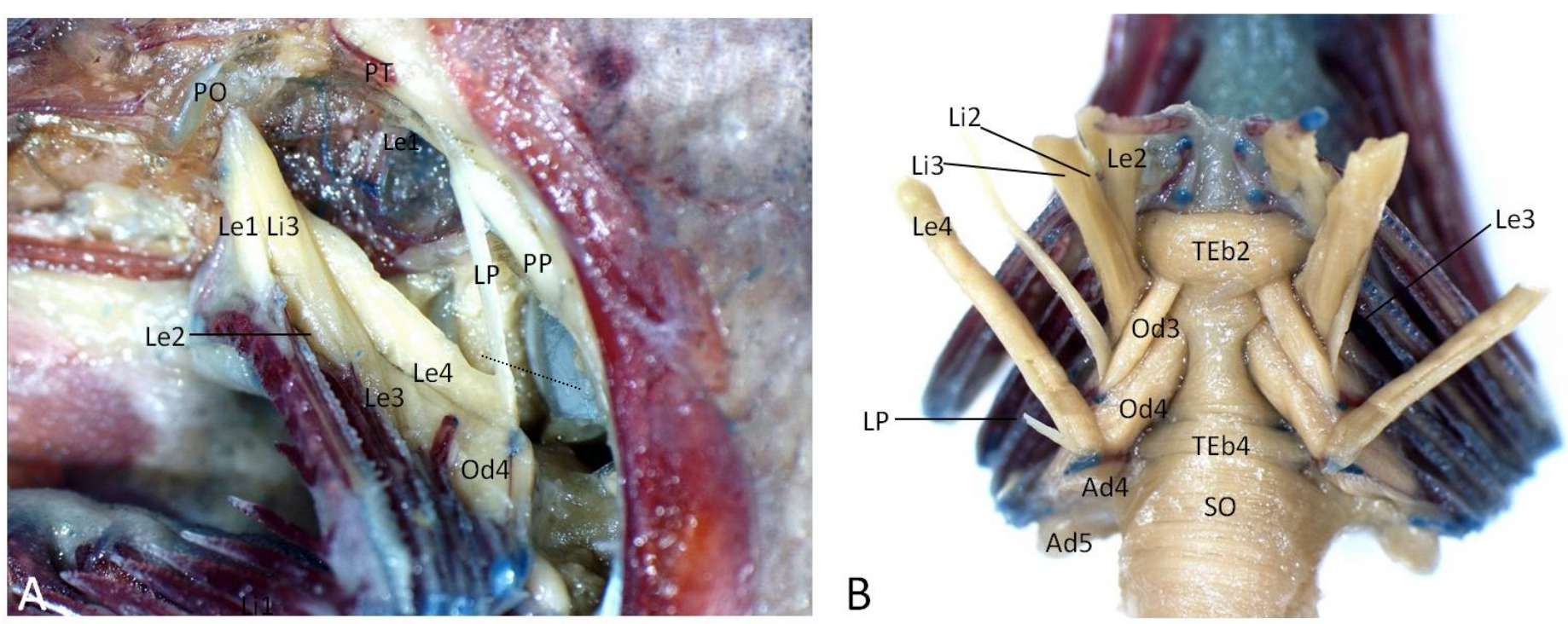

Fig.39. Cynopotamus kincaidi (MZUSP 19987 105,7 mm CP). Vista lateral dos músculos dorsais dos arcos branquiais (A). Vista dorsal dos músculos dorsais dos arcos branquiais (B). 

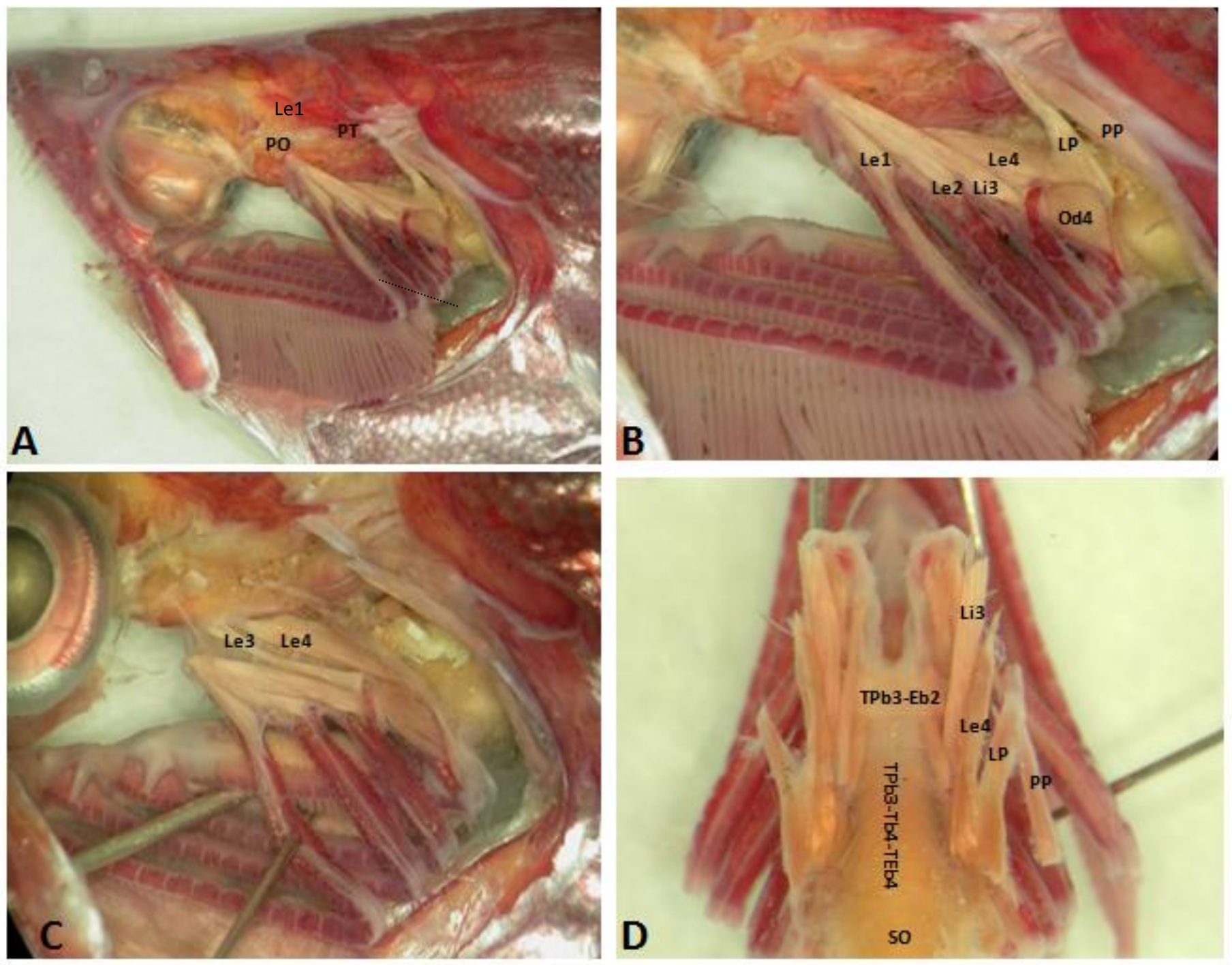

Fig.40. Raphiodon vulpinus (MZUSP 15219 126,7 mm CP). A, B e C: vista lateral esquerda. D: vista dorsal. 

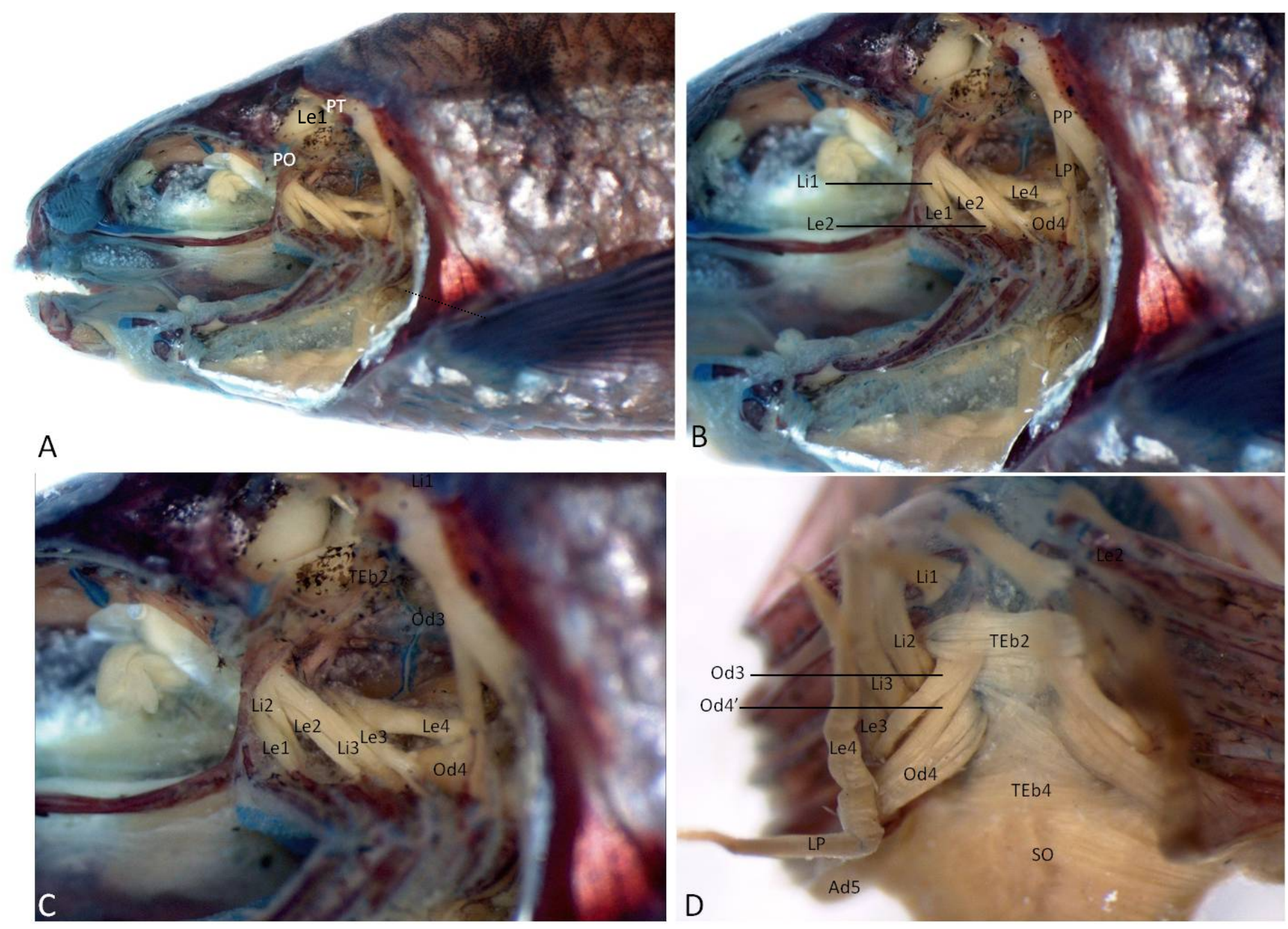

Fig.41. Bryconamericus turiuba (MZUSP 79799 56,5 mm CP). Vista lateral dos músculos dorsais dos arcos branquiais (A, B e C). Vista dorsal dos músculos dorsais dos arcos branquiais (D). 

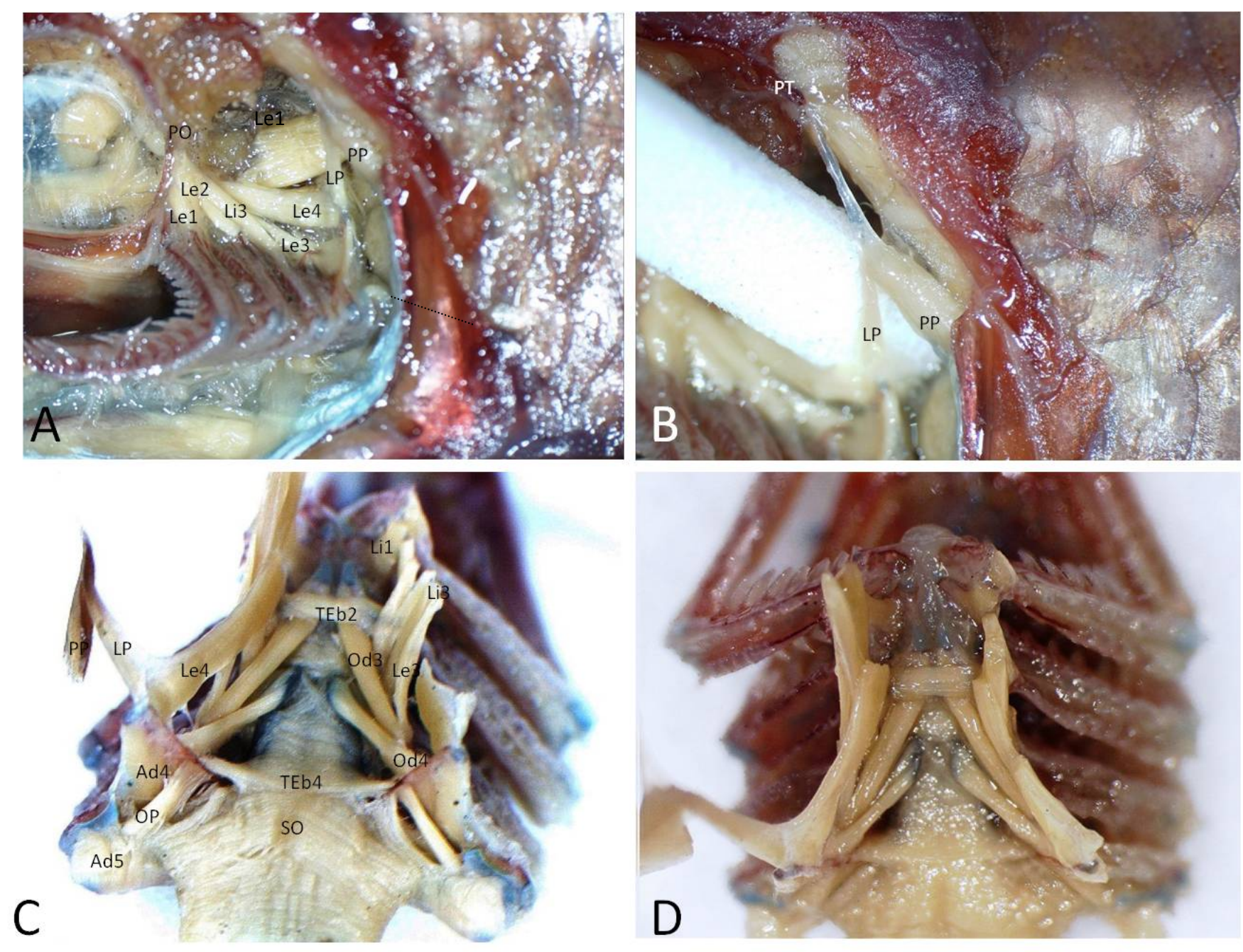

Fig.42. Agoniates halecinus (MUZUSP 101617 163,04 mm CP). Vista lateral dos músculos dorsais dos arcos branquiais (A e B). Vista dorsal dos músculos dorsais dos arcos branquiais (C e D). 

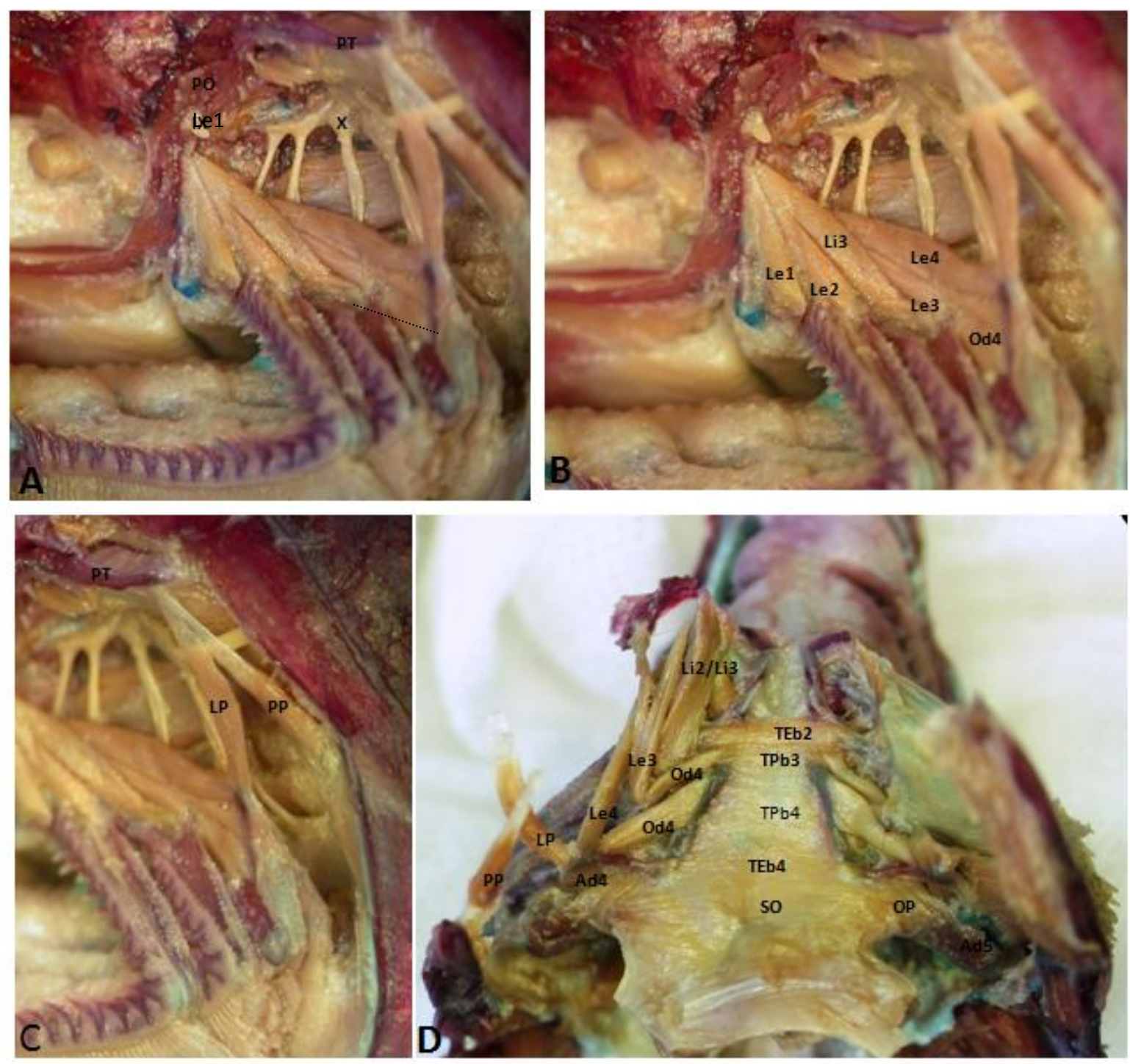

Fig.43. Brycon opalinus (MZUSP 28338 176,2 mm CP). A, B e C: vista lateral esquerda. D: vista dorsal. 
Li3
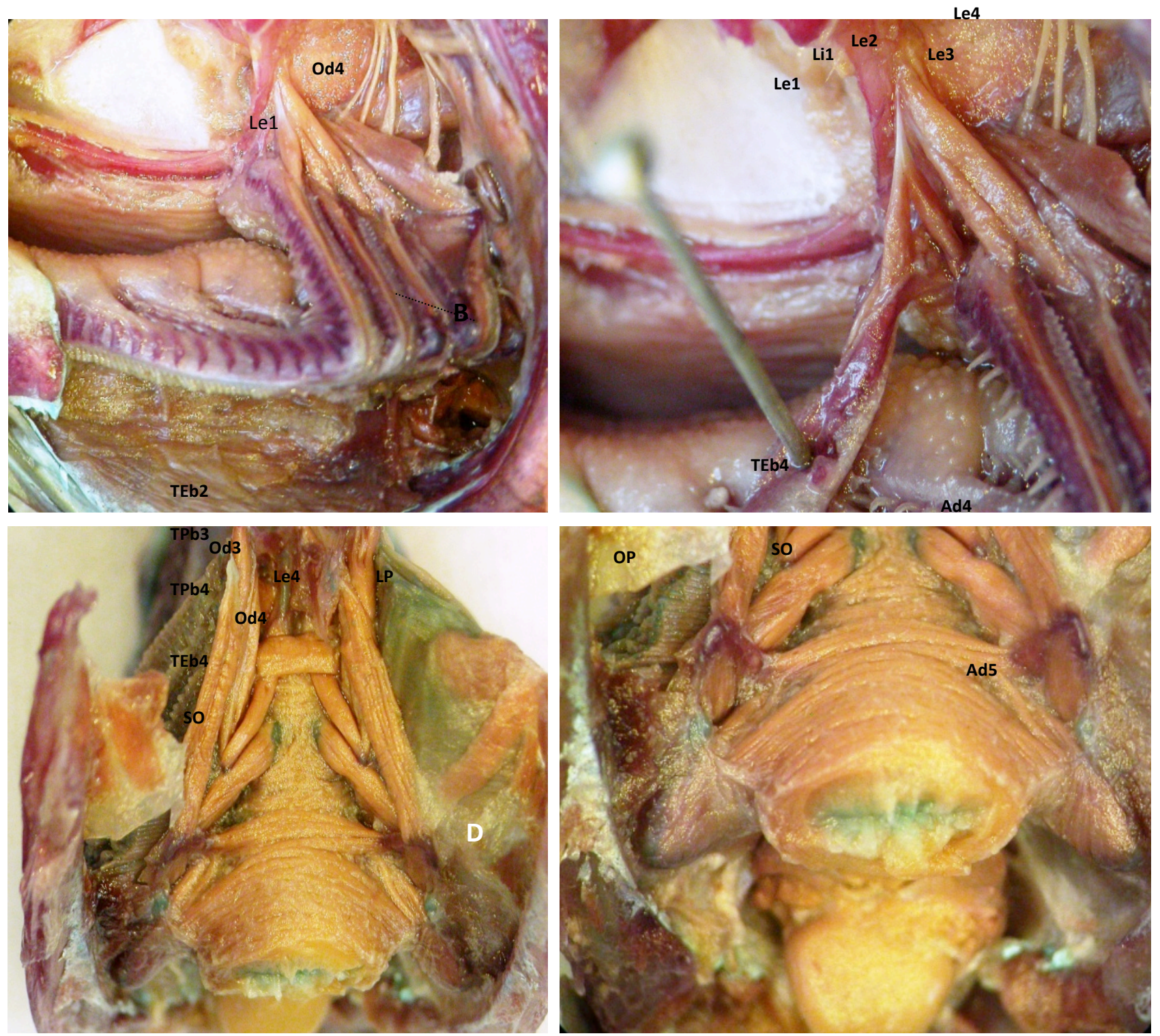

Fig.44. Brycon falcatus (MZUSP 56945 175,4 mm CP). A e B: vista lateral esquerda. C e D: vista dorsal 

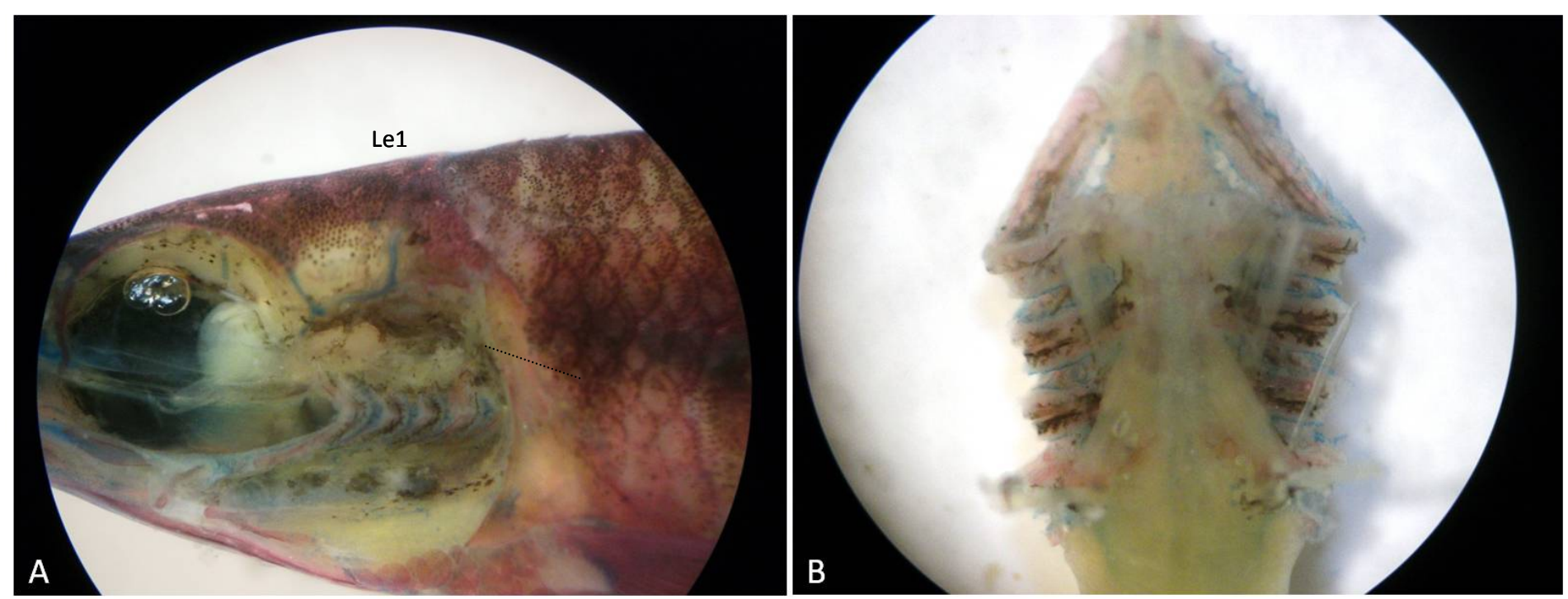

Fig.45. Hemigrammocharax multifasciatus (SAIAB 72800 34,7mm CP). Vista lateral dos músculos dorsais dos arcos branquiais (A). Vista dorsal dos músculos dorsais dos arcos branquiais (B).
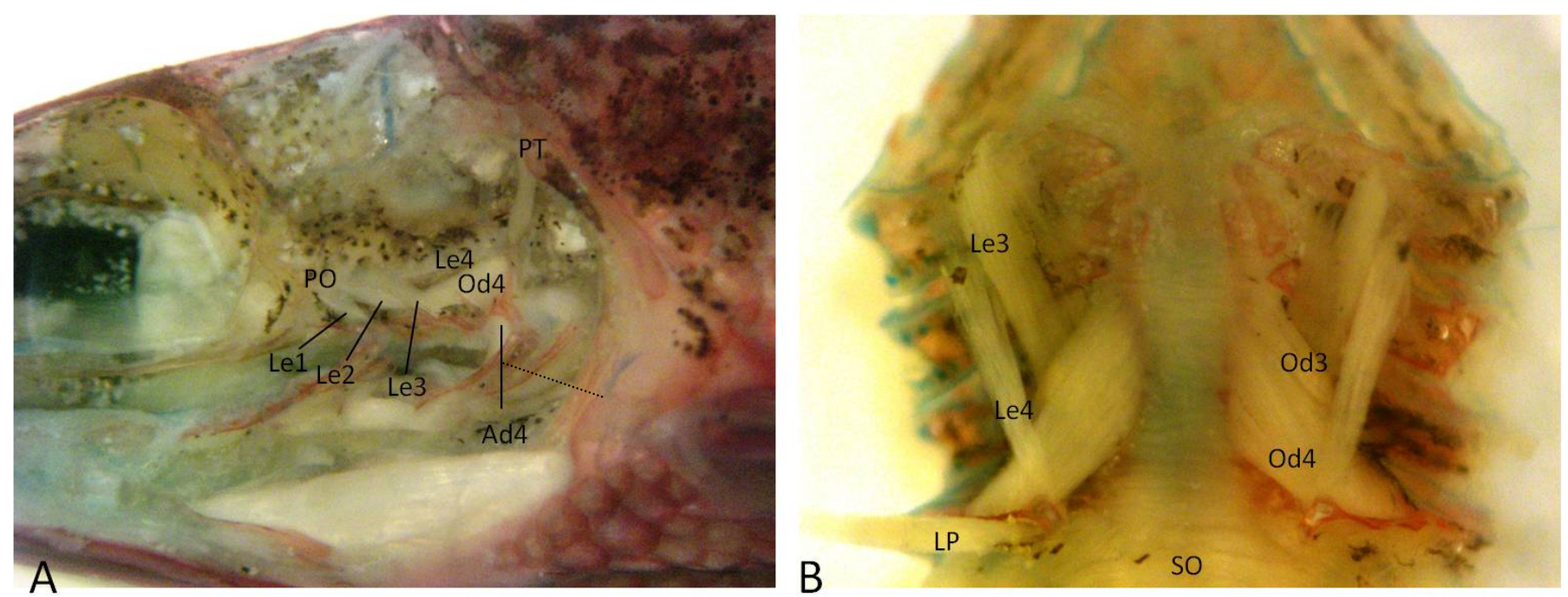

Fig.46. Nannocharax SP (SAIAB 76637 46,1mm CP). Vista lateral dos músculos dorsais dos arcos branquiais (A). Vista dorsal dos músculos dorsais dos arcos branquiais (B). 
Anexos 


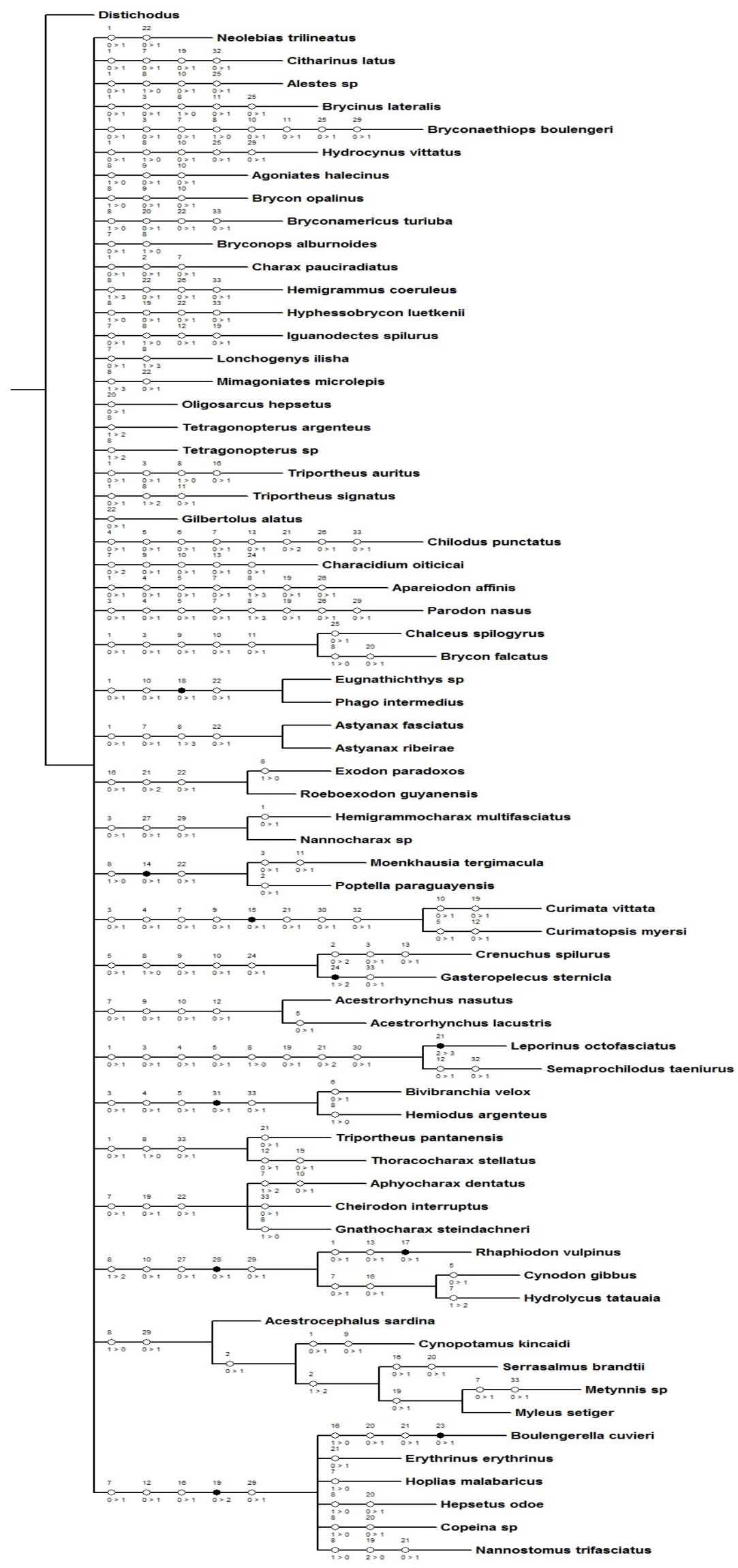

AnexoX. Cladograma de consenso estrito das 18829 árvores mais parcimoniosas obtidas da análise filogenética 
dos caracteres da matriz de dados. $\mathrm{O}$ símbolo $(\bullet)$ : corresponde aos caracteres exclusivos.

Anexo X. Lista de sinapomorfias.

A maioria das sinapomorfias que sustentam os clados a seguir são homoplásticas. As sinapomorfias exclusivas serão destacadas em negrito quando presentes.

1. Clado Chalceus spilogyrus e Brycon falcatus.

i. Tipo de origem tendínea do Levator externus 1 [caráter 1, $0>1$ ].

ii. Ausência da inserção do Levator externus 1 no processo uncinado do epibranquial 1 [caráter $3,0>1$ ].

iii. Tipo de origem tendínea do Levator posterioris [caráter 9, $0>1$ ].

iv. Presença de origem compartilhada entre o Levator posterioris e o Protractor pectoralis [caráter $10,0>1$ ].

v. Tipo de origem tendínea do Levator internus 1 [caráter 11, $0>1$ ].

2. Clado Eugnathichthys sp e Phago intermedius.

vi. Tipo de origem tendínea do Levator externus 1 [caráter 1, $0>1$ ].

vii. Presença de origem compartilhada entre o Levator posterioris e o Protractor pectoralis [caráter $10,0>1$ ].

viii. Ausência do Obliquus dorsalis 3 [caráter 18, $0>1$ ].

ix. Presença do Obliquus dorsalis 4' [caráter 22, $0>1$ ].

3. Clado Astyanax fasciatus e Astyanax ribeirae.

x. Tipo de origem tendínea do Levator externus 1 [caráter $1,0>1$ ].

xi. Local de inserção do Levator externus 3 na extremidade dorsal do processo uncinado do epibranquial 3 [caráter 7, $0>1$ ].

xii. Local de inserção do Levator externus 4 na extremidade dorsal do processo levantador do epibranquial 4 [caráter $8,0>1$ ].

xiii. Presença do Obliquus dorsalis 4' [caráter 22, $0>1$ ].

4. Clado Exodon paradoxus e Roeboexodon guyanensis.

xiv. Presença de origem compartilhada entre o Levator internus 3 e o Levator internus 2 [caráter 16, $0>1$ ].

xv. Local de inserção do Obliquus dorsalis 4 na margem anterior do processo levantador do epibranquial 4 [caráter 21, $0>2$ ].

xvi. Presença do Obliquus dorsalis 4 '[caráter 22, $0>1]$.

5. Clado Hemigrammocharax multifasciatus e Nannocharax sp.

xvii. Ausência da inserção do Levator externus 1 no processo uncinado do epibranquial 1 [caráter $3,0>1$ ].

xviii. Presença de limite definido entre o Transversus epibranquialis 4, Sphicter oesophagus e Transversus pharingobranchialis 4 [caráter 27, $0>1$ ].

xix. Presença de limite definido entre o Transversus pharyngobranchialis $3 \mathrm{e}$ Transversus pharyngobranchialis 4 [caráter 29, $0>1$ ].

6. Clado Moenkhausia terginacula e Poptella paraguayensis. 
xx. Local de inserção do Levator externus 4 na extremidade dorsal do processo levantador do epibranquial 4 [caráter $8,0>1$ ].

xxi. Ausência do levator internus 3 [caráter, 14, $0>1$ ].

xxii. Presença do Obliquus dorsalis 4 '[caráter 22, $0>1$ ].

\section{Clado Curimata vittata e Curimatopsis myersi.}

xxiii. Ausência da inserção do Levator externus 1 no processo uncinado do epibranquial 1 [caráter $3,0>1$ ].

xxiv. Presença de divisão do Levator externus 1 no local de inserção [caráter 4, $0>$ $1]$.

xxv. Local de inserção do Levator externus 3 na extremidade dorsal do processo uncinado do epibranquial 3 [caráter 7, $0>1$ ] .

xxvi. Tipo de origem tendínea do Levator posterioris [caráter 9, $0>1$ ].

xxvii. Local de inserção do Levator internus 3 no faringobranquial 3 e 4 [caráter $15,0>1]$.

xxviii. Local de inserção do Obliquus dorsalis 4 na margem anterior do processo levantador do epibranquial 4 [caráter 21, $0>1$ ].

xxix. Ausência do Transversus pharyngobranchialis 4 [caráter 30, $0>1$ ].

xxx. Presença de Órgãos epibranquiais [caráter 32, $0>1$ ].

8. Clado Crenuchus spilurus e Gasteropelecus sternicla.

xxxi. Origens afastadas dos músculos Levator externus 1 e 2 e Levator internus 1 e 3 no proótico [caráter $5,0>1$ ].

xxxii. Local de inserção do Levator externus 4 na extremidade dorsal do processo levantador do epibranquial 4 [caráter $8,0>1$ ].

xxxiii. Tipo de origem tendínea do Levator posterioris [caráter 9, $0>1$ ].

xxxiv. Presença de origem compartilhada entre o Levator posterioris e o Protractor pectoralis [caráter $10,0>1$ ].

xxxv. Local de origem do Obliquus posterioris no epibranquial 4 e no transverso epibranquial 4 [caráter 24, $0>1$ ].

9. Clado Acestrorhynchus lacustris e A.nasutus.

xxxvi. Local de inserção do Levator externus 3 na extremidade dorsal do processo uncinado do epibranquial 3 [caráter 7, $0>1$ ] .

xxxvii. Tipo de origem tendínea do Levator posterioris [caráter 9, $0>1$ ].

xxxviii. Presença de origem compartilhada entre o Levator posterioris e o Protractor pectoralis [caráter 10, $0>1$ ].

xxxix. Local de inserção do Levator internus $1 \mathrm{em}$ dois pontos distintos do faríngobranquial 2 [caráter $12,0>1$ ].

10. Clado Leporinus octofasciatus e Semaprochilodus taeniurus.

xl. Tipo de origem tendínea do Levator externus 1 [caráter 1, $0>1$ ].

xli. Ausência da inserção do Levator externus 1 no processo uncinado do epibranquial 1 [caráter $3,0>1$ ] .

xlii. Presença de divisão do Levator externus 1 no local de inserção [caráter 4, 0 > $1]$.

xliii. Origens afastadas dos músculos Levator externus 1 e 2 e Levator internus 1 e 3 no proótico [caráter $5,0>1$ ].

xliv. Local de inserção do Levator externus 4 na margem anterior do processo levantador do epibranquial 4 [caráter $8,1>0$ ]. 
xlv. Local de inserção do Obliquus dorsalis 3 na margem anterior do processo uncinado do epibranquial 3 [caráter 19,0 $>1$ ].

xlvi. Local de inserção do Obliquus dorsalis 4 na margem anterior do processo levantador do epibranquial 4 [caráter 21, $0>2$ ].

xlvii. Ausência do Transversus pharyngobranchialis 4 [caráter 30, $0>1$ ].

11. Clado Bivibranchia velox e Hemiodus argenteus.

xlviii. Ausência da inserção do Levator externus 1 no processo uncinado do epibranquial 1 [caráter $3,0>1$ ].

xlix. Presença de divisão do Levator externus 1 no local de inserção [caráter 4, $0>$ $1]$.

1. Origens afastadas dos músculos Levator externus 1 e 2 e Levator internus 1 e 3 no proótico [caráter 5, $0>1$ ].

li. Presença de dois ou mais ventres musculares no Transversus pharyngobranchialis 4 [caráter 31, $0>1$ ].

lii. Presença ou ausência de projeção mediana anterior conspícua das fibras musculares do Sphincter esophagi [caráter 33, $0>1$ ].

12. Clado Triportheus pantanensis e Thoracocharax stellatus.

liii. Tipo de origem tendínea do Levator externus 1 [caráter 1, $0>1$ ].

liv. Local de inserção do Levator externus 4 na margem anterior do processo levantador do epibranquial 4 [caráter $8,1>0$ ].

Iv. Presença ou ausência de projeção mediana anterior conspícua das fibras musculares do Sphincter esophagi [caráter 33, $0>1$ ].

13. Clado Aphyocharax dentatus, Cheirodon interruptus e Gnathocharax steindachneri.

lvi. Local de inserção do Levator externus 3 na extremidade dorsal do processo uncinado do epibranquial 3 [caráter 7,0 $>1$ ].

1vii. Local de inserção do Obliquus dorsalis 3 na margem anterior do processo uncinado do epibranquial 3 [caráter 19, $0>1$ ].

lviii. Presença do Obliquus dorsalis 4'[caráter 22, $0>1$ ].

14. Clado Rhaphiodon vulpinus, Cynodon gibbus e Hydrolycus tatauaia.

lix. Local de inserção do Levator externus 4 na face medial do processo levantador do epibranquial 4 [caráter $8,1>2$ ]

1x. Presença de origem compartilhada entre o Levator posterioris e o Protractor pectoralis [caráter 10, $0>1$ ].

1xi. Presença de limite definido entre o Transversus epibranquialis 4, Sphicter oesophagus e Transversus pharingobranchialis 4 [caráter 27, $0>1$ ].

1xii. Presença do Transversus pharyngobranchialis 2 [caráter 28, $0>1$ ].

1xiii. Ausência de limite definido entre o Transversus pharyngobranchialis $3 \mathrm{e}$ Transversus pharyngobranchialis 4 [caráter 29, $0>1$ ].

15. Clado Cynodon gibbus e Hydrolycus tatanaia.

lxiv. Local de inserção do Levator externus 3 na extremidade dorsal do processo uncinado do epibranquial 3 [caráter 7,0 $>1$ ].

lxv. Presença de origem compartilhada entre o Levator internus 3 e o Levator internus 2 [caráter $16,0>1]$. 
16. Clado Acestrocephalus sardina, Cynopotamus kincaidi, Serrasalmus brandtii, Metynnis sp e Myleus setiger.

lxvi. Local de inserção do Levator externus 4 na margem anterior do processo levantador do epibranquial 4 [caráter $8,1>0$ ]

lxvii. Ausência de limite definido entre o Transversus pharyngobranchialis 3 e Transversus pharyngobranchialis 4 [caráter $29,0>1$ ]

17. Clado Cynopotamus kincaidi, Serrasalmus brandtii, Metynnis sp e Myleus setiger.

1xviii. Local de origem do Levator externus 1 no proótico e no faringobranquial 1 [caráter $2,0>1]$.

18. Serrasalmus brandtii, Metynnis sp e Myleus setiger.

lxix. Local de origem do Levator externus 1 exclusivamente no faringobranquial 1 [caráter $2,1>2]$.

19. Metynnis sp e Myleus setiger.

lxx. Local de inserção do Obliquus dorsalis 3 na margem anterior do processo uncinado do epibranquial 3 [caráter 19, $0>1$ ] .

20. Boulengerella cuvieri, Erythrinus erythrinus, Hoplias malabaricus, Hepsetus odoe, Copeina sp e Nannostomus trifasciatus.

lxxi. Local de inserção do Levator externus 3 na extremidade dorsal do processo uncinado do epibranquial 3 [caráter 7, $0>1$ ] .

1xxii. Local de inserção do Levator internus 1 em dois pontos distintos do faríngobranquial 2 [caráter $12,0>1$ ].

lxxiii. Presença de origem compartilhada entre o Levator internus 3 e o Levator internus 2 [caráter $16,0>1$ ].

lxxiv. Local de inserção do Obliquus dorsalis 3 na face medial do processo uncinado do epibranquial 3 [caráter 19, $0>2$ ].

lxxv. Ausência de limite definido entre o Transversus pharyngobranchialis $3 \mathrm{e}$ Transversus pharyngobranchialis 4 [caráter 29, $0>1$ ]. 


\section{Estudo da musculatura dorsal dos arcos branquiais de Characiformes (Teleostei: Ostariophysi): diversidade morfológica e significado filogenético}

Study of the dorsal musculature of the branchial arch of the Characiformes (Teleostei:

Ostariophysi): morphologic diversity and phylogenetic significance

Tese apresentada ao Instituto de Biociências da

Universidade de São Paulo, para a obtenção de Título de Doutor em Ciências, na Área de Zoologia.

Orientadora: Mônica de Toledo-Piza Ragazzo

São Paulo

2012 
Casas, André Luis da Silva

Estudo da musculatura dorsal dos arcos branquiais de Characiformes (Teleostei: Ostariophysi): diversidade morfológica e significado filogenético

257 páginas.

Tese (Doutorado) - Instituto de Biociências da Universidade de São Paulo, Departamento de Zoologia.

1.Characiformes 2. Musculatura 3. Arcos branquiaisI. Universidade de São Paulo. Instituto de Biociências. Departamento de Zoologia.

Comissão Julgadora:

$\operatorname{Prof}(\mathrm{a}) . \operatorname{Dr}(\mathrm{a})$.

$\operatorname{Prof}(\mathrm{a}) . \operatorname{Dr}(\mathrm{a})$.

$\operatorname{Prof}(\mathrm{a}) . \operatorname{Dr}(\mathrm{a})$.

$\operatorname{Prof}(a) . \operatorname{Dr}(a)$.

Profa. Dra. Mônica de Toledo-Piza Ragazzo

Orientadora 
Dedico esse trabalho aos meus pais, Dario e Clarice Casas 


\section{Agradecimentos}

Agradeço imensamente a Professora Dra.. Mônica de Toledo-Piza Ragazzo, por toda a paciência, orientação e dedicação ao presente estudo. Seu exemplo foi o meu maior aprendizado.

Agradeço à ilustradora científica France Pedreira Martin por realizar todas as ilustrações dos músculos dorsais dos arcos branquias e por ter me acompanhado ao longo desse estudo com seu olhar crítico sobre a anatomia, pelas conversas e discussões. Agradeço o Dr. Osvaldo Oyakawa do Museu de Zoologia da Universidade de São Paulo (MZUSP) pelo suporte prestado durante as minhas visitas à coleção Ictiológica. Estendo os agradecimentos a todos os colegas do MZUSP com quem tive o prazer de me relacionar ao longo desses anos de doutorado.

Agradeço ao MZUSP pelo empréstimo de grande parte das espécies necessárias à elaboração desse estudo.

Agradeço o Dr. Rogger Bills curador da coleção do South African Institute of Aquatic Biodiversity (SAIAB), Grahamstowm, África do Sul, por ter me recebido em sua coleção e ter prestado todo o auxílio necessário durante minha estada nessa instituição. Estendo esse agradecimento a todos os técnicos e colegas do SAIAB que tornaram esse período tão produtivo e descontraído.

Agradeço ao SAIAB pelo empréstimo do valioso material africano, examinado no presente estudo.

Agradeço ao Dr. George Mattox por toda sua ajuda e valiosa consultoria sobre os programas de análise, mas principalmente as breves e ricas discussões sobre "Anatomia de Peixes" assim como agradeço sua amizade e incentivo ao longo desse estudo.

Agradeço o Dr. Ralf Britz e a Dra. Mônica de Toledo-Piza Ragazzo por terem sugerido o objeto desse estudo. Aproveito o espaço para agradecer também a grande oportunidade de aprendizado durante o curso de Anatomia Comparada de Peixes: um enfoque evolutivo (BIZ5704-6/1). Esse curso reforçou o sentimento de que devo sempre me dedicar à anatomia e evolução dos peixes. Estendo esses agradecimentos a todos os colegas de turma que tornaram a estada no CEBIMAR divertida e produtiva.

Agradeço a todos os técnicos do Departamento de Zoologia da Universidade de São Paulo pelo apoio ao longo desse estudo.

Agradeço o Dr. Marcelo de Carvalho por todas as conversas formais e informais e pelo apoio ao longo desses anos de doutorado. Estendo os agradecimentos a todos os amigos do laboratório de "Elasmo" (Akemi Shibuya, Carol Ramiro, Diego Vaz, João Pedro Fontenelle, João Paulo Capretz, Maíra Portella, Matheus Soares, Sarah Viana, Thiago Loboda, Juliana Binelli e Flávia Petean) pelas conversas, histórias, estórias, mas principalmente pela convivência.

Agradeço em especial a todos os amigos do "LAB" (Laboratório de Ictiologia) que me mostraram que estão errados os que pensam que as relações entre colegas no meio acadêmico são áridas e hostis. A "turma da Mônica" (Andrea Paixão, Emerson Barão, George Mattox, Kleber Leite, Rodrigo Nakagawa, Victor Giovannetti) é exceção a regra e me orgulho muito e agradeço a oportunidade de ter convivido esses anos todos com vocês.

Agradeço imensamente aos maus pais Dario e Clarice e aos meus irmãos João e Ana, pelo incentivo incansável. Estendo esses agradecimentos aos meus sogros Dario e Regina e a meus cunhados Lilian, Guilherme, Flávio, Kenny, Yuri e Edmur.

Agradeço a Monique por todo amor e carinho. Por ter sido tão importante nos momentos difíceis pelos quais passei durante esse período. Por ser meu porto seguro, 
minha fortaleza. Agradeço a você pelo maior presente de todos: o nosso pequeno "Brycon" Miguel que chegou para fundamentar a nossa vida.

Esse estudo foi financiado pela FAPESP (Processo 08/55034-9) e também teve apoio do Programa de Pós-graduação em Zoologia do IBUSP, Universidade de São Paulo. 
In the present study the anatomy of the dorsal gill-arch muscles of 70 species, comprising 64 genera, representing all currently recognized families of the Characiformes was examined in detail. A total of 22 muscles were described and documented for each examined species, and based on the variation observed 33 characters of the dorsal musculature of the gill arch were proposed. Overall, many of the observed character states are widely distributed across species in different families, and in many instances they vary within a single family, and a smaller number of characters states restricted to a few taxa. A phylogenetic analysis including only characters derived from the dorsal gill-arch musculature resulted in 18829 most parsimonious cladograms (157 steps, $\mathrm{CI}=16 \mathrm{RI}=34$ ), with a poorly resolved strict consensus, due not only to the reduced number of characters relative to the number of taxa, but also to the high level of incongruence in the distribution of characters states. However, the discussion of the variation observed in this anatomical complex, in the context of hypotheses available in the literature about phylogenetic relationships within the Characiformes, highlights the presence of various character states from the dorsal gill arch muscles that corroborate hypotheses based on different character complexes, at various supraespecific levels within the order.
\end{abstract}




\section{Resumo}

No presente estudo foi examinado em detalhe a anatomia da musculatura dorsal dos arcos branquiais de 70 espécies, pertencentes a 64 gêneros, representando todas as famílias atualmente reconhecidas de Characiformes. Um total de 22 músculos foram descritos e documentados para cada espécie examinada, e com base nas variações observadas foram propostos 33 caracteres exclusivos da musculatura dorsal dos arcos branquiais. De modo geral, muitos dos estados de caracteres observados estão amplamente distribuídos em espécies representantes de diversas famílias, variando muitas vezes em representantes da mesma família, com um número menor de caracteres restritos a alguns táxons. Uma análise filogenética incluindo apenas os caracteres de musculatura dorsal dos arcos branquiais resultou em 18829 cladogramas igualmente mais parcimoniosos (157 passos, $\mathrm{IC}=16 \mathrm{IR}=34)$ com consenso estrito muito pouco resolvido devido não só ao reduzido número de caracteres em relação ao número de táxons, mas também há grande incongruência na distribuição dos estados de caracteres. Contudo, a discussão da variação observada neste complexo anatômico, em um contexto filogenético, tomando por base hipóteses já disponíveis na literatura sobre relações de parentesco na ordem Characiformes evidencia a presença de caracteres que corroboram a hipóteses baseadas em outros complexos de caracteres, em diversos níveis supraespecíficos. 


\section{Sumário}

1. Introdução

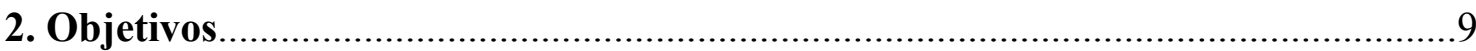

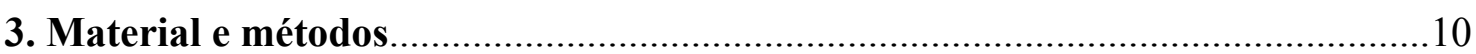

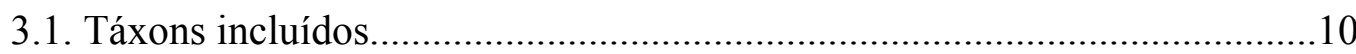

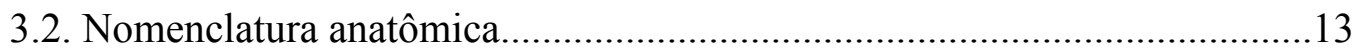

3.3. Preparação do material e dissecção...........................................................16

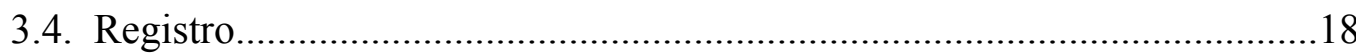

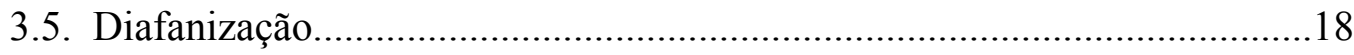

3.6. Utilização dos nomes dos táxons na descrição de caracteres.......................18

3.7. Procedimentos para discussão da variação encontrada................................19

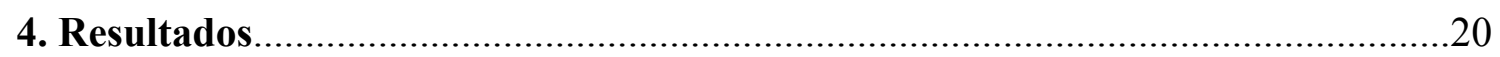

4.1. Descrição da musculatura.......................................................................20

4.1.1. Família Acestrorhynchidae......................................................20

4.1.2. Família Alestidae.......................................................................24

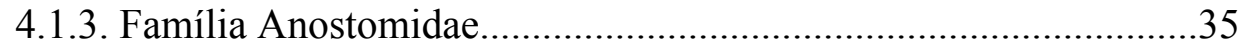

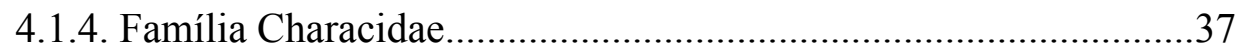

4.1.5. Família Chilodontidae..............................................................105

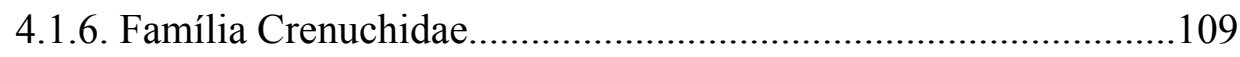

4.1.7 Família Cynodontidae................................................................112

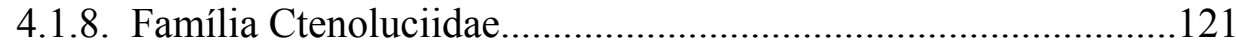

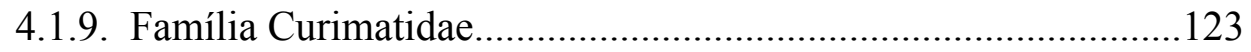

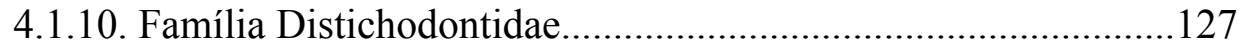

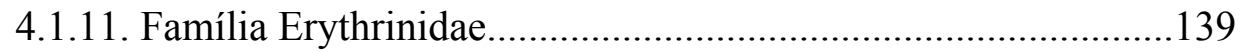

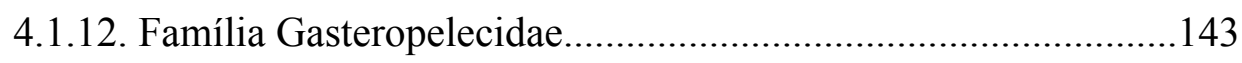

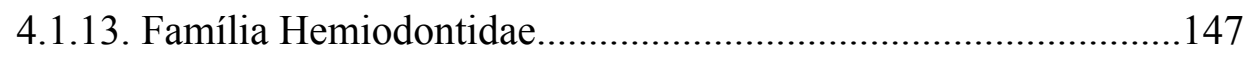

4.1.14. Família Hepsetidae..................................................................152

4.1.15. Família Parodontidae................................................................ 160

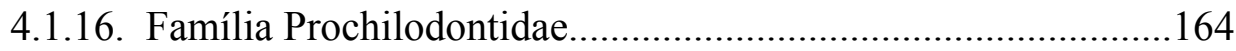

4.2. Generalizações sobre os músculos dorsais dos arcos branquiais em Characiformes 166

4.3. Descrição dos caracteres. .169 


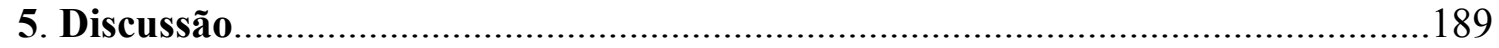

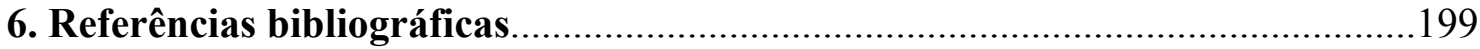

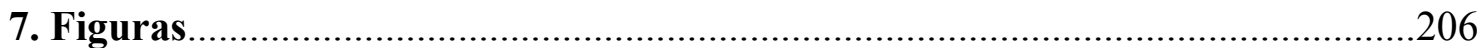

ANEXOS 